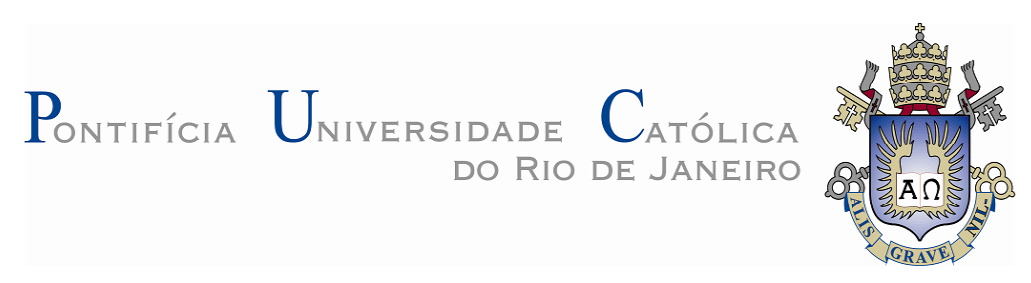

Daniel Salvador Velez Parra

\title{
Análise numérica do comportamento de taludes de solo submetidos a carregamentos dinâmicos
}

Dissertação apresentada como requisito parcial para obtenção do grau de Mestre pelo Programa de PósGraduação em Engenharia Civil do Departamento de Engenharia Civil da PUC-Rio.

Orientador: Prof. Celso Romanel 


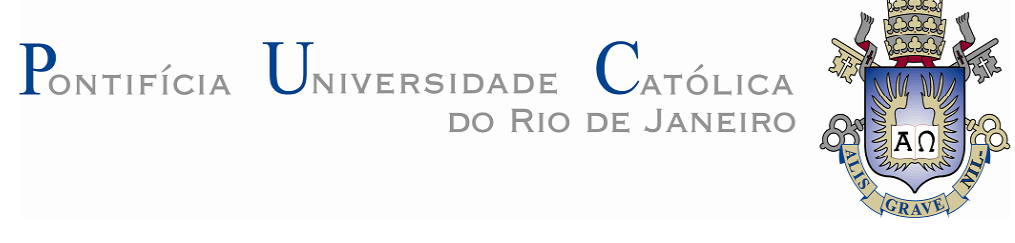

Daniel Salvador Velez Parra

\section{Análise numérica do comportamento de taludes de solo submetidos a carregamentos dinâmicos}

Dissertação apresentada como requisito parcial para obtenção do grau de Mestre pelo Programa de Pós-Graduação em Engenharia Civil do Departamento de Engenharia Civil do Centro Técnico Científico da PUC-Rio. Aprovada pela Comissão Examinadora abaixo assinada.

\section{Prof. Celso Romanel} Orientador

Departamento de Engenharia Civil - PUC-Rio

Prof ${ }^{\mathrm{a}}$. Deane de Mesquita Roehl

Departamento de Engenharia Civil - PUC-Rio

$\mathrm{Dr}^{\mathrm{a}}$. Jackeline Rosemery Castañeda Huertas

Consultora Independente

Prof. Márcio da Silveira Carvalho

Coordenador Setorial do

Centro Técnico Científico - PUC-Rio

Rio de Janeiro, 16 de fevereiro de 2017. 
Todos os direitos reservados. É proibida a reprodução total ou parcial do trabalho sem autorização da universidade, do autor e do orientador.

\section{Daniel Salvador Velez Parra}

Graduou-se em Engenharia Civil pela Universidade de Cuenca (Cuenca - Equador) em 2009. Principais áreas de interesse: dinâmica de solos, estabilidade de taludes, engenharia de barragens, geomecânica computacional.

Ficha Catalográfica

Velez Parra, Daniel Salvador

Análise numérica do comportamento de taludes de solo submetidos a carregamentos dinâmicos / Daniel Salvador Velez Parra; orientador: Celso Romanel. - 2017. 239 f. : il. color. ; $30 \mathrm{~cm}$

\section{Dissertação} (mestrado)-Pontifícia Universidade Católica do Rio de Janeiro, Departamento de Engenharia Civil, 2017. Inclui bibliografia

1. Engenharia civil - Teses. 2. Carregamento cíclico. 3. Taludes de solo. 4. Análise numérica. 5. Terremotos. I. Romanel, Celso. II. Pontifícia Universidade Católica do Rio de Janeiro. Departamento de Engenharia Civil. III. Título. 


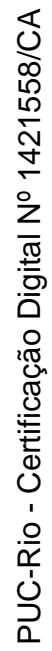

To my Family the greatest blessing 


\section{Agradecimentos}

A Deus pela vida e por um dia mais de vida e saúde e cuidar sempre de mim e da minha família.

Ao governo do Brasil e à Coordenação de Aperfeiçoamento de Pessoal de Nível Superior Capes pelos auxílios concedidos, sem os quais este trabalho não poderia ter sido realizado, meu sincero agradecimento.

Ao meu orientador Professor Celso Romanel pela ajuda, amizade, apoio e todos os conhecimentos transmitidos.

Aos meus pais, pela educação, apoio incondicional e a formação em valores e minha irmã Mary. À minha avô meu anjo, e meu tio Jorge.

À banca examinadora pelos valiosos comentários e sugestões para melhorar o presenta trabalho.

Aos meus amigos JP Ortiz, F Ortiz, Pablo Torres, Marcelo Iniguez, Christian Mejia, Tania Bustamente, Diego Orellana por sempre estarem presentes.

Aos meus grandes amigos da PUC Danilo "Mohammed" Jimenez Ugalde, Raul "chato" Contreras, Lizardo "assu” Romero, Juan Manuel Girão, Juliana Carvalho, Karlo Aguinda, Jainor Cabrera, Jorge Gomez, Jefferson Ferraz, Nathy Passos.

À igreja da PUC onde sempre encontrei forças para continuar.

Ao grande povo deste imenso pais chamado Brasil, muito obrigado.

Finalmente a Deus pela vida. 


\section{Resumo}

Velez Parra, Daniel Salvador; Romanel, Celso (orientador). Análise numérica do comportamento de taludes de solo submetidos a carregamentos dinâmicos. Rio de Janeiro, 2017. 239p. Dissertação de Mestrado - Departamento de Engenharia Civil, Pontifícia Universidade Católica do Rio de Janeiro.

Os efeitos catastróficos de terremotos que frequentemente acontecem na costa ocidental da América do Sul motivaram a realização desta pesquisa. O Equador, em particular, encontra-se localizado em uma zona de alta atividade sísmica devido a processos de subducção de placas tectônicas que originam sismos de grande magnitude, como o terremoto de magnitude $M_{w}=7.8$ acontecido em 16 de abril de 2016 na cidade costeira de Pedernales, que produziu grandes danos à infraestrutura e perdas de vidas humanas. A presente pesquisa tem como objetivo estudar o comportamento dinâmico de dois tipos de estruturas de terra: um talude de encosta composto de solo coluvial de altura aproximada de $70 \mathrm{~m}$ e a barragem de enrocamento de Mazar construída com altura de $166 \mathrm{~m}$ para fins de aproveitamento hidrelétrico. A barragem de Mazar, em função da sua altura, é classificada como barragem de grande tamanho pela International Commission on Large Dams (ICOLD) e qualificada pela Norma Equatoriana da Construção (NEC, 2014) como estrutura de importância essencial, com obrigatoriedade de verificação do seu desempenho sísmico para dois terremotos de projeto: o terremoto operacional base (OBE) e o máximo terremoto provável (MCE) com períodos de retorno de 475 anos e 2500 anos, respectivamente. As análises efetuadas neste trabalho incluíram a geração de sismos de projeto, investigação da estabilidade estática e pseudoestática de taludes, determinação de deslocamentos permanentes mediante métodos analíticos simplificados e simulações numéricas. Diferenças significativas nos deslocamentos permanentes máximos foram observadas empregando as abordagens analítica e numérica.

\section{Palavras - chave}

Carregamento cíclico; taludes de solo; análise numérica; terremotos. 


\section{Abstract}

Velez Parra, Daniel Salvador; Romanel, Celso (Advisor). Numerical analysis of the behavior of soil slopes subjected to dynamic loads. Rio de Janeiro, 2017. 239p. Dissertação de Mestrado - Departamento de Engenharia Civil, Pontifícia Universidade Católica do Rio de Janeiro.

The catastrophic effects of earthquakes that frequently occur on the West coast of South America motivated this research. Ecuador, in particular, is located in a zone of high seismic activity due to processes of tectonic plate subduction that give rise to earthquakes of great magnitude, such as the seismic motion of magnitude $M_{w}=7.8$ that struck the coastal city of Pedernales on April 16 2016, producing great damages to the infrastructure and losses of human lives. The present research aims to study the dynamic behavior of two types of earth structures: a slope composed of colluvial soil of approximately $70 \mathrm{~m}$ height and the Mazar rockfill dam constructed for hydroelectric generation. The Mazar dam, according to its height $(166 \mathrm{~m})$, is classified as a large dam by the International Commission on Large Dams (ICOLD) and qualified by the Ecuadorian Construction Standard (NEC, 2014) as a structure of essential importance, with mandatory analysis of seismic performance under two seismic design ground motions: the operating basis earthquake (OBE) and the maximum credible earthquake (MCE) with return periods of 475 years and 2500 years, respectively. The analyses carried out in this work included the generation of the OBE and MCE earthquakes, investigation of static and pseudo static stability of slopes, determination of permanent displacements using simplified analytical methods and numerical simulations. Significant differences in the maximum permanent displacements were observed using analytical and numerical approaches.

\section{Keywords}

Cyclic loading; soil slopes; numerical analysis; earthquakes. 


\section{Sumário}

1. Introdução 29

1.1. Organização da dissertação 32

2. Conceitos básicos de sismicidade e propagação de ondas elásticas

2.1. Ondas de tensão 35

$\begin{array}{ll}\text { 2.1.1. Ondas de corpo } & 37\end{array}$

2.1.1.1. Ondas P 37

$\begin{array}{ll}\text { 2.1.1.2. Ondas S } & 37\end{array}$

2.1.2. Ondas de superfície $\quad 38$

2.1.2.1. Ondas R 38

2.1.2.2. Ondas L 39

2.2. Magnitude de um terremoto 41

$\begin{array}{ll}\text { 2.2.1. Magnitude local } & 41\end{array}$

2.2.2. Magnitude de ondas de superfície 43

2.2.3. Magnitude de ondas de corpo 43

2.2.4. Momento sísmico e Magnitude de momento 44

2.2.5. Energia e magnitude de energia liberada 46

2.3. Intensidade de um terremoto $\quad 47$

2.4. Fontes sísmicas $\quad 48$

2.4.1. Bordas de placas tectônicas $\quad 48$

2.4.1.1. Bordas divergentes ou de criação 49

2.4.1.2. Bordas convergentes ou de destruição 50

2.4.1.3. Bordas transformantes ou de conservação 51

3. Métodos para análise da resposta dinâmica de taludes 52

3.1. Método pseudoestático $\quad 52$

3.2. Modelos para cálculo de deslocamentos permanentes 60

3.2.1. Modelo de bloco rígido $\quad 60$

3.2.1.1. Método de Saygili e Rathje (2008) 67

3.2.2. Modelos desacoplados 69

3.2.2.1. Método simplificado de Makdisi e Seed (1978) 69

3.2.2.2. Método simplificado de Bray e Rathje (1998) 73

3.2.3. Modelo acoplado 76

3.2.3.1. Método simplificado de Bray e Travasarou (2007) 76

3.2.4. Modelos numéricos $\quad 80$

3.2.4.1. Modelo linear equivalente $\quad 80$

3.2.4.2. Modelos cíclicos 83 
4. Aspectos de modelagem numérica no comportamento dinâmico de geoestruturas $\quad 85$

4.1. Software FLAC $2 \mathrm{D}$ v. 8

4.2. Processamento do registro de aceleração 86

4.2.1. Frequência de corte $\quad 87$

4.2.2. Correção da linha base 88

4.3. Convolução e deconvolução do registro sísmico 90

4.4. Base rígida / base flexível 92

4.5. Condições de contorno em problemas dinâmicos 93

4.5.1. Contornos silenciosos 93

4.5.2. Contornos de campo livre 94

4.6. Tamanho de zona (elemento) e frequência de corte 95

4.7. Amortecimento do material 96

4.7.1. Amortecimento de Rayleigh 96

4.7.2. Amortecimento histerético 98

5. Ameaça sísmica e sismos de projeto 101

5.1. Ameaça sísmica no Equador $\quad 101$

5.1.1. Análise determinística 101

5.1.2. Análise probabilística 102

5.2. Curvas de ameaça sísmica no Equador 103

5.3. Espectro elástico de projeto 105

5.3.1. Espectro elástico de projeto na Norma Equatoriana da Construção (NEC, 2014) 108

5.4. Sismos de projeto 111

5.4.1. Geração de sismos artificiais 112

5.4.2. Espectros de Fourier, de potência e de resposta 115

6. Exemplos analisados 118

6.1. Talude natural ao sul do Equador 118

6.1.1. Propriedades dos materiais $\quad 119$

6.1.2. Sismos de projeto 121

6.1.2.1. Ajuste ao espectro de acelerações 124

6.1.2.2. Filtragem de frequências e correção da linha base $\quad 127$

6.1.3. Tamanho máximo do elemento na malha 130

6.1.4. Análise estática da estabilidade do talude 131

6.1.4.1. Fator de segurança estático 132

6.1.5. Análise de estabilidade pseudo-estática 136

6.1.6. Métodos simplificados para estimativa de deslocamentos
permanentes

6.1.6.1 Método simplificado de Newmark 138

6.1.6.1.1. Método de Newmark - versão de Houston et al (1987) 141 
6.1.6.2. Método simplificado de Bray e Travasarou (2007) 143

6.1.6.3. Método simplificado de Rathje e Saygili (2011) 145

6.1.6.4. Resumo dos deslocamentos permanentes obtidos por métodos simplificados 146

6.1.7. Análise dinâmica 148

6.1.7.1. Análise dinâmica considerando comportamento elástico linear não amortecido

6.1.7.2. Análise dinâmica considerando comportamento não linear e não amortecido 153

6.1.7.3. Consideração do amortecimento histerético 154

6.1.7.4. Comparação com o programa SHAKE 2000

6.1.7.5. Análise dinâmica com amortecimento histerético 159

7. Exemplo 2 - Barragem de enrocamento de Mazar - Equador 166

7.1. Descrição da barragem de Mazar 166

7.1.1. Propriedades dos materiais 168

7.1.2. Sismos de projeto 169

7.1.3. Tamanho máximo do elemento no modelo numérico 172

7.2. Análise de estabilidade estática 174

7.3. Análise de estabilidade pseudo-estático 177

7.4. Métodos simplificados para estimativa de deslocamentos permanentes

180

7.4.1. Métodos baseados no bloco rígido deslizante $\quad 180$

7.4.2. Método de Bray e Travasarou (2007) 181

7.4.3. Método de Makdisi e Seed (1978) 184

7.4.4. Método de Rathje e Saygili (2011) 185

7.4.5. Resumo dos deslocamentos permanentes calculados com métodos simplificados $\quad 187$

7.5. Análise dinâmica 187

7.5.1. Determinação das frequências naturais e deformações cisalhantes cíclicas máximas $\quad 187$

7.5.2. Análise dinâmica considerando comportamento elasto-plástico e amortecimento histerético 193

7.5.2.1. Reservatório cheio 195

7.5.2.2. Reservatório vazio 208

8. Conclusões e sugestões 224

$\begin{array}{ll}\text { Referências bibliográficas } & 228\end{array}$ 


\section{Lista de figuras}

Figura 2.1 - O circulo de fogo no oceano Pacífico (www.bbc.com)

Figura 2.2 - Parâmetros geométricos para localização de um sismo (Adaptado de Kramer, 1996)

Figura 2.3 - Movimentos de partícula produzidos pelos diferentes tipos de ondas planas de tensão (Teixeira et al., 2003).

Figura 2.4 - Identificação dos tempos de chegada das ondas $P$, $S$ e de superfície em um acelerograma

Figura 2.5 - Diferença entre efeitos das ondas de superfície e ondas de corpo na superfície do terreno em função da profundidade de foco: a) foco profundo; b) foco superficial (Sauter, 1989).

Figura 2.6 - Determinação da magnitude na escala de Richter (1935) $\left(M_{L}\right)$. Fonte: csegrecorder.com

Figura 2.7 - Escalas de magnitude $M_{W}, M_{s}, M_{L}$ e $m_{b}$ (Idriss, 1985)

Figura 2.8 - Escala Modificada de Intensidade de Mercalli (Teixeira et al., 2003)

Figura 2.9 - Esquema da estrutura da Terra. Fonte: www.ige.unicamp.br

Figura 2.10 - Efeitos de correntes de convecção do magma com formação de bordas divergentes (oceano Atlântico) e convergentes (placas de Nazca e Sul Americana).

Figura 3.1 - Forças atuantes em uma fatia vertical e na superfície potencial de ruptura.

Figura 3.2 - Valores de $f_{e q}$ em função da PGA $_{\text {rocha }}$ e distância focal para deslocamentos permanentes admissíveis de: a) $5 \mathrm{~cm}$; b) $15 \mathrm{~cm}$. (Adaptado de Califórnia Geological Survey, 2008). 
Figura 3.4 - Dupla integração da aceleração no tempo para obtenção dos deslocamentos permanentes no método de Newmark (Wilson e Keefer, 1983)

Figura 3.5 - Influência da rigidez do solo e das frequências de excitação na resposta sísmica de taludes: a) baixa frequência, grande comprimento da onda; $b$ ) alta frequência, pequeno comprimento da onda. (Adaptado de Kramer, 1996)

Figura 3.6 - Analogia do bloco deslizante de Newmark (1965) aplicada em talude de solo (Houston et al. 1987).

Figura 3.7 - Curva força $x$ deslocamento medida e modelo de degradação do coeficiente sísmico em aterro sanitário com revestimento de geomembrana (Matasovic et al., 1997)

Figura 3.8 - Estimativa do coeficiente sísmico em função da máxima aceleração horizontal na crista (PGA) e da profundidade da massa de solo deslizante (Makdisi e Seed, 1978).

Figura 3.9 - Variação do deslocamento permanente normalizado em relação à razão de acelerações $k_{y} / k_{\max }$. (Makdisi e Seed, 1978)

Figura 3.10 - Caracterização simplificada de um movimento sísmico em afloramento rochoso em função da distância epicentral: a) variação da aceleração máxima horizontal MHA (Abrahamson e Silva, 1997); b) variação do período fundamental $T_{m}$ (Rathje et al., 2004); c) variação da duração significativa $\mathrm{D}_{5-95}$ (Abrahamson e Silva, 1996).

Figura 3.11 - Período fundamental inicial $\left(T_{s}\right)$ da massa de solo potencialmente instável (Bray, 2007).

Figura 3.12 - Máxima aceleração horizontal equivalente normalizada (MHEA) versus razão entre períodos fundamentais da massa instável $\left(T_{s}\right)$ e do terremoto $T_{m}$ - Bray e Rathje (1998). 
Figura 3.13 - Deslocamentos normalizados na base (Bray e Rathje, 1998).

Figura 3.14 - Estimativa simplificada do coeficiente sísmico de escoamento $k_{y}$ : a) deslizamentos superficiais;

b) deslizamentos profundos (Bray e Travasarou, 2007).

Figura 3.15 - Probabilidade de deslocamento nulo $(D \leq 1 \mathrm{~cm})$ em relação: a) coeficiente sísmico de escoamento $k_{y}$;

b) período fundamental inicial do talude $T_{s}$; c) aceleração espectral $S_{a}\left(1,5 T_{s}\right)$; (Adaptado de Bray e Travasarou, 2007).

Figura 4.1 - Exemplo de um registro sísmico saturado devido à proximidade do movimento captado mediante sismógrafo (ingeominas.gov.com)

Figura 4.2 - Efeitos de ruídos no sinal sísmico: a) ruído de alta frequência; b) ruído de baixa frequência (Hudson, 1979)

Figura 4.3 - Erros introduzidos nas velocidades e deslocamento pela falta de correção da linha base no acelerograma. (Modificado de Hudson (1979), apud de Carreño et al. (1999)).

Figura 4.4 - História de acelerações com e sem correção da linha base

Figura 4.5 - Localização do registro sísmico de entrada (Itasca, 2011).

Figura 4.6 - Processo de deconvolução e de convolução de registros sísmicos (Huertas, 2012).

Figura 4.7 - Processo de deconvolução considerando condições de contorno: a)base rígida b)base flexível (Mejia e Dawson 2006)

Figura 4.8 - Condições de contorno de campo livre (Loayza 2009)

Figura 4.9 - Variação da razão de amortecimento crítico normalizado em relação à frequência angular (Itasca, 2011)

Figura 4.10 - Limite superior da curva de redução do módulo de cisalhamento para areias, proposta por Seed \& Idriss (1970). 
Figura 4.11 - Ajuste do programa FLAC v.8 às curvas experimentais de Seed e ldriss (1970) para areias: a) degradação do módulo de cisalhamento; b) aumento da razão de amortecimento.

Figura 5.1 - Análise Determinística de Ameaça Sísmica (Kramer, 1996)

Figura 5.2 - a) Isozonas sísmicas no territorio equatoriano;

b) PGA rock na área do projeto (Norma Equatoriana da Construção NEC, 2014)

Figura 5.3 - Curvas de ameaça sísmica para a cidade de Azogues para períodos estruturais de 0,$1 ; 0,2 ; 0,5$ e 1,0 s (NEC, 2014)

Figura 5.4 - Espectros de resposta propostos por Newmark (Newmark \& Hall, 1969)

Figura 5.5 - Espectro de resposta para o terremoto El Centro a partir da aceleração, velocidade e deslocamento máximos (Clough \& Pezien, 1993)

Figura 5.6 - Espectro de resposta a partir de informação sísmica (Adaptado de Almeida, 1997)

Figura 5.7 - Espectro sísmico elástico em acelerações representativo de sismo de projeto no Equador (NEC, 2014)

Figura 5.8 - Geração de sismos artificiais por normalização de registros: a) acelerograma inicial; b) acelerograma modificado na escala 1,5 (Kramer, 1996)

Figura 5.9 - Geração de sismos artificiais no domínio do tempo:

a) função de ruído branco é filtrada para produzir; b) função ruído branco filtrada no domínio do tempo; c) função envoltória; d) sismo artificial no domínio do tempo (Kramer, 1996).

Figura 5.10 - Geração de sismos no domínio da frequência:

a) função de ruído branco ajustada à envoltória; b) função de ruído branco no domínio do tempo; c) espectro de fase de Fourier; d) espectro de amplitude de Fourier; e) acelerograma artificial no domínio do tempo (Kramer, 1996).

Figura 5.11 - Geração de movimentos mediante funções de Green (Kramer, 1996) 
Figura 5.12 - Espectro de potência do registro de velocidades (modificado de Flac v.8 User's manual)

Figura 6.1 - Rede rodoviária federal do Equador (Ministério de Transportes e Obras Públicas - Equador)

Figura 6.2 - Talude natural na abscissa 4+990

Figura 6.3 - Ensaios geofísicos de propagação de ondas de cisalhamento nas vizinhanças do talude (Ministério de Transporte e Obras Públicas - Equador)

Figura 6.4 - Localização de epicentros dos sismos: a) cidade de La Troncal 15/11/2015; b) cidade de Bucay 25/03/2014; c) cidade de Bahia de Caraquez 4/08/1998 (Red Sísmica del Austro, Instituto Geofísico Ecuador).

Figura 6.5 - Espectro elástico de resposta em acelerações de acordo com a Norma Equatoriana da Construção (NEC, 2014).

Figura 6.6 - Sismo de La Troncal: a) ajuste ao espectro elástico de resposta da norma NEC (2014); b) registro acelerográfico de projeto.

Figura 6.7 - Sismo de Bucay: a) ajuste ao espectro elástico de resposta da norma NEC (2014); b) registro acelerográfico de 125 projeto.

Figura 6.8 - Sismo de Bahia de Caraquez: a) ajuste ao espectro elástico de resposta da norma NEC (2014); b) registro acelerográfico de projeto

Figura 6.9 - Ajuste ao espectro elástico da norma NEC (2014) e história de acelerações sismo artificial sismo 1.

Figura 6.10 - Comparação dos acelerogramas após filtragem de frequência e correção da linha base no intervalo inicial dos registros de 0 a 30 segundos: a) sismo de La Troncal; b) sismo de Bucay; c) sismo de Bahia de Caraquez.

Figura 6.11 - Frequências de corte $\left(f_{c}=12 \mathrm{~Hz}\right)$ estimadas a partir dos espectros de potência: a) sismo de La Troncal; b) sismo de Bucay; c) sismo de Bahia de Caraquez. 
Figura 6.12 - Estratos de solo presentes na análise de estabilidade do talude.

Figura 6.13 - Malha de diferenças finitas e condições de contorno para a análise estática.

Figura 6.14 - Fator de segurança estático em potenciais superfícies locais de ruptura: a) método de redução dos parâmetros de resistência (Flac 2D) FS =0,94; b) método das fatias de Spencer (Slide 6.0) FS = 1,02.

Figura 6.15 - Estudo de estabilidade na abscissa 4+990:

a) seção típica de reforço estrutural; b) ancoragens executadas no talude (Caminosca S.A.).

Figura 6.16 - Fator de segurança talude com reforço: a) método de redução da resistência $F S=1,16$ b) equilíbrio limite com superfície de ruptura circular $\mathrm{FS}=1,4$. c) equilíbrio limite com superfície de ruptura poligonal $F S=1,2$.

Figura 6.17 - Fator de segurança pseudo-estático talude com reforço estrutural pelos métodos de equilíbrio limite (Slide 6.0) de Spencer e Bishop simplificado considerando: a) superfície planar; b) superfície circular.

Figura 6.18 - Fator de segurança pseudo-estático do talude com reforço estrutural pelo método de redução dos parâmetros de resistência (Flac 2D v 7.0).

Figura 6.19 - Colunas de solo para estimativa da história de acelerações em pontos da potencial superfície de deslizamento determinada na análise de estabilidade pseudo-estática.

Figura 6.20 - Deslocamentos permanentes pelo método de Newmark (1965) considerando os sismos de projeto: a) Bahia de Caraquez; b) Bucay; c) La Troncal; d) sismo 1.

Figura 6.21 - Deslocamento permanente pelo método de Newmark para sismo Bucay estimado no programa Slide v7.0

Figura 6.22 - Método de Newmark na versão proposta por Houston et al. (1987) 
Figura 6.23 - Método de Newmark, versão de Houston et al (1987): a) sismo de Bahia de Caraquez; b) sismo de Bucay; c) sismo de La Troncal; d) sismo artificial 1.

Figura 6.24 - Deslocamentos permanentes estimados pelo método de Bray e Travasarou (2007): a) sismo de Bahia de Caraquez;b) sismo de Bucay; c) sismo de La Troncal.

Figura 6.25 - Deslocamento permanente médio $D$ e $D+/-\sigma$ pelo método de Rathje e Saygili (2011).

Figura 6.26 - Comparação da variação com a profundidade da aceleração máxima na coluna de solo: a) método de Newmark; b) método de Newmark - versão Houston et al (1987).

Figura 6.27 - Condições de contorno na simulação do comportamento dinâmico do talude.

Figura 6.28 - Comparação entre velocidades de entrada (registro sísmico) e na base do modelo calculada pelo programa Flac 2D, em simulação elástica linear, não amortecida: a) sismo de Bahia de Caraquez; b) sismo de Bucay; c) sismo de La Troncal.

Figura 6.29 - Espectro de potência das velocidades na hipótese de material elástico linear não amortecido: a) sismo de Bahia de Caraquez; b) sismo de Bucay; c) sismo de La Troncal.

Figura 6.30 - Contornos de máximas deformações cisalhantes:

a) sismo de Bahia de Caraquez; b) sismo de Bucay; c) sismo de La Troncal

Figura 6.31 - Rotação da base do modelo: a) sem aplicação da correção; b) com aplicação de correção no programa Flac 2D v7.0.

Figura 6.32 - Comparação de funções de degradação do modulo de cisalhamento publicadas na literatura e ajustadas no programa Flac 2D no modelo Sig3.

Figura 6.33 - Coluna de solo simulada no programa SHAKE2000.

Figura 6.34 - Comparação da resposta dinâmica entre os programas SHAKE2000 e FLAC 2D v7: a) aceleração horizontal horizontal máxima; b) tensão cisalhante cíclica máxima. 
Figura 6.35 - Contornos de deslocamentos permanentes causados pelo terremoto de Bahia de Caraquez: a) deslocamentos horizontais; b) deslocamentos verticais.

Figura 6.36 - Contornos de deslocamentos permanentes causados pelo sismo de Bucay: a) deslocamentos horizontais; b) deslocamentos verticais.

Figura 6.37 - Contornos de deslocamentos permanentes causados pelo sismo de La Troncal: a) deslocamentos horizontais; b) deslocamentos verticais.

Figura 6.38 - Contornos de deslocamentos permanentes causados pelo sismo artificial sismo 1: a) deslocamentos horizontais; b) deslocamentos verticais.

Figura 6.39 - Historia de acelerações horizontais na crista do talude: a) sismo de Bahia de Caraquez; b) sismo de Bucay; c) sismo de La Troncal; d) sismo 1.

Figura 6.40 - Historia de deslocamentos horizontal e vertical na crista do talude: a) sismo de Bahia de Caraquez; b) sismo de Bucay; c) sismo de La Troncal; d) sismo 1.

Figura 6.41 - Espectro de resposta em aceleração horizontal na crista do talude para os terremotos Bahia de Caraquez, Bucay, La Troncal e sismo artificial 1.

Figura 6.42 - Distribuição de deslocamentos permanentes causados pelos sismos de projeto: a) deslocamento horizontal; b) deslocamento vertical.

Figura 7.1 - CFRD Mazar - Equador: a) vista geral do projeto; b) seção máxima (Toledo, 2009); c) localização no mapa de isozonas sísmicas (NEC-2014)

Figura 7.2 - Variação do ângulo de atrito de enrocamento em função da tensão vertical atuante (Adaptado de Leps, 1970).

Figura 7.3 - Distâncias epicentrais da CFRD Mazar aos sismos de projeto: a) La Troncal; b) Paute Base 1; c) Paute Base 3.

Figura 7.4 - Espectros elásticos OBE, MCE (Norma Equatoriana da Construção NEC, 2014). 
Figura 7.5 - Sismos de projeto (OBE), após ajuste ao espectro elástico, correção da linha base e filtragem de frequências $(0,1-12 \mathrm{~Hz})$ : a) La Troncal; b) Paute Base 1; c) Paute Base 3.

Figura 7.6 - Sismos de projeto (MCE), após ajuste ao espectro elástico de projeto, correção da linha base e filtragem de frequências $(0,1-12 \mathrm{~Hz})$ : a) La Troncal; b) Paute Base 1; c) Paute Base 3.

Figura 7.7 - Frequências de corte determinadas dos espectros de potência dos sismos de projeto OBE: a) La Troncal;

b) Paute Base 1; c) Paute Base 3

Figura 7.8 - Frequências de corte determinadas dos espectros de potência dos sismos de projeto MCE: a) La Troncal;

b) Paute Base 1; c) Paute Base 3.

Figura 7.9 - Geometria da barragem de Mazar.

Figura 7.10 - Superfícies de ruptura locais com reservatório na máxima capacidade: a) $F S=1,3$; b) $F S=1,35$.

Figura 7.11 - Fatores de segurança para superfícies de ruptura globais na barragem de Mazar: a) reservatório na máxima capacidade $F S=1,70 ;$ b) reservatório vazio $F S=1,55$.

Figura 7.12 - Fatores de segurança calculados com método das fatias (método de Spencer) na barragem de Mazar:

a) reservatório na máxima capacidade $F S=1,73$;

b) reservatório vazio $\mathrm{FS}=1,43$.

Figura 7.13 - Fator de segurança pseudoestático no caso de reservatório vazio com o método das fatias de Spencer:

a) $\mathrm{OBE} F S=1,06$; b) $\mathrm{MCE} F \mathrm{~F}=0,91$.

Figura 7.14 - Fator de segurança pseudo-estático no caso de reservatório cheio com o método das fatias de Spencer a) $\mathrm{OBE} F \mathrm{~F}=1,3$; b) MCE FS = 1,15.

Figura 7.15 - Fator de segurança pseudoestático pelo método de redução dos parâmetros de resistência (software Flac 2D v8.0); a) reservatório vazio $\mathrm{OBE} F S=1,09$; b) reservatório cheio MCE FS $=1,14$ 
Figura 7.16 - Deslocamentos permanentes na barragem de Mazar com reservatório cheio pelo método de Bray e Travasarou: a) MCE; b) OBE

Figura 7.17 - Deslocamentos permanentes na barragem de Mazar com reservatório vazio pelo método de Bray e Travasarou: a) MCE; b) OBE

Figura 7.18 - Dependência da probabilidade de deslocamento nulo em função de: a) coeficiente de escoamento; b) período fundamental inicial; c) aceleração espectral em 1,5 vezes 0 período fundamental inicial (Bray and Travasarou, 2007).

Figura 7.19 - Deslocamentos permanentes médio e afastados (+/-) de um desvio padrão, pelo método de Rathje e Saygili: a) MCE, reservatório cheio; b) MCE, reservatório vazio.

Figura 7.20 - Comparação das histórias de velocidade de entrada (registro sísmico) e calculada na base do modelo (Flac 2D v8) na simulação elástica linear não amortecida: a) sismo La Troncal;b) sismo Paute Base 1; c) sismo. Paute Base 3.

Figura 7.21 - Determinação da frequência fundamental da Barragem de Mazar; a) sismo La Troncal; b) sismo Paute Base 1; c) sismo Paute Base 3.

Figura 7.22 - Contornos de máximas deformações cisalhantes cíclicas: a) sismo de La Troncal OBE; b) Sismo de La Troncal MCE c) Sismo Paute Base 1 OBE; d) Sismo Paute Base 1 MCE e) Sismo Paute Base 3 OBE; f) Sismo Paute Base 3 MCE.

Figura 7.23 - Zonas na barragem com diferentes ângulos de atrito (Gazetas and Dakoulas, 1992).

Figura 7.24 - Curvas de degradação do modulo cisalhante e aumento da razão de amortecimento para os materiais componentes da CFRD Mazar.

Figura 7.25 - Resposta em aceleração horizontal na crista da barragem para o sismo La Troncal: a) MCE; b) OBE.

Figura 7.26 - Deslocamentos horizontais causados pelo sismo La Troncal: a) MCE; b) OBE. 
Figura 7.27 - Deslocamentos verticais causados pelo sismo La Troncal: a) MCE; b) OBE.

Figura 7.28 - Histórias de deslocamentos horizontal e vertical no ponto central da crista da barragem no sismo La Troncal:

a) MCE; b) OBE.

Figura 7.29 - Espectro de resposta em aceleração horizontal na crista da barragem, reservatório máxima capacidade, sismo de La Troncal: a) MCE; b) OBE.

Figura 7.30 - Resposta em aceleração horizontal na crista da barragem, terremoto Paute Base 1: a) MCE; b) OBE.

Figura 7.31 - Deslocamentos horizontais causados pelo sismo Paute Base 1: a) MCE; b) OBE.

Figura 7.32 - Deslocamentos verticais causados pelo sismo Paute Base 1: a) MCE; b) OBE.

Figura 7.33 - Histórias de deslocamentos horizontal e vertical no ponto central da crista da barragem, terremoto Paute Base 1 a) MCE; b) OBE.

Figura 7.34 - Espectro de resposta em aceleração horizontal na crista da barragem, reservatório máxima capacidade, sismo de La Troncal: a) MCE; b) OBE.

Figura 7.35 - Resposta em aceleração horizontal na crista da barragem, terremoto Paute Base 3: a) MCE; b) OBE.

Figura 7.36 - Contornos de deslocamentos horizontais causados pelo sismo Paute Base 3: a) MCE; b) OBE.

Figura 7.37 - Contornos de deslocamentos verticais causados pelo sismo Paute Base 3: a) MCE; b) OBE.

Figura 7.38 - Histórias de deslocamentos horizontal e vertical no ponto central da crista da barragem, terremoto Paute Base 3:

a) MCE; b) OBE.

Figura 7.39 - Espectro de resposta em aceleração horizontal na crista da barragem, reservatório máxima capacidade, terremoto Paute Base 3: a) MCE; b) OBE. 
Figura 7.40 - Distribuição de deslocamentos permanentes na condição de reservatório cheio MCE: a) deslocamento horizontal; b) deslocamento vertical.

Figura 7.41 - Distribuição de deslocamentos permanentes na condição de reservatório cheio OBE: a) deslocamento horizontal; b) deslocamento vertical.

Figura 7.42 - Acelerações de pico ao longo da coluna de solo representativa da barragem de Mazar obtidas com o programa computacional SHAKE2000.

Figura 7.43 - Resposta em aceleração horizontal na crista da barragem, condição de reservatório vazio, terremoto La Troncal: a) MCE; b) OBE.

Figura 7.44 - Deslocamentos horizontais permanentes, reservatório vazio, sismo La Troncal: a) MCE; b) OBE.

Figura 7.45 - Deslocamentos verticais permanentes, reservatório vazio, sismo La Troncal: a) MCE; b) OBE.

Figura 7.46 - Histórias de deslocamentos horizontal e vertical no ponto central da crista da barragem, reservatório vazio, sismo La Troncal: a) MCE; b) OBE.

Figura 7.47 - Espectro de resposta em aceleração horizontal na crista da barragem, reservatório vazio, sismo de La Troncal: a) MCE; b) OBE.

Figura 7.48 - Resposta em aceleração horizontal na crista da barragem, condição de reservatório vazio, sismo Paute Base 1: a) MCE; b) OBE.

Figura 7.49 - Deslocamentos horizontais, reservatório vazio, sismo Paute Base 1: a) MCE; b) OBE.

Figura 7.50 - Deslocamentos verticais, reservatório vazio, sismo Paute Base 1: a) MCE; b) OBE.

Figura 7.51 - Histórias de deslocamentos horizontal e vertical no ponto central da crista da barragem, reservatório vazio, sismo Paute Base 1: a) MCE; b) OBE. 
Figura 7.52 - Espectro de resposta em aceleração horizontal na crista da barragem, reservatório vazio, sismo Paute Base 1: a) MCE; b) OBE.

Figura 7.53 - Resposta em aceleração horizontal na crista da barragem, condição de reservatório vazio, sismo Paute Base 3:

a) MCE; b) OBE.

Figura 7.54 - Deslocamentos horizontais, reservatório vazio, sismo Paute Base 3: a) MCE; b) OBE.

Figura 7.55 - Deslocamentos verticais, reservatório vazio, sismo Paute Base 3: a) MCE; b) OBE.

Figura 7.56 - Histórias de deslocamentos horizontal e vertical no ponto central da crista da barragem, reservatório vazio, sismo Paute Base 3: a) MCE; b) OBE.

Figura 7.57 - Espectro de resposta em aceleração horizontal na crista da barragem, reservatório vazio, sismo Paute Base 3: a) MCE; b) OBE.

Figura 7.58 - Distribuição de deslocamentos permanentes na condição de reservatório vazio MCE: a) deslocamento horizontal; b) deslocamento vertical.

Figura 7.59 - Distribuição de deslocamentos permanentes na condição de reservatório vazio OBE: a) deslocamento horizontal; b) deslocamento vertical.

Figura 7.60 - Curvas de histerese tensão cisalhante cíclica deformação cisalhante cíclica no sismo La Troncal, terremoto de projeto MCE: a) ponto 1 do enrocamento $3 \mathrm{~B}$; b) ponto 2 do enrocamento $3 \mathrm{C}$.

Figura 7.61 - Curvas de histerese tensão cisalhante cíclica deformação cisalhante cíclica, sismo La Troncal, terremoto de projeto OBE: a) ponto 1 do enrocamento $3 \mathrm{~B}$; b) ponto 2 do enrocamento $3 \mathrm{C}$. 


\section{Lista de tabelas}

Tabela 2.1 - Terremotos no Equador com magnitude superior a 6 entre 1924 e 2016 (GEER-ATC Earthquake Reconnaissance, National Science Foundation US Government).

Tabela 3.1 - Coeficientes sísmicos recomendados na literatura. Adaptado de Melo e Sarma (2004).

Tabela 3.2 - Critérios sugeridos por Duncan e Wright (2005) para análises pseudo-estáticas em taludes de solo não suscetíveis à liquefação.

Tabela 3.3 - Parâmetros para o modelo escalar e modelo vetorial no método de Saygili e Rathje (Rathje e Saygili, 2009).

Tabela 3.4 - Modelos constitutivos elasto-plásticos comuns para carregamentos cíclicos (Contreras, 2014).

Tabela 5.1 - Classificação do perfil do terreno (NEC, 2014).

Tabela 5.2 - Coeficientes de amplificação $\left(F_{\mathrm{a}}, F_{d}\right.$ e $\left.F_{s}\right)$ para o espectro elástico de projeto segundo a zona sísmica, conforme a Norma Equatoriana de Construção (Adaptado da NEC, 2014)

Tabela 6.1 - Propriedades geotécnicas dos materiais da encosta (Ministério de Obras Públicas Equador).

Tabela 6.2 - Classificação de solos em função da velocidade de propagação da onda cisalhante $\left(V_{s}\right)$ - International Building Code (IBC, 2009) - American Society of Civil Engineering (ASCE 7-10)

Tabela 6.3 - Parâmetros do terreno na região de estudo (NEC, 2014) utilizados para gerar o espectro de resposta.

Tabela 6.4 - Sismos de projeto, Intensidade de Arias $\left(I_{a}\right)$, intensidade característica $\left(I_{c}\right)$.

Tabela 6.5 - Fatores de segurança determinados nas análises pseudo-estáticas do talude utilizando estruturas de reforço. 
Tabela 6.6 - Deslocamentos permanentes estimados pelo método de Newmark (1965) com o programa computacional SHAKE 2000.

Tabela 6.7 - Deslocamentos máximos permanentes pelo método de Newmark calculados pelo programa computacional Slide $\mathbf{7} 7.0$.

Tabela 6.8 - Deslocamentos permanentes computados no método de Newmark, versão de Houston et al. (1987).

Tabela 6.9 - Deslocamentos permanentes pelo método de Bray e Travasarou (2007).

Tabela 6.10 - Deslocamentos permanentes $(\mathrm{cm})$ pelo método de Rathje e Saygili (2011).

Tabela 6.11 - Resumo dos deslocamentos permanentes (cm).

Tabela 6.12 - Parâmetros do modelo Sig3 (Flac 2D) para ajuste das funções de degradação do módulo cisalhante propostas na literatura.

Tabela 6.13 - Deslocamentos permanentes $(\mathrm{m})$ na simulação dinâmica não linear, amortecida.

Tabela 7.1 - Materiais e método construtivo da CFRD Mazar (Cruz, 2014).

Tabela 7.2 - Propriedades dos materiais da fundação e corpo da barragem de Mazar (Hidropaute, 2011).

Tabela 7.3 - Terremotos de projeto (OBE, MCE) para a barragem de enrocamento de Mazar.

Tabela 7.4 - Sismos de projeto CFRD Mazar, Intensidade de Arias $I_{a}$, intensidade característica $I_{c}$.

Tabela 7.5 - Resumo dos fatores de segurança obtidos da análise pseudo-estática da barragem de Mazar.

Tabela 7.6 - Deslocamentos permanentes mediante as funções analíticas propostas por Cai e Bathurst (1996). 
Tabela 7.7 - Deslocamentos permanentes $(\mathrm{cm})$ pelo método simplificado de Rathje e Saygili (2011).

Tabela 7.8 - Resumo de deslocamentos permanentes, reservatório vazio, métodos simplificados.

Tabela 7.9 - Constantes de ajuste modelo Sig3 CFRD Mazar.

Tabela 7.10 - Resumo dos deslocamentos permanentes e acelerações de pico produzidas na crista da CFRD Mazar, com o reservatório cheio.

Tabela 7.11 - Resumo dos deslocamentos permanentes e acelerações de pico produzidas na crista da CFRD Mazar, com o reservatório vazio. 


\section{Lista de símbolos}

\begin{tabular}{|c|c|c|}
\hline & ASCE & American Society of Civil Engineering \\
\hline & $a, b, x_{o}$ & Parâmetros do modelo Sig3 \\
\hline & $a(t)$ & Historia de acelerações \\
\hline & $a_{y}$ & Aceleração de escoamento \\
\hline & $\alpha$ & Coeficiente de amortecimento de Rayleigh \\
\hline & $\beta$ & Coeficiente de amortecimento de Rayleigh \\
\hline & $c$ & Coesão modelo Mohr Coulomb \\
\hline & {$[\mathrm{C}]$} & Matriz de amortecimento viscoso \\
\hline & $\mathrm{D}$ & Deslocamento permanente \\
\hline & $\mathrm{D}_{5-95}$ & Duração significativa do terremoto \\
\hline & $\Delta$ & Distância epicentral \\
\hline & $\Delta l$ & Tamanho do elemento na malha \\
\hline & $\mathrm{E}$ & Módulo de Young \\
\hline$\underset{\infty}{\infty}$ & $\varepsilon_{v d}$ & Deformação volumétrica acumulada \\
\hline 贶 & $\xi$ & Razão de amortecimento \\
\hline$\underset{+}{2}$ & $f$ & Fator de calibração adimensional \\
\hline 光 & $f_{c}$ & Frequência de corte do registro sísmico \\
\hline : & FS & Fator de segurança \\
\hline 0 & $f_{\max }$ & Frequência máxima transmitida \\
\hline 焉 & $G$ & Módulo de cisalhamento do material \\
\hline 总 & $g$ & Aceleração da gravidade \\
\hline 仓ั & $G_{\max }$ & Módulo de cisalhamento máximo do material \\
\hline 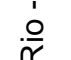 & $\gamma$ & Peso específico \\
\hline 峁 & $\mathrm{H}$ & Altura da estrutura \\
\hline & $H E A$ & Aceleração Horizontal Equivalente \\
\hline & $I_{a}$ & Intensidade de Arias \\
\hline & $I_{c}$ & Intensidade característica \\
\hline & $I P$ & Índice de plasticidade \\
\hline & $\mathrm{K}$ & Módulo de deformação volumétrica \\
\hline & {$[\mathrm{K}]$} & Matriz de rigidez \\
\hline & $k_{h}$ & Coeficiente pseudo-estático horizontal \\
\hline & $k_{v}$ & Coeficiente pseudo-estático vertical \\
\hline & $k_{y}$ & Coeficiente de escoamento \\
\hline & {$[\mathrm{M}]$} & Matriz de massa \\
\hline & $m_{b}$ & Magnitude de ondas de corpo \\
\hline & $M_{L}$ & Magnitude local \\
\hline & $M_{s}$ & Magnitude de ondas de superfície \\
\hline & $M_{w}$ & Magnitude de momento \\
\hline & $\varnothing$ & Ângulo de atrito modelo Mohr Coulomb \\
\hline & $\mathrm{P}$ & Ondas de corpo primarias \\
\hline
\end{tabular}




$\begin{array}{ll}\text { PGA } & \text { Aceleração pico no terreno } \\ \text { PGV } & \text { Velocidade pico no terreno } \\ \rho & \text { Massa específica } \\ \mathrm{R} & \text { Ondas de Rayleigh } \\ \mathrm{S} & \text { Ondas de corpo secundarias } \\ S_{a} & \text { Aceleração espectral } \\ \mathrm{S}_{\mathrm{u}} & \text { Resistência ao cisalhamento não drenada } \\ \tau & \text { Tensão cisalhante } \\ T_{s} & \text { Período inicial fundamental da estrutura } \\ \mathrm{USGS} & \text { United States Geological Survey } \\ v & \text { Coeficiente de Poisson } \\ V_{\mathrm{s}} & \text { Velocidade da onda cisalhante } \\ w_{n} & \text { Frequência de vibração }\end{array}$




\section{1 \\ Introdução}

O estudo da resposta dinâmica de barragens de enrocamento e taludes naturais submetidos a carregamentos sísmicos compreende análises que envolvem complexos modelos para simulação do comportamento não linear e inelástico de solos reais, o que necessariamente implica na utilização de ferramentas numéricas, como o método dos elementos finitos, para obter resultados aproximados dos efeitos produzidos por eventos sísmicos em termos de deslocamentos, tensões e estabilidade destas geoestruturas.

Devido à complexidade inerente na aplicação de métodos numéricos, principalmente na definição da natureza dos carregamentos impostos por terremotos e do amortecimento dos diferentes materiais que constituem o maciço de fundação e a estrutura analisada, avaliações de deslocamentos permanentes e da estabilidade de taludes são ainda feitas na prática da engenharia por métodos simplificados, como o método pseudoestático (Terzaghi, 1950) para cálculo do fator de segurança, e os métodos de Newmark (Newmark, 1965), Makdisi e Seed (1978), Bray e Travasarou (2007) e Rathje e Saygili (2011) para determinação dos deslocamentos permanentes.

O método pseudoestático, baseado no conhecido método das fatias para determinação do fator de segurança de taludes sob carregamento estático, simplifica o efeito do carregamento sísmico pela introdução de uma força inercial horizontal aplicada no centro de gravidade da massa susceptível à instabilidade. $\mathrm{O}$ fato deste método utilizar uma força com módulo constante, dependente unicamente do valor de um coeficiente sísmico, com direção e sentido invariáveis, impossibilita uma análise no domínio do tempo e tampouco produz informações sobre os deslocamentos permanentes sofridos pelo talude pois no método de equilíbrio limite o solo é modelado como material rígido-perfeitamente plástico. Limitações na aplicação deste método são conhecidas, relacionadas à seleção adequada do coeficiente sísmico $k$, como, por exemplo, na inesperada ruptura da 
barragem Lower San Fernando, na Califórnia, onde análises pseudoestáticas prévias garantiam fatores de segurança superiores a 1 (Seed et al., 1973).

A necessidade de se determinar a condição de servicibilidade de geoestruturas após a ocorrência de terremotos requer a estimativa do desenvolvimento de deslocamentos permanentes ao longo do tempo. O fato de que as acelerações induzidas pelo sismo variam com o tempo, faz com que as forças de inércia e os correspondentes fatores de segurança pseudoestáticos também variem durante um terremoto. Se as forças de inércia atuantes na potencial massa de solo instável tornaram-se grandes o suficiente de modo que a resultante das forças ativas (estáticas e dinâmicas) seja superior à resistência ao cisalhamento desenvolvida ao longo da potencial superfície de deslizamento, então o fator de segurança pseudoestático será inferior a 1 e a massa de solo não estará mais em equilíbrio estático.

A situação é semelhante à de um bloco rígido sobre um plano inclinado excitado na sua base, analogia usada por Newmark (1965) para desenvolver o método que hoje leva o seu nome. Este método utiliza o registro sísmico de acelerações, que é integrado duplamente no tempo para produzir deslocamentos permanentes, sempre que o valor absoluto da aceleração ultrapassar o valor da aceleração de escoamento, esta determinada quando o fator de segurança pseudoestático atingir FS = 1. Como já pode ser notado, o método de Newmark (1965) incorpora dois parâmetros importantes, que o diferencia do método pseudoestático: a duração do sismo e as amplitudes das acelerações.

O fato de que uma massa de solo é um corpo deformável que não pode ser fielmente representada por um bloco rígido, fez surgir um novo método para cálculo dos deslocamentos permanentes de taludes de barragens, conhecido como método simplificado de Makdisi e Seed (1978). Este modelo, apresentado sob forma de gráficos, foi desenvolvido em duas etapas de cálculo: a) obtenção da história no tempo da aceleração horizontal média equivalente (HEA) na massa de solo instável com base em análises pelo método dos elementos finitos e método da viga de cisalhamento (Seed e Martin, 1966; Ambraseys e Sarma, 1967); b) cálculo dos deslocamentos permanentes com a dupla integração das parcelas das acelerações superiores à aceleração de escoamento, conforme método de Newmark (1965). 
Com o aumento exponencial de registros acelerográficos de boa qualidade a partir do extensivo monitoramento efetuado pelo Serviço Geológico dos Estados Unidos (USGS) e em adição ao comportamento observado de barragens de terra e enrocamento assim como aterros de resíduos sólidos durante eventos sísmicos, deu como resultado novas abordagens do problema baseadas no desempenho destas estruturas avaliado mediante modelos simplificados empíricos utilizando-se métodos estadísticos e probabilísticos tais como os métodos de Bray e Travasarou (2007) e Rathje e Saygili (2011).

Modernamente, análises mais precisas no domínio do tempo podem ser executadas pela aplicação de métodos numéricos (método dos elementos finitos, método das diferenças finitas) considerando modelos cíclicos para representação da relação tensão x deformação do solo sob excitação sísmica, que incorporam características específicas como o amortecimento do material, definido como a perda de energia devido ao comportamento viscoso e inelástico do material. Modelos constitutivos para carregamentos cíclicos podem ser agrupados em 3 classes: a) modelo linear equivalente SHAKE (Schnabel et al., 1972); b) modelos não-lineares cíclicos que geralmente seguem as regras estendidas de Masing (Kramer, 1996) que estabelecem a forma do ciclo para representação das situações de carregamento inicial, descarregamento e recarregamento; c) modelos constitutivos elasto-plásticos, que permitem análises drenada e não drenada considerando uma grande variedade de história de tensões, mas cujos parâmetros requerem uma cuidadosa avaliação experimental para a descrição completa do modelo.

O objetivo do presente trabalho é estabelecer uma comparação entre modelos numéricos e os diversos modelos analíticos simplificados para análise do comportamento sísmico de taludes de encostas e de barragem de enrocamento situados no Equador. Os resultados se referem principalmente à condição de servicibilidade pós-sismo dos taludes que, na prática da engenharia, depende da aceitabilidade ou não dos deslocamentos permanentes acumulados, uma indicação empírica da "ruptura" do talude baseada não no critério usual de tensões cisalhantes máximas (fator de segurança) mas em deformações admissíveis. 


\section{1.}

\section{Organização da dissertação}

A dissertação está composta por oito capítulos, com os seguintes conteúdos específicos, além do presente capítulo de introdução onde é apresentado o tema de pesquisa:

- Capítulo 2: apresenta conceitos básicos de propagação de ondas sísmicas em um meio elástico, assim como as principais características de terremotos.

- Capítulo 3: resume os métodos mais comumente utilizados na engenharia geotécnica para estimativa de deslocamentos permanentes e comportamento dinâmico em geral de estruturas de terra.

- Capítulo 4: apresenta algumas considerações sobre modelos constitutivos cíclicos para análise numérica do comportamento dinâmico de geoestruturas.

- Capítulo 5: contém considerações sobre as características de sismicidade no Equador e apresenta o estudo de ameaça sísmica contido na Norma Equatoriana da Construção (NEC, 2014).

- Capítulo 6: apresenta o primeiro estudo de caso, considerando um talude de encosta situado ao longo de uma das principais estradas federais do Equador.

- Capítulo 7: apresenta o segundo caso analisado, a Barragem de enrocamento CFRD de Mazar que forma parte do projeto hidroelétrico Paute localizada na região sudeste do Equador no leito do rio Paute.

- Capítulo 8: as conclusões do trabalho são discutidas e temas são sugeridos para futuras pesquisas na área de comportamento sísmico de geoestruturas. 


\section{2 \\ Conceitos básicos de sismicidade e propagação de ondas elásticas}

Desde o ponto de vista da engenharia geotécnica define-se sismo ou terremoto como um movimento do terreno, que libera bruscamente grande quantidade de energia produzido, por duas possíveis fontes:

- Convergência, divergência (afastamento) ou contato, sob forma de movimento relativo lateral, entre placas tectônicas, caracterizando os sismos de subducção;

- Deformação ou ruptura de rochas adjacentes a uma falha geológica, caracterizando os sismos intraplacas.

A ocorrência de sismos de subducção agrupa-se principalmente nas zonas situadas nos limites de placas tectônicas, como no denominado "Círculo de Fogo do Pacifico“ (Figura 2.1), uma grande série de arcos vulcânicos e fossas oceânicas de 40 mil km de extensão, onde se registram $80 \%$ dos sismos do planeta, que se estende da costa ocidental sul-americana até a Nova Zelândia. Em média os sismógrafos captam algum tipo de abalo a cada cinco minutos. Alguns dos piores desastres naturais já registrados ocorreram em países localizados ao longo do Círculo de Fogo do Pacífico, como o tsunami de dezembro de 2004 na Indonésia, após um sismo de magnitude 9.1, o terremoto do Chile de 1960, de magnitude 9.6 a maior já registrada na história, e os recentes terremotos do Chile, em 2010, com magnitude 8.8 e do Equador, em 2016, com magnitude 7.8.

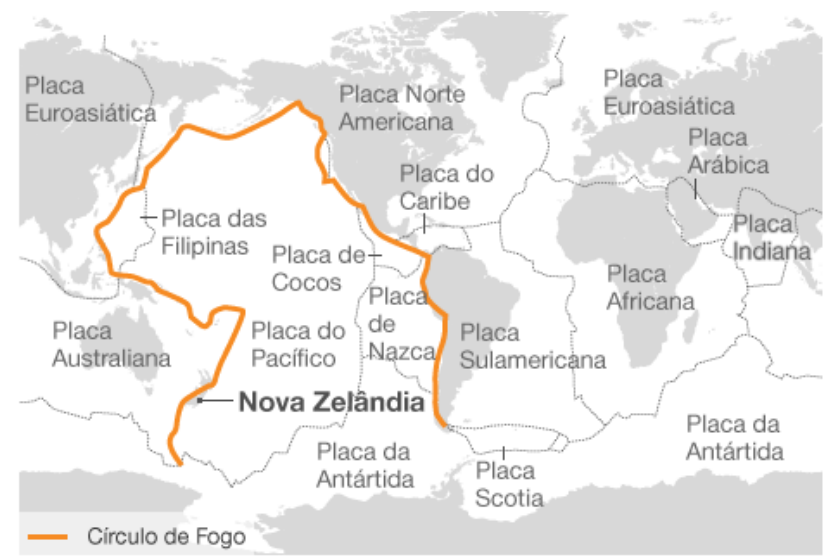

Figura 2.1 - O círculo de fogo no oceano Pacífico (www.bbc.com) 
Os sismos de intraplaca ocorrem na mesma litosfera, como em parte do território do Equador situado no interior da placa Sul-Americana e distante de suas bordas, caracterizados como de falhamento superficial. Ocorrem entre 5 e 20 $\mathrm{km}$ de profundidade, região onde se localizam as rochas de maior dureza e de maior capacidade de armazenamento de energia de deformação. Estes sismos estão indiretamente associados com o fenômeno da subducção, pois são causados pelas concentrações superficiais de tensões no interior das placas tectônicas, por sua vez geradas pelos movimentos de subducção. Por serem de pouca profundidade produzem em geral danos significativos nas regiões mais próximas ao seu epicentro, não acompanhados por condições térmicas que afetem as propriedades mecânicas dos materiais da crosta, capazes de parcialmente derreter a rocha sólida formando magma que é expelido por vulcões.

No Equador foram registrados vários terremotos com magnitude $M_{w}$ superior a 6 desde 1924 até 2016 já seja com origem de subducção ou provocados por falhas locais (Tabela 2.1). O número de terremotos de baixa magnitude (entre 2 a 5) tem crescido a nível mundial, pelo fato de que cada vez mais sismógrafos são instalados para detectá-los. Em contrapartida, a frequência de terremotos com magnitude 6 ou superior tem permanecido constante; 17 terremotos com magnitude 8 ou superior ocorreram desde o ano 2000 e o número de terremotos com magnitudes entre 5 a 7.9 desde o ano 1990 foi próximo a 1500, segundo a USGS (United States Geological Survey). 
Tabela 2.1 - Terremotos no Equador com magnitude superior a 6 entre 1924 e 2016 (GEER-ATC Earthquake Reconnaissance, National Science Foundation US Government).

\begin{tabular}{|c|ccc|cc|}
\hline \multirow{2}{*}{ Data } & \multicolumn{2}{|c|}{ Localização } & & Parâmetros \\
\cline { 2 - 6 } & Cidade & Latitude & Longitude & Profundidade $(\mathrm{km})$ & $M_{w}$ \\
\hline $03 / 03 / 1924$ & Ecuador & -1.600 & -78.600 & & 6.9 \\
$02 / 10 / 1933$ & Ecuador & -2.000 & -81.000 & 33 & 6.9 \\
$10 / 08 / 1938$ & Alangasi & -0.300 & -78.400 & 10 & 6.3 \\
$14 / 05 / 1942$ & Guayaquil & -0.750 & -81.500 & 30 & 7.9 \\
$30 / 01 / 1943$ & Guayaquil & -2.100 & -80.500 & 100 & 6.9 \\
$04 / 08 / 1949$ & Pelileo & -1.400 & -78.500 & 10 & 6.7 \\
$05 / 08 / 1949$ & Ecuador & -1.500 & -78.200 & 60 & 6.8 \\
$05 / 08 / 1950$ & Ecuador & -1.500 & -78.200 & 60 & 6.8 \\
$16 / 01 / 1956$ & Ecuador & -0.500 & -80.500 & & 7.3 \\
$31 / 01 / 1958$ & Ecuador-Colombia & -1.500 & -79.500 & & 7.6 \\
$30 / 07 / 1960$ & Ecuador & -1.500 & -79.000 & 21 & \\
$17 / 12 / 1969$ & Saquisili & -0.800 & -78.300 & 27 & 6.2 \\
$09 / 04 / 1976$ & Esmeraldas & 0.780 & -79.800 & 9 & 6.7 \\
$31 / 12 / 1979$ & Tumaco & -1.500 & -79.500 & & 8.2 \\
$18 / 08 / 1980$ & W. Guayaquil & -1.948 & -80.017 & 55 & 5.6 \\
$06 / 03 / 1987$ & Napo-Quito & 0.083 & -77.785 & 10 & 7.2 \\
$22 / 09 / 1987$ & Ambato & -0.978 & -78.050 & 10 & 6.2 \\
$25 / 06 / 1989$ & Esmeraldas & 1.134 & -79.616 & 15 & 6.1 \\
$11 / 08 / 1990$ & Pamasqui & -0.059 & -78.449 & 5 & 6.4 \\
$03 / 10 / 1995$ & Quito & -2.750 & -77.881 & 24 & 7.0 \\
$28 / 03 / 1996$ & Cotopaxi & -1.036 & -78.737 & 33 & 5.9 \\
$04 / 08 / 1998$ & Bahia de Caraquez & -0.593 & -80.393 & 33 & 7.2 \\
$24 / 01 / 2005$ & W. Coast Ecuador & -1.364 & -80.785 & 17 & 6.1 \\
$24 / 10 / 2005$ & Baeza & -0.507 & -77.745 & 35 & 4.8 \\
$13 / 07 / 2007$ & Zaruma & -3.987 & -79.836 & 50 & 4.5 \\
$16 / 11 / 2007$ & Guayaquil & -2.312 & -77.838 & 123 & 6.8 \\
$09 / 10 / 2009$ & Tena & -0.962 & -77.817 & 35 & 5.4 \\
$12 / 08 / 2010$ & Manta & -1.266 & -77.306 & 207 & 7.1 \\
$29 / 10 / 2011$ & Pomasqui & -0.130 & -78.370 & 3 & 6 \\
$12 / 08 / 2014$ & Quito & -0.076 & -78.302 & 5 & 6.1 \\
$16 / 04 / 2016$ & Muisne, Manabi & 0.371 & -79.970 & 19 & 7.8 \\
$18 / 05 / 2016$ & Manabi & 0.465 & -79.641 & 31 & 6.8 \\
\hline
\end{tabular}

\section{1.}

\section{Ondas de tensão}

Quando uma rocha se fratura devido a tensões desenvolvidas na crosta, libera energia acumulada no material que se dissipa sob forma de calor e de ondas que se propagam através dos materiais geológicos sólidos (ondas de tensão). O ponto onde ocorre a fratura é conhecido como foco ou hipocentro e a projeção 
deste foco sobre a superfície é chamada de epicentro. A distância do local onde é registrado o movimento do terreno (sismógrafo) até o foco é chamada de distância hipocentral enquanto que a distância até o epicentro é denominada distância epicentral (Figura 2.2).

A distância epicentral é determinada pela diferença entre a chegada da onda P e a onda S na estação sismográfica. Determinando-se as distâncias epicentrais em relação a três estações sismográficas, separadas entre si de no mínimo 100 km, calcula-se o epicentro do sismo na interseção de três circunferências desenhadas com centro nas estações e raios iguais às distâncias epicentrais determinadas.

A distância epicentral pode ser expressa em quilômetros ao longo da superfície $\Delta_{\mathrm{km}}$ ou pelo ângulo central $\Delta^{\mathrm{o}}=\left(180^{\circ} / \pi\right)\left(\Delta_{\mathrm{km}} / \mathrm{R}\right)$ traçado do epicentro e do sismógrafo, ao centro da Terra, considerando o raio médio do planeta $\mathrm{R}=6371$ $\mathrm{km}$.

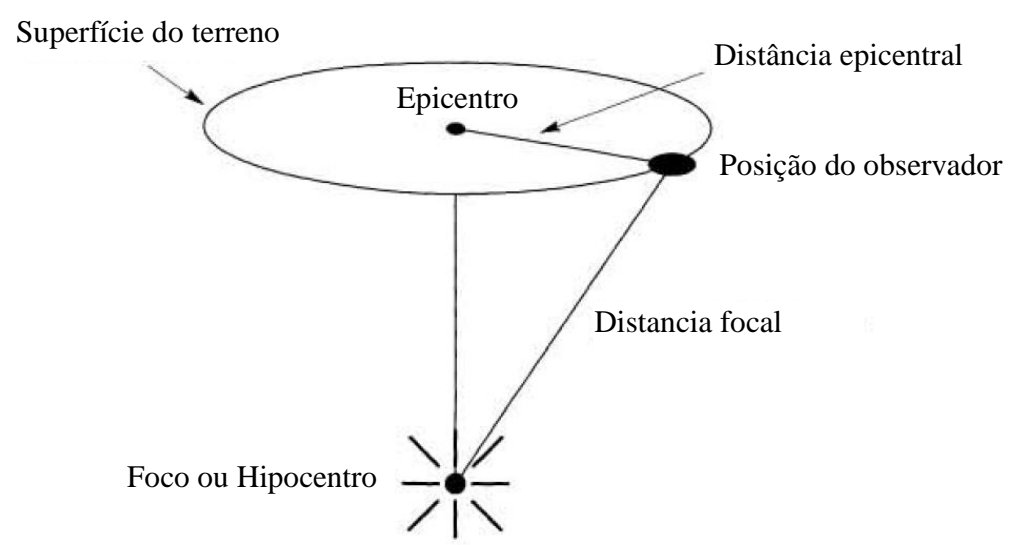

Figura 2.2 - Parâmetros geométricos para localização de um sismo (Adaptado de Kramer, 1996).

As ondas de tensão inicialmente propagam-se no subsolo em forma de ondas esféricas, mas com o aumento da distância percorrida a curvatura das trajetórias de propagação decresce; assim, em grandes distâncias, a frente de ondas pode ser considerada como uma superfície plana.

Soluções analíticas de propagação de ondas planas consideram a hipótese que o meio geológico é formado por material linearmente elástico, podendo esta hipótese ser levantada no caso da aplicação de métodos numéricos para obtenção de soluções inelásticas.

Ondas de tensão podem ser classificadas em dois grupos: ondas de corpo (P, $\mathrm{S})$, que se propagam no interior do subsolo, e ondas de superfície (R, L). 


\subsection{1. \\ Ondas de corpo}

\subsubsection{1.}

\section{Ondas P}

Denominadas também de ondas longitudinais, primárias ou compressivas, as ondas $\mathrm{P}$ se propagam na mesma direção de vibração das partículas do meio (sólido, líquido, gasoso) - Figura 2.3a. Como a rigidez à compressão de materiais geológicos é alta, a onda $\mathrm{P}$ se propaga rapidamente, sendo a primeira a ser captada nos sismógrafos durante a ocorrência de sismos - Figura 2.4. A velocidade de propagação $\alpha$ de ondas $P$ é dada pela teoria da elasticidade linear como:

$$
\alpha=\sqrt{\frac{\lambda+2 G}{\rho}}=\sqrt{\frac{E(1-v)}{\rho(1+v)(1-2 v)}}
$$

onde $\rho$ é a massa específica do material, $\lambda$ e $G$ são as constantes de Lamé ( $G$ é também conhecido como módulo de cisalhamento), $E$ é o módulo de Young e $v$ o coeficiente de Poisson.

\subsubsection{2.}

\section{Ondas S}

Conhecidas como ondas transversais, secundárias ou cisalhantes, as ondas $\mathrm{S}$ se propagam na direção perpendicular à direção de vibração das partículas do meio (sólido, apenas) - Figura 2.3b. Em função do movimento da partícula podem ser denominadas ondas SV, quando este acontece no plano de propagação do trem de ondas, ou ondas $\mathrm{SH}$, quando o movimento da partícula é normal ao plano. A velocidade de propagação $\beta$ de ondas $\mathrm{S}$ é dada pela teoria da elasticidade linear como:

$$
\beta=\sqrt{\frac{G}{\rho}}=\sqrt{\frac{E}{2 \rho(1+v)}}
$$

A relação entre as velocidades de propagação das ondas $\mathrm{P}$ e $\mathrm{S}$ pode ser estabelecida como: 


$$
\frac{\alpha}{\beta}=\sqrt{\frac{\lambda+2 G}{\rho}}=\sqrt{\frac{2(1-v)}{(1-2 v)}}
$$

de onde facilmente se verifica que

$$
\alpha / \beta \geq 2 \quad \operatorname{para} v=0
$$

\subsection{2.}

\section{Ondas de superfície}

Quando movimentos sísmicos são gerados próximos à superfície e o trem de ondas incide na superfície com inclinação em relação à vertical, a aplicação das condições de contorno na superfície do terreno (tensões normal e cisalhantes nulas) é possível obter pela teoria da elasticidade linear soluções adicionais da equação do movimento (Kramer, 1996). Estas soluções descrevem o movimento de ondas em uma zona pouco profunda, próxima da superfície do terreno, por esta razão denominadas ondas de superfície.

\subsubsection{1.}

\section{Ondas R}

Chamadas de ondas Rayleigh, originam-se da interação entre ondas de corpo (P, SV) com a superfície do terreno - Figura 2.3c. Causam um movimento de partícula com componentes vertical e horizontal, com amplitude decrescente com a profundidade sob forma exponencial. A trajetória do movimento da partícula é aproximadamente elíptica e paralela à direção de propagação da onda na superfície. Na ocorrência de terremotos são as ondas mais destrutivas, pelo fato de propagarem-se junto à superfície, onde se encontram as obras de engenharia, e por sua menor dissipação de energia com a distância de propagação (amortecimento geométrico).

A velocidade de propagação $c$ de ondas R situa-se entre $50 \mathrm{~m} / \mathrm{s}$ a $300 \mathrm{~m} / \mathrm{s}$, ligeiramente inferiores à velocidade de propagação das ondas $\mathrm{S}$, podendo ser aproximadamente estimada pela seguinte equação:

$$
c=\frac{0,862+1,14 v}{1+v} \beta
$$




\subsubsection{2.}

\section{Ondas L}

Conhecidas como ondas Love ou L, resultam da interação das ondas SH em um meio elástico com estratificação na superfície e velocidade de propagação de ondas S inferior àquela de propagação no semi-espaço (Kramer, 1996). O tipo de movimento da partícula apresenta polarização horizontal normal à direção de propagação da onda - Figura $2.3 \mathrm{~d}$ - cuja amplitude também decai rapidamente com a profundidade.

Quando o hipocentro de um terremoto situa-se a grande profundidade, as ondas de corpo terão maior influência no movimento produzido na superfície do terreno, pois estas tendem a incidir, à medida que trafegam por camadas de solo de menor rigidez, com ângulos próximos à vertical. Perto do epicentro, são de alta frequência (períodos baixos) e afetam de forma mais prejudicial as edificações baixas e rígidas (estruturas de baixos períodos naturais).

Por outro lado, quando o hipocentro é pouco profundo, prevalecem as ondas de superfície. A Figura 2.5 mostra os registros de dois sismos com origem no Arquipélago de Tonga, no Pacífico, sendo o primeiro de foco profundo e o segundo de foco superficial, ambos detectados em Albuquerque, Novo México, a 10.000 quilômetros de distância. O sismo de foco profundo gerou ondas de corpo $\mathrm{P}$ e $\mathrm{S}$ de grande amplitude mas relativamente pouca atividade produzida por ondas de superfície. Por outro lado, no caso do sismo de foco superficial observa-se claramente que a maior parte da energia foi liberada sob forma de ondas de superfície de grande amplitude pois ocorreu maior interação entre a superfície e as ondas de corpo que chegaram bastante mais inclinadas do que no caso do sismo de grande profundidade. 


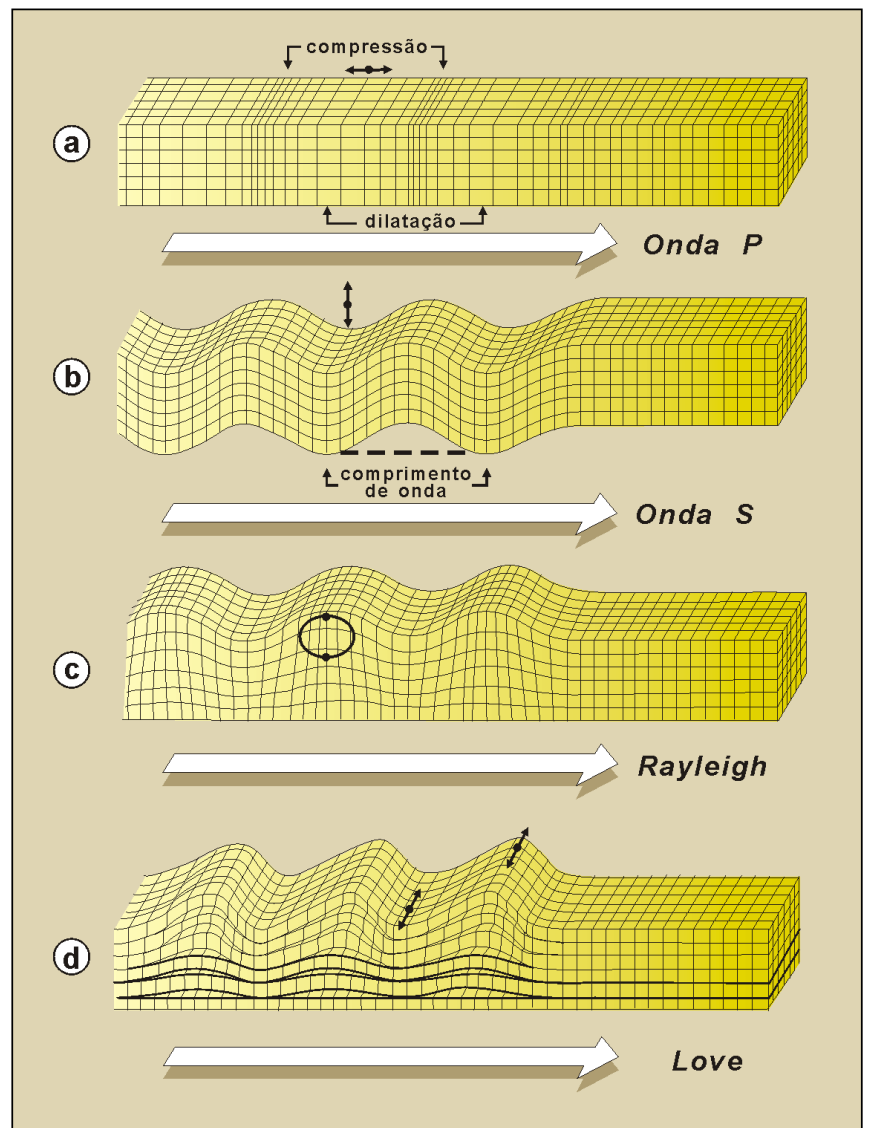

Figura 2.3 - Movimentos de partícula produzidos pelos diferentes tipos de ondas planas de tensão (Teixeira et al., 2003).

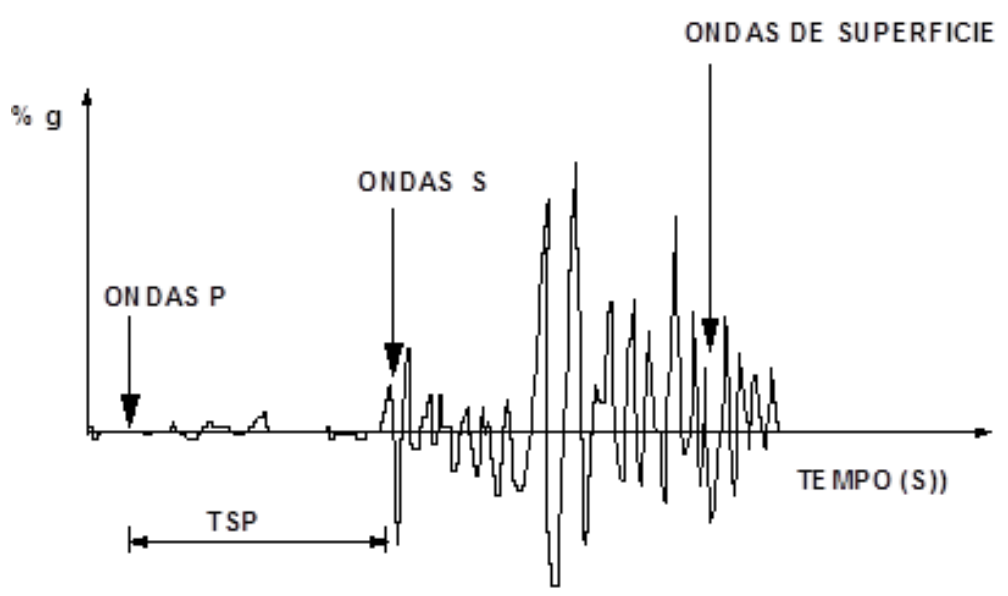

TSP = TE MPO DE CHE GADA ENTRE AS ONDAS P E ONDAS S

Figura 2.4 - Identificação dos tempos de chegada das ondas $\mathrm{P}, \mathrm{S}$ e de superfície em um acelerograma. 


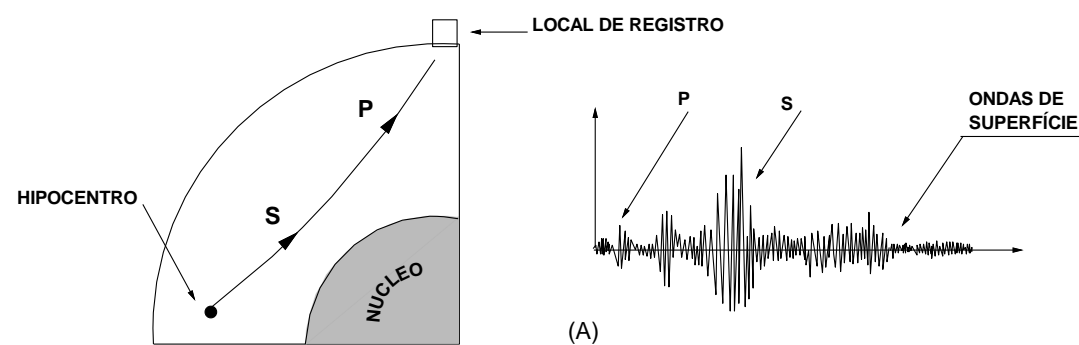

(A)

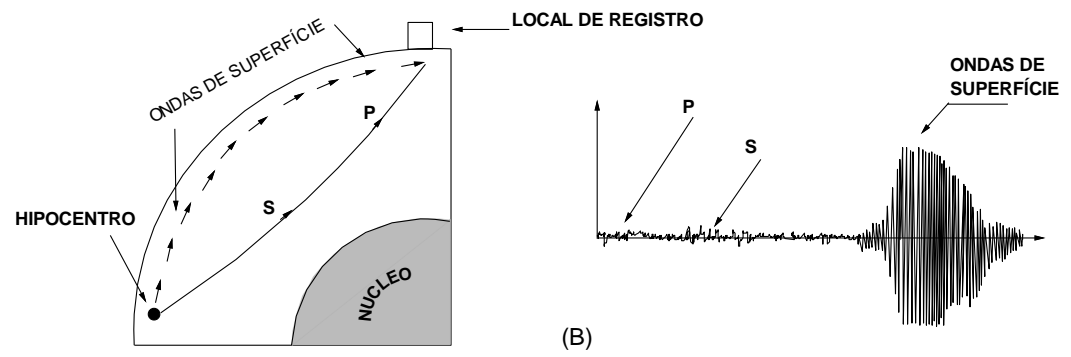

Figura 2.5 - Diferença entre efeitos das ondas de superfície e ondas de corpo na superfície do terreno em função da profundidade do foco: a) foco profundo; b) foco superficial (Sauter, 1989).

\section{2.}

\section{Magnitude de um terremoto}

\subsection{1. Magnitude local}

Historicamente, Ritcher (1935) desenvolveu no estado de Califórnia, EUA, a primeira escala de magnitude, conhecida como Magnitude Local $\left(M_{L}\right)$, elaborada para terremotos de pouca profundidade. É uma escala logarítmica arbitrária, de base 10, que relaciona a distância epicentral (inferior a 600 km), com a máxima amplitude do deslocamento horizontal registrado em um sismógrafo Wood-Anderson, sensível a ondas $S$ com período de 1s - Figura 2.6. O logaritmo incorporado na escala faz com que os valores atribuídos a cada nível de magnitude aumentem de forma não linear; assim em um terremoto de magnitude 5 a amplitude do movimento é 10 vezes maior do que a correspondente em um terremoto de magnitude 4, com liberação de energia 32 vezes maior. Embora o trabalho original de Richter tenha sido desenvolvido somente para sismógrafos Wood-Anderson e especificamente para terremotos do sul da Califórnia, sismologistas desenvolveram fatores de escala para adaptar a escala de Richter em outros tipos de sismógrafos instalados ao redor do mundo (equação 2.6).

$$
M_{L}=\log A(\Delta)-\log A_{o}(\Delta)
$$


onde $A$ representa a máxima amplitude do deslocamento horizontal em milímetros, registrada em um sismógrafo Wood-Anderson para um terremoto ocorrido na distância epicentral $\Delta$ e $A_{o}$ representa a máxima amplitude do deslocamento horizontal na distância epicentral $\Delta$ para um terremoto padrão. A magnitude local $\left(M_{L}\right)$ é portanto uma medida característica do terremoto e independente da localização do sismógrafo. Três escolhas arbitrárias foram feitas na definição da escala: a) a utilização do sismógrafo Wood-Anderson; b) o uso de logarítmos na base $10 ;$ c) a seleção de um terremoto padrão. Richter definiu a magnitude de $A_{o}=0,001 \mathrm{~mm}$ a uma distância de $100 \mathrm{~km}$ do epicentro como aquela que induz uma amplitude de deslocamento horizontal igual a um micrômetro (1 $\mu \mathrm{m})$ para um epicentro localizado à uma distância de $100 \mathrm{~km}$ de uma estação Wood-Anderson. Logo, um terremoto que produz um deslocamento horizontal A = $1 \mathrm{~mm}$ em um sismógrafo Wood-Anderson na distância epicentral de $100 \mathrm{~km}$ corresponde a uma magnitude local $M_{L}=3$. Richter deliberadamente escolheu $\log \left(A_{o}\right)=3$ para que terremotos não tivessem magnitudes negativas. Para diferentes tipos de estações sismográficas, é necessário aplicar-se uma correção no termo da distância associado à definição da constante $A_{o}$.

A saturação da escala de Richter é atingida para terremotos com magnitudes superiores a $M_{L}>6,8$ pois além deste limite os valores registrados na escala são similares.

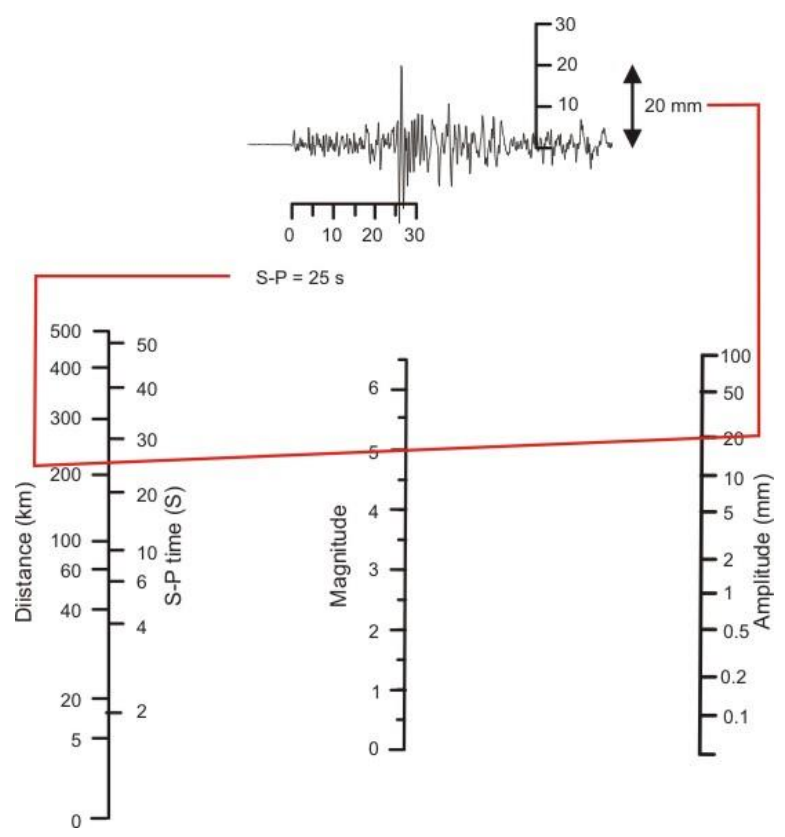

Figura 2.6 - Determinação da magnitude na escala de Richter (1935) $\left(M_{L}\right)$. Fonte: csegrecorder.com 


\subsection{2.}

\section{Magnitude de ondas de superfície}

Magnitude de ondas de superfície $\left(M_{\mathrm{s}}\right)$ foi proposta por Gutenberg e Richter (1936) para terremotos pouco profundos $(<50 \mathrm{~km})$ e medidas registradas a grandes distâncias epicentrais onde o movimento é basicamente influenciado pela propagação de ondas $\mathrm{R}$.

$$
M_{S}=\log _{10}\left(\frac{A}{T}\right)+1,66 \log \Delta+3,3
$$

onde A representa o valor máximo das amplitudes combinadas dos deslocamentos horizontais, em micras, para ondas de superfície com período de $\mathrm{T}=20 \pm 2 \mathrm{~s}$, e $\Delta$ é a distância epicentral em graus $\left(20^{\circ} \leq \Delta \leq 160^{\circ}\right)$. A magnitude de ondas de superfície satura sua escala para $M_{s}>8.3$.

\subsection{3. \\ Magnitude de ondas de corpo}

Magnitude de ondas de corpo $m_{b}$ é definida em relação ao início do registro sísmico (primeiros 5s) da chegada do trem de ondas de corpo, utilizando-se geralmente a parte associada às ondas $\mathrm{P}$.

$$
m_{b}=\log _{10}\left(\frac{A}{T}\right)+Q(\Delta, h)
$$

onde A é a máxima amplitude vertical (em micras) de ondas $\mathrm{P}$ com período $\mathrm{T}<3 \mathrm{~s}$ (geralmente $\mathrm{T}=1 \mathrm{~s}$ ) e $Q$ um termo de calibração, no intervalo entre 6 a 8 , função da distância epicentral $\Delta$ em graus $\left(\Delta<100^{\circ}\right)$ e da profundidade focal $h$ em quilômetros. A magnitude de ondas de corpo satura para $m_{b}>6,2$.

Como medidas do tamanho de terremotos, as magnitudes apresentam duas grandes vantagens: a) são obtidas diretamente de sismógrafos, sem a necessidade de sofisticados tratamentos de sinais; b) produzem estimativas que são intuitivamente significativas (i.e. um sismo de magnitude 5 é moderado enquanto que um sismo de magnitude 7 é severo). Entretanto, apresentam várias limitações: i) são grandezas empíricas sem conexão direta com os mecanismos de geração de terremotos; ii) as equações usadas nem ao menos são dimensionalmente corretas; 
por exemplo, a quantidade A/T não é adimensional mas o logaritmo da mesma é mesmo assim considerado; iii) as magnitudes variam consideravelmente com os azimutes, em parte devido ao padrão de radiação das ondas sísmicas; iv) diferentes escalas de magnitude produzem diferentes valores para definição de um mesmo sismo; por exemplo: o sismo de San Fernando, em 1971, com magnitudes $m_{b}=6,2$ e $M_{S}=6,6$; o sismo do Alaska, 1964, com $m_{b}=6,2$ e $M_{S}=8,4$ e o sismo de Loma Prieta, 1989, com $m_{b}=6,2$ e $M_{S}=7,1$. Neste caso vale notar que terremotos maiores do que o de San Fernando apresentam a magnitude $m_{b}=6,2$ devido à saturação da escala, conforme mencionado.

Quando inicialmente desenvolvidas, as escalas de magnitude foram consideradas equivalentes, ou seja, terremotos de todos os tamanhos foram admitidos liberar proporções fixas de energia em diferentes períodos. Contudo, grandes terremotos sistematicamente irradiam energia de longos períodos, com as escalas $m_{b}$ e $M_{S}$ subestimando as magnitudes a partir dos respectivos valores de saturação.

Modernamente, a sismologia se concentra em dois parâmetros para descrição física dos efeitos de um terremoto: o momento sísmico e a energia liberada no terremoto.

\subsection{4.}

\section{Momento sísmico e Magnitude de momento}

O momento sísmico $M_{o}$ (dina.cm ou $10^{-7} \mathrm{~N} . \mathrm{m}$ ), está fisicamente relacionado com os parâmetros fundamentais do processo de falhamento:

$$
M_{0}=\mu D S
$$

onde $\mu$ é a resistência ao cisalhamento da rocha onde ocorreu a ruptura, $D$ o deslizamento médio da falha e $S$ a área de ruptura ao longo da falha geológica. Devido a que a geometria da falha e o azimute do observador são parte do processo de cálculo, o momento sísmico é uma medida mais consistente do tamanho do terremoto do que a magnitude e, mais importante, não apresenta nenhum limite superior de saturação.

Se o terremoto ocorre com falhamento na superfície, é possível medir o comprimento da ruptura $\mathrm{L}$ e o deslizamento médio $\mathrm{D}$, com a área da ruptura sendo 
calculada como $\mathrm{S}=\mathrm{Lh}$ onde $\mathrm{h}$ é a profundidade do foco ${ }^{1}$. Uma estimativa razoável da resistência ao cisalhamento da rocha esta na ordem de $\mu=(3-3,5) \mathrm{x}$ $10^{11}$ dinas $/ \mathrm{cm}^{2}$ (dePolo e Slemmons, 1990).

Estes fatos levaram à definição da Magnitude de Momento $M_{W}$ (Kanamori, 1977; Hanks e Kanamori, 1979) com base no momento sísmico:

$$
M_{W}=\frac{2}{3} \log _{10} M_{0}-10,7
$$

Assim, o maior terremoto já registrado mundialmente (Chile, 1960) apresentou magnitude $M_{S}=8,5$ e $M_{W}=9,6$ enquanto que o terremoto do Alaska (1964), magnitude $M_{S}=8,3$ e $M_{W}=9,2$.

A Figura 2.7 apresenta uma comparação entre as diferentes medidas de magnitude de terremotos, com a saturação das escalas interpretada como a tendência assintótica aos valores de saturação. A magnitude de momento é consistente com $3<M_{L}<6$ e $5<M_{S}<8$. No caso de terremotos moderados com foco pouco profundo $(<50 \mathrm{~km})$ é suficiente, em termos de engenharia, considerar $M_{W}, M_{L}$ e $M_{S}$ aproximadamente iguais. Outras escalas de magnitude têm sido desenvolvidas levando em conta diferentes parâmetros do registro sísmico, a magnitude de duração $M_{D}$, baseada na duração total do terremoto pode ser utilizada para descrição de pequenos terremotos que tem maior significância no campo da sismologia do que na engenharia (Real e Teng, 1973). A Agencia Meteorológica Japonesa utiliza ondas de longo período para determinar uma escala de magnitude local denominada $M_{J M A}$, que é observada na Figura 2.7 consistente com a magnitude de momento na faixa $5.5<M_{J M A}<8$.

\footnotetext{
${ }^{1} \mathrm{O}$ método assume que a área de ruptura é retangular.
} 


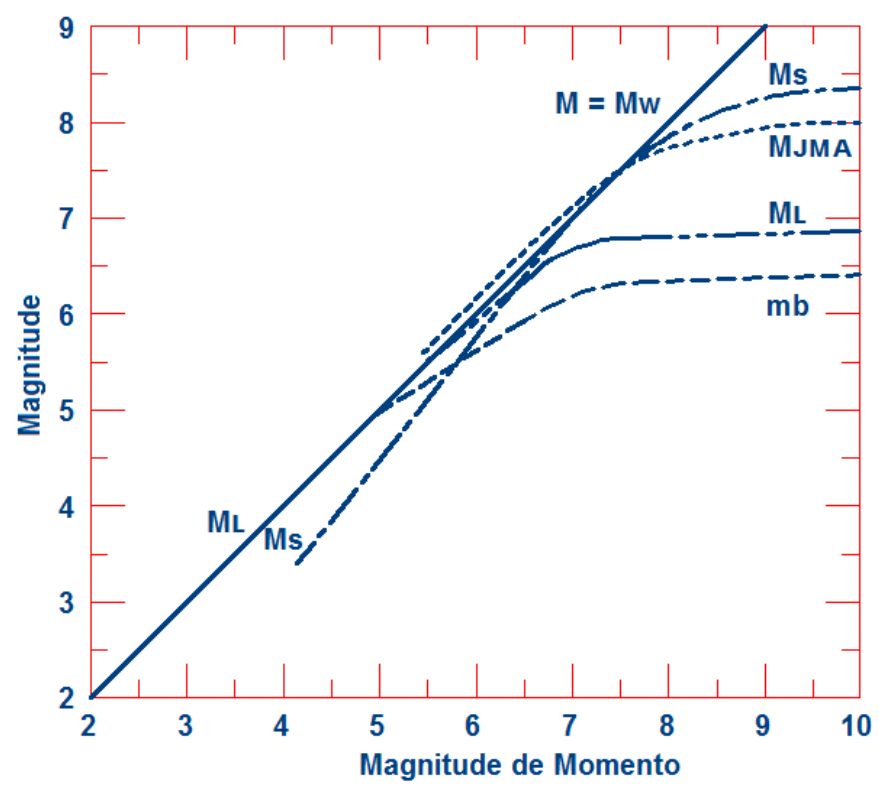

Figura 2.7 - Escalas de magnitude $M_{W}, M_{s}, M_{L}$ e $m_{b}$ (Idriss, 1985).

\subsection{5.}

\section{Energia e magnitude de energia liberada}

A quantidade de energia irradiada por um terremoto é uma medida do potencial dano a estruturas de engenharia. Gutenberg e Richter (1956) propuseram uma correlação entre energia $E$ (ergs) e a magnitude de ondas de superfície $M_{S}$ para uma largura de banda entre 18 a $22 \mathrm{~s}$. Modernamente, sabe-se porém que a energia liberada concentra-se em diferentes larguras de banda em altas frequências, sendo possível definir uma magnitude de energia liberada $M_{e}$ de acordo com:

$$
M_{e}=\frac{2}{3} \log _{10} E-2,9
$$

com o cálculo da energia liberada $E$ sendo feito por métodos computacionais com base nos registros de sismógrafos digitais operando em largas faixas de respostas. Para cada aumento unitário de $M_{e}$, a energia associada ao sismo cresce 32 vezes.

Ainda que $M_{W}$ e $M_{e}$ sejam ambas estimativas de magnitude, frequentemente não têm o mesmo valor numérico. A magnitude de momento $M_{W}$ é computada com base nos dados sísmicos de baixa frequência e representa uma medida da área de ruptura causada pelo terremoto, enquanto que a magnitude de energia $M_{e}$, determinada com dados de alta frequência dos registros sísmicos, é uma medida do potencial de dano do terremoto. 


\section{3.}

\section{Intensidade de um terremoto}

A intensidade é uma grandeza meramente qualitativa dos efeitos provocados por um terremoto, baseada nos danos observados em estruturas, objetos e na natureza além da percepção das pessoas. É de utilidade em estudos de ameaça sísmica que normalmente necessitam da consideração de terremotos ocorridos em datas anteriores à medição de magnitudes através de sismógrafos ${ }^{2}$. Uma escala de intensidade foi originalmente desenvolvida por Mercalli e posteriormente modificada por Wood e Neuman (1931), sendo mundialmente conhecida como escala modificada de intensidade de Mercalli (Figura 2.8).

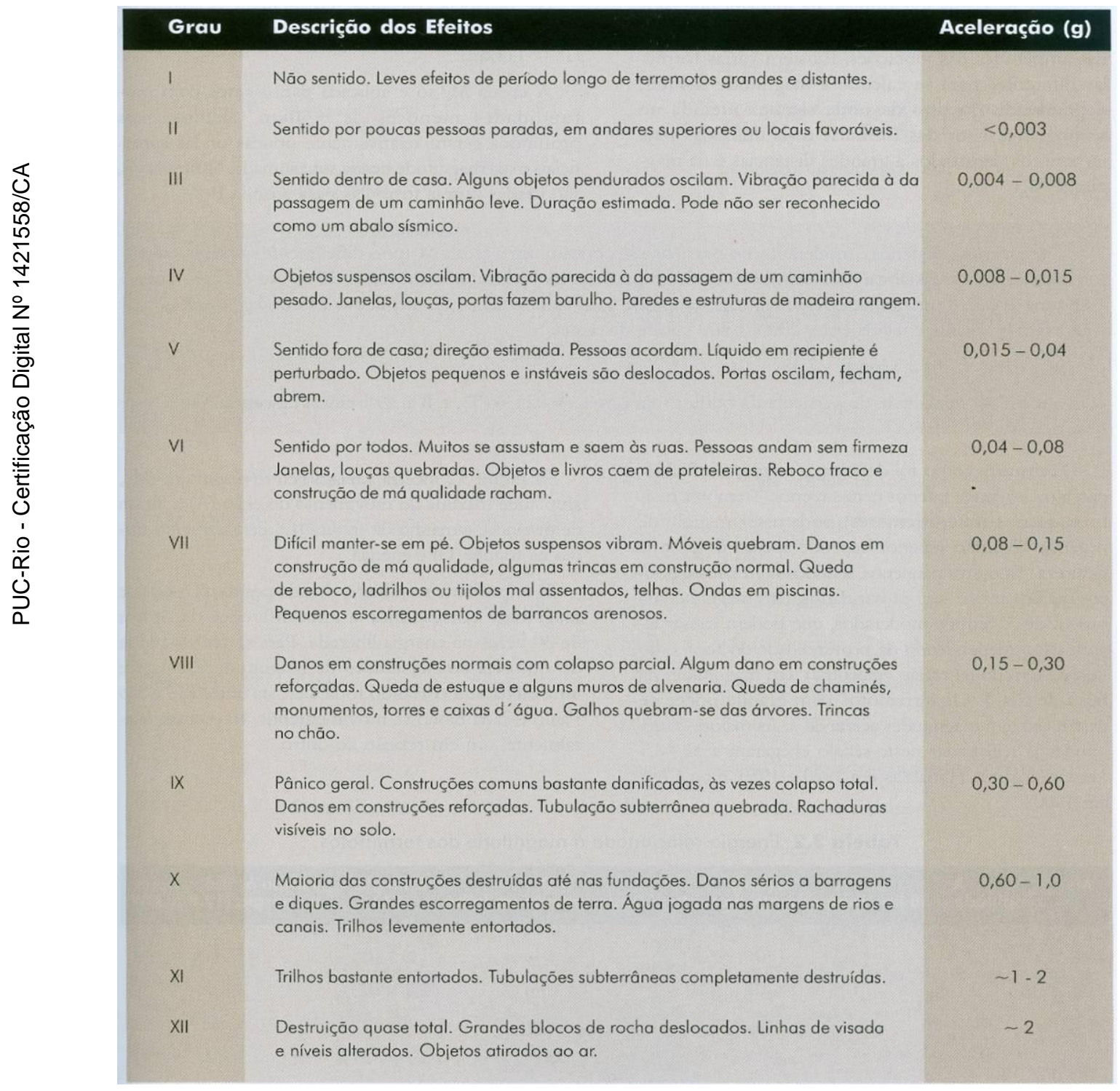

Figura 2.8 - Escala Modificada de Intensidade de Mercalli (Teixeira et al., 2003).

${ }^{2}$ O primeiro sismógrafo do Brasil foi instalado na UnB em 1968. 


\section{4. \\ Fontes sísmicas}

A sismicidade em uma região pode ser considerada como proveniente de duas possíveis fontes: a) fontes pontuais ou lineares; b) fontes difusas.

$\mathrm{Na}$ primeira categoria agrupam-se as falhas geológicas de pequena ou grande extensão, com contato entre placas tectônicas, enquanto que nas fontes de origem difusa, como o próprio nome indica, estas se encontram distribuídas em uma grande área, como no caso do Sudeste do Brasil, e não estão associadas diretamente à atividade de placas tectônicas.

\subsection{1.}

\section{Bordas de placas tectônicas}

A Terra é conformada por três zonas: núcleo, manto e crosta (Figura 2.9). O núcleo é formado por um núcleo interno e um externo, o primeiro com $1.400 \mathrm{~km}$ de diâmetro e o segundo com $2.000 \mathrm{~km}$, sendo composto principalmente por metais de ferro e níquel fundido, com uma densidade 13,5 vezes maior do que a da água.

O manto, que constitui $83 \%$ do volume e $65 \%$ da massa do planeta. Sua parte inferior é um material magmático com temperatura variando entre $1200^{\circ} \mathrm{C}$ a $3700^{\circ} \mathrm{C}$ e a parte superior, compreendida entre os 100 e $350 \mathrm{~km}$ de profundidade, é conhecida como astenosfera (do grego asthenes = fraqueza), flexível, parcialmente fundida e capaz de deformar-se plasticamente para acomodar os movimentos das placas tectônicas.

A crosta, ou litosfera, é a capa exterior do planeta e sua espessura é muito delgada em relação ao raio da Terra, na proporção da espessura da casca de um ovo. Ela é uma zona rígida formada principalmente por rochas cristalinas de basalto e granito de grande dureza e resistência, com uma espessura de aproximadamente $35 \mathrm{~km}$, mas podendo alcançar valores de até $75 \mathrm{~km}$ abaixo de cadeias montanhosas. Na litosfera desenvolvem-se os terremotos causados por processos de tectonismo entre as 17 placas principais que a constituem (teoria das placas).

A teoria das placas foi desenvolvida em 1915 pelo cientista alemão Alfred Wegener, conhecida como a Teoria da Deriva dos Continentes. Esta supõe que há 200 milhões de anos todos os continentes estavam unidos, formando uma só 
massa continental, denominada Pangea. No início da era geológica do Mesozóico, esta massa universal começou a fraturar e dividir-se, formando as massas continentais que hoje existem.

As placas tectônicas se movimentam $10 \mathrm{~cm}$ por ano, em média, porém com diferentes velocidades e direções. Por isso, estão submetidas a estados de tensão que se aliviam através de erupções vulcânicas e geração de terremotos. As placas são impulsionadas por correntes de convecção térmica no manto, originadas por diferenças de temperatura que o magma alcança de acordo com a proximidade ao centro do planeta. A porção mais próxima ao centro aquece, sua densidade cai e sobe em direção à superfície, enquanto que a porção mais fria desce, formando então correntes de convecção térmica que se repetem há bilhões de anos.

Dependendo da direção do movimento identificam-se três tipos de bordas de placas: divergente (de criação), convergente (de destruição) e transformantes (de conservação).

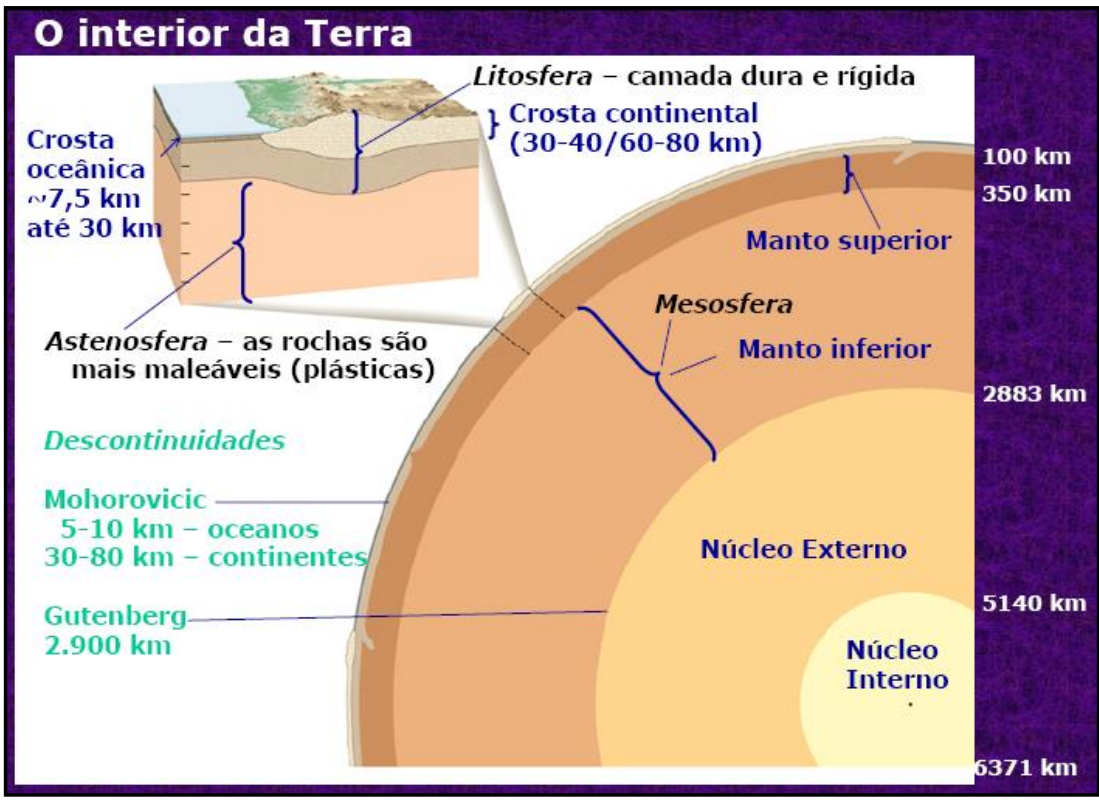

Figura 2.9 - Esquema da estrutura da Terra. Fonte: www.ige.unicamp.br

\subsubsection{1.}

\section{Bordas divergentes ou de criação}

Em algumas áreas ocorre um afastamento entre placas tectônicas, com a rocha em estado pastoso ascendendo do manto à superfície, onde esfria. Mediante medições batimétricas, oceanógrafos encontraram no meio do Oceano Atlântico (Figura 2.10) um sistema montanhoso que se expande e ramifica formando uma 
cadeia de montanhas de aproximadamente $40.000 \mathrm{~km}$. Estudos geofísicos e oceanográficos têm demonstrado que esta cordilheira é formada por material magmático proveniente do manto da Terra, em um processo dinâmico de transformação do Oceano Atlântico. Outros casos de bordas divergentes ocorrem na cadeia do Pacífico Leste, próximo à ilha de Páscoa, no oceano Índico e na África oriental (rift valley africano) envolvendo Etiópia, Uganda, Quênia, República do Congo, Tanzânia, Mali e Moçambique.

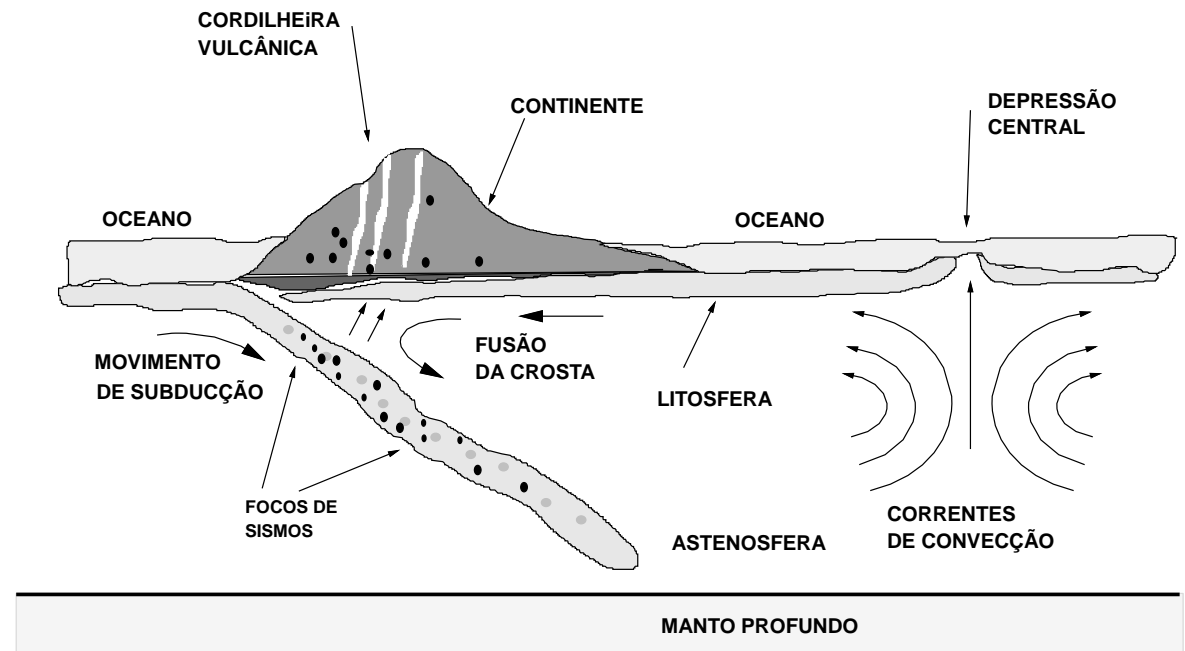

Figura 2.10 - Efeitos de correntes de convecção do magma com formação de bordas divergentes (oceano Atlântico) e convergentes (placas de Nazca e Sul Americana).

\subsubsection{2.}

\section{Bordas convergentes ou de destruição}

As dimensões das massas continentais não variaram significativamente desde a formação do planeta há 4,5 bilhões de anos. Isto sugere que a crosta deve ser destruída na mesma medida em que é criada. Esta reciclagem ocorre ao longo de bordas convergentes das placas tectônicas, por colisão ou porque uma placa mergulha sob a outra (subducção) ou coloca-se sobre a outra (obducção) em regime tectônico compressivo.

Na Figura 2.10, para compensar a saída do material magmático no meio do oceano Atlântico é necessário que correntes descendentes mergulhem material da crosta, em movimentos de subducção, como o mergulho da placa de Nazca sob a placa Sul Americana, o que deu origem à cordilheira dos Andes e a um arco vulcânico, com a elevação da borda ocidental da placa Sul Americana. Junto à 
borda da placa Sul Americana existe uma estreita fossa, com desnível de 8 a 10 $\mathrm{km}$, criada por subducção entre placas convergentes.

Os sismos produzidos nas zonas de subducção têm focos em profundidades ${ }^{3}$ superiores a $70 \mathrm{~km}$. Na crosta continental (massa específica 2,8 g/ $\mathrm{cm}^{3}$ ), a maior parte dos sismos ocorre até $20 \mathrm{~km}$ de profundidade, sendo muito raros abaixo, uma vez que temperatura e pressão são elevadas, fazendo com que o material tenha comportamento dúctil. Como a crosta oceânica é mais fria (massa específica $3,2 \mathrm{~g} / \mathrm{cm}^{3}$ ), nas zonas de subducção os sismos podem ser mais profundos.

\subsubsection{3.}

\section{Bordas transformantes ou de conservação}

Este tipo de borda ocorre quando não há criação nem destruição de crosta, com as placas deslizando lateralmente uma em relação à outra, ao longo de fraturas denominadas falhas transformantes como a falha de San Andreas, na Califórnia, EUA. Neste caso a placa do Pacífico, onde está situada a cidade de Los Angeles, se desloca em direção norte, enquanto que a placa Norte-Americana, onde está a cidade de São Francisco, se movimenta para o sul. Quando a energia concentrada ao longo das bordas é liberada, produz terremotos com focos superficiais e altamente destrutivos.

Os tsunamis são formados quando o fundo oceânico é deformado, na sequência de liberação de energia sísmica, deslocando verticalmente a coluna d'água que repousa sobre ele.

\footnotetext{
${ }^{3}$ Sismos superficiais $(85 \%)$ - entre a superfície e $70 \mathrm{~km}$ de profundidade; sismos intermediários (12\%) - entre 70 e $350 \mathrm{~km}$ de profundidade; sismos profundos (3\%) - entre 350 e $700 \mathrm{~km}$ de profundidade.
} 


\section{3 Métodos para análise da resposta dinâmica de taludes}

Neste capitulo apresenta-se um resumo de alguns dos métodos para avaliação do coeficiente de segurança e do cálculo dos deslocamentos permanentes em taludes sujeitos a excitações sísmicas. O primeiro dos métodos abordado é o denominado método pseudoestático que fornece informação unicamente sobre a estabilidade, enquanto que os demais determinam o deslocamento permanente causado pelo sismo e, em função deste, uma condição de ruptura pode ser presumida pelo engenheiro com base na servicibilidade do talude.

\section{1. Método pseudoestático}

As diversas soluções de equilíbrio limite (método das fatias) para análise das condições de estabilidade de taludes de solo sob carregamento estático, que podem ser consideradas familiares ao engenheiro geotécnico, são possíveis de serem estendidas para um contexto pseudoestático ${ }^{1}$ adicionando-se forças aplicadas no centro de gravidade da massa de solo instável conservando-se o mesmo módulo, direção, porém sentido oposto ao das forças inerciais geradas pela propagação da excitação sísmica (princípio de d'Alembert). Neste tipo de análise geralmente a componente vertical da força de inércia é desprezada em função da hipótese de que as ondas cisalhantes incidentes SV são verticais, e a componente horizontal é obtida pela multiplicação do coeficiente sísmico horizontal $k$ pelo peso total da massa de solo instável.

No método das fatias a região de solo delimitada pela potencial superfície de ruptura é dividida em um número qualquer de fatias verticais (Figura 3.1), analisando-se as condições de equilíbrio em cada fatia isoladamente. O método tem várias versões na literatura, dependendo das hipóteses adotadas para satisfazer

\footnotetext{
${ }^{1}$ Segundo Duncan e Wright (2005) a denominação pseudoestático é inconsistente, pois o método de análise é verdadeiramente estático, com a introdução de forças inerciais. A denominação mais correta neste caso seria método pseudodinâmico.
} 
parcial ou totalmente as equações de equilíbrio de forças e de momentos. Os efeitos do terremoto são representados por uma aceleração horizontal que multiplicada pelo peso da massa potencialmente instável produz uma força estática aplicada no centro de gravidade de cada fatia. Por simplicidade, a aceleração horizontal é normalizada respeito da gravidade e expressa como um coeficiente adimensional chamado de coeficiente sísmico $k$.

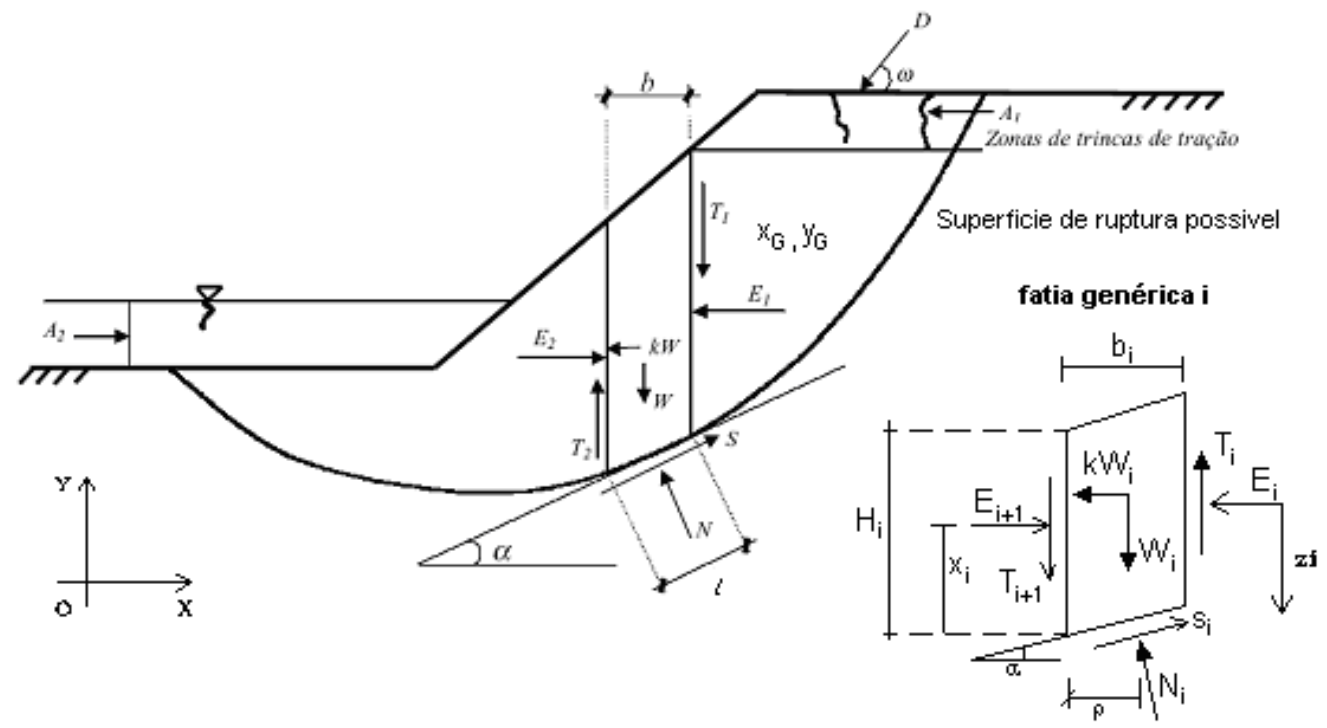

Onde $W$ é o peso da fatia, $k W$ a componente horizontal da força de inércia, $N$ a força normal à base da fatia, $S$ a força tangencial à base da fatia $(S=\tau l), E_{1}$ e $E_{2}$ as componentes horizontais das forças entre as fatias, $T_{1}$ e $T_{2}$ as componentes verticais das forças entre as fatias, $D$ a força aplicada na superfície, $b$ representa a largura da fatia, $l$ o comprimento da base da fatia, $A_{l}$ e $A_{2}$ são forças hidrostáticas.

Figura 3.1 - Forças atuantes em uma fatia vertical e na superfície potencial de ruptura.

O fator de segurança $F S$ pseudo-estático local é definido por:

$$
F S_{\text {local }}=\frac{S}{\tau}
$$

Onde $s$ representa a resistência ao cisalhamento e $\tau$ a tensão cisalhante atuante no ponto.

Considerando o critério de resistência de Mohr-Coulomb, é possível reescrever a equação 3.1 como:

$$
S=\tau l=\frac{s l}{F S_{\text {local }}}=\frac{l}{F S_{\text {local }}}\left[c^{\prime}+(\sigma-u) \tan \phi^{\prime}\right]
$$


onde $\sigma=\frac{\mathrm{N}}{l}$ é a tensão normal média na base da fatia, $u$ a poropressão atuante no centro da base da fatia e $c^{\prime}, \phi^{\prime}$ os parâmetros de resistência em termos de tensões efetivas.

Fatores de segurança pseudo-estáticos globais $F S$ podem ser determinados com base nas equações de equilíbrio de forças ou momentos. Considerando o equilíbrio de momentos em relação a um ponto qualquer, causados pelas forças que atuam em todas as fatias,

$$
\sum W x-\sum S r-\sum N f+\sum k W e \pm D d \pm \sum_{i=1}^{2} A_{i} h=0
$$

onde $x, r, f, e, d, h$ representam os braços de alavanca dos momentos das diferentes forças em relação ao ponto selecionado.

Admitindo-se, como usualmente, que os fatores de segurança pseudoestáticos local $\left(F S_{\text {local }}\right)$ e global $(F S)$ são iguais em todos os pontos da superfície potencial de ruptura, é possível combinar-se as equações 3.2 e 3.3 para produzir:

$$
F S_{\text {momentos }}=\frac{\sum\left[c^{\prime} l r+(N-u l) r \tan \phi^{\prime}\right]}{\sum W x-\sum N f+\sum k W e \pm D d \pm \sum_{i=1}^{2} A_{i} h}
$$

Considerando-se o equilíbrio das forças horizontais que atuam em todas as fatias, obtém-se por sua vez:

$$
\sum\left(E_{1}-E_{2}\right)-\sum N \operatorname{sen} \alpha+\sum S \cos \alpha-\sum k W-D \cos \omega \pm \sum_{i=1}^{2} A_{i}=0
$$

Novamente combinando-se as equações 3.2 e 3.5 é possível escrever, observandose que a parcela $\sum\left(E_{2}-E_{1}\right)$ é nula para toda a massa deslizante.

$$
F S_{\text {forgas }}=\frac{\sum\left[c^{\prime} l \cos \alpha+(N-u l) \tan \phi^{\prime} \cos \alpha\right]}{\sum N \operatorname{sen} \alpha+\sum k W+D \cos \omega \mp \sum_{i=1}^{2} A_{i}}
$$


Ambas as equações para cálculo dos fatores de segurança pseudo-estáticos globais $\left(F S_{\text {momentos }}\right.$ e $\left.F S_{\text {forças }}\right)$ são não lineares, visto que a força normal $N$ atuante em cada base da fatia é também dependente do fator de segurança. As equações (3.4) e (3.6) são gerais, porém contendo um número excessivo de incógnitas (problema hiperestático). Como equações adicionais que considerem o comportamento tensão-deformação dos materiais não são consideradas nos métodos de equilíbrio limite, hipóteses simplificadoras devem então ser introduzidas. Os diferentes métodos de fatias propostos na literatura (Bishop Simplificado, 1955; Janbu Simplificado, 1968; Morgenstern \& Price, 1965; entre outros) se diferenciam conforme as hipóteses adotadas no processo de cálculo, geralmente em relação às forças entre fatias e no modo de se determinar a força normal $N$ na base das mesmas.

A sugestão de Terzaghi (1950) de aplicar a força pseudo-estática no centro de gravidade das fatias implica que a aceleração é constante, mas análises sísmicas em taludes (principalmente de barragens) indicam que a mesma cresce com a altura do talude, atingindo-se o pico da aceleração na crista. Seed (1979) mostrou que a variação do ponto de aplicação da força pseudo-estática pode ter um pequeno efeito no valor do fator de segurança pseudo-estático (variando entre 1,32 a 1,21 na análise da Sheffield Dam para um coeficiente sísmico de 0,1), concluindo que o fator de segurança cresce quando a força pseudo-estática é aplicada acima do centro de gravidade da fatia. Esta redução se verifica porque em método de equilíbrio limite baseado nas equações de momentos, como no método de Bishop Simplificado (1955), ocorre um decréscimo do momento devido ao menor braço de alavanca da força pseudo-estática em relação ao centro de rotação (é evidente que o ponto de aplicação da força pseudo-estática não tem nenhuma influência se o método de equilíbrio limite empregado envolver apenas equilíbrio de forças). Embora a hipótese de Terzaghi (op.cit.) possa ser levemente conservativa em alguns casos, de maneira geral a força pseudo-estática é assumida atuar no centro de gravidade da fatia.

Porque terremotos são de curta duração, é razoável assumir, exceto para pedregulhos e enrocamentos, que a resistência ao cisalhamento não drenada deve ser usada nos métodos pseudo-estáticos para análise da estabilidade de taludes. Makdisi e Seed (1977) recomendaram para solos argilosos, solos granulares secos ou parcialmente saturados e para solos granulares densos saturados, onde não se 
espera significativa perda de resistência devido ao fenômeno da liquefação, a utilização de $80 \%$ da resistência não drenada estática como valor da resistência dinâmica do solo. Observaram em ensaios de laboratório um comportamento elástico das amostras de solo quando submetidas a um grande número de ciclos (superior a 100 ciclos) de até $80 \%$ da resistência não drenada estática. Deformações permanentes substanciais foram produzidas para carregamentos cíclicos próximos do valor total da resistência não drenada estática. Outros pesquisadores (Hynes-Griffin e Franklin, 1984; Kavazanjian et al., 1997) também sugeriram uma redução de $20 \%$ do valor da resistência ao cisalhamento estática não drenada, para utilização nos métodos de cálculo pseudo-estáticos.

Duncan e Wright (2005) consideram que esta redução pode ser ignorada para materiais não propensos à liquefação devido aos efeitos da velocidade de aplicação do carregamento sísmico. A maioria dos solos sujeita a rápidos carregamentos cíclicos exibe uma resistência não drenada de $20 \%$ a 50\% superior àquela determinada em ensaios estáticos convencionais de laboratório, onde o tempo para atingir a ruptura pode ser de vários ou muitos minutos. $\mathrm{O}$ aumento da resistência devido à velocidade de aplicação do carregamento dinâmico poderia contrabalançar a redução proposta por Makdisi e Seed (1977) para estimativa da resistência dinâmica de solos argilosos, solos granulares secos ou parcialmente saturados e para solos granulares densos saturados.

A escolha do coeficiente pseudoestático $k$ é o aspecto mais importante e representa a maior incerteza na aplicação deste método. A suposição do solo como material rígido, faz com que as acelerações horizontais na massa de solo em análise sejam iguais às acelerações do registro sísmico, cujo valor máximo $\left(\right.$ PGA $\left.^{\text {rocha }}\right)$ é momentâneo e de curtíssima duração. Do ponto de vista de engenharia é razoável adotar um valor inferior, na literatura várias sugestões foram publicadas (Tabela 3.1) comparando-se os resultados de análises pseudoestáticas com a experiência de campo e valores obtidos com métodos numéricos que, de forma mais realista, podem representar a massa de solo como material deformável. Seed e Martin (1966) e Dakoulas e Gazetas (1986), utilizando modelos de viga de cisalhamento, concluíram que o coeficiente sísmico para uma superfície de ruptura profunda no talude é consideravelmente menor do que aquele calculado para o caso de superfície de ruptura rasa. 
Duncan e Wright (2005) apresentam na Tabela 3.2 alguns critérios da literatura para análise pseudo-estática da estabilidade de taludes, incluindo valores do coeficiente sísmico, do percentual da resistência não drenada (obtida em ensaios estáticos) a ser considerado na análise, e do deslocamento permanente admissível.

Tabela 3.1 - Coeficientes sísmicos recomendados na literatura. Adaptado de Melo e Sarma (2004).

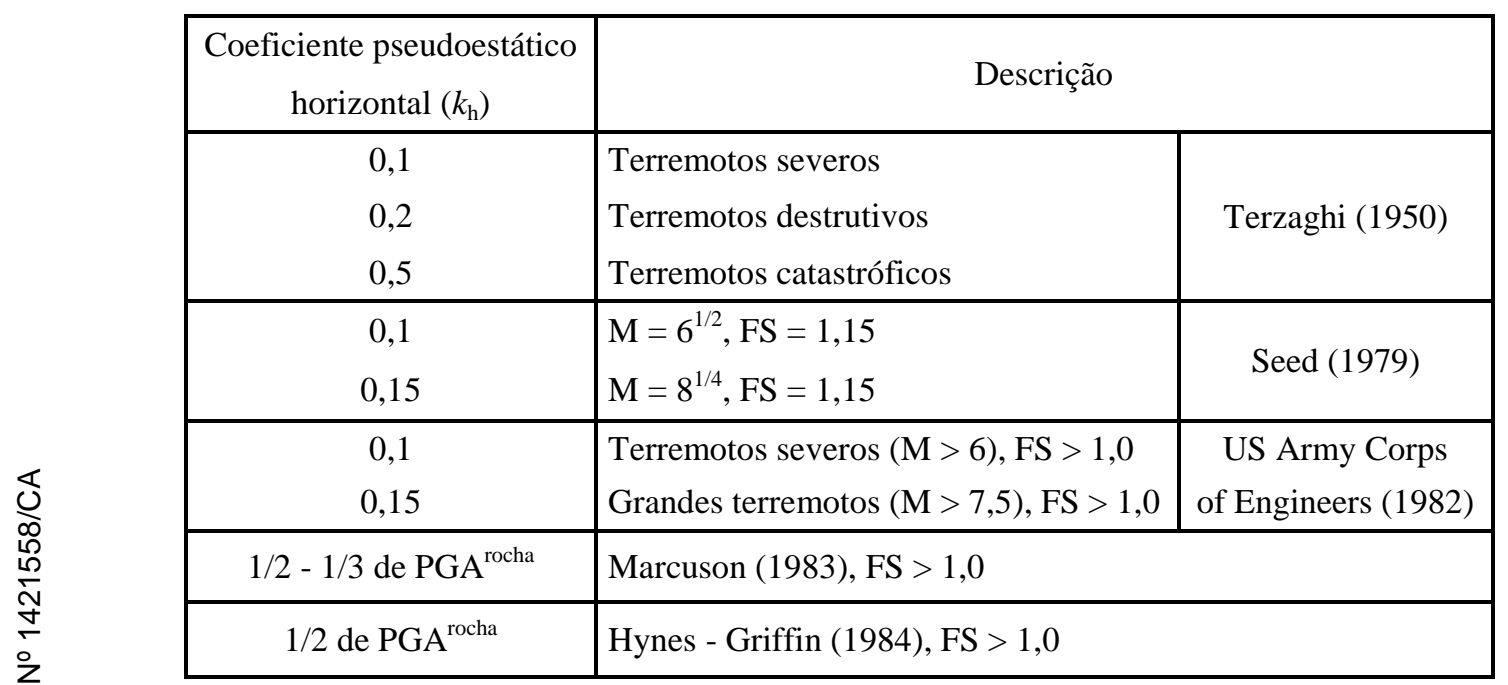

Tabela 3.2 - Critérios sugeridos por Duncan e Wright (2005) para análises pseudo-estáticas em taludes de solo não suscetíveis à liquefação.

\begin{tabular}{|c|c|c|c|c|c|}
\hline Critério & $\begin{array}{c}\text { Aceleração de } \\
\text { referência }\end{array}$ & $\begin{array}{l}\text { Multiplicador da } \\
\text { aceleração }\end{array}$ & $\begin{array}{l}\text { Fator de redução } \\
\text { da resistência }\end{array}$ & $\begin{array}{c}\text { FS } \\
\text { mínimo }\end{array}$ & $\begin{array}{c}\text { Deslocamentos } \\
\text { admissíveis }\end{array}$ \\
\hline $\begin{array}{l}\text { Makdissi e Seed } \\
\text { (1978) }\end{array}$ & $\begin{array}{c}0,2 \mathrm{~g} \text { na crista } \\
(\mathrm{M} \approx 61 / 2)\end{array}$ & 0,5 & 0,8 & 1,15 & Aproximadamente $1 \mathrm{~m}$ \\
\hline $\begin{array}{l}\text { Makdissi e Seed } \\
\text { (1978) }\end{array}$ & $\begin{array}{c}0,75 \mathrm{~g} \text { na crista } \\
(\mathrm{M} \approx 81 / 4)\end{array}$ & 0,2 & 0,8 & 1,15 & Aproximadamente $1 \mathrm{~m}$ \\
\hline $\begin{array}{l}\text { Hynes - Griffin e } \\
\text { Franklin }(1984)^{\mathrm{b}}\end{array}$ & PHA $_{\text {rocha }}$ & 0,5 & 0,8 & 1,0 & $1 \mathrm{~m}$ \\
\hline $\begin{array}{l}\text { Bray et al. } \\
(1998)^{\mathrm{b}}\end{array}$ & $\mathrm{PHA}_{\text {rocha }}$ & 0,75 & $\begin{array}{l}\text { Recomenda resistência } \\
\text { residual }\end{array}$ & 1,0 & $\begin{array}{l}0,30 \mathrm{~m} \text { para coberturas } \\
\text { de aterros; } 0,15 \mathrm{~m} \text { para } \\
\text { deslizamentos na base }\end{array}$ \\
\hline $\begin{array}{l}\text { Kavazanjian et al. } \\
\text { (1997) }\end{array}$ & $\mathrm{PHA}_{\text {solo }}$ & $\begin{array}{l}0,17 \text { (com análise de } \\
\text { resposta dinâmica) }\end{array}$ & $0,8^{\mathrm{a}}$ & 1,0 & $1 \mathrm{~m}$ \\
\hline $\begin{array}{l}\text { Kavazanjian et al. } \\
\text { (1997) }\end{array}$ & $\mathrm{PHA}_{\text {solo }}$ & $\begin{array}{l}0,5 \text { (sem análise de } \\
\text { resposta dinâmico) }\end{array}$ & $0,8^{\mathrm{a}}$ & 1,0 & $1 \mathrm{~m}$ \\
\hline
\end{tabular}

${ }^{\text {a }}$ Para argilas totalmente saturadas ou sensíveis.

${ }^{\mathrm{b}}$ Os critérios de Hynes-Griffin and Franklin (1984) e de Bray et al. (1998) foram propostos para barragens de terra e aterros de resíduos sólidos, respectivamente. 
A interpretação da Tabela 3.2 deve ser a seguinte: se em uma análise pseudo-estática, o coeficiente sísmico for calculado com base na aceleração de referência (coluna 2) vezes o multiplicador de aceleração (coluna 3), considerando o fator de redução da resistência não drenada determinada em ensaio estático (coluna 4), e o fator de segurança pseudo-estático resultar igual ou superior ao valor $\mathrm{FS}_{\text {mínimo }}$ (coluna 5) então os deslocamentos permanentes no talude não serão maiores do que os listados na coluna 6.

De acordo com Kramer (1996), ainda que julgamento de engenharia seja fundamental em todos os casos, o critério de Hynes-Griffin e Franklin (1984) deve ser apropriado para a maioria dos taludes. Hynes-Griffin e Franklin (1984) também sugeriram que uma análise pseudo-estática não é necessária quando o fator de segurança para a condição estática $\mathrm{FS}_{\text {estático }}>1,7$.

As principais limitações na seleção do coeficiente sísmico com base nos critérios da Tabela 3.2 são as seguintes: a) a magnitude dos deslocamentos permanentes admissíveis para taludes de solo, de até $1 \mathrm{~m}$, é muito grande para a maioria das obras de engenharia; b) os critérios abordam de maneira superficial as diferenças em termos de magnitude e distâncias epicentrais, implicando que em alguns casos a análise de estabilidade pode resultar em superestimativas e, em outros, subestimativas do fator de segurança pseudo-estático.

Blake et al. (2002) e Stewart et al. (2003) usaram procedimentos simplificados de projeto para determinar o coeficiente sísmico $k$ com base na sismicidade antecipada do local e considerando diferentes níveis de deslocamentos admissíveis. Assim o coeficiente sísmico $\left(k_{e q}\right)$ é calculado mediante a expressão:

$$
k_{e q}=f_{e q} * P G A_{\text {rocha }}
$$

onde $P G A_{\text {rocha }}$ representa a aceleração horizontal máxima em rocha branda e $f_{e q}$ é um fator relacionado com atividade sísmica da região, determinado pela equação 3.8 .

$$
f_{\text {eq }}=\frac{N R F}{3,477}\left[1,87-\log _{10}\left(\frac{u}{\frac{\text { PGA } \text { rocha }_{g} \times N R F \times D_{5-95}}{g}}\right)\right]
$$

onde $N R F$ é um fator que leva em conta a resposta não linear do material acima da superfície de ruptura, $g$ é aceleração da gravidade, $u$ é o deslocamento horizontal 
permanente e $D_{5-95}$ a duração do registro sísmico que por sua vez é função da magnitude do terremoto e da distância epicentral.

Blake et al. (2002) simplificaram a determinação do fator $f_{e q}$ mediante curvas (Figura 3.2) considerando a magnitude do terremoto $\left(M_{\mathrm{w}}\right)$ e distância focal ( $r$ ) para dois deslocamentos permanentes admissíveis: $u=5 \mathrm{~cm} \mathrm{e} u=15 \mathrm{~cm}$.
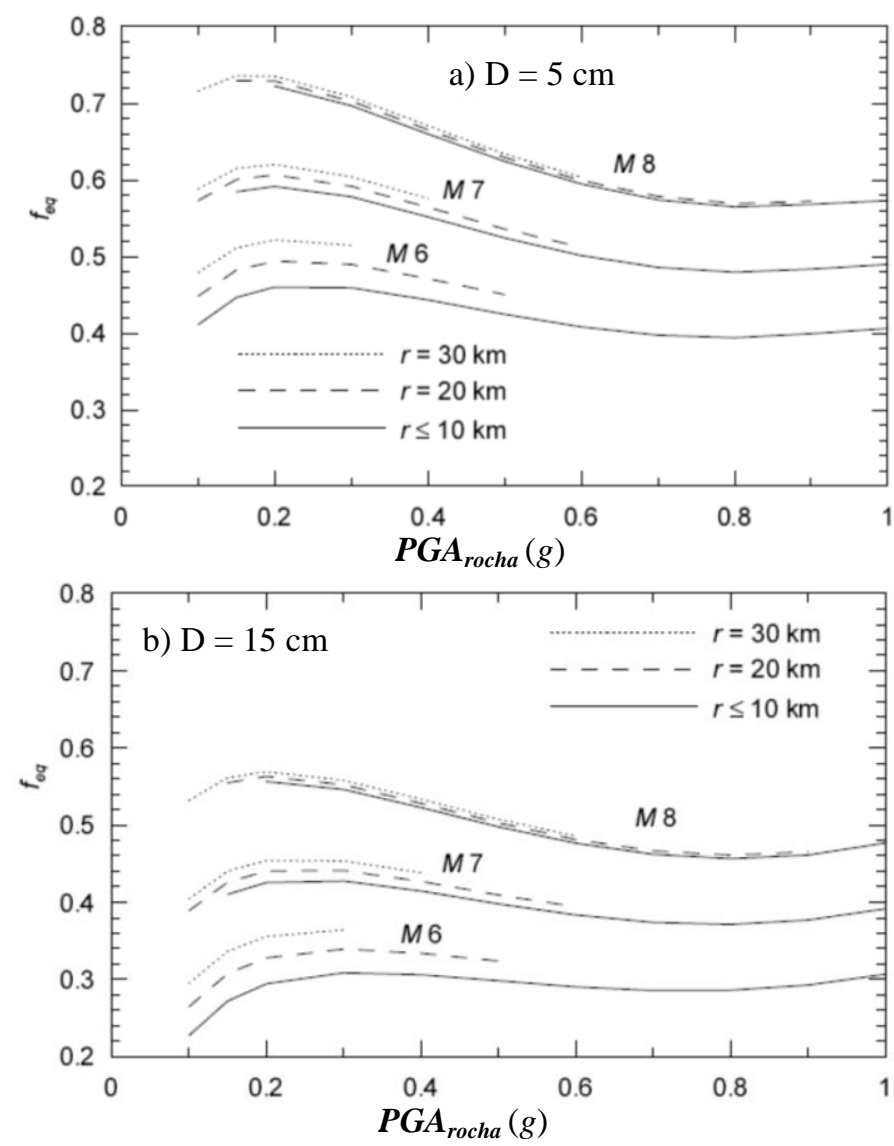

Figura 3.2 - Valores de $f_{e q}$ em função da $\mathrm{PGA}_{\text {rocha }}$ e distância focal para deslocamentos permanentes admissíveis de: a) $5 \mathrm{~cm}$; b) $15 \mathrm{~cm}$. (Adaptado de Califórnia Geological Survey, 2008).

De acordo com o California's Seismic Hazards Mapping Act - Special Publication 117A (2008) se em análise pseudo-estática o fator de segurança resultar superior a 1 , usando um coeficiente sísmico obtido pelos métodos de Blake et al. (2002) ou Stewart et al. (2003), então o talude pode ser considerado estável. Se o coeficiente de segurança for inferior a 1, então é necessário uma análise em termos de deslocamentos para determinar a magnitude dos deslocamentos do talude induzidos pelo terremoto ou tomar providências para minimizar seus efeitos. De acordo com Kramer (1996) para taludes formados com solos que podem desenvolver significativas poropressões devido ao carregamento 
sísmico, com perda de resistência da ordem de $15 \%$ da resistência de pico, análises de estabilidade pseudo-estáticas não são recomendadas.

Bray e Travasarou (2007) apresentaram um procedimento para cálculo do coeficiente sísmico considerando os efeitos dos deslocamentos admissíveis, magnitude do terremoto e acelerações espectrais. Este método será discutido em detalhe na seção 3.2.3.1.

O método pseudo-estático também é empregado em conjunto com alguns dos métodos baseados no cálculo dos deslocamentos (Newmark, Makdisi-Seed). O primeiro passo é determinar o valor do coeficiente sísmico de escoamento $\left(k_{y}\right)$ e a superfície crítica pseudo-estática. O coeficiente $k_{y}$ é interpretado como a mínima aceleração horizontal necessária para produzir um fator de segurança pseudoestático igual a 1. Em simples termos, este coeficiente representa a resistência do talude às acelerações induzidas pelo terremoto. A determinação de $k_{y}$ é feita por tentativa e erro no método das fatias até que o fator de segurança se reduza a 1. A superfície relacionada com o valor de coeficiente sísmico de escoamento é chamada de superfície crítica pseudo-estática e geralmente não coincide com aquela correspondente ao mínimo fator de segurança de análises estáticas (Blake et al. 2002; Duncan e Wright, 2005).

\section{2. \\ Modelos para cálculo de deslocamentos permanentes}

\subsection{1.}

\section{Modelo de bloco rígido}

As diferentes acelerações provocadas durante um terremoto se traduzem em variações ao longo do tempo de forças inerciais desestabilizadoras aplicadas no talude. É possível supor que o fator de segurança atinja momentaneamente um valor inferior a 1, que não provoca o colapso imediato do talude mas induz a ocorrência de deslocamentos permanentes. Utilizando este raciocínio, Newmark (1965) considerou a analogia de um bloco rígido sobre um plano inclinado (Figura 3.3) sujeito a uma história de acelerações. 


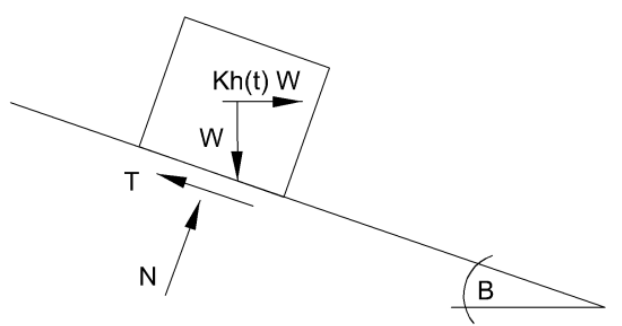

Figura 3.3 - Modelo do bloco rígido de Newmark (1965).

A força inercial resultante $\left(k_{h(t)} * W\right)$ devido à aceleração horizontal produzida pelo sismo influirá de maneira adversa na estabilidade do bloco. Quando esta aceleração, com amplitude A, for superior à aceleração de escoamento $a_{y}$ calculada com o método pseudo-estático na condição $\mathrm{FS}=1$, então

$$
a(t)=A-a_{y}
$$

onde $a(t)$ representa a aceleração relativa do bloco em relação ao plano inclinado em certo intervalo de tempo $t_{o} \leq t \leq t_{o}+\Delta t$ (entre os pontos $\mathrm{X}$ e Y da Figura 3.4a). A velocidade e o deslocamento relativos do bloco podem ser obtidos mediante integrações sucessivas no tempo da equação (3.9):

$$
\begin{gathered}
v(t)=\int_{t_{o}}^{t} a(t) d t=\left(A-a_{y}\right)\left(t-t_{o}\right) \\
u(t)=\int_{t_{o}}^{t} v(t) d t=\frac{\left(A-a_{y}\right)}{2}\left(t-t_{o}\right)^{2}
\end{gathered}
$$

No tempo $t=t_{o}+\Delta t$ (ponto Y na Figura 3.4) a velocidade atinge seu máximo valor e o deslocamento relativo ainda progride,

$$
\begin{gathered}
v\left(t_{o}+\Delta t\right)=\left(A-a_{y}\right) \Delta t \\
u\left(t_{o}+\Delta t\right)=\frac{1}{2}\left(A-a_{y}\right) \Delta t^{2}
\end{gathered}
$$




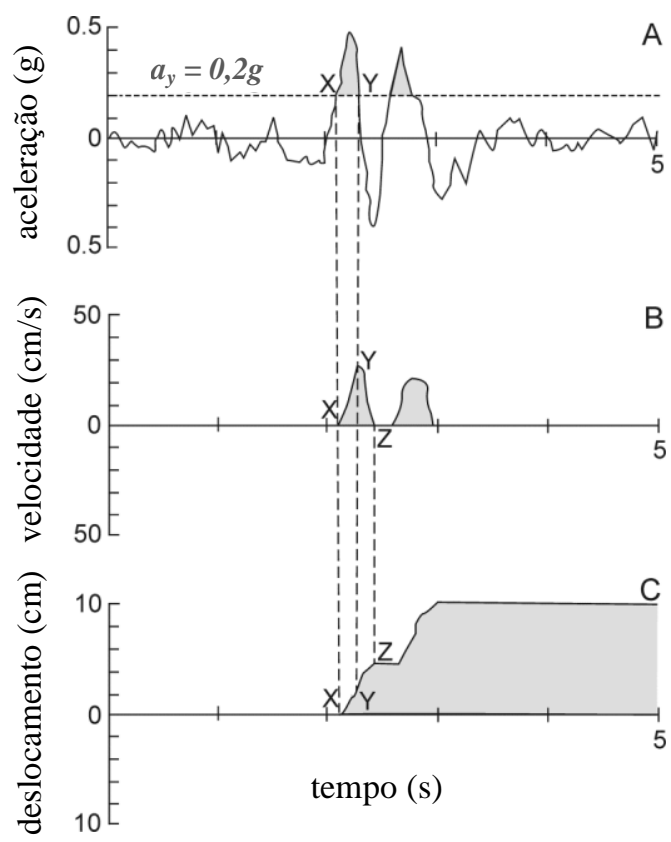

Figura 3.4 - Dupla integração da aceleração no tempo para obtenção dos deslocamentos permanentes no método de Newmark (Wilson e Keefer, 1983).

O bloco continua a se movimentar com velocidade decrescente (equação 3.14) até que as duas seguintes condições sejam satisfeitas (ponto $\mathrm{Z}$ da Figura 3.4b): i) $A<a_{y}$;ii) $v(t)=0$.

$$
\begin{gathered}
v(t)=v\left(t_{o}+\Delta t\right)+\int_{t_{o}+\Delta t}^{t} a(t) d t=A \Delta t-a_{y}\left(t-t_{o}\right) \\
u(t)=\int_{t_{o}+\Delta t}^{t} v(t) d t
\end{gathered}
$$

O deslocamento permanente total do bloco é dado por

$$
u(t)=\frac{\Delta t^{2}}{2}\left(A-a_{y}\right) \frac{A}{a_{y}}
$$

No artigo original de Newmark (1965) a força de inércia é aplicada no centro de gravidade da massa de solo instável, paralela ao plano inclinado (ou na direção do movimento inicial do centro de gravidade), mas na maioria das aplicações da literatura a força de inércia é admitida horizontal. Kramer e Lindwal (2004) compararam os resultados obtidos considerando ambas as hipóteses e concluíram que a estabilidade não é sensível à direção da força de inércia, podendo-se obter resultados com boa aproximação através da usual hipótese de acelerações horizontais. Sarma (1975) também concluiu que o fator de segurança 
pseudo-estático e os deslocamentos permanentes são insensíveis à inclinação da força de inércia e, consequentemente, as acelerações horizontais podem ser usadas em análises de estabilidade sem provocar muito erro. Yan et al. (1996) e Ling et al. (1997) observaram também apenas modestas variações de deslocamento permanente do talude quando acelerações verticais são consideradas.

Newmark (1965) introduziu a aceleração horizontal de pico (PGA) e a velocidade horizontal de pico (PGV) do embasamento rochoso como parâmetros sísmicos de projeto para delimitar a estimativa dos deslocamentos permanentes máximos $\delta^{\max } \mathrm{em}$ dois intervalos da razão de aceleração $a_{y} / \mathrm{PGA}$. Estas envoltórias foram matematicamente expressas por Cai e Bathurst (1996) como:

$$
\begin{aligned}
& \delta^{\max }=3\left(\frac{a_{y}}{P G A}\right)^{-1} \frac{P G V^{2}}{P G A^{*} g} \text { para } \quad a_{y} / P G A<0,16 \\
& \delta^{\max }=0,5\left(\frac{a_{y}}{P G A}\right)^{-2} \frac{P G V^{2}}{P G A^{*} g} \text { para } \quad a_{y} / P G A>0,16
\end{aligned}
$$

onde $a_{y}$ é a aceleração de escoamento (fração de g), PGA e PGV os valores de pico da aceleração horizontal (fração de g) e da velocidade horizontal (em m/s) do embasamento rochoso, respectivamente.

Para estimativa do deslocamento permanente médio Cai e Bathurst (1996) propuseram, com base em análises de regressão com os acelerogramas utilizados por Newmark, a seguinte correlação, com $50 \%$ de probabilidade deste valor ser ultrapassado.

$$
D=9,2 \frac{P G V^{2}}{P G A}\left(-5,87 \frac{a_{y}}{P G A}\right)\left(\frac{a_{y}}{P G A}\right)^{-0,49}
$$

O método de Newmark (1965) incorpora dois dos principais fatores que influenciam os deslocamentos permanentes provocados em taludes por terremotos: a aceleração de escoamento $a_{y}$ e as características do registro sísmico (amplitude e duração). Todavia, sua precisão é limitada pela hipótese de bloco rígido pois solos são materiais deformáveis. 
Para taludes de solo muito rígido ou taludes submetidos a movimentos de baixa frequência (uma combinação que produz grandes comprimentos de onda) ou massas instáveis de pequena espessura (deslizamentos superficiais), os deslocamentos horizontais ao longo da superfície potencial de deslizamento estarão aproximadamente em fase (Figura 3.5a) e a hipótese de bloco rígido será aproximadamente satisfeita. Entretanto, para solos de baixa rigidez ou taludes sujeitos a excitações de alta frequência (uma combinação que resulta em pequenos comprimentos de onda) ou massas instáveis de grande espessura (deslizamentos profundos), os deslocamentos laterais do talude estarão fora de fase (Figura 3.5b), com forças de inércia agindo em sentidos opostos em diferentes pontos da massa de solo instável. A força de inércia resultante para toda a massa de solo poderá ser significativamente menor do que aquela obtida com a hipótese de bloco rígido.

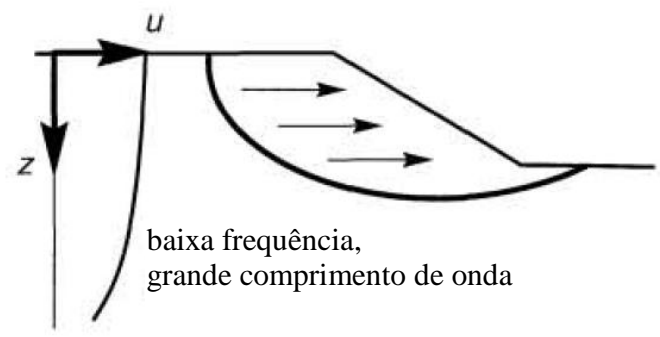

(a)

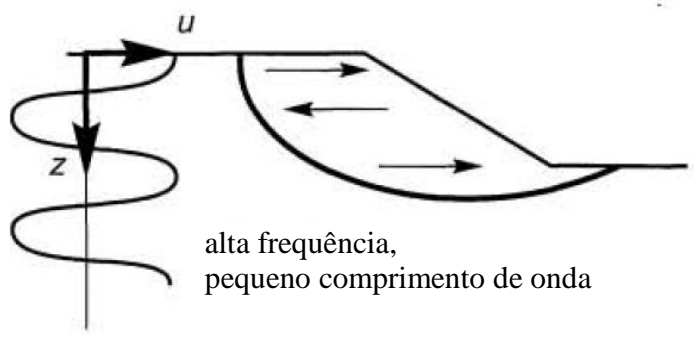

(b)

Figura 3.5 - Influência da rigidez do solo e das frequências de excitação na resposta sísmica de taludes: a) baixa frequência, grande comprimento da onda; b) alta frequência, pequeno comprimento da onda (Adaptado de Kramer, 1996).

Uma das dificuldades na aplicação do método de Newmark (1965) é considerar a massa de solo (bloco) e a superfície de ruptura (plano inclinado) como corpos rígidos. Houston et al. (1987) utilizaram um programa computacional (SHAKE, 1972) baseado na propagação 1D de ondas de tensão para determinar as acelerações na profundidade da superfície de ruptura (ponto A) a partir do acelerograma aplicado na base rochosa (ponto R) na Figura 3.6. É também admitida a existência de uma camada de material mole abaixo da superfície potencial de deslizamento, cujas propriedades são obtidas por processo de tentativa e erro até que as acelerações horizontais máximas em alguns pontos (como $B_{1}, B_{2}$ e $B_{3}$ na Figura 3.6) sejam aproximadamente iguais entre si para satisfazer a hipótese de rigidez do bloco deslizante. Quando esta condição é satisfeita, então a correspondente história de acelerações do ponto A é comparada 
com a aceleração de escoamento $a_{y}$ para aplicação da dupla integração do método de Newmark.

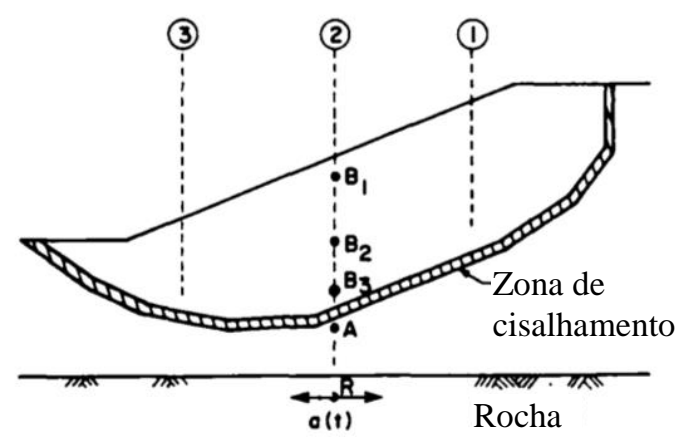

Figura 3.6 - Analogia do bloco deslizante de Newmark (1965) aplicada em talude de solo (Houston et al. 1987).

Houston et al. (1987) avaliaram os deslocamentos permanentes do talude em três perfis de solo (Figura 3.6) localizados próximos à crista, ao pé e na altura média do talude. Em virtude da hipótese de rigidez do bloco deslizante, o deslocamento final do talude foi tomado como uma média dos deslocamentos calculados nestes perfis, ainda que seja boa prática de engenharia levar também em conta o deslocamento máximo calculado.

Outra característica deste programa para microcomputadores desenvolvido em FORTRAN (listagem disponível em Houston et al., 1987) é que os cálculos são feitos duas vezes, adotando-se na segunda execução um sinal reverso para a história de acelerações, com o objetivo de considerar casos onde este registro seja fortemente assimétrico. Os dois valores calculados são considerados válidos, como indicadores do provável intervalo de resposta do talude. Houston et al. (1987) também consideraram a componente ascendente da aceleração de escoamento para determinar movimentos do bloco "talude acima". De acordo com Ordoñez (2004), os resultados assim obtidos são bastante similares aos calculados somente com movimentos descendentes, hipótese usualmente empregada no modelo de Newmark.

Matasovic et al. (1997) sugeriram uma variação do modelo de Newmark para materiais que apresentem pronunciado amolecimento com o nível de deformações, como areias densas, argilas pré-adensadas e interfaces com geomembranas onde a diferença entre os parâmetros de resistência de pico e residuais pode ser significativa. O coeficiente sísmico de escoamento $k_{y}$ é diretamente relacionado com a resistência ao cisalhamento ao longo da potencial 
superfície de ruptura; para revestimentos de aterros sanitários, onde a geometria do sistema é relativamente simples e a superfície de ruptura geralmente acompanha a geomembrana, $k_{y}$ pode ser diretamente proporcional à resistência na interface.

Matosovic et al. (1997) sugeriram um modelo trilinear para degradação do coeficiente sísmico na interface com membrana geosintética (Figura 3.7) delimitado por valores de deslocamento permanente correspondentes ao pico da curva força $\mathrm{x}$ deslocamento e quando a mesma atinge um patamar correspondente à resistência ao cisalhamento residual para grandes deformações.

Como o método de Newmark depende do registro de acelerações do terremoto, e não é tarefa simples fazer a previsão de acelerogramas para um futuro evento sísmico em um sítio particular, Jibson (1993) propôs uma abordagem mais simples onde a história de acelerações é representada por uma única medida qualitativa da intensidade do evento, usando a intensidade Arias. Após analisar muitos registros de terremotos de moderada a grande magnitude, Jibson (op.cit.) desenvolveu a seguinte correlação para previsão de deslocamentos permanentes:
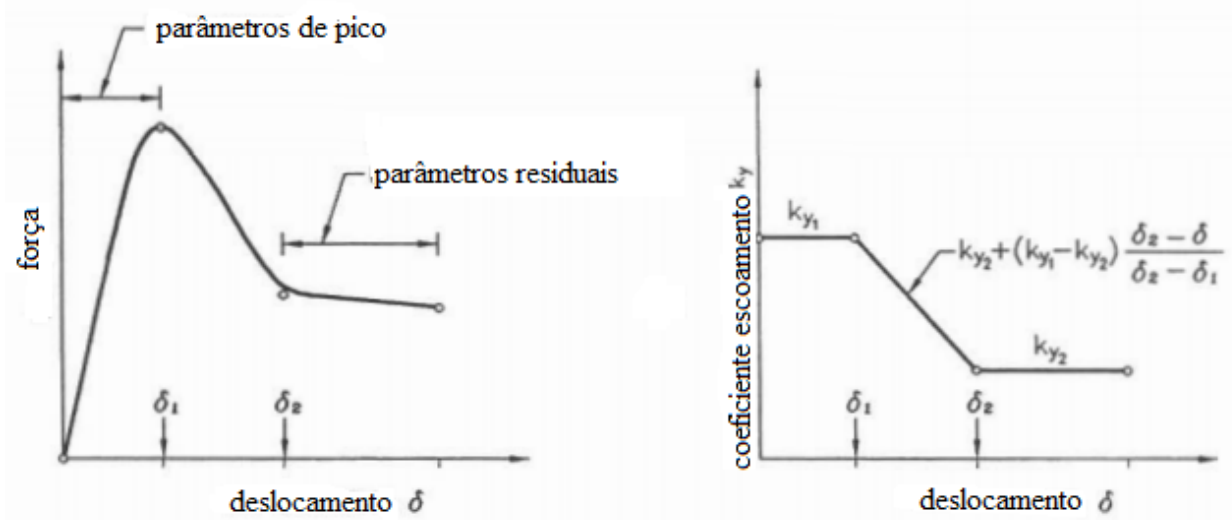

Figura 3.7 - Curva força $x$ deslocamento medida e modelo de degradação do coeficiente sísmico em aterro sanitário com revestimento de geomembrana (Matasovic et al., 1997).

$$
\begin{gathered}
\log D=1.460 \log I_{a}-6.642 a_{y}+1.546 \\
I_{a}=\frac{\pi}{2 g} \int a^{2} d t
\end{gathered}
$$

onde $D$ é o deslocamento permanente $(\mathrm{cm}), I_{a}$ representa a intensidade Arias $(\mathrm{m} / \mathrm{s})$ e $a_{y}$ a aceleração de escoamento (g). A intensidade Arias $I_{a}=$ 
$(\pi / 2 g) \int a^{2} d t$ pode ser estimada com base em equações empíricas de leis de atenuação.

Devido às muitas simplificações do método de Newmark convencional (1965) muitos engenheiros consideram as estimativas de deslocamento permanente assim calculadas como meros índices gerais do comportamento de taludes do que valores que possam satisfatoriamente quantificar uma previsão de deslocamentos causados por carregamentos sísmicos.

\subsubsection{1.}

\section{Método Saygili e Rathje (2008)}

Este método simplificado para estimativa de deslocamentos permanentes de taludes apresenta dois possíveis enfoques de solução: abordagem determinística e abordagem pseudo-probabilística, considerando o modelo de bloco rígido deslizante de Newmark (1965). Foi desenvolvido a partir de uma base de dados composta por 2383 registros sísmicos ocorridos na costa oeste dos Estados Unidos (Estado da Califórnia) com magnitude $\mathrm{M}_{\mathrm{w}}$ entre 5,0 a 7,9.

Os deslocamentos permanentes para as análises de regressão foram obtidos pela dupla integração no tempo dos acelerogramas. Os pesquisadores procuraram então determinar relações entre deslocamentos, coeficiente sísmico $k_{y}$ e vários outros parâmetros do movimento como a aceleração máxima (PGA), velocidade máxima (PGV), intensidade de Arias $(I a)$, período médio quadrático $\left(T_{m}\right)$ e duas definições de duração significativa do terremoto (D5-75, D5-95).

Saygili e Rathje (2008) observaram que PGA e $I_{a}$ foram os parâmetros que isoladamente mais efetivos se mostraram na redução da variância dos deslocamentos enquanto que os parâmetros de conteúdo de frequências e de duração ( $T m, D 5-75, D 5-95)$ não contribuíram significativamente. Mais importante foi a observação de que as previsões de deslocamento melhoraram quando dois parâmetros de movimento foram usados simultaneamente (PGA e PGV ou $I_{a}$ e $T_{m}$ ).

Baseados nestes resultados então propuseram dois métodos para estimativa dos deslocamentos permanentes em taludes como função de um (modelo escalar) ou mais (modelo vetorial) parâmetros de movimento. O modelo escalar é representado pelas equações 3.22 enquanto que o modelo vetorial pelas equações 3.23. As constantes $a_{1}, a_{2}, a_{3}$ até $a_{10}$ estão listadas na Tabela 3.3. 
$\ln D=a_{1}+a_{2}\left(\frac{k_{y}}{P G A}\right)+a_{3}\left(\frac{k_{y}}{P G A}\right)^{2}+a_{4}\left(\frac{k_{y}}{P G A}\right)^{3}+a_{5}\left(\frac{k_{y}}{P G A}\right)^{4}+a_{6} \ln (P G A)+a_{7}\left(M_{w}-6\right)$

$$
\sigma_{l n D}=a_{8}+a_{9}\left(\frac{k_{y}}{P G A}\right)+a_{10}\left(\frac{k_{y}}{P G A}\right)^{2}
$$

$\ln D=a_{1}+a_{2}\left(\frac{k_{y}}{P G A}\right)+a_{3}\left(\frac{k_{y}}{P G A}\right)^{2}+a_{4}\left(\frac{k_{y}}{P G A}\right)^{3}+a_{5}\left(\frac{k_{y}}{P G A}\right)^{4}+a_{6} \ln (P G A)+a_{7} \ln (P G V)$

$$
\sigma_{l n D}=a_{8}+a_{9}\left(\frac{k_{y}}{P G A}\right)
$$

Rathje e Saygili (2011) adicionaram o termo de magnitude do terremoto $M_{w}$ na equação 3.22a em relação à originalmente proposta por Saygili e Rathje (2008). Aqueles pesquisadores recomendaram o modelo vetorial porque incorpora de melhor forma o conteúdo de frequências do movimento além de produzir valores de desvio padrão (equação 3.23b) mais baixos.

Tabela 3.3 - Parâmetros para o modelo escalar e modelo vectorial no método de Saygili e Rathje (Rathje e Saygili, 2009).

\begin{tabular}{lcc}
\hline Parameter & Scalar model $(\mathrm{PGA}, M)$ & Vector model $(\mathrm{PGA}, \mathrm{PGV})$ \\
\hline$a_{1}$ & 4.89 & -1.56 \\
$a_{2}$ & -4.85 & -4.58 \\
$a_{3}$ & -19.64 & -20.84 \\
$a_{4}$ & 42.49 & 44.75 \\
$a_{5}$ & -29.06 & -30.50 \\
$a_{6}$ & 0.72 & -0.64 \\
$a_{7}$ & 0.89 & 1.55 \\
$a_{8}$ & 0.73 & 0.41 \\
$a_{9}$ & 0.79 & 0.52 \\
$a_{10}$ & -0.54 & - \\
\hline
\end{tabular}

Geralmente os valores da PGA se referem a uma probabilidade de excedência de $2 \%$ ou $10 \%$ em estudos de ameaça sísmica na região de interesse, considerando uma vida útil do talude de 50 anos. Pode haver dificuldade na estimativa da velocidade esperada de pico, ainda que funções de atenuação 
desenvolvidas recentemente incluam formulações para determinação da PGV em estudos de ameaça sísmica.

Bommer e Alarcon (2006) e Alarcon et al. (2006) sugerem determinar a PGV $(\mathrm{cm} / \mathrm{s})$ com base na função de aceleração espectral $S_{a}\left(\mathrm{~cm} / \mathrm{s}^{2}\right)$ para um período de vibração $T=0,5$ segundos, conforme equação 3.24 .

$$
\mathrm{PGV}=\frac{S_{a}(T=0.5 \mathrm{~s})}{20}
$$

\subsection{2. \\ Modelos desacoplados}

\subsubsection{1. Método simplificado de Makdisi e Seed (1978)}

Makdisi e Seed (1978) desenvolveram uma relação que modela a variação das acelerações horizontais ao longo da profundidade na potencial massa de deslizamento. Dois métodos foram utilizados para estabelecer esta relação: (a) análises 2D pelo método dos elementos finitos; (b) resultados de análises dinâmica 1D publicados na literatura com base no método da viga de cisalhamento.

As análises pelo método dos elementos finitos foram executadas utilizando programa computacional incorporando o modelo linear equivalente (degradação do módulo de cisalhamento e do aumento da razão de amortecimento com o nível das deformações de cisalhamento cíclicas), representando a geometria da seção transversal de uma barragem de aterro como um aterro triangular de várias alturas e inclinações dos taludes, com diferentes propriedades de material.

Makdisi e Seed expressaram seus resultados por meio de gráficos que relacionam os valores de $k_{\max } / \mathrm{PGA} / \mathrm{g}$ como uma função da profundidade normalizada $\mathrm{y} / \mathrm{H}$ onde $k_{\max }$ é o coeficiente sísmico máximo, PGA a aceleração na crista da barragem, y representa a profundidade da potencial superfície de ruptura medida a partir da crista e $\mathrm{H}$ a altura da barragem (aterro), conforme a Figura 3.8. 


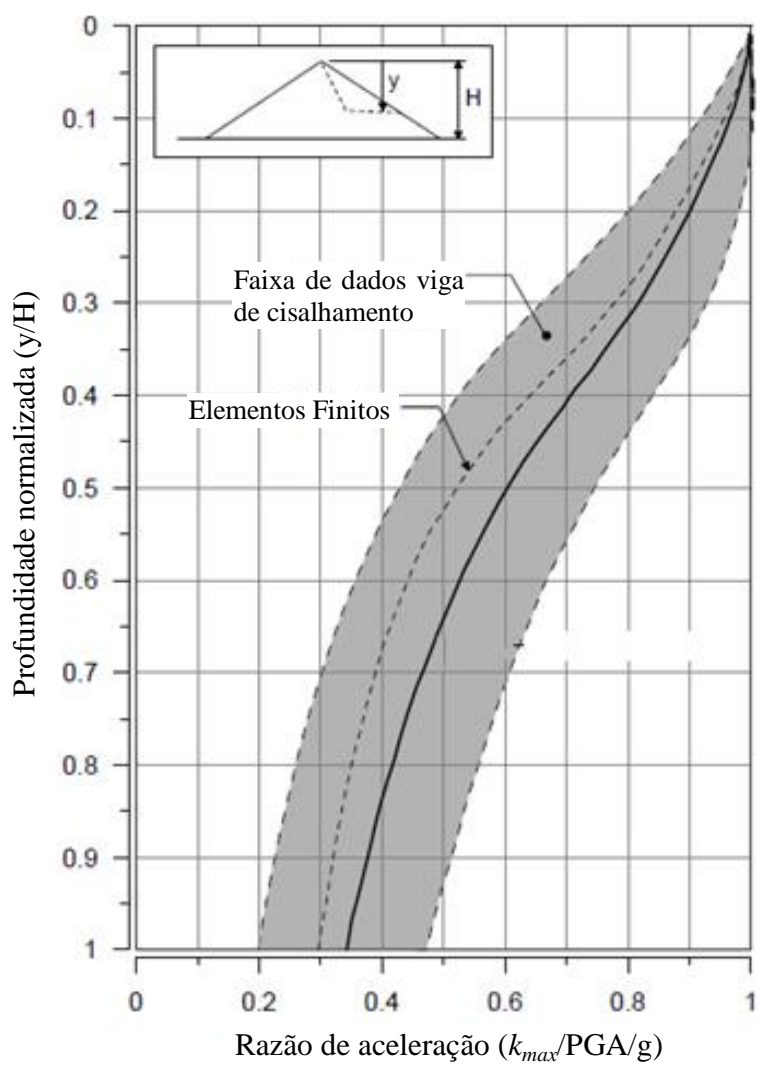

Figura 3.8 - Estimativa do coeficiente sísmico em função da máxima aceleração horizontal na crista (PGA) e da profundidade da massa de solo deslizante (Makdisi e Seed, 1978).

O cálculo da aceleração horizontal PGA na crista da barragem é a grande limitação do método de Makdisi-Seed. Uma das possibilidades é utilizar um programa computacional para análise numérica 2D (por exemplo, FLAC ou Plaxis 2D) mas esta alternativa é conflitante com a intenção de método simplificado, proposto com o objetivo de ser simples e de fácil aplicação.

Outra opção seria empregar um programa computacional para análise da resposta dinâmica 1D (Shake e suas versões) mas os resultados variam muito em função de amplificações devido à geometria da barragem (efeitos topográficos), com reflexões nos taludes gerando ondas de superfície.

Normalmente a aceleração horizontal na crista é estimada com base em solução analítica considerando o modelo de uma viga de cisalhamento com seção transversal triangular; por esta razão, o método de Makdisi-Seed é limitado a aterros e barragens e não é aplicável a taludes de encostas, pois se espera simetria da estrutura em relação a um eixo vertical central.

Para estimativa dos deslocamentos permanentes, Makdisi e Seed (1977) analisaram pelo método dos elementos finitos, considerando o modelo linear 
equivalente, a resposta dinâmica de aterros com altura variando de 22,5m a 45m, com diferentes inclinações de taludes e materiais, submetidos a terremotos com magnitude 6.5, 7.5 e 8.25. Em cada uma das análises numéricas, as histórias das acelerações na crista do aterro e da aceleração média em uma potencial massa de deslizamento se estendendo através da quase totalidade da altura do aterro foram determinadas, bem como o primeiro período natural de vibração. Em um dos casos as histórias de aceleração média para superfícies de deslizamento em 5 diferentes profundidades foram obtidas e os correspondentes deslocamentos permanentes foram calculados admitindo várias acelerações de escoamento $k_{y} \mathrm{~g}$. Makdisi e Seed (1977) concluíram que para a mesma razão de aceleração $k_{y} / k_{\max }$ os deslocamentos permanentes variam uniformemente entre um valor máximo, obtido com a história das acelerações da crista, e um valor mínimo, obtido com a história de acelerações média para uma massa deslizante passando pela altura total do aterro. A partir desta constatação, foi considerado suficiente computar os deslocamentos permanentes apenas para estes dois níveis: crista e base do aterro. Para diferentes histórias de aceleração (crista e base) e da razão de aceleração $k_{y} / k_{\max }$ os deslocamentos permanentes foram calculados por dupla integração no tempo, à semelhança do método convencional de Newmark (1965).

Makdisi-Seed (1977) apresentaram na Figura 3.9 os resultados de deslocamento permanente, para os três terremotos analisados, normalizados em relação ao primeiro período natural de vibração $\mathrm{T}_{\mathrm{o}} \mathrm{e}$ do valor máximo $k_{\max } \mathrm{g}$ da história de aceleração média, os dois parâmetros que tem a maior influência no cálculo dos deslocamentos permanentes. Observaram que para valores baixos da razão de aceleração $\left(k_{y} / k_{\max } \leq 0,1\right.$ para terremoto com magnitude 6.5 e $k_{y} / k_{\max } \leq$ 0,2 para terremoto com magnitude 8.25) as hipóteses básicas de cálculo empregada no método dos elementos finitos (modelo linear equivalente e hipótese de deformações infinitesimais) tornam-se inválidas e os deslocamentos permanentes assim estimados podem não ser realistas.

Pode ser esperado que para uma determinada massa de solo e coeficiente sísmico de fluência, a magnitude dos deslocamentos permanentes causados por um terremoto seja função dos seguintes fatores: (a) a amplitude média das acelerações induzidas na massa de solo, as características de amplificação do aterro e a localização da superfície de deslizamento no aterro; (b) o conteúdo de frequências da história de acelerações média, que é governada pela altura do 
aterro e características de rigidez, que é usualmente dominado pelo primeiro período natural de vibração do aterro; (c) a duração do terremoto que é função de sua magnitude.

Na Figura 3.9 as curvas para $k_{y} / k_{\max }$ aparecem em linhas tracejadas sempre que a hipótese de cálculo pelo método dos elementos finitos, conforme mencionado anteriormente, foi julgada não satisfeita.

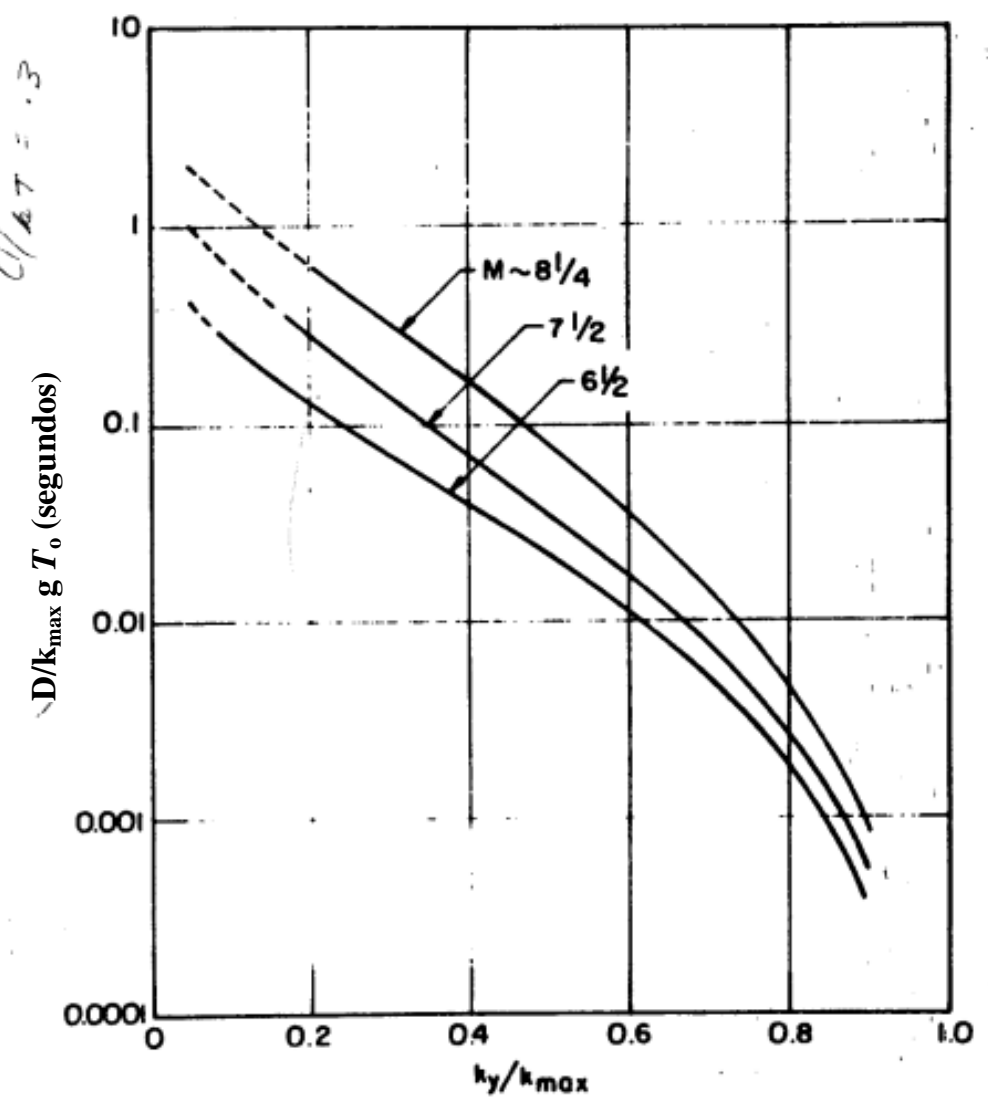

Figura 3.9 - Variação do deslocamento permanente normalizado em relação à razão de acelerações $k_{y} / k_{\max }$ (Makdisi e Seed, 1978).

Logo, para calcular o deslocamento permanente em aterro construído com solo que não perde resistência significativa durante a excitação sísmica, é suficiente deteminar a aceleração máxima na crista do aterro e o primeiro modo de vibração do aterro provocado por determinado terremoto. $\mathrm{O}$ valor do coeficiente sísmico de fluência $k_{y}$, correspondente a um fator de segurança pseudo-estático FS $=1$, é determinado por meio de um método de equilíbrio limite (método das fatias), considerando a resistência ao cisalhamento dinâmica não drenada equivalente a $80 \%$ da resistência não drenada estática. 
De acordo com Kramer (1996), o método simplificado de Makdisi e Seed (1978) tem a vantagem de incorporar resultados de análises numéricas da resposta dinâmica de barragens e aterros, mas seus resultados devem ser tomados com cautela quando aplicado a outro tipo de taludes, como em encostas naturais.

Segundo Bray (2007), os valores superior e inferior da relação entre altura da crista e profundidade da superfície de deslizamento versus coeficiente sísmico máximo (Figura 3.8) não são limites reais. Por exemplo, no caso de taludes rígidos, submetidos a movimentos com período fundamental próximo do período de ressonância, podem ocorrer valores de $k_{\max } 50 \%$ superiores à aceleração máxima na crista $(\mathrm{PGA})$ no caso de deslizamentos profundos $(y / h=1)$; por outro lado, para taludes de menor rigidez submetidos a movimentos com baixo período fundamental, os valores de $k_{\max }$ podem ser $20 \%$ menores do que a aceleração máxima da crista para $y / h=1$.

Jibson (2011) menciona ainda as seguintes observações em relação ao método simplificado de Makdisi e Seed (1978):

a) uma estimativa satisfatória da aceleração na crista da barragem é necessária, visto ser esta a principal fonte de incertezas do método;

b) as correlações gráficas mostram amplas faixas para valores das deformações permanentes, que podem variar em até uma ordem de grandeza, o que transfere ao engenheiro a responsabilidade pela escolha de um valor julgado o mais adequado.

\subsubsection{2.}

\section{Método simplificado de Bray e Rathje (1998)}

Este método baseia-se nos resultados de análises dinâmicas não lineares unidimensionais, desacopladas, efetuadas por Matasovic e Vucetic (1995) utilizando o modelo de bloco rígido de Newmark (1965). Segundo Bray (2007) tem a vantagem de levar em consideração um comportamento mais próximo da realidade dos materiais, em termos da redução do módulo de cisalhamento $G$ e do acréscimo da razão de amortecimento em função da deformação cisalhante cíclica, por incorporar uma importante quantidade de registros sísmicos disponíveis até a data (1998), com acelerações de pico variando entre 0,2g a 0,8g. A aferição do modelo foi feita com base no comportamento observado em alguns aterros de 
resíduos sólidos durante os terremotos de Loma Prieta (1989) e Northridge (1994).

Os parâmetros do movimento são definidos em termos da aceleração horizontal máxima $(M H A)$, período fundamental do movimento $\left(T_{m}\right)$, duração significativa $\left(D_{5-95}\right)$ do registro sísmico em afloramento rochoso. Alternativamente, podem ser utilizadas as relações empíricas em função da distância epicentral mostradas na Figura 3.10.

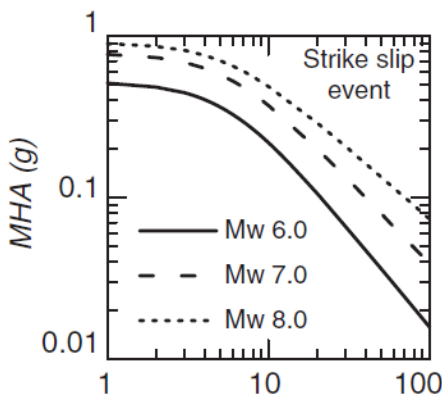

(a) Distância $(\mathrm{km})$

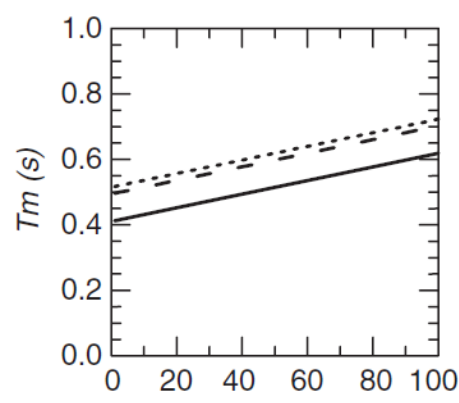

(b) Distância $(\mathrm{km})$

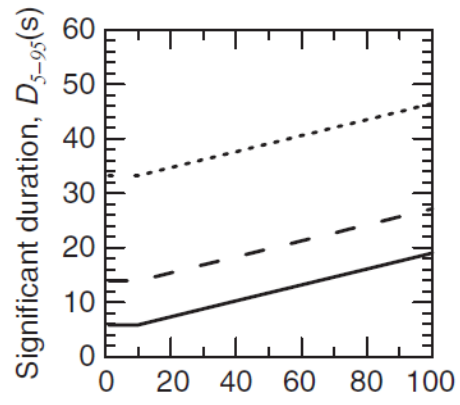

(c) Distância $(\mathrm{km})$

Figura 3.10 - Caracterização simplificada de um movimento sísmico em afloramento rochoso em função da distância epicentral: a) variação da aceleração máxima horizontal MHA (Abrahamson e Silva, 1997); b) variação do período fundamental $T_{m}$ (Rathje et al., 2004); c) variação da duração significativa $D_{5-95}$ (Abrahamson e Silva, 1996).

Para deslizamentos profundos o período fundamental inicial da massa de solo instável $\left(T_{s}\right)$ é determinado mediante a razão entre a altura do talude $H$ e velocidade da onda de cisalhamento $V_{s}$ (Figura 3.11). O período fundamental do terremoto $T_{m}$ (em segundos) pode ser estimado pela seguinte correlação, desenvolvida por Rathje et al. (2004) com base em terremotos ocorridos na costa oeste dos Estados Unidos, em função da magnitude de momento $\left(M_{w}\right)$ e da distância à fonte ( $r$, em quilômetros):

$$
\begin{gathered}
\ln \left(T_{m}\right)=-1,00+0,18\left(M_{w}-6\right)+0,0038 r \quad \text { para } M_{w} \leq 7.25 \\
\ln \left(T_{m}\right)=-0,775+0,0038 r \quad \text { para } M_{w}>7.25
\end{gathered}
$$

O carregamento sísmico máximo normalizado $M H E A /\left(M H A_{\text {rock }}{ }^{*} N R F\right)$ é determinado com auxílio da razão entre o período fundamental da estrutura de terra e o período fundamental do terremoto $\left(T_{s} / T_{m}>0,5\right)$ utilizando a Figura 3.12 ou, alternativamente, a equação 3.26 onde MHEA é a aceleração máxima horizontal equivalente, $N R F$ o fator de resposta não linear do solo e $\varepsilon=0,298$. 
$\ln \left(M H E A /\left(M H A_{\text {rock }} * N R F\right)\right)=-0,624-0,7831 \ln \left(T_{s} / T_{m}\right) \pm \varepsilon$

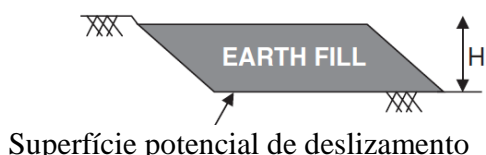

(a) $\mathrm{T}_{\mathrm{s}}=4 \mathrm{H} / \mathrm{V}_{\mathrm{s}}$
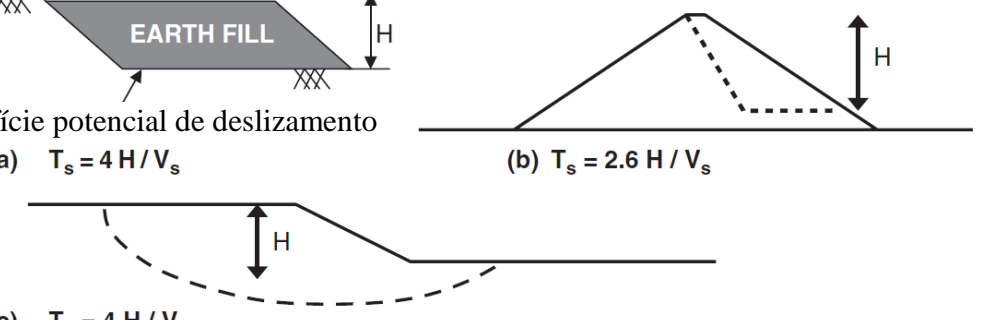

(c) $\mathrm{T}_{\mathrm{s}}=4 \mathrm{H} / \mathrm{V}_{\mathrm{s}}$

Figura 3.11 - Período fundamental inicial $\left(T_{s}\right)$ da massa de solo potencialmente instável (Bray, 2007).

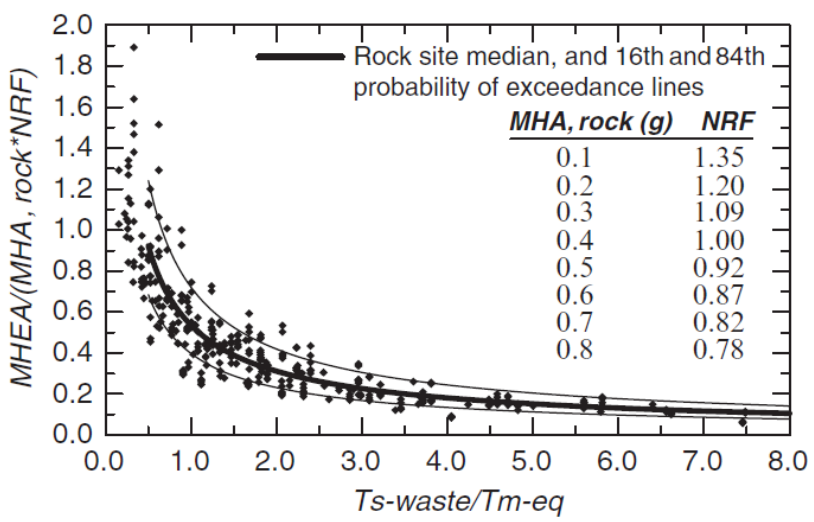

Figura 3.12 - Máxima aceleração horizontal equivalente normalizada (MHEA) versus razão entre períodos fundamentais da massa instável $\left(T_{s}\right)$ e do terremoto $\left(T_{m}\right)$ - Bray e Rathje (1998).

Finalmente, com o coeficiente sísmico de escoamento $k_{y}(\mathrm{FS}=1 \mathrm{em}$ análise pseudoestática) o deslocamento permanente normalizado causado pelo terremoto é calculado em função de $k_{y} / k_{\max }$, considerando $k_{\max }=M H E A / g$, mediante as relações indicadas na Figura 3.13 ou utilizando a equação 3.27.

$$
\log _{10}\left(U /\left(k_{\max } * D_{5-95}\right)\right)=1,87-3,477\left(k_{\mathrm{y}} / k_{\max }\right) \pm \varepsilon
$$

onde $U$ é o deslocamento horizontal permanente $(\mathrm{cm})$ e $\varepsilon=0,35$. Segundo Bray (2007), os valores dos deslocamentos sísmicos normalizados $U /\left(k_{\max } * D_{5-95}\right)$ são estabelecidos para valores entre a media $+16 \%$ de probabilidade de excedência para fornecer uma adequada faixa estimada de deslocamentos. 


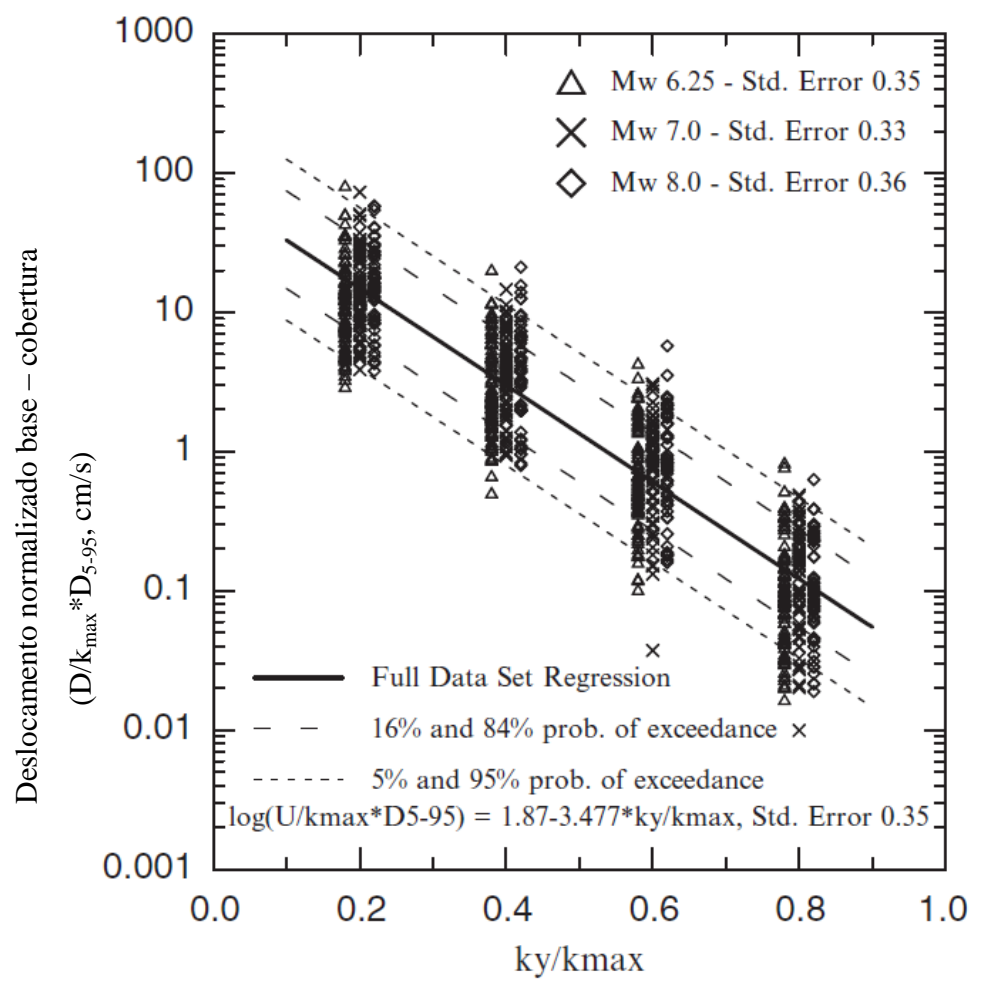

Figura 3.13 - Deslocamentos normalizados na base (Bray e Rathje, 1998).

O método de Bray e Rathje (1998) ainda tem a limitação da formulação desacoplada, mas sua contribuição fundamenta-se na incorporação de um número maior de registros sísmicos de boa qualidade, em comparação ao método simplificado de Makdisi e Seed (1978).

\subsection{3.}

\section{Modelo acoplado}

\subsubsection{1.}

Método simplificado de Bray e Travasarou (2007)

No decorrer dos anos recentes, com o crescente número de registros sísmicos de boa qualidade, Bray e Travasarou (2007) utilizaram 688 registros provenientes de 41 terremotos disponíveis no Pacific Earthquake Engineering Research Center (PEER), da Universidade de Berkeley, Califórnia, para desenvolver um método simplificado onde o coeficiente sísmico de escoamento $k_{y}$ é determinado em função de uma potencial superfície de deslizamento, rasa ou profunda, mediante as expressões indicadas na Figura 3.14. 
Os seguintes critérios devem ser satisfeitos para aplicação do método: i) terremotos com magnitude de momento $5.5 \leq M_{w} \leq 7.6$; ii) distância focal $R \leq 100$ $\mathrm{km}$; iii) frequências não filtradas de $0,25 \mathrm{~Hz}$ a $10 \mathrm{~Hz}$; iv) consideração dos seguintes tipos de materiais geológicos de acordo com a classificação de Rodriguez-Marek et al. (2001): rocha com $V_{s} \geq 760 \mathrm{~m} / \mathrm{s}$ (tipo B), rocha alterada e solo rígido com profundidade $\mathrm{z}<60 \mathrm{~m}$ (tipo $\mathrm{C}$ ), solo rígido com profundidade $60 \mathrm{~m}<\mathrm{z}<200 \mathrm{~m}$ (tipo D).

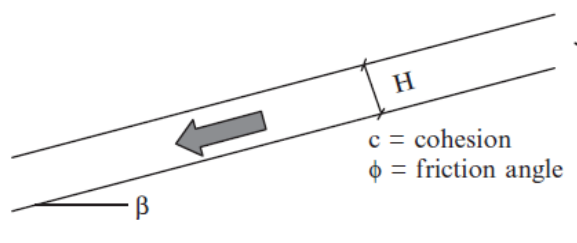

$k_{y}=\tan (\phi-\beta)+\frac{c}{\gamma \cdot H \cdot \cos ^{2} \beta \cdot(1+\tan \phi \cdot \tan \beta)}$

(a)

(b)

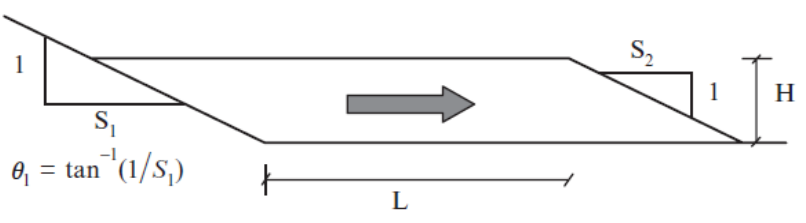

$$
\begin{aligned}
& F S_{\text {static }}= \frac{\tan \phi \cdot\left(S_{1} \cdot H / 2 \cdot \cos ^{2} \theta_{1}+L+S_{2} \cdot H / 2\right)}{\cos \theta_{1} \cdot \sin \theta_{1} \cdot S_{1} \cdot H / 2} \\
& k_{y}=\frac{\left(F S_{\text {static }}-I\right) \cdot \cos \theta_{1} \cdot \sin \theta_{1} \cdot S_{1} \cdot H / 2}{H \cdot\left(S_{1}+S_{2}\right) / 2+L}
\end{aligned}
$$

Figura 3.14 - Estimativa simplificada do coeficiente sísmico de escoamento $k_{y}$ : a) deslizamentos superficiais; b) deslizamentos profundos (Bray e Travasarou, 2007).

Para aproximar o comportamento não linear do solo, assim como de materiais contidos em aterros de resíduos sólidos, utiliza-se um modelo linear equivalente viscoelástico dependente do nível de deformações cisalhantes; especificamente, foram adotadas as curvas de redução do módulo de cisalhamento $\left(G / G_{\max }\right)$ e do aumento da razão de amortecimento $(\lambda)$ conforme indicadas por Vucetic e Dobry (1991) considerando solo com índice de plasticidade IP = 30 .

Bray e Travasarou (2007) calcularam os deslocamentos permanentes usando um modelo unidimensional, não linear, acoplado, com múltiplos graus de liberdade (Rathje e Bray, 2000) para representar o comportamento de uma massa de solo instável. No entanto, segundo Rathje e Bray (2001), análises 1D podem subestimar a resposta sísmica na crista do talude devido a efeitos de amplificação topográfica. Assim, recomenda-se para o caso de deslizamentos superficiais que o carregamento sísmico representado pelo valor de $P G A$ determinado em análises 1D seja multiplicado pelos seguintes fatores:

- $1,25^{*} P G A$ para taludes moderadamente escarpados (Rathje e Bray, 2001).

- $1,5^{*} P G A$ para taludes com declividade $>60^{\circ}$ (Ashford e Sitar, 2002). 
O método também admite as seguintes hipóteses em sua formulação: coeficiente sísmico de escoamento $k_{y}$ entre 0,02 a 0,4 e período inicial fundamental da massa de solo $T_{s}$ entre 0 e 2 segundos.

Em uma primeira fase, determina-se a probabilidade de ocorrência de deslocamento permanente $\mathrm{D}$ nulo (i.e. $D \leq 1 \mathrm{~cm}$ ) em função das propriedades iniciais $\left(k_{y}, T_{s}\right)$ e da aceleração espectral para um período equivalente a 1.5 vezes o período inicial fundamental do talude $S_{a}\left(1,5 T_{s}\right)$. O coeficiente sísmico de escoamento $k_{y}$ deve estar situado entre 0,02 a 0,4 e período inicial fundamental $T_{s}$ entre 0 e 2 segundos, conforme Figura 3.15.

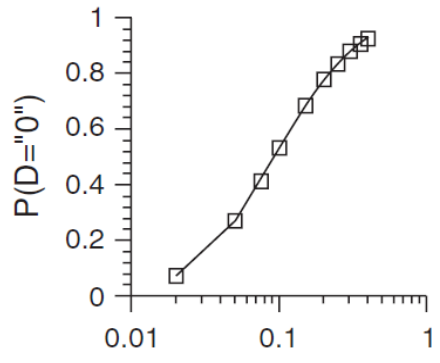

(a)

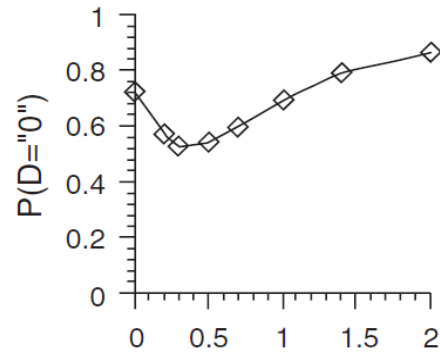

(b)

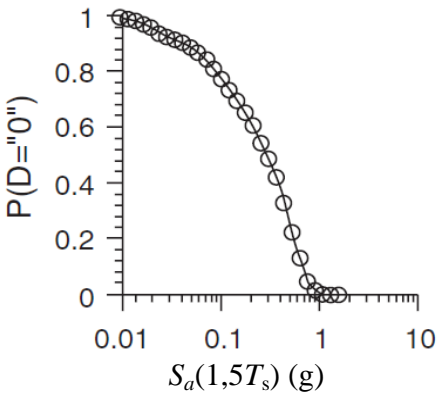

(c)

Figura 3.15 - Probabilidade de deslocamento nulo $(D \leq 1 \mathrm{~cm})$ em relação: a) coeficiente sísmico de escoamento $k_{y}$; b) período fundamental inicial do talude $T_{s}$; c) aceleração espectral $S_{a}\left(1,5 T_{s}\right)$; (Adaptado de Bray e Travasarou, 2007).

Pode-se observar que a probabilidade de ocorrência de deslocamento nulo $\mathrm{P}(\mathrm{D}=0)$ aumenta com o valor do coeficiente sísmico de escoamento $k_{y}$ (Figura 3.15a) mas diminui rapidamente com o incremento da aceleração espectral (Figura 3.15c). Com relação ao período fundamental inicial de vibração do talude $T_{s}$ a probabilidade de deslocamento nulo diminui à medida que esta se aproxima do período fundamental da maioria dos terremotos utilizados na concepção do modelo para em seguida aumentar à medida que o período se afasta da condição de ressonância (Figura 3.15b). Assim, a probabilidade de deslocamento permanente nulo é expressa por:

$$
\mathrm{P}(D=0)=1-\phi\left(-1,76-3,22 \ln k_{y}-0,484 T_{s} \ln k_{y}+3,52 \ln \left(\mathrm{S}_{\mathrm{a}}\left(1,5 T_{s}\right)\right)\right)
$$

onde o deslocamento horizontal $D$ é medido em $\mathrm{cm}, \phi$ é a distribuição normal padrão acumulada (média $\mu=0$, desvio padrão $\sigma=1$ ), $k_{y}$ o coeficiente sísmico de escoamento, $T_{s}$ o período inicial fundamental da massa instável em segundos, e 
$S_{a}\left(1,5 T_{s}\right)$ a aceleração espectral $(\mathrm{g})$ para um movimento com período igual a $1,5 T_{s}$ que representa o período degradado da massa de solo deslizante.

Para deslocamentos permanentes não nulos, análises de regressão executadas por Bray e Travasarou (2007) produziram as seguintes expressões, dependentes do período fundamental da massa de solo deslizante. Para solos de baixa rigidez com $0,05 \mathrm{~s} \leq T_{s} \leq 2 \mathrm{~s}$,

$$
\begin{gathered}
\ln (D)=-1,10-2,83 \ln \left(k_{y}\right)-0,333\left(\ln k_{y}\right)^{2}+0,566 \ln \left(k_{y}\right) \ln \left(S_{a}\left(1,5 T_{\mathrm{s}}\right)\right)+ \\
3,04 \ln \left(S_{a}\left(1,5 \mathrm{~T}_{\mathrm{s}}\right)\right)-0,244\left[\ln \left(S_{a}\left(1,5 T_{\mathrm{s}}\right)\right)\right]^{2}+1,5 T_{\mathrm{s}}+0,278\left(M_{w}-7\right) \pm S \sigma_{\operatorname{lnD}}
\end{gathered}
$$

onde $\sigma_{\ln D}$ é o desvio padrão do logaritmo do deslocamento previsto e $S$ a variação de padrão normal com média $\mu=0$ e desvio padrão $\sigma=1$. Este último termo pode ser usado para obter previsões de deslocamento com diferentes probabilidades de excedência; Bray and Travasarou (2007) reportaram um valor de $\sigma=0,66$ para esta variável. Segundo a Califórnia Geological Survey (Guidelines for Evaluating and Mitigating Seismic Hazards in Califórnia, 2008) este termo pode ser desconsiderado para estimativa do deslocamento permanente.

Para solos de alta rigidez $\left(T_{s}<0,05 \mathrm{~s}\right)$ o primeiro termo no lado direito da equação 3.29 deve ser substituído pela constante $-0,22$, como segue:

$$
\begin{aligned}
& \ln (D)=-0,22-2,83 \ln \left(k_{y}\right)-0,333\left(\ln k_{y}\right)^{2}+0,566 \ln \left(k_{y}\right) \ln \left(S_{a}\left(1,5 T_{\mathrm{s}}\right)\right)+ \\
& 3,04 \ln \left(S_{a}\left(1,5 \mathrm{~T}_{\mathrm{s}}\right)\right)-0,244\left[\ln \left(S_{a}\left(1,5 T_{\mathrm{s}}\right)\right)\right]^{2}+1,5 T_{\mathrm{s}}+0,278\left(M_{w}-7\right) \pm S \sigma_{\operatorname{lnD}}
\end{aligned}
$$

É recomendado estabelecer uma faixa condicional de deslocamentos permanentes como resposta aceitável da geoestrutura e depois estimar a probabilidade de excedência destes limites. Uma potencial massa de solo instável com período fundamental $T_{s}$, coeficiente sísmico de escoamento $k_{y}$ e submetida a um movimento com aceleração espectral $S_{\mathrm{a}}\left(1,5 T_{s}\right)$, terá uma probabilidade de que o deslocamento permanente $(D)$ ultrapasse um deslocamento admissível $(d)$ de acordo com:

$$
P(D>d)=[1-P(D=0)] \cdot P(D>d \mid D>0)
$$


onde $P(D=0)$ é calculada mediante a equação 3.28. O termo $P(D>d \mid D>0)$ é estimado assumindo que os deslocamentos previstos apresentam uma distribuição log-normal, assim:

$$
P(D>d \mid D>0)=1-P(D \leq d \mid D>0)=1-\phi\left(\frac{\ln d-\ln d^{\prime}}{\sigma}\right)
$$

onde $\ln d^{\prime}$ determina-se mediante a equação 3.29 e $\sigma=0,66$.

\subsection{4.}

\section{Modelos numéricos}

A resposta dinâmica de taludes submetidos a carregamentos sísmicos depende de uma série de condicionantes, dentre os quais a não-linearidade do comportamento mecânico dos materiais, a topografia do relevo, a heterogeneidade dos solos que compõem o talude e o maciço de fundação, o conteúdo de frequências do registro sísmico, sua duração e amplitudes, etc.

Um dos fatores mais importantes, conforme discutido nas adaptações do modelo de Newmark (1965), é que solos são materiais deformáveis, podendo apresentar comportamento tensão $\mathrm{x}$ deformação altamente não linear quando dinamicamente carregados por terremotos de grande magnitude.

A utilização de métodos numéricos para análise da resposta dinâmica de maciços de solo dependerá portanto do modelo constitutivo implementado no programa computacional. Os principais modelos propostos na literatura são apresentados a seguir.

\subsubsection{1.}

\section{Modelo linear equivalente}

É o modelo utilizado na maioria das aplicações e implementado em grande parte dos programas computacionais elaborados para investigação da resposta dinâmica de maciços de solo. A relação tensão x deformação de solos sob carregamento cíclico exibe normalmente um laço de histerese entre as trajetórias de carregamento e de descarregamento, que pode ser mecanicamente modelado descrevendo-se as trajetórias ou considerando-se parâmetros do material que possam representar de maneira aproximada a forma geral do laço. Na segunda alternativa, adotada no modelo linear equivalente, a inclinação do laço de 
histerese, proporcional à rigidez do solo, é descrita pelo módulo de cisalhamento secante e a abertura do laço, com área proporcional à energia dissipada no ciclo, pela razão de amortecimento.

Ambos os parâmetros, referidos como parâmetros lineares equivalentes, são atualizados iterativamente em função dos níveis de deformação cisalhante cíclica induzidos na massa de solo. Para a seleção dos novos valores, utiliza-se uma distorção média ou efetiva empiricamente estimada como $2 / 3$ da deformação cisalhante máxima (65\% de acordo com Seed e Martin (1966), ou (M-1)/10, de acordo com Idriss e Sun (1992) onde M é a magnitude do terremoto). Em programas de elementos finitos a seleção dos parâmetros lineares equivalentes é feita para o elemento, de acordo com o seguinte procedimento:

Os valores iniciais do módulo cisalhante $\left(G_{\max }\right)$ e do amortecimento são estimados para cada elemento finito da malha. A resposta dinâmica do sistema é então determinada, calculando-se a história das deformações cisalhantes cíclicas em cada elemento. A partir destes resultados, as amplitudes da deformação cisalhante efetiva em cada elemento são computadas, consultando-se as curvas do material correspondente para observar se o nível de deformação é compatível com os valores das propriedades dinâmicas utilizadas na avaliação da resposta. Se as propriedades do solo não foram compatíveis, as propriedades lineares equivalentes são atualizadas e o processo é repetido até atingir a convergência, o que ocorre geralmente após 3 a 5 iterações.

Entretanto, como apenas o valor da deformação cisalhante máxima não fornece informações a respeito de toda a história de deformações, é possível que este procedimento possa levar a sistemas artificialmente amortecidos e enrijecidos / amolecidos. No caso de movimentos relativamente uniformes, por exemplo, a tendência é de subestimar a razão de amortecimento $\lambda$ e a superestimar o módulo de cisalhamento $G$. Como o método é essencialmente linear, é também possível que uma das frequências predominantes da excitação dinâmica possa coincidir com uma das frequências naturais do talude, com tendência ao desenvolvimento de ressonâncias espúrias. Como o método é essencialmente elástico, não tem condições de calcular deformações ou deslocamentos permanentes, necessitando ser complementado por outra técnica aplicada separadamente ou de modo desacoplado. 
Diferenças entre os resultados de análises com os modelos linear equivalente e não linear depende, naturalmente, do grau de não-linearidade da resposta do solo. Para problemas onde o nível de deformações permanece baixo (solos rígidos e/ou movimentos sísmicos de baixa magnitude), ambas as análises devem produzir estimativas razoáveis da resposta dinâmica do solo. No entanto, para situações onde os valores das tensões cisalhantes induzidas pelo terremoto aproximam-se da resistência ao cisalhamento do solo, as análises não lineares devem fornecer resultados mais confiáveis. De acordo com Bray et al. (1995) o programa SHAKE91 (Idriss e Sun, 1992), e suas versões mais recentes, em virtude da incorporação do modelo linear equivalente, somente deve ser empregado para movimentos com $\mathrm{PHA}^{\text {rocha }} \leq 0,35 \mathrm{~g}$. De acordo com informações da literatura, o modelo linear equivalente não produz resultados confiáveis para situações onde $\mathrm{PHA}^{\text {solo }}>0,4 \mathrm{~g}$ (Ishihara, 1986) ou a deformação cisalhante de pico exceder aproximadamente 0,2\% (Kavazanjian et al., 1997). Segundo Gazetas e Dakoulas (1992) em barragens modernas análises lineares podem ser suficientes para movimentos com $\mathrm{PHA}^{\text {solo }} \leq 0,2 \mathrm{~g}$.

Kramer (1996) sugere que análises lineares equivalentes são mais eficientes quando o movimento do solo pode ser caracterizado com boa precisão por um pequeno número de termos da série de Fourier, i.e. quando os registros sísmicos contém pouca energia acima de frequências de $15 \mathrm{~Hz}$ a $20 \mathrm{~Hz}$.

Análises pós-sismo de taludes, envolvendo redistribuição dos excessos de poropressão causados por terremotos, não são possíveis de serem efetuados com o modelo linear equivalente, formulado em termos de tensões totais e cujos resultados representam uma resposta instantânea do sistema em relação ao carregamento sísmico atuante. Quando este cessa, o talude recupera sua geometria inicial sem a ocorrência de deformações permanentes.

A relação entre a variação dos parâmetros lineares equivalentes com o nível das deformações cisalhantes cíclicas foi estudada por vários autores, dentre os quais (Seed e Idriss, 1970), Kokushu et al. (1982), Dobry e Vucetic (1987), Sun et al. (1988), Vucetic e Dobry (1991). 


\subsubsection{2.}

\section{Modelos cíclicos}

O comportamento não-linear do solo é representado por um modelo cíclico que segue a trajetória tensão - deformação durante a aplicação do ciclo de carregamento. Vários modelos cíclicos foram propostos na literatura (Iwan, 1987; Finn et al., 1977; Vucetic, 1990; Pyke, 1990; dentre outros) baseados na existência de uma curva tensão x deformação geral (backbone curve) e uma série de regras que governam o comportamento de carregamento - descarregamento, a variação da rigidez do solo, o desenvolvimento de poropressões sob condições não-drenadas, etc. Vários modelos seguem as regras estendidas de Masing (Kramer, 1996) que estabelecem a forma do ciclo para representação das situações de carregamento inicial, descarregamento e recarregamento.

Os modelos cíclicos têm vantagens à medida que conseguem representar deformações permanentes e a variação da rigidez do solo também em função da história de tensões e não somente da amplitude das deformações cisalhantes cíclicas como no modelo linear equivalente. Entretanto, sua aplicabilidade está ainda restrita a determinadas trajetórias de tensão.

\subsubsection{3. \\ Modelos elasto-plásticos}

Modelos constitutivos elasto-plásticos avançados são os mais precisos e gerais para representação do comportamento do solo, permitindo análises com uma grande variedade de história de tensões, comportamento drenado e não drenado, carregamento cíclico, etc., mas a avaliação experimental dos parâmetros necessários à completa descrição do modelo pode ser difícil de ser executada em ensaios de laboratório. Apesar desta dificuldade de ordem prática, o uso de modelos constitutivos elasto-plásticos avançados tende a aumentar, assim como já vem ocorrendo nas aplicações geotécnicas envolvendo apenas carregamentos estáticos.

Segundo Jibson (2011) este tipo de abordagem pode se tornar bastante complexo devido à necessidade das seguintes informações:

- determinação dos parâmetros de resistência ao cisalhamento cíclica em ensaios de laboratório; 
- seleção do registro sísmico adequado e representativo das condições geológicas da região, envolvendo análises de ameaça sísmica;

- seleção de um modelo constitutivo não linear para solos sob carregamentos cíclicos, incluindo potencial de desenvolvimento de liquefação dinâmica, com determinação de parâmetros por meio de ensaios de campo ou laboratório;

- disponibilidade de programas computacionais especializados, tanto para as análises numéricas em si, quanto para tratamento prévio de registros sísmicos: correção de linha base, filtragem de frequências, determinação de períodos fundamentais de vibração, etc.

Na Tabela 3.4 apresentam-se alguns modelos constitutivos elasto-plásticos para carregamentos cíclicos, observando-se que geralmente necessitam de um grande número de parâmetros determinados em ensaios de campo ou laboratório.

Tabela 3.4 - Modelos constitutivos elasto-plásticos comuns para carregamentos cíclicos (Contreras, 2014).

\begin{tabular}{|c|c|c|c|c|c|c|c|c|}
\hline \multirow[b]{2}{*}{$\begin{array}{l}\text { Tipo de } \\
\text { modelo }\end{array}$} & \multirow[b]{2}{*}{$\begin{array}{c}\text { Modelo } \\
\text { constitutivo }\end{array}$} & \multirow[b]{2}{*}{ Referência } & \multicolumn{3}{|c|}{ Componentes de plasticidade } & \multicolumn{3}{|c|}{ Praticidade e potencialidade } \\
\hline & & & $\begin{array}{c}\text { Tipo de } \\
\text { superfície } \\
\text { de } \\
\text { escoamento } \\
4 \\
4\end{array}$ & $\begin{array}{c}\begin{array}{c}\text { Lei de } \\
\text { fluxo } \\
\text { (dilatância) }\end{array} \\
5\end{array}$ & $\begin{array}{c}\text { Parâmetros de } \\
\text { endurecimento } \\
6\end{array}$ & $\begin{array}{c}\begin{array}{c}\text { Número } \\
\text { de } \\
\text { parâme- } \\
\text { tros }\end{array} \\
7\end{array}$ & $\begin{array}{c}\text { Validado } \\
\text { em } \\
\begin{array}{c}\text { deformação } \\
\text { plana }^{(i)}\end{array} \\
8 \\
\end{array}$ & $\begin{array}{c}\text { Modelos } \\
\text { PSR }^{(i i)} \\
9\end{array}$ \\
\hline \multirow{2}{*}{$\begin{array}{l}\text { Superfície } \\
\text { limite }\end{array}$} & DYSAC2 & $\begin{array}{c}\text { Muraleethara } \\
\text { n } \text { et al., } 2004\end{array}$ & Cap elíptica & $\begin{array}{c}\text { Não } \\
\text { associada }\end{array}$ & $\begin{array}{c}\text { Deformações } \\
\text { volumétricas e } \\
\text { cisalhantes } \\
\text { plásticas }\end{array}$ & 13 & Não & Não \\
\hline & MIT-S1 & $\begin{array}{l}\text { Pestana et al., } \\
2000,2002\end{array}$ & $\begin{array}{l}\text { Lemniscata } \\
\text { distorcida }\end{array}$ & $\begin{array}{c}\text { Não } \\
\text { associada }\end{array}$ & $\begin{array}{c}\text { Deformações } \\
\text { volumétricas e } \\
\text { cisalhantes } \\
\text { plásticas } \\
\end{array}$ & 13 & Sim & Não \\
\hline \multirow[t]{2}{*}{$\begin{array}{l}\text { Superfícies } \\
\text { aninhadas }\end{array}$} & ALTERNAT & $\begin{array}{c}\text { Woodward \& } \\
\text { Molenkamp, } \\
1999\end{array}$ & $\begin{array}{c}\text { Cone } \\
\text { (Lade) }\end{array}$ & $\begin{array}{c}\text { Não } \\
\text { associada } \\
\& \\
\text { Associada, } \\
\text { Rowe } \\
\text { Riii) }\end{array}$ & $\begin{array}{c}\text { Deformações } \\
\text { volumétricas e } \\
\text { cisalhantes } \\
\text { plásticas }\end{array}$ & 22 & Não & Não \\
\hline & DYNAFLOW & $\begin{array}{c}\text { Azizian \& } \\
\text { Popescu, } 2001\end{array}$ & $\begin{array}{c}\text { Cone } \\
\text { (Drucker- } \\
\text { Prager) } \\
\end{array}$ & $\begin{array}{c}\text { Associada } \\
\text { ou Não } \\
\text { associada }\end{array}$ & $\begin{array}{c}\text { Módulo de } \\
\text { trabalho } \\
\text { plástico }^{\text {iv) }} \\
\end{array}$ & 8 & Não & Não \\
\hline $\begin{array}{l}\text { Plasticidade } \\
\text { generalizada }\end{array}$ & $\begin{array}{c}\text { DIANA- } \\
\text { SWANDYNE } \\
\text { II }\end{array}$ & $\begin{array}{l}\text { Aydingun \& } \\
\text { Adalier, } 2003\end{array}$ & Cap elíptica & $\begin{array}{c}\text { Não } \\
\text { associada, } \\
\text { Nova }^{(v)}\end{array}$ & $\begin{array}{c}\text { Deformações } \\
\text { volumétricas e } \\
\text { cisalhantes } \\
\text { plásticas }\end{array}$ & 11 & Não & Não \\
\hline $\begin{array}{c}\text { Plasticidade } \\
\text { do estado } \\
\text { crítico }\end{array}$ & NorSand & $\begin{array}{l}\text { Been et al. } \\
\quad 1993\end{array}$ & $\begin{array}{c}\text { Forma de } \\
\text { bala }\end{array}$ & $\begin{array}{l}\text { Associada, } \\
\text { Nova }\end{array}$ & $\begin{array}{c}\text { Trabalho } \\
\text { plástico }\end{array}$ & 9 & Sim & Sim \\
\hline \multirow{2}{*}{$\begin{array}{c}\text { Plasticidade } \\
\text { tipo Mohr- } \\
\text { Coulomb }\end{array}$} & UBCSAND & $\begin{array}{l}\text { Byrne et al., } \\
\text { 2004a }\end{array}$ & $\begin{array}{c}\text { Cone } \\
\text { (Mohr- } \\
\text { Coulomb) }\end{array}$ & $\begin{array}{c}\text { Não } \\
\text { associada, } \\
\text { Rowe }\end{array}$ & $\begin{array}{c}\text { Deformacõoes } \\
\text { cisalhantes } \\
\text { plásticas }\end{array}$ & 6 & Sim & Não \\
\hline & UBCSAND2 & $\begin{array}{l}\text { Park et al. } \\
\quad 2005\end{array}$ & $\begin{array}{c}\text { Cone } \\
\text { (Mohr- } \\
\text { Coulomb) } \\
\end{array}$ & $\begin{array}{c}\text { Não } \\
\text { associada, } \\
\text { Rowe }\end{array}$ & $\begin{array}{c}\text { Deformações } \\
\text { cisalhantes } \\
\text { plásticas }\end{array}$ & 7 & Sim & Sim \\
\hline
\end{tabular}

(i) Ensaio de cisalhamento direto; (ii) modelos que consideram rotação das tensões principais (PSR - Principal Stress Rotation); (iii) Rowe denota a relação stress-dilatancy de Rowe (1962); (iv) referido a Iwan (1967), Mroz (1967), Prevost (1977); (v) Nova denota a relação stress-dilatancy de Nova (1982); Col. 7: o numero de parâmetros foi obtido a partir da referência da col. 3, e tensões iniciais, densidade relativa inicial e coesão foram excluídos na contagem dos parâmetros; col. 8: a informação é baseada na referência citada e pode ser diferente em diferentes versões. 
Aspectos de modelagem numérica no comportamento dinâmico de geoestruturas

Nesta dissertação as análises do comportamento dinâmico de taludes foram feitas com auxílio do programa de diferenças finitas FLAC 2D v.8 (Fast Lagrangian Analysis of Continua) desenvolvido pela empresa americana ITASCA. Apresentam-se a seguir algumas das principais características deste software, bem como recomendações gerais que devem ser cuidadosamente consideradas na modelagem dinâmica de geoestruturas.

\section{1. \\ Software FLAC 2D v.8}

Uma característica particular deste programa com base no método das diferenças finitas é que resolve numericamente as equações do movimento, o que o torna menos eficiente, sob ponto de vista do esforço computacional, para o caso de problemas estáticos (equações de equilíbrio) mas o deixa bastante recomendável para situações de carregamento dinâmico e de instabilidade física envolvendo grandes deslocamentos. Adota também um método explícito para solução do sistema de equações, evitando assim a formação de uma grande matriz de rigidez como usualmente acontece em programas computacionais baseados no método dos elementos finitos.

Os modelos constitutivos disponíveis no programa FLAC 2D podem ser divididos nas seguintes categorias:

- modelo nulo ou vazio: utilizado para representar ausência de material, por exemplo, uma área escavada;

- modelo linearmente elástico, isotrópico e transversalmente isotrópico: geralmente empregado para geração de tensões iniciais em maciços de solo ou rocha; 
- modelos elasto-plásticos: Mohr - Coulomb, Drucker - Prager, Cam Clay Modificado, Strain Hardening/Strain Softening, Hoek - Brown, dentre outros;

- modelos para simulação de comportamento viscoso (creep);

- modelos para simular geração de poropressões: Finn - Byrne, Finn Martin, geralmente utilizados na investigação de problemas de liquefação dinâmica.

O programa também oferece a possibilidade de utilizar modelos constitutivos definidos pelo próprio usuário, mediante programação em linguagem própria do software (FISH) ou por DLLs.

\section{2. \\ Processamento do registro de aceleração}

Diferentes aparelhos têm sido desenvolvidos na coleta de informações referentes a terremotos, os mais comumente usados são sismógrafos e acelerômetros. Um sismógrafo é um equipamento de alta sensibilidade ao movimento (deslocamento), de forma que quando um terremoto de grande magnitude ocorre, muitas vezes fornece um registro sísmico saturado (Figura 4.1). Um acelerômetro, por outro lado, consegue capturar o movimento sem o problema de saturação do registro; assim acelerogramas são a melhor forma de representar a excitação do terreno para análises dinâmicas de estruturas.

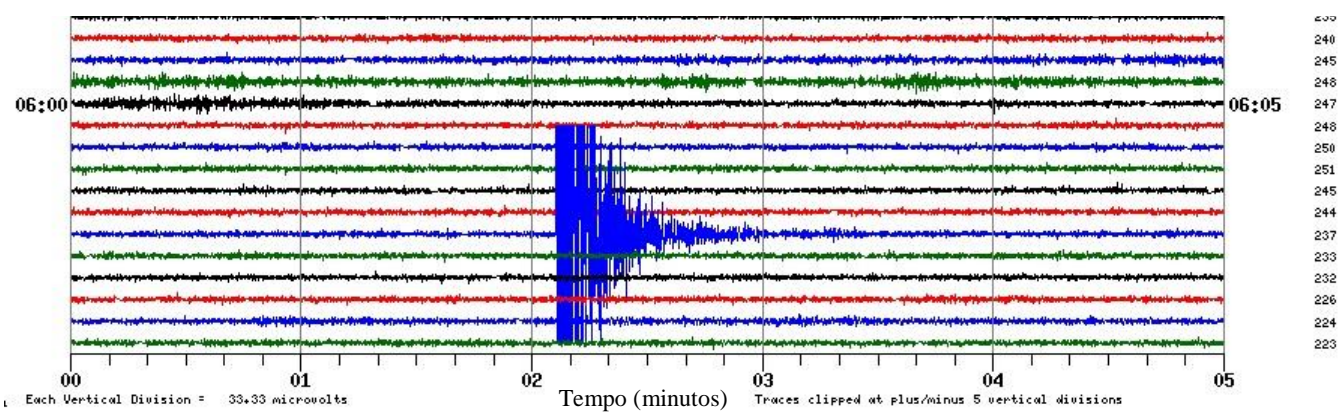

Figura 4.1 - Exemplo de um registro sísmico saturado devido à proximidade do movimento captado mediante sismógrafo (ingeominas.gov.co).

Um registro de acelerações no tempo fornece importantes informações para a engenharia sísmica tais como: 
- a partir da construção dos espectros de resposta obtêm-se os máximos deslocamentos, máximas velocidades e máximas acelerações provocadas pelo terremoto;

- mediante a transformada de Fourier estimam-se as amplitudes para as diferentes frequências de vibração;

- são aplicados para definição de funções de atenuação de ondas sísmicas em determinada região;

- constituem o carregamento dinâmico aplicado em análises sísmicas no domínio do tempo envolvendo solos com comportamento não linear.

\subsection{1.}

\section{Frequência de corte}

Os acelerômetros muitas das vezes estão localizados nos primeiros andares de edificações ou assentados próximos a grandes obras como barragens. Assim, quando um movimento do terreno acontece, o registro sísmico sofre influência da estrutura adjacente (períodos de vibração da estrutura), o que constitui em um ruído no acelerograma propriamente dito. Este ruído, quando de alta frequência, afeta a aceleração de pico e quando de baixa frequência influi na integração do registro de acelerações, podendo causar valores de velocidade não nulos após a ocorrência do sismo (Figura 4.2).
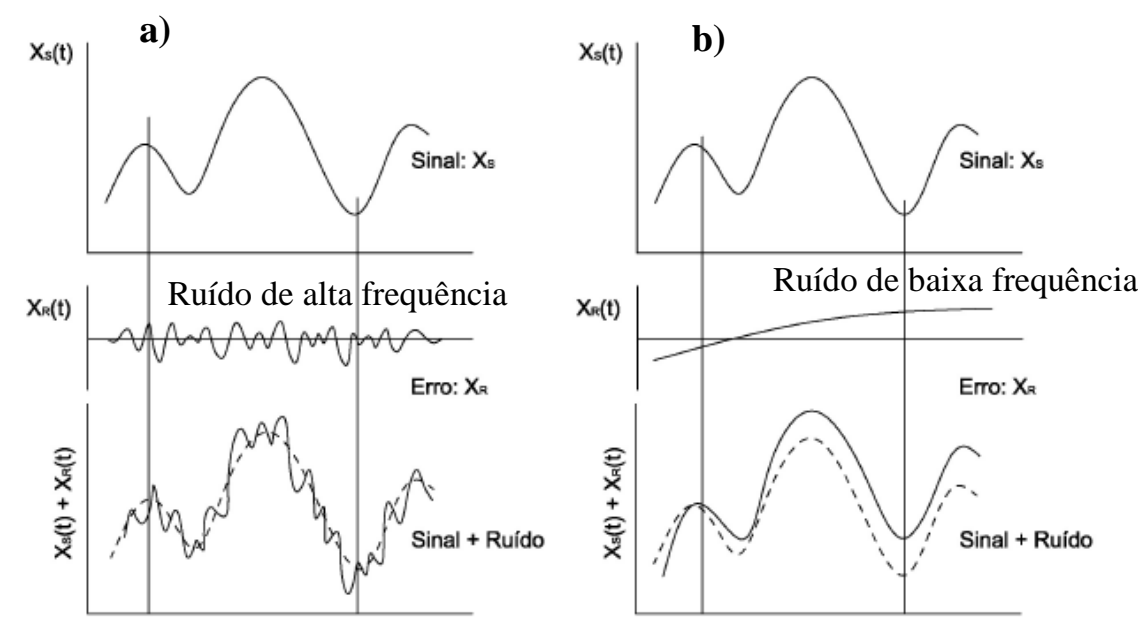

Figura 4.2 - Efeitos de ruídos no sinal sísmico: a) ruído de alta frequência; b) ruído de baixa frequência (Hudson, 1979).

$\mathrm{Na}$ maioria dos casos quando o registro contém frequências elevadas, as correspondentes amplitudes não precisam ser consideradas, já que a maior parte da potência do sismo provém das frequências baixas. Tal fenômeno pode ser 
observado quando se plota a função densidade de espectro de potência (PSDF) versus frequência. Aquela frequência que permite ter uma perda de potência de $1 \%$ (ou menos) se denomina frequência de corte $\left(f_{c}\right)$.

Obtida a frequência de corte, procede-se a remoção das frequências superiores por meio de um filtro de passa-baixa. Pode-se também aplicar um filtro de passa-alta ou um filtro de passa-banda. O filtro de passa-alta é utilizado para remover as frequências baixas cujos períodos são maiores do que a duração do terremoto, pois tendem a causar valores não nulos no final das histórias de velocidades e de deslocamentos. O filtro de passa banda elimina aqueles possíveis ruídos de frequências altas e baixas simultaneamente.

O mais importante ao se aplicar os filtros é determinar a frequência de corte adequada, já que uma má escolha pode apagar parte do sinal de interesse e não remover aquelas frequências desnecessárias ao sinal, que gerariam uma malha mais fina e consequentemente, um tempo elevado de processamento e um grande consumo de memória.

\subsection{2.}

\section{Correção da linha base}

Após a filtragem, o registro sísmico encontra-se com valores de aceleração, velocidade e deslocamento finais diferentes de zero. Às vezes, ocorre que os valores do acelerograma se encontram deslocados em relação à linha de aceleração nula. Este erro acontece porque o acelerograma não está perfeitamente nivelado devido à filtragem. Ainda que este erro possa ser inapreciável na aceleração, pode ser muito importante quando se obtêm a velocidade e o deslocamento pela integração no tempo, já que se contabiliza a área que existe entre a curva da aceleração e a linha base. Para uma ideia da importância deste erro, pode-se supor um deslocamento constante do acelerograma em relação à linha base de 0,001g, como se ilustra na Figura 4.3, ao se integrar com este erro, obtém-se um incremento linear da velocidade e um incremento parabólico do deslocamento, fazendo com que após 20 segundos o erro cometido no deslocamento atinja o valor de $196 \mathrm{~cm}$. Outro exemplo ilustrando a necessidade de correção da linha base encontra-se indicado na Figura 4.4. 
Cabe mencionar que existem muitos programas desenvolvidos para efetuar o processamento de registros sísmicos como o Degtra A4 (UNAM - Universidade Nacional Autônoma do México) e o SeismoSignal (SeismoSoft).

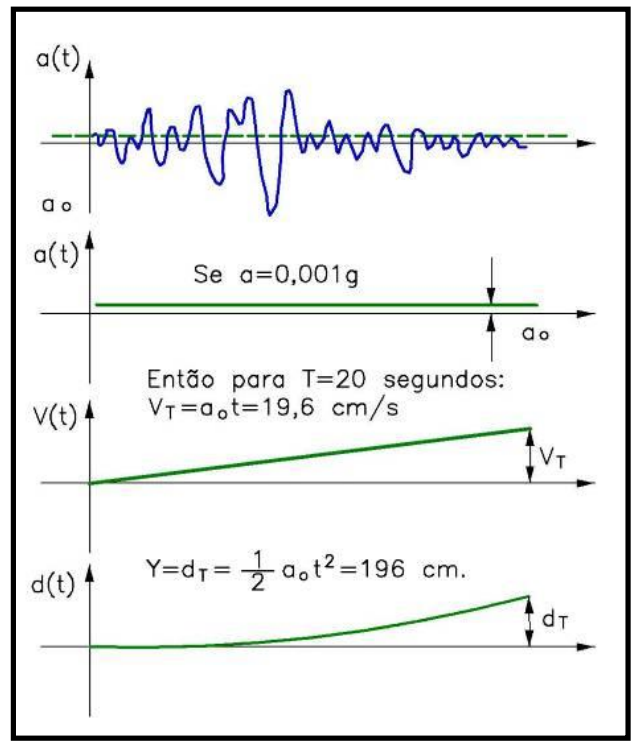

Figura 4.3 - Erros introduzidos nas velocidades e deslocamentos pela falta da correção da linha base no acelerograma. (Modificado de Hudson (1979), apud de Carreño et al. (1999)).
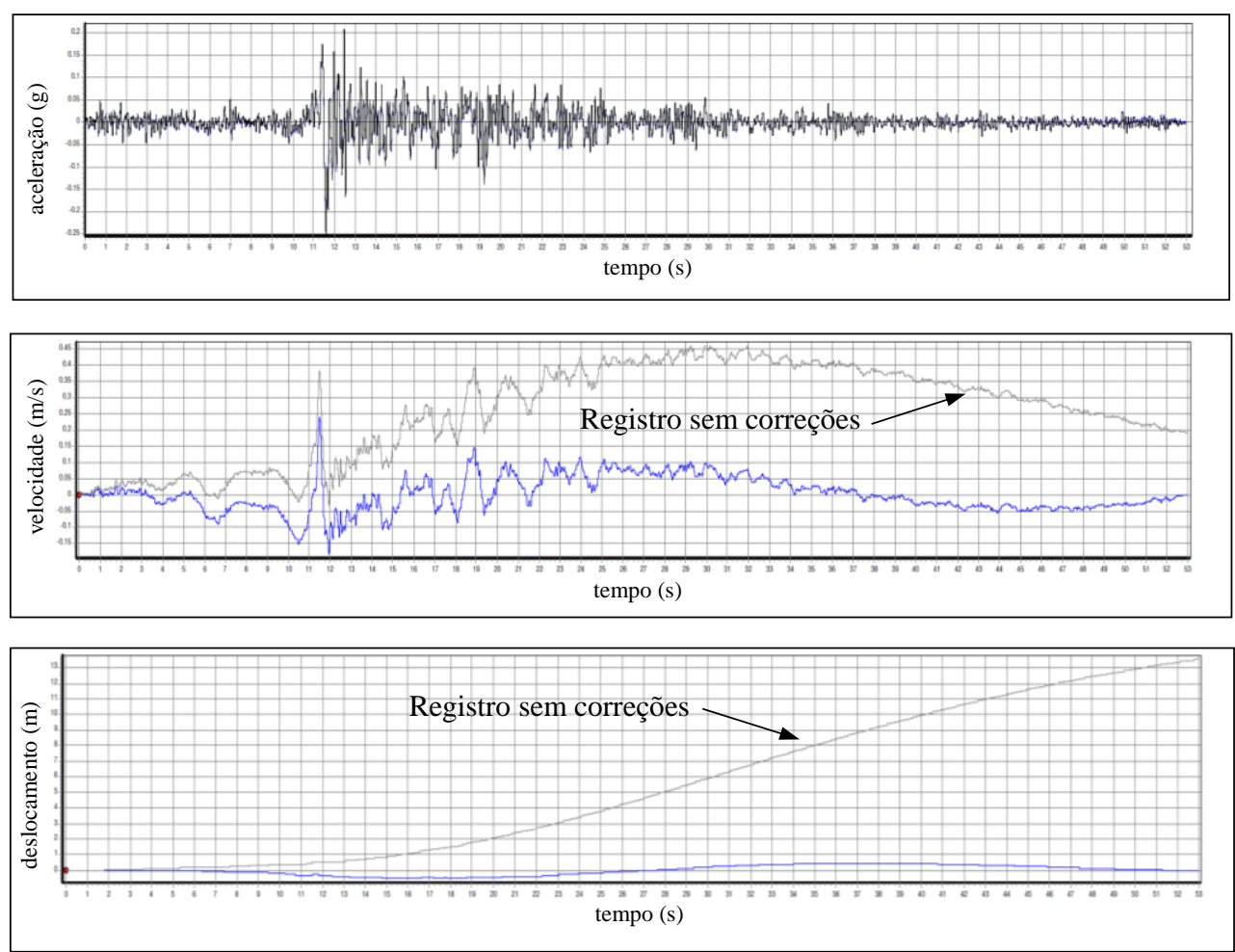

Figura 4.4 - História de acelerações com e sem correção da linha base. 


\section{3.}

\section{Convolução e deconvolução do registro sísmico}

O movimento sísmico para estimativa da resposta dinâmica de uma estrutura deve ser inserido na base de um modelo numérico (Figura 4.5), sendo necessário fazer a deconvolução deste registro quando o mesmo corresponder a uma medida na superfície (outcrop - solo ou rocha aflorante) por meio de uma análise da propagação unidimensional de ondas $\mathrm{S}$ com o programa computacional SHAKE (Schnabel et al, 1972) e suas versões mais recentes.

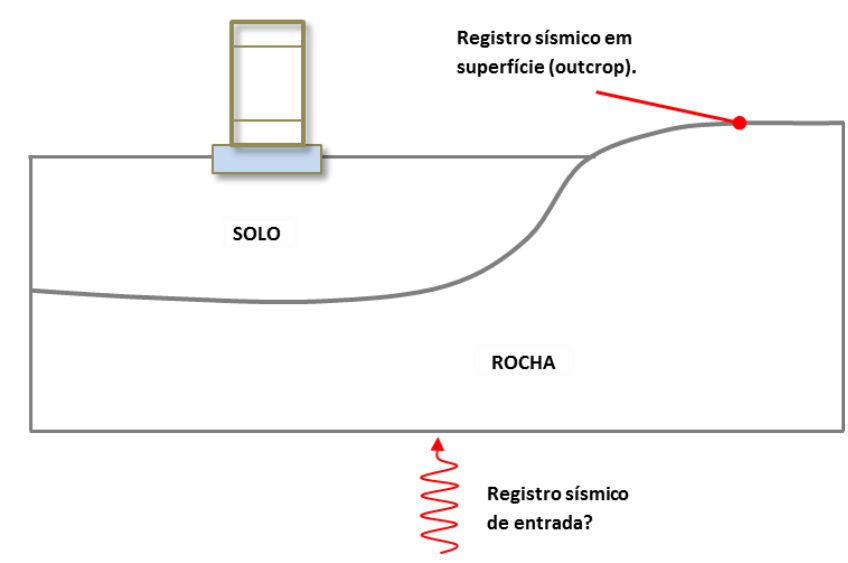

Figura 4.5 - Localização do registro sísmico de entrada (Itasca, 2011).

O processo inverso de levar o sinal de certa profundidade (rocha ou solo) até a superfície é chamado de análise de amplificação sísmica ou convolução (Figura 4.6). De acordo com Huertas (2012) os processos de convolução são frequentemente realizados para análises dinâmicas de campo livre ou quando há necessidade de se limitar o tamanho da malha que representa o modelo numérico, por questões de tempo de processamento ou memória de computador, transportando o registro sísmico para menores profundidades correspondentes à localização da base do modelo.

Mejia e Dawson (2006) revisaram o desempenho do programa SHAKE como ferramenta numérica para análise de deconvolução e a aplicabilidade de seus resultados como sismos de entrada na base de modelo numéricos. A Figura 4.7 ilustra as duas condições de contorno dinâmicas analisadas: base rígida e base flexível, de onde se observa que no caso de base flexível apenas as ondas ascendentes são prescritas na base da malha. 


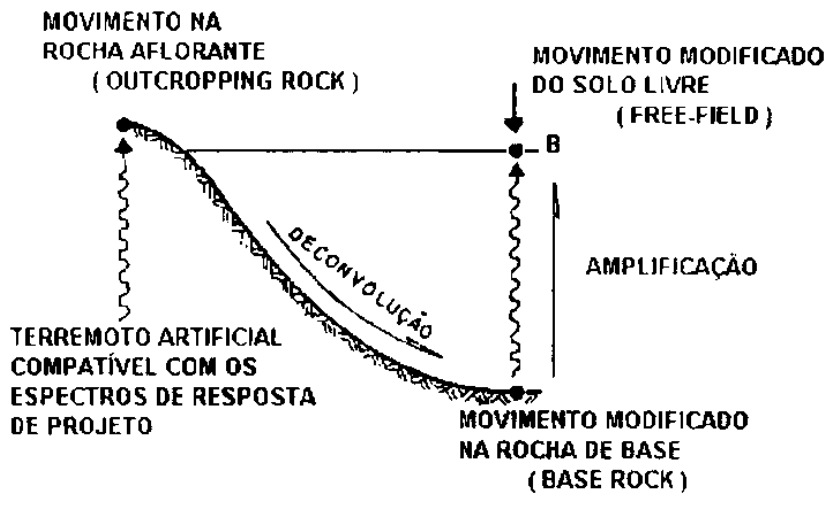

Figura 4.6 - Processo de deconvolução e de convolução de registros sísmicos (Huertas, 2012).

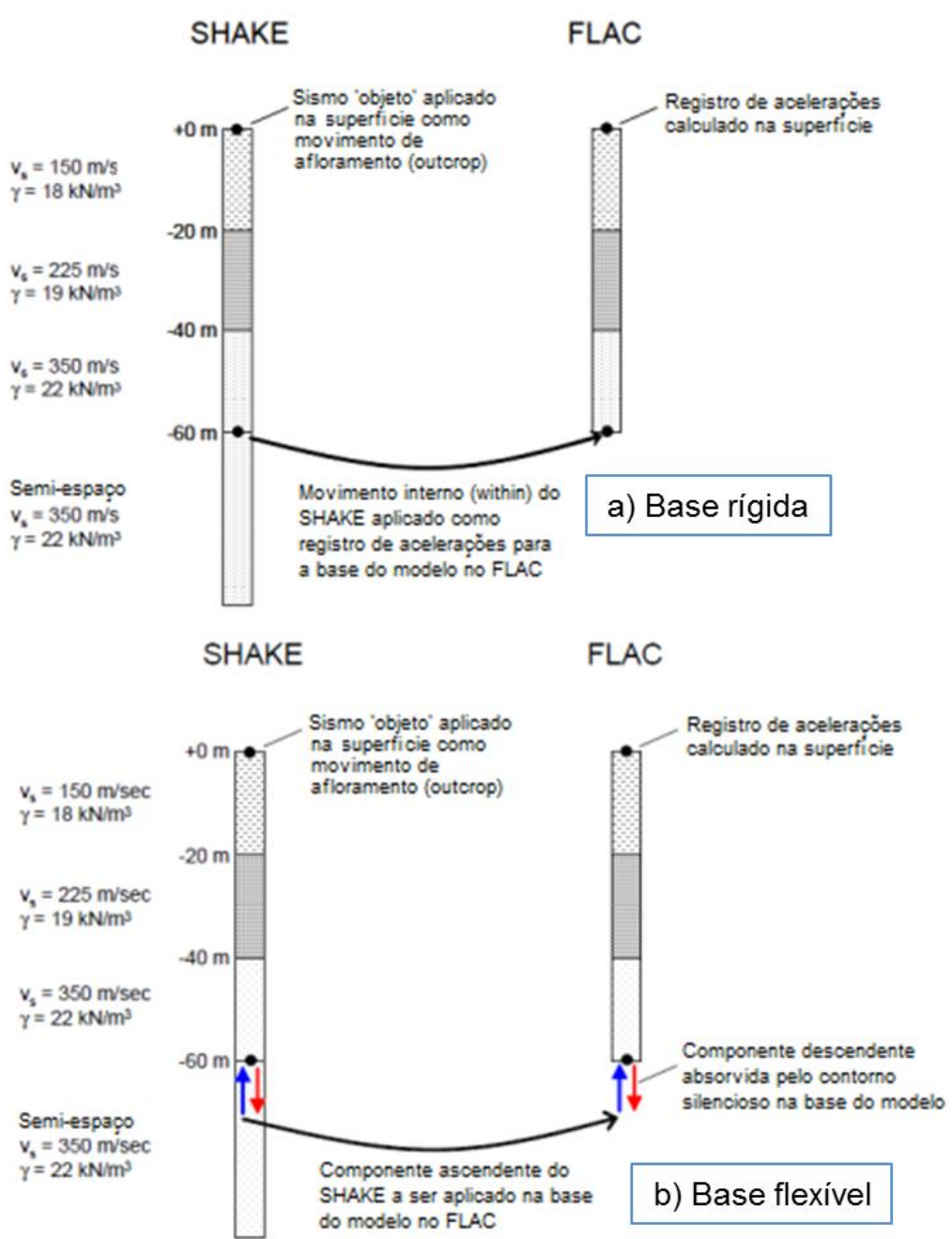

Figura 4.7 - Processo de deconvolução considerando condições de contorno: a) base rígida; b) base flexível, (Mejia e Dawson, 2006)

Embora a deconvolução de um sistema linear teoricamente deva produzir uma única solução, algumas dificuldades podem surgir neste processo. Kramer (1996) chamou a atenção para dois pontos: o primeiro, já mencionado anteriormente no Capítulo 3, relacionado com a utilização do modelo linear 
equivalente, incorporado no programa SHAKE, para altos níveis de deformações cisalhantes; o segundo ponto diz respeito ao fato de que o movimento registrado na superfície não é causado exclusivamente por ondas $\mathrm{SV}$, como assumido no processo de deconvolução, mas pode conter importante contribuição das ondas de superfície. Silva (1988) encontrou que só $75 \%$ da potência do sismo (87\% das amplitudes) em um movimento de superfície poderia ser atribuído à propagação vertical de ondas cisalhantes até $15 \mathrm{~Hz}$, e que o restante seria devido a ondas dispersas ou ondas de superfície. Neste caso, uma filtragem dos efeitos das ondas de superfície é recomendada antes do processo de deconvolução.

\section{4.}

\section{Base rígida / base flexível}

Há duas alternativas de modelagem para a base da malha do modelo numérico: base rígida (rigid base) ou base flexível (compliant base).

Com a base rígida, o carregamento é prescrito em termos de acelerações ou velocidades enquanto que na alternativa de base flexível é imposto por meio de tensões ou forças. A base rígida reflete para o interior da malha as ondas sísmicas que sobre ela incidem e sua utilização em geral não é recomendada, a não ser que ocorra um alto contraste de impedâncias entre o embasamento rochoso e o solo sobrejacente (Mejia e Dawson, 2006; Itasca, 2011).

Em uma condição de base flexível, o movimento sísmico é aplicado em termos de tensões determinadas em função da velocidade de vibração da partícula de solo,

$$
\begin{gathered}
\sigma_{n}=2\left(\rho \mathrm{v}_{p}\right) v_{n} \\
\sigma_{t}=2\left(\rho \mathrm{v}_{s}\right) v_{t}
\end{gathered}
$$

onde $\sigma_{n}$ e $\sigma_{t}$ são as componentes de tensão normal e cisalhante, $\rho$ a massa específica, $v_{p}$ a velocidade da onda $P, v_{s}$ a velocidade da onda $\mathrm{S}$ e $v_{n}$ e $v_{t}$ as velocidades normal e tangencial da partícula.

$\mathrm{O}$ fator 2 que acompanha as equações anteriores considera o fato de que as tensões aplicadas devem ser o dobro das observadas num meio infinito, já que a metade da energia é absorvida pelo contorno silencioso aplicado na base. Em certos casos, se o modelo for superficial, a superfície livre pode originar um 
incremento na velocidade da base. Assim, na execução da análise dinâmica, devese primeiramente avaliar a resposta na base da estrutura. Se a aceleração ou a velocidade na base não forem similares à do registro sísmico utilizado, então se deve efetuar um ajuste alterando o fator 2 até que a resposta da estrutura na base e o sismo de entrada coincidam. Quispe (2008) apresenta um exemplo deste caso, usando um fator de 1,15 com o objetivo de concordar os registros na base de modo satisfatório.

\section{5.}

\section{Condições de contorno em problemas dinâmicos}

\subsection{1.}

\section{Contornos silenciosos}

A representação de grandes domínios por meio de malhas de tamanho finito sempre foi uma dificuldade na aplicação de métodos numéricos na solução de problemas de geotecnia. Uma técnica bastante utilizada em análises estáticas é truncar a malha a alguma distância e empregar contornos elementares (rígidos) como "aproximação" da real geometria do problema. De fácil implementação, produz resultados desastrosos em análises dinâmicas devido às reflexões de onda ocorridas nestes contornos rígidos artificialmente introduzidos.

Várias técnicas para contornos especiais (silent boundaries) em problemas dinâmicos foram propostas na literatura, dentre as quais a utilização de contornos de transmissão imperfeita (amortecedores) propostos por Lysmer e Kuhlemeyer (1969), que podem ser empregados em análises dinâmicas no domínio do tempo ou da frequência.

Este esquema pode ser interpretado como contornos viscosos conectados de forma independente aos nós do contorno da malha, cujas propriedades são função do tipo de solo existente naquela região. Absorvem perfeitamente as ondas planas incidentes com ângulo normal $\left(90^{\circ}\right)$, mas perdem gradualmente a eficiência com a diminuição deste ângulo (daí a razão do termo contorno de transmissão imperfeita).

Amortecedores viscosos podem ser utilizados nos contornos laterais e na base da malha para a simulação de uma base flexível. É necessário ressaltar que neste caso 
não se pode especificar o sismo em termos de aceleração ou de velocidade porque a ação dos contornos silenciosos impediria a propagação das ondas de entrada.

\subsection{2.}

\section{Contornos de campo livre}

As condições de contorno de campo livre, aplicadas nas laterais da malha, permitem simular o movimento de um meio de grande extensão, excitado por ondas SV propagando-se verticalmente, que existiriam sem a presença da estrutura. As malhas auxiliares de campo livre são discretizadas em zonas (ou elementos) correspondentes ao número de zonas da malha principal junto aos contornos laterais (Figura 4.8). As malhas de campo livre vibram considerando a propagação 1D de ondas SV. Com a existência da estrutura, e as consequentes reflexões das ondas sísmicas por ela refletidas, bem como as ondas geradas pela vibração da própria estrutura (problema de interação solo-estrutura), os movimentos dos nós da malha principal nos contornos laterais apresentariam movimentos distintos em relação aos calculados pelas malhas auxiliares. Nesta situação, atuam os amortecedores viscosos que, mesmo imperfeitamente, simulam a continuidade dos movimentos, ou seja, representam um depósito de solo de grande extensão lateral com irradiação de ondas para o infinito.

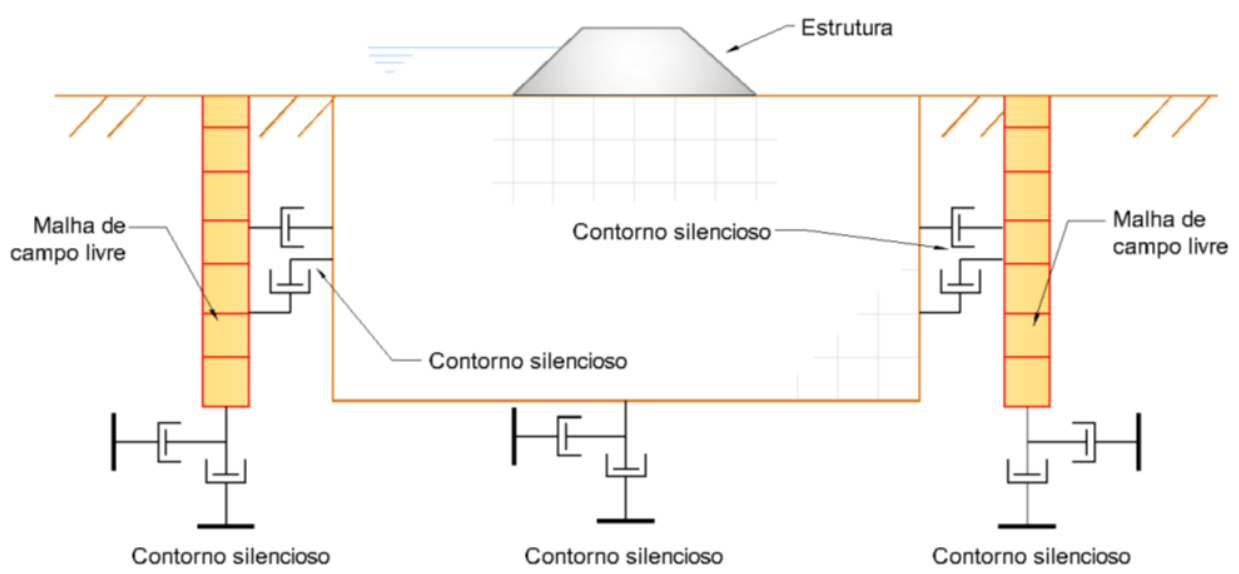

Figura 4.8 - Condições de contorno de campo livre (Loayza, 2009).

De modo geral, é recomendável utilizar contornos de campo livre para carregamentos causados por terremotos (excitação aplicada na base da malha) e contornos silenciosos quanto à fonte excitante encontrar-se no interior da malha ou na superfície. 


\section{6.}

\section{Tamanho de zona (elemento) e frequência de corte}

A definição do registro sísmico que será utilizado na análise dinâmica de geoestruturas permitirá também calcular o tamanho máximo das zonas da malha de diferenças finitas de modo a assegurar uma correta transmissão das ondas sísmicas através do modelo. Kuhlemeyer e Lysmer (1973) concluíram que a altura da zona $\Delta L$ na direção de propagação da onda (onda $\mathrm{S}$ vertical) deve ser menor do que 1/8 a 1/10 do mínimo comprimento de onda presente no problema.

$$
\Delta L \leq \frac{\lambda}{10} \text { a } \frac{\lambda}{8}
$$

onde $\lambda$ é o comprimento de onda $S$ associado à máxima frequência do carregamento (frequência de corte $f_{c}$ ) obtida do espectro de acelerações de Fourier.

A velocidade de propagação $v_{\mathrm{S}}$ de uma onda $\mathrm{S}$ é determinada por

$$
v_{s}=\sqrt{\frac{G}{\rho}}
$$

e seu comprimento de onda $\lambda$ por

$$
\lambda=v_{s} f_{c}
$$

onde $G$ é o módulo de cisalhamento e $\rho$ a massa específica do material.

A limitação da largura da zona não é tão estrita quanto a sua altura, sendo geralmente escolhida entre $3 \triangle L$ a $5 \Delta L$ embora o recomendável seja manter a razão altura/largura tão próxima da unidade quanto possível. Na equação 4.4 deve-se também observar que o valor de $G$ se refere ao valor correspondente ao final da análise, pois em modelagens com amortecimento tipo histerético o módulo de cisalhamento decai com o nível de deformações imposto causado pelo carregamento sísmico.

Como o tamanho da zona (elemento) depende do comprimento de onda, resulta que a otimização do modelo computacional depende da escolha da máxima frequência de onda considerada na análise numérica, chamada de frequência de corte $f_{c}$ (cut-off frequency). 
A estimativa da frequência de corte é feita com base no espectro de potência do sismo (PSDF) utilizando a transformada de Fourier (Fast Fourier Transform FFT) do registro de velocidades. No programa FLAC 2D v.8 o carregamento sísmico é inserido na base flexível do modelo em termos de tensões cisalhantes, as quais são função do registro de velocidades, razão pela qual a frequência de corte $f_{c}$ é estabelecida mediante o espectro de potência determinado com base no registro de velocidades.

Define-se a frequência de corte $\left(f_{c}\right)$ como o valor limite além do qual é possível desconsiderar as frequências mais elevadas do registro de acelerações sem alteração significativa da energia do sismo. Em geral se considera aceitável que a frequência de corte assegure $98 \%$ da energia do acelerograma original.

\section{7. \\ Amortecimento do material}

Todo material quando submetido a carregamentos dinâmicos apresenta algum grau de amortecimento, caso contrário o sistema oscilaria indefinidamente. $\mathrm{O}$ amortecimento se origina pela perda de energia devido ao atrito interno entre partículas do solo e pela ocorrência de deformações irreversíveis. Na análise de problemas sísmicos, dois tipos de amortecimento viscoso são geralmente utilizados: o amortecimento de Rayleigh e o amortecimento histerético.

Idealmente o amortecimento do material deveria ser completamente simulado com utilização de um modelo elasto-plástico adequado para carregamentos cíclicos, mas até o momento este modelo ainda não é disponível ou plenamente aceito. Assim, continua sendo necessário a utilização da formulação de Rayleigh e/ou histerética para amortecer as componentes elásticas do modelo constitutivo de Mohr-Coulomb, por exemplo.

\subsection{1.}

\section{Amortecimento de Rayleigh}

Este tipo de amortecimento foi originalmente utilizado na análise dinâmica de estruturas e corpos elásticos para amortecer os modos de oscilação natural do sistema. Em um intervalo restrito e específico de frequências, o amortecimento de Rayleigh pode ser aproximadamente considerado independente da frequência de 
vibração. É formulado em termos das contribuições das matrizes de massa e de rigidez,

$$
[C]=\alpha[M]+\beta[K]
$$

onde $C$ é a matriz de amortecimento, $\alpha$ é a constante de amortecimento proporcional à massa $\mathrm{e} \beta$ é a constante de amortecimento proporcional à rigidez.

A Figura 4.9 apresenta a variação do amortecimento crítico normalizado em relação à frequência. Para frequências de valores altos, $\alpha$ é a constante predominante, e consequentemente a massa é o fator prevalecente, enquanto que para frequências com valores baixos a constante $\beta$ domina o sistema e, portanto, a rigidez é a grandeza predominante. Para um único valor de frequência, a chamada frequência mínima $\left(f_{\min }\right)$, o amortecimento de Rayleigh está composto por partes igualmente proporcionais tanto de contribuições da massa quanto da rigidez.
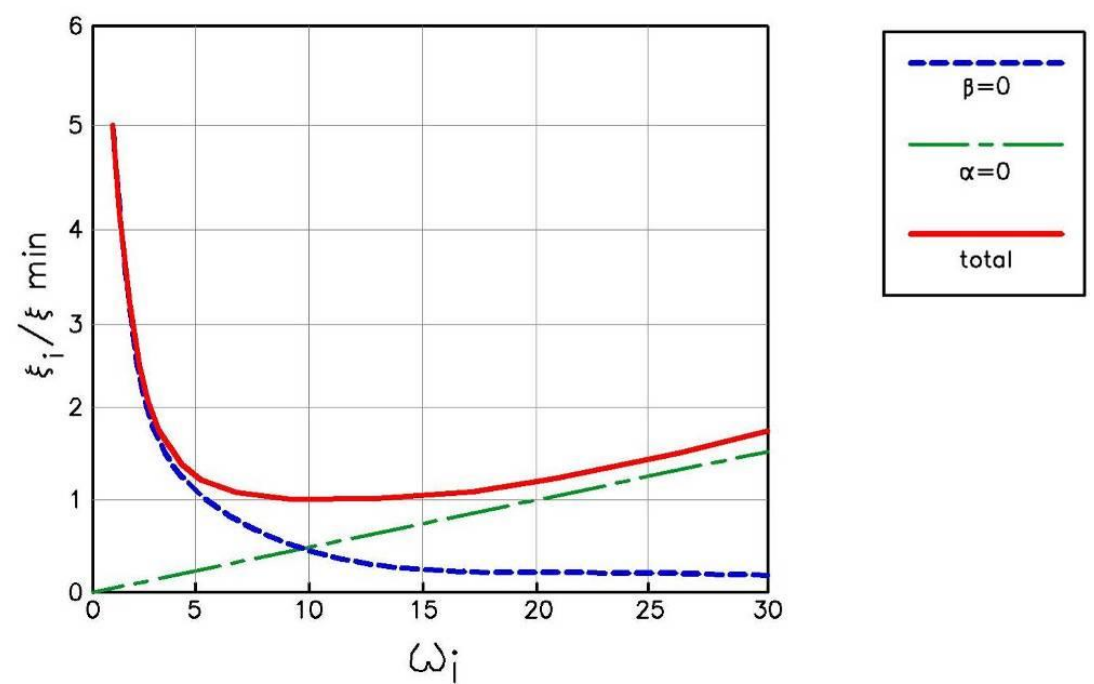

Figura 4.9 - Variação da razão de amortecimento crítico normalizado em relação à frequência angular (Itasca, 2011).

O amortecimento de Rayleigh somente pode ser usado para um intervalo limitado de frequências e envolve, para soluções explícitas como no programa FLAC, uma redução severa nos passos de tempo e, em consequência, um aumento do tempo de processamento do problema. 


\subsection{2.}

\section{Amortecimento histerético}

O modelo linear equivalente é usado frequentemente para estimar a resposta dinâmica de maciços de solos e rochas. Não captura diretamente qualquer efeito não linear, pois assume linearidade durante o processo de resolução, executado por meio de reajustes dos valores do módulo de cisalhamento $G$ e da razão de amortecimento $\xi$ em sucessivas iterações lineares. A degradação do módulo de cisalhamento (Figura 4.10) e o aumento da razão de amortecimento com os níveis das deformações cisalhantes foram obtidas por meio de ensaios de laboratório para diversos tipos de solos coesivos e granulares bem como para rochas.

O amortecimento histerético independe da frequência de vibração sendo determinado com base nos níveis de deformação cisalhante. O processo de cálculo, além de mais rápido do que na alternativa de amortecimento de Rayleigh, reproduz mais fielmente o comportamento de materiais geológicos.

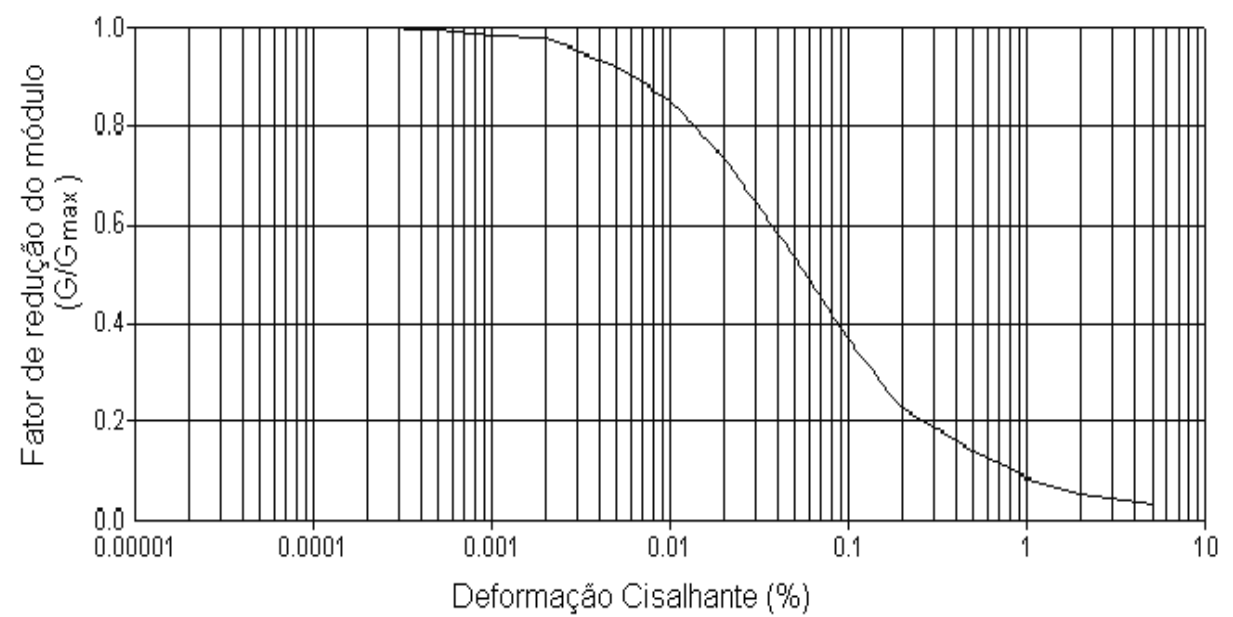

Figura 4.10 - Limite superior da curva de redução do módulo de cisalhamento para areias, proposta por Seed \& Idriss (1970).

A dificuldade de utilização do amortecimento histerético no programa FLAC é que a curva de degradação do módulo de cisalhamento $G$ (ou $G_{\mathrm{sec}}$ ) é utilizada para uma estimativa teórica do aumento da razão de amortecimento $\xi$ conforme equação 4.7, enquanto que em outros programas computacionais ambas as relações obtidas em ensaios de laboratório podem ser introduzidas de modo independente.

$$
\xi=\frac{W_{d}}{4 \pi W_{s}}=\frac{1}{2 \pi} \cdot \frac{A_{\text {laco }}}{G_{\mathrm{sec}} \gamma_{c}^{2}}
$$


onde $W_{d}$ é a energia dissipada no ciclo, $W_{s}$ é a energia de deformação máxima, $A_{\text {laço }}$ é a área do laço de histerese e $G_{\text {sec }}$ o módulo de cisalhamento secante.

Em consequência, as curvas de aumento da razão de amortecimento são frequentemente incompatíveis, para todo o intervalo de deformações, com aquelas obtidas de ensaios de laboratório. Neste caso sugere-se adotar uma solução de compromisso, procurando-se concordar as curvas teóricas e de laboratório no intervalo de deformações esperado para o problema em análise.

A Figura 4.11 exemplifica que para o intervalo de deformações cisalhantes $0,001 \%$ a $0,3 \%$ existe uma concordância razoável entre as versões do modelo linear equivalente proposto por Seed e Idriss (1970) para areias, implementadas no programa FLAC 2D (razão de amortecimento depende teoricamente da degradação do módulo de cisalhamento pela equação 4.7) e no programa computacional SHAKE (formulações independentes da degradação do módulo $G$ e o aumento da razão de amortecimento $\xi$ ).

Neste processo de calibração o amortecimento histerético em geral apresenta valores menores do que os determinados pela curva experimental da variação da razão de amortecimento, podendo ser produzidos ruídos especialmente em altas frequências. Para removê-los aconselha-se utilizar uma pequena quantidade de amortecimento Rayleigh (de $0,2 \%$ a $0,5 \%$ ) em conjunto com o amortecimento histerético. 

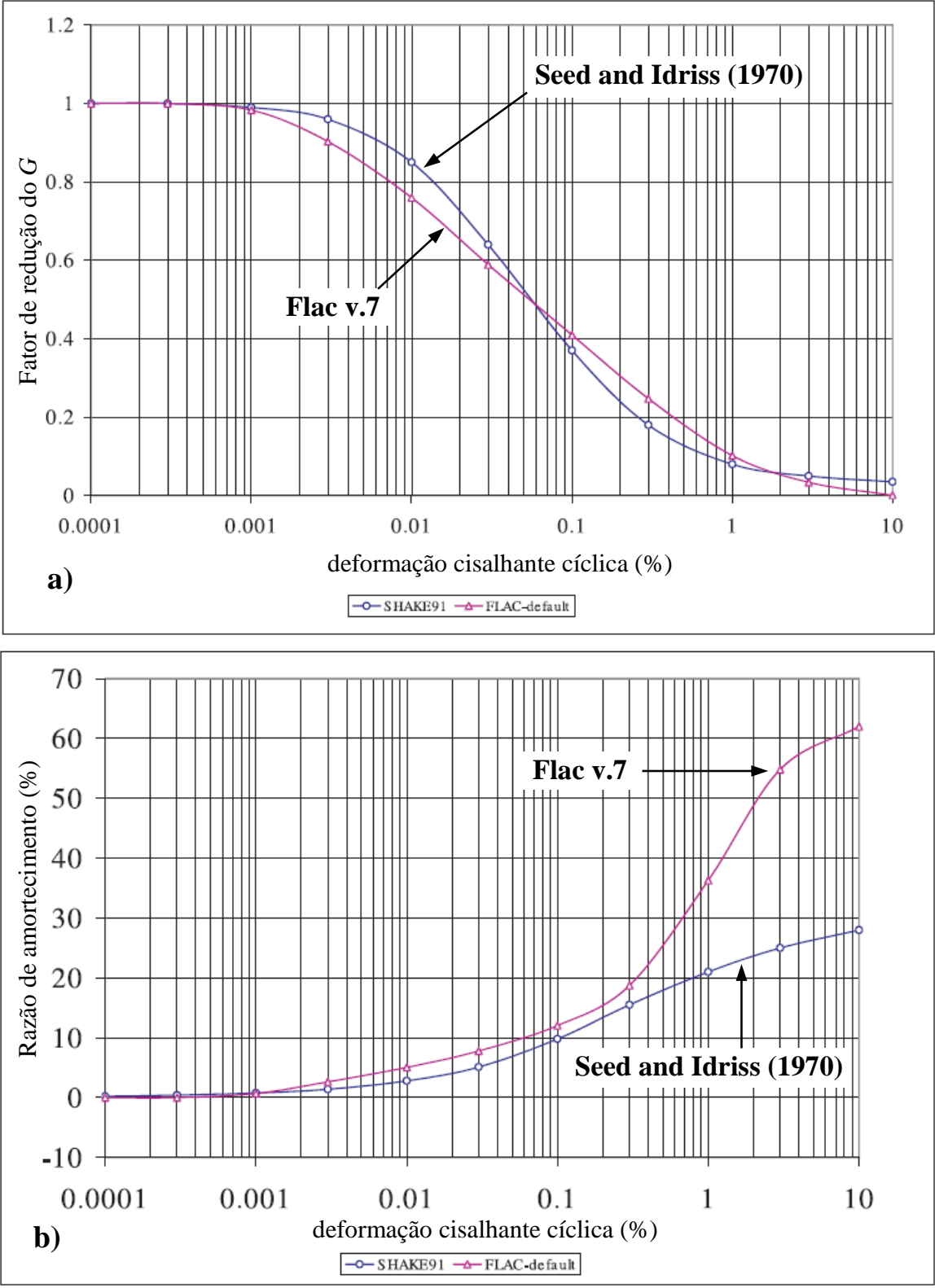

Figura 4.11 - Ajuste do programa FLAC v.8 às curvas experimentais de Seed e Idriss (1970) para areias: a) degradação do módulo de cisalhamento; b) aumento da razão de amortecimento. 


\section{5 Ameaça sísmica e sismos de projeto}

\section{1. Ameaça sísmica no Equador}

Em projetos de engenharia que envolvem grandes investimentos ou obras de essencial importância é frequente implementar uma análise de risco sísmico procurando-se obter uma previsão realista do desempenho da estrutura quando submetida a excitações sísmicas. O comportamento da geoestrutura durante e após um evento sísmico terá influência direta de múltiplos fatores como acelerações máximas, conteúdo de frequências, duração do movimento, etc. Todos estes parâmetros compõem as análises de risco sísmico que podem ser elaboradas conforme duas metodologias: determinística e probabilística.

\subsection{1.}

\section{Análise determinística}

Risco sísmico avaliado de forma determinística implica assumir a ocorrência de um determinado terremoto correspondente a um cenário particular (Kramer, 1996). Este estudo compreende a adoção de um movimento sísmico de magnitude específica ocorrendo em uma região na qual as características do subsolo são conhecidas. Segundo Reiter (1990) o processo consiste em 4 etapas básicas:

1. identificar todas as possíveis fontes sísmicas que exercem influência sobre a área estudada (Figura 5.1);

2. determinar a menor distância de cada fonte sísmica ao sítio de interesse;

3. selecionar o sismo esperado que produza o nível mais forte de vibração, em função das fontes sísmicas identificadas na etapa 1 e das distâncias estimadas na etapa 2;

4. estabelecer a ameaça sísmica para a região analisada, expressa em função de parâmetros do movimento como aceleração de pico (PGA), velocidade 
de pico (PGV) e, na maioria das vezes, na forma de espectros de resposta de acelerações.

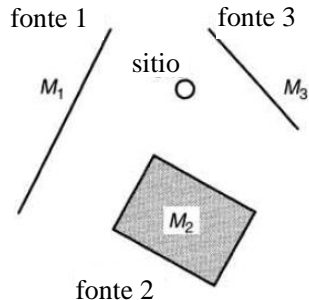

Paso 1

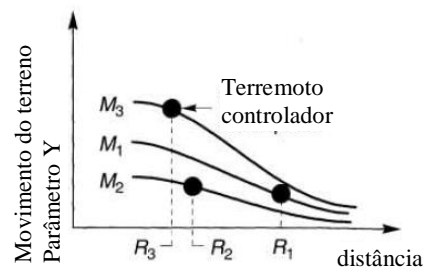

Paso 3

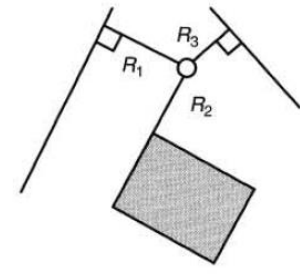

Paso 2

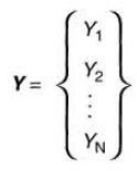

Paso 4

Figura 5.1 - Análise Determinística de Ameaça Sísmica (Kramer, 1996).

As desvantagens implícitas em uma análise determinística são não levar em conta a probabilidade de ocorrência de determinado terremoto selecionado no estudo de ameaça sísmica, assim como o período de recorrência do evento em comparação com o tempo de vida útil da geoestrutura. Este tipo de análise envolve decisões subjetivas, em particular na escolha do terremoto de projeto (etapa 1), e requer conhecimentos, experiência e participação de profissionais de diversas formações como sismologistas, geólogos, engenheiros, analistas de risco, economistas e funcionários governamentais, o que dificulta a execução de uma investigação objetiva e técnica.

\subsection{2.}

\section{Análise probabilística}

$\mathrm{Na}$ avaliação da ameaça sísmica utilizam-se ferramentas estatísticas para estimar as incertezas implícitas deste processo, levando em consideração as seguintes etapas (Reiter, 1990):

1. identificação geográfica e das características das fontes sísmicas próximas à área de análise; 
2. uma distribuição de probabilidades (distribuição uniforme de probabilidades) do potencial de ruptura para cada fonte sísmica;

3. a caracterização da distribuição de terremotos no tempo, através de uma relação magnitude - recorrência que reflete o número de terremotos que excedem certa magnitude;

4. utilização de relações de prognóstico para estimar o movimento produzido por terremotos de qualquer magnitude em qualquer ponto da área de interesse;

5. avaliação das incertezas de localização, magnitude e dos parâmetros do movimento (PGA, PGV), combinando-as de forma a obter a probabilidade de cada parâmetro ser ultrapassado durante um determinado intervalo de tempo.

Uma analise de ameaça sísmica probabilística incorpora a complexa caraterização da área sismogênica assim como dos parâmetros inerentes ao movimento, o que faz com que este tipo de abordagem seja mais refinado em comparação com as análises determinísticas.

\section{2. \\ Curvas de ameaça sísmica no Equador}

As curvas de ameaça sísmica são gráficos indicando para as áreas de interesse os parâmetros do movimento obtidos mediante análises de ameaça sísmica. Geralmente, como padrão internacional da engenharia sísmica geotécnica, estas curvas são expressas em função das acelerações de pico no substrato rochoso $\left(\mathrm{PGA}_{\text {rock }}\right)$.

A Norma Equatoriana da Construção (NEC, 2014), atualizada em dezembro de 2014, destina um capítulo à ameaça sísmica e efeitos locais no território equatoriano. De forma análoga às normas americanas, define um parâmetro $Z$ referente à aceleração máxima esperada na rocha (como fração da gravidade) para o sismo de projeto. O território foi dividido em isozonas, considerando 6 regiões sísmicas propensas a sofrer terremotos nas quais os valores da aceleração máxima na rocha são especificados, conforme Figura 5.2. Este mapa de zoneamento sísmico se refere à análise probabilística de ameaça sísmica para uma probabilidade de $10 \%$ de ser ultrapassada em 50 anos (período de retorno de 475 
anos). A subzona contendo o valor máximo de aceleração horizontal em rocha foi determinada na parte costeira norte do país (zona VI), com um valor esperado $\mathrm{PGA}_{\text {rock }}=0,50 \mathrm{~g}$.

Adicionalmente, a norma equatoriana da construção fornece curvas probabilísticas de ameaça sísmica relacionando aceleração máxima do terreno (PGA) com uma probabilidade anual de excedência, com o período de retorno correspondendo ao inverso desta probabilidade.

A geoestrutura analisada no presente trabalho (talude natural) localiza-se próxima à cidade de Azogues na serra do país, na subzona sísmica II com valor PGA $_{\text {rocha }}$ de $0,25 \mathrm{~g}$. A Figura 5.3 mostra as acelerações máximas espectrais para períodos de 0,$1 ; 0,2 ; 0,5$ e 1,0 segundos.

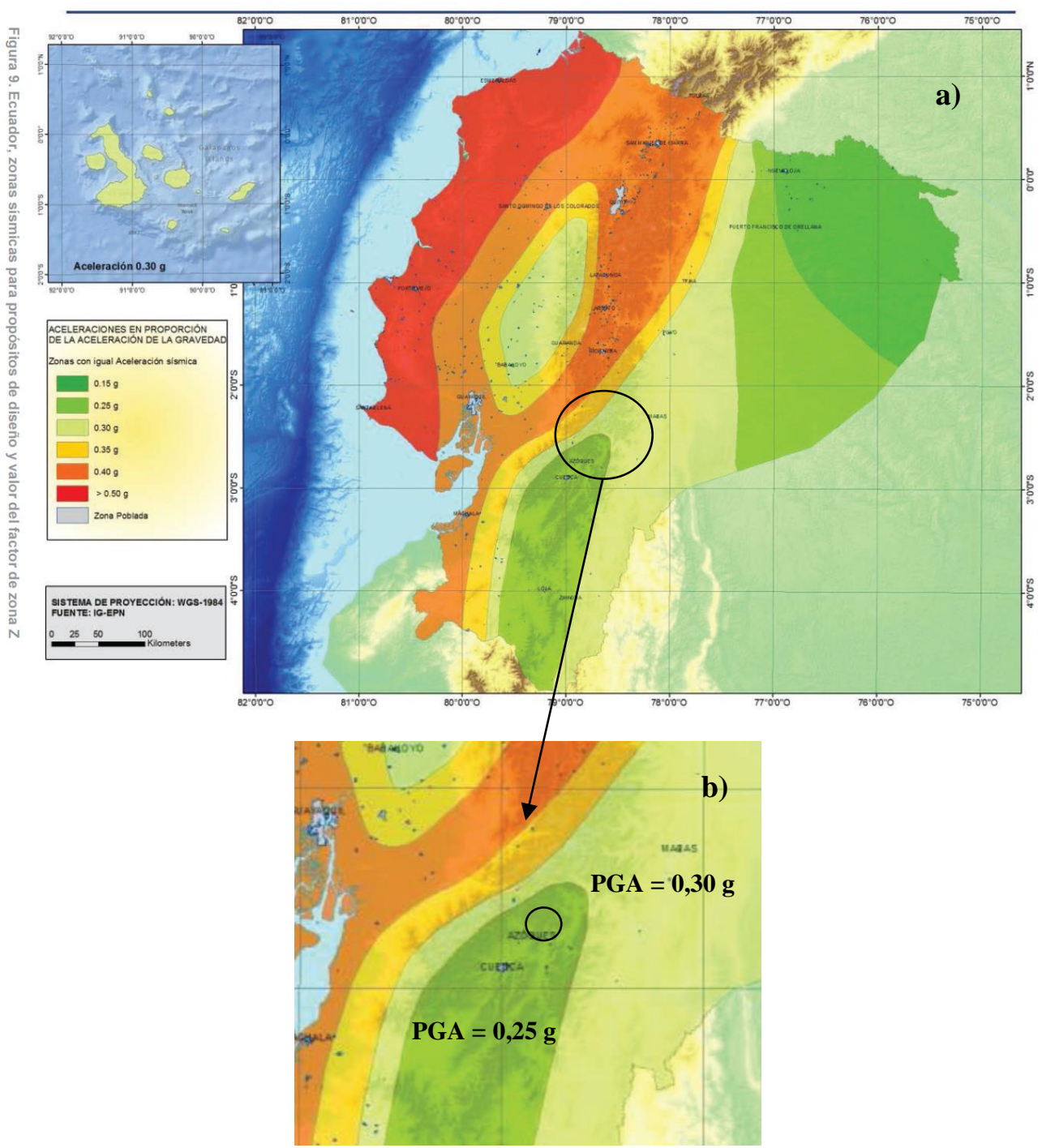

Figura 5.2 - a) Isozonas sísmicas no território equatoriano; b) $P G A_{\text {rock }}$ na área do projeto (Norma Equatoriana da Construção NEC, 2014). 


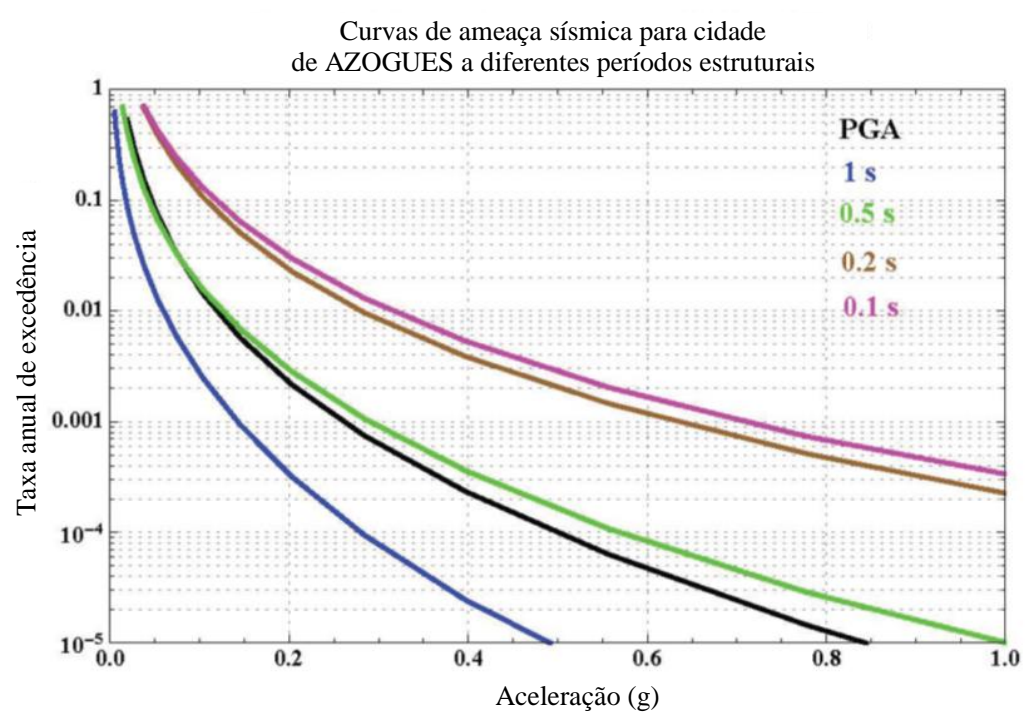

Figura 5.3 - Curvas de ameaça sísmica para a cidade de Azogues para períodos estruturais de 0,$1 ; 0,2 ; 0,5$ e 1,0 s (NEC, 2014).

\section{3.}

\section{Espectro elástico de projeto}

O espectro elástico de projeto é utilizado para determinar a máxima resposta da estrutura mediante análise de resposta modal no domínio da frequência. No entanto, no caso de solos, devido ao seu comportamento não linear, é necessária a aplicação do carregamento dinâmico no domínio do tempo (acelerograma) para determinar de forma mais exata os efeitos do movimento em estruturas de terra. Este acelerograma comumente determinado em afloramento rochoso deve previamente ser ajustado a um espectro de resposta que é construído com base em terremotos reais ocorridos na região de interesse.

$\mathrm{Na}$ falta de um espectro de projeto para a região, este pode ser construído mediante diversos critérios, como os citados a seguir:

1. Espectros de projeto recomendados por órgãos internacionais: são construídos em base de dados coletados em grande variedade de solos de diferentes locais; portanto, não refletem fielmente as condições sísmicas para um local especifico. Foram concebidos para aplicação de organismos governamentais como a Comissão de Energia Atômica dos Estados Unidos (USAEC) a partir dos trabalhos de Newmark \& Hall (1969) Figura 5.4 e Newmark (1973). Atualmente são considerados muito conservadores. 


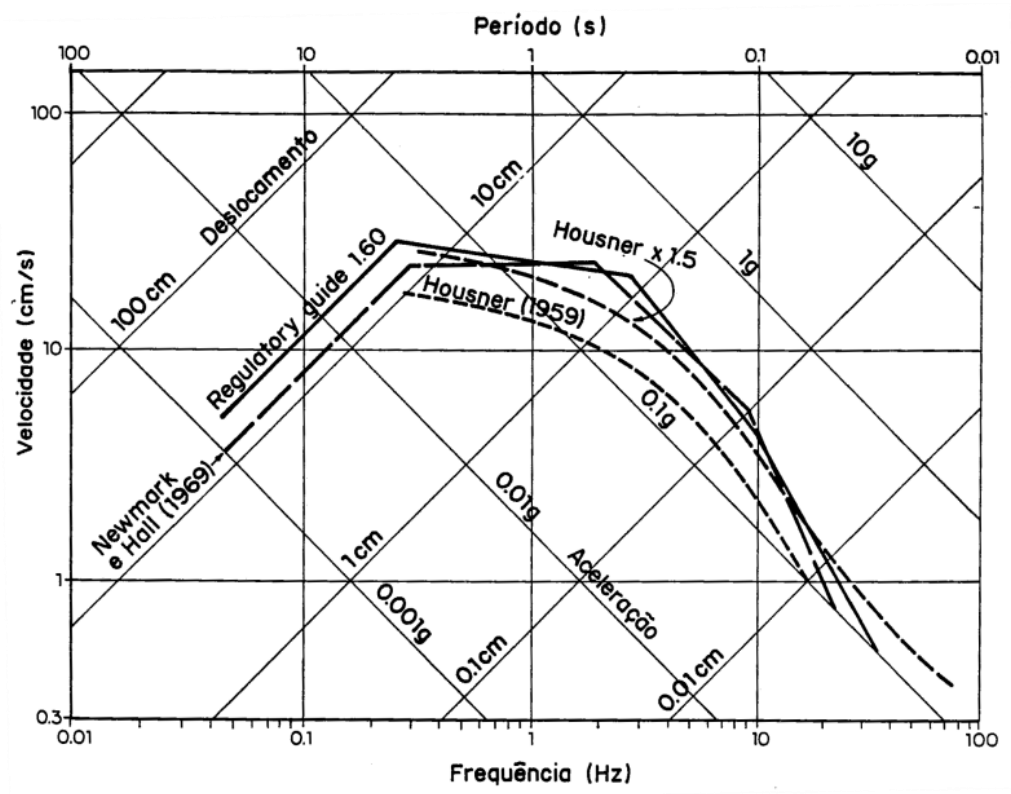

Figura 5.4 - Espectros de resposta propostos por Newmark (Newmark \& Hall, 1969).

2. Espectros dependentes dos parâmetros do movimento: espectros de resposta podem ser construídos mediante parâmetros amplificadores dos valores de aceleração, velocidade e deslocamentos máximos $\left(a_{\max }, V_{\max }\right.$, $\left.D_{\max }\right)$. Newmark \& Hall (1969) consideraram espectros gerados a partir de amplificações escalares de registros medidos em rocha, dentro de determinadas faixas de frequência. A Figura 5.5 apresenta o espectro para o terremoto El Centro (maio de 1940) onde as linhas tracejadas representam a aceleração máxima, velocidade máxima e deslocamento máximo do solo, enquanto as linhas cheias representam os diferentes espectros de resposta. O espectro final de resposta, constituído por linhas retas (envoltória), é determinado com base na amplificação direta da máxima aceleração, máxima velocidade e máximo deslocamento.

Newmark \& Hall (1982) refinaram este procedimento, incorporando constantes dependentes das condições locais do terreno para determinação da velocidade e deslocamento máximos, necessitando da aceleração máxima no substrato rochoso estimada para o sismo de projeto. 

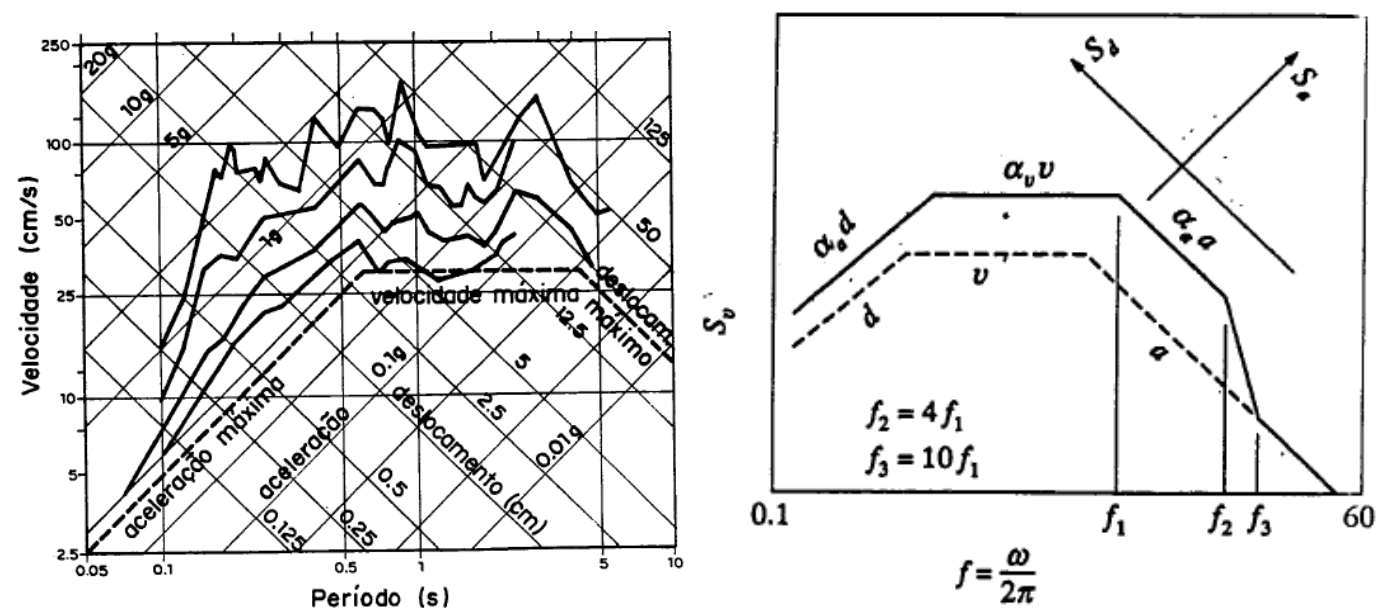

Figura 5.5 - Espectro de resposta para o terremoto El Centro a partir da aceleração, velocidade e deslocamento máximos (Clough \& Pezien, 1993).

3. Espectro dependente das condições do terreno: constitui-se na metodologia de maior utilização para geração de espectros de resposta. Utilizam a aceleração horizontal espectral como função do período $S_{\mathrm{a}}(T)$ correspondente à resposta elástica para o sistema de um grau de liberdade e amortecimento de $5 \%$ com respeito ao valor do amortecimento crítico. A vantagem deste procedimento está no fato de considerar as condições locais do terreno (tipos de solo presentes no estrato). No caso da Norma Equatoriana da Construção (NEC, 2014) o espectro de resposta elástico foi obtido mediante este critério.

4. Espectros a partir de informação sísmica: levam em conta três aspectos fundamentais do movimento: fontes sísmicas locais, magnitudes e distâncias do epicentro. Para sua geração é efetuada uma aproximação, ou suavização, de conjuntos de espectros de resposta previamente construídos a partir de famílias de acelerogramas com características similares de magnitude e distância epicentral que sejam representativos das condições do terreno (Figura 5.6).

Segundo Newmark \& Hall (1973) o espectro deve ser aproximado mediante linhas retas correspondentes às parcelas de aceleração, velocidade e deslocamento. De acordo com Kramer (1996), quando um determinado local pode ser afetado por terremotos originados de mais de uma fonte sísmica, a construção do espectro de resposta é complicada, como no caso da Califórnia onde terremotos de diferentes características podem ser produzidos em falhas existentes nesta região. 

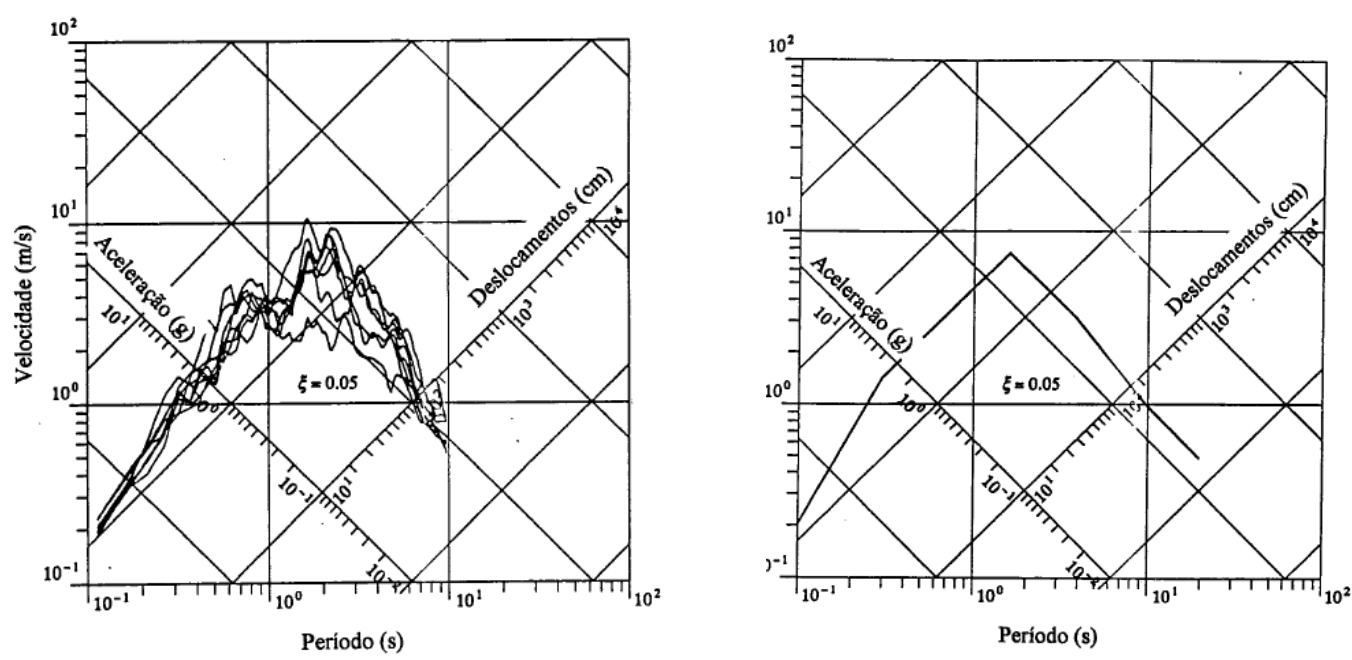

Figura 5.6 - Espectro de resposta a partir de informação sísmica (Adaptado de Almeida, 1997).

\subsection{1.}

\section{Espectro elástico de projeto na Norma Equatoriana da Construção (NEC, 2014)}

O espectro horizontal elástico de resposta em acelerações espectrais $\left(S_{a}\right)$ para o terremoto de projeto, especificado pela Norma Equatoriana da Construção (NEC, 2014), é apresentado na Figura 5.7.

Para a construção deste espectro a Norma Equatoriana da Construção classifica subsolo em 6 diferentes tipos de solo e rocha segundo características de velocidade de propagação da onda cisalhante $\left(V_{s}\right)$, resistência ao cisalhamento não drenada $\left(S_{u}\right)$, teor de umidade e índice de plasticidade, segundo a Tabela 5.1. Estes parâmetros são utilizados para classificar o terreno até uma profundidade de 30 metros. 
Tabela 5.1 - Classificação do perfil do terreno (NEC, 2014).

\begin{tabular}{|c|c|c|}
\hline Solo tipo & Descrição & Parâmetros \\
\hline A & Rocha competente & $\mathrm{V}_{\mathrm{s}} \geq 1500 \mathrm{~m} / \mathrm{s}$ \\
\hline $\mathrm{B}$ & Rocha de mediana rigidez & $1500 \mathrm{~m} / \mathrm{s} \geq \mathrm{V}_{\mathrm{s}} \geq 760 \mathrm{~m} / \mathrm{s}$ \\
\hline $\mathrm{C}$ & $\begin{array}{l}\text { Solos muito densos ou rocha branda } \\
\text { que satisfaçam qualquer um dos critérios }\end{array}$ & $\begin{array}{l}760 \mathrm{~m} / \mathrm{s} \geq \mathrm{V}_{\mathrm{s}} \geq 360 \mathrm{~m} / \mathrm{s} \\
\mathrm{N}_{\mathrm{SPT}} \geq 50 \\
S_{u} \geq 100 \mathrm{kPa}\end{array}$ \\
\hline $\mathrm{D}$ & $\begin{array}{l}\text { Solos rígidos com velocidade da onda } \\
\text { cisalhante ou com condições de resistência } \\
\text { não drenada }\end{array}$ & $\begin{array}{l}360 \mathrm{~m} / \mathrm{s} \geq \mathrm{V}_{\mathrm{s}} \geq 180 \mathrm{~m} / \mathrm{s} \\
50>\mathrm{N}_{\mathrm{SPT}} \geq 15 \\
100 \mathrm{kPa}>S_{u} \geq 50 \mathrm{kPa}\end{array}$ \\
\hline & Solos com velocidade de onda cisalhante ou & $\mathrm{V}_{\mathrm{s}}<180 \mathrm{~m} / \mathrm{s}$ \\
\hline $\mathrm{E}$ & $\begin{array}{l}\text { perfil contendo espessura } \mathrm{H}>3 \mathrm{~m} \text { de } \\
\text { argila mole }\end{array}$ & $\begin{array}{l}I P>20 \\
w \geq 40 \% \\
S_{u}<50 \mathrm{kPa}\end{array}$ \\
\hline \multirow{7}{*}{$\mathrm{F}$} & \multicolumn{2}{|c|}{$\begin{array}{l}\text { Solos tipo F requerem avaliação de campo por engenheiro geotécnico, } \\
\text { classificando-os nos seguintes sub tipos: }\end{array}$} \\
\hline & \multicolumn{2}{|c|}{$\begin{array}{l}\text { F1 - Solos suscetíveis a colapso ou falha por excitação sísmica, como por } \\
\text { exemplo, solos suscetíveis a liquefação, argilas sensitivas, solos dispersivos } \\
\text { ou pouco cimentados. }\end{array}$} \\
\hline & \multicolumn{2}{|l|}{ F2 - Turfa e argila orgânica (espessura $\mathrm{H}>3 \mathrm{~m}$ ) } \\
\hline & \multicolumn{2}{|c|}{ F3 - Argilas de alta plasticidade (espessura $\mathrm{H}>7.5 \mathrm{~m}$ com $I P>75$ ) } \\
\hline & \multicolumn{2}{|c|}{ F4 - Perfil de grande espessura de argila de rigidez mediana a mole $(\mathrm{H}>30 \mathrm{~m})$} \\
\hline & \multicolumn{2}{|c|}{$\begin{array}{l}\text { F5 - Contrastes entre solos moles e rocha e variações bruscas de velocidade } \\
\text { de onda cisalhante }\end{array}$} \\
\hline & \multicolumn{2}{|l|}{ F6 - Aterros feitos sem controle de engenharia } \\
\hline
\end{tabular}




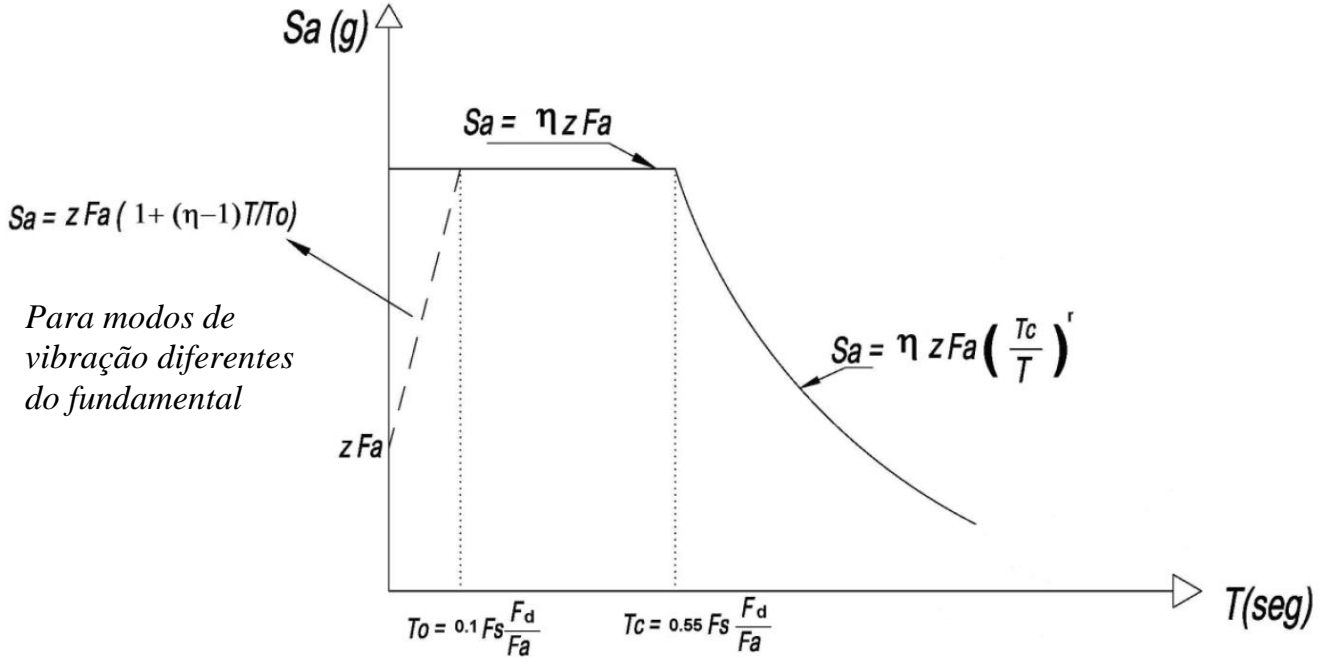

$\eta$ é a razão de amplificação espectral (razão entre a aceleração espectral $S_{a}$ para um período $T=$ 0,1s e a aceleração máxima PGA no período de retorno escolhido). Para uma probabilidade de excedência de $10 \%$ em 50 anos (período de retorno 475 anos) o valor de $\eta$ na área onde se localiza o talude deste estudo é $\eta=2,48$;

$F_{\text {a }}$ é o coeficiente de amplificação do solo em zonas de pequeno período (Tabela 5.2);

$F_{\mathrm{d}}$ é o coeficiente de amplificação do espectro elástico de resposta em deslocamentos (Tabela 5.2);

$F_{\text {s }}$ é o coeficiente de amplificação que leva em consideração o comportamento não linear do solo (Tabela 5.2);

$T$ é o período fundamental de vibração da estrutura;

$T_{\mathrm{o}}$ é o período limite de vibração no espectro sísmico de aceleração que representa o terremoto de projeto;

$T_{\mathrm{c}}$ é o período limite de vibração;

$z$ é a aceleração máxima no substrato rochoso para o sismo de projeto, conforme a zona sísmica de interesse (Figura 5.2).

Figura 5.7 - Espectro sísmico elástico em acelerações representativo de sismo de projeto no Equador (NEC, 2014).

Tabela 5.2 - Coeficientes de amplificação $\left(F_{\mathrm{a}}, F_{\mathrm{d}}\right.$ e $\left.F_{\mathrm{s}}\right)$ para o espectro elástico de projeto segundo a zona sísmica, conforme a Norma Equatoriana de Construção (Adaptado da NEC, 2014).

\begin{tabular}{|c|ccc|ccc|}
\hline Perfil de & \multicolumn{3}{|c|}{ Zona sísmica II (PGA $=0,25 \mathrm{~g})$} & \multicolumn{3}{|c|}{ Zona sísmica III (PGA = 0,30g) } \\
solo tipo & $F_{\mathrm{a}}$ & $F_{\mathrm{d}}$ & $F_{\mathrm{s}}$ & $F_{\mathrm{a}}$ & $F_{\mathrm{d}}$ & $F_{\mathrm{s}}$ \\
\hline $\mathrm{A}$ & 0.9 & 0.9 & 0.75 & 0.9 & 0.9 & 0.75 \\
$\mathrm{~B}$ & 1.0 & 1.0 & 0.75 & 1.0 & 1.0 & 0.75 \\
$\mathrm{C}$ & 1.3 & 1.28 & 0.94 & 1.25 & 1.19 & 1.02 \\
$\mathrm{D}$ & 1.4 & 1.45 & 1.06 & 1.30 & 1.36 & 1.11 \\
$\mathrm{E}$ & 1.4 & 1.75 & 1.6 & 1.25 & 1.7 & 1.7 \\
\hline
\end{tabular}

O espectro de acelerações, como indicado na Figura 5.7, é construído para uma razão de amortecimento de 5\%, de acordo com as expressões:

$$
\begin{array}{cc}
S_{a}=\eta z F_{\mathrm{a}} & \text { para } 0 \leq T \leq T_{\mathrm{c}} \\
S_{a}=\eta z F_{\mathrm{a}}\left(\frac{T_{c}}{T}\right)^{r} & \text { para } T>T_{\mathrm{c}}
\end{array}
$$


onde $r$ representa um fator dependente do tipo de solo $(r=1$ para todos os tipos de solos com exceção do solo tipo E no qual $r=1,5$ ).

Para avaliar a resposta dinâmica nos modos de vibração superiores ao modo fundamental (parte esquerda da Figura 5.7) a curva do espectro de resposta em acelerações é determinada pela equação:

$$
S_{a}=z F_{a}\left[1+(\eta-1) \frac{T}{T_{0}}\right] \quad \text { para } T \leq T_{\mathrm{o}}
$$

Os períodos limites de vibração para o espectro de acelerações $\left(T_{\mathrm{c}}\right.$ e $\left.T_{\mathrm{o}}\right)$ são obtidos mediante as equações:

$$
\begin{aligned}
& T_{c}=0,55 F_{s} \frac{F_{d}}{F_{a}} \\
& T_{o}=0,1 F_{s} \frac{F_{d}}{F_{a}}
\end{aligned}
$$

\section{4 . \\ Sismos de projeto}

Apesar da literatura especializada citar várias denominações para os terremotos utilizados em análises de geoestruturas, os sismos de uso mais frequente são o terremoto máximo esperado (MCE Maximum Credible Earthquake) e o terremoto base de operação (OBE Operating Basis Earthquake).

O espectro de resposta de acelerações probabilísticas do terremoto base de projeto OBE é determinado como o espectro de resposta com razão de amortecimento de 5\%, probabilidade de excedência de $50 \%$ e 50 anos de exposição sísmica (vida útil), correspondente a um período de retorno $T_{R}=72$ anos.

O espectro de resposta de acelerações probabilísticas do terremoto máximo esperado MCE é determinado como o espectro de resposta com razão de amortecimento de 5\%, probabilidade de excedência de $2 \%$ e 50 anos de exposição sísmica (vida útil), correspondente a um período de retorno $T_{R}=2475$ anos.

Devido à pouca disponibilidade de registros sísmicos com epicentros localizados nas proximidades da área do projeto (Estado de Canar, Equador) 
considerou-se também adequada a geração de acelerogramas artificiais no domínio da frequência ajustando-os ao espectro de resposta elástico especificado na Norma Equatoriana da Construção (Figura 5.7). A seguir apresenta-se um resumo das principais metodologias para geração destes acelerogramas artificiais.

\subsection{1.}

\section{Geração de sismos artificiais}

Segundo Kramer (1996) os principais desafios na geração de movimentos artificiais residem na concordância entre os parâmetros dos registros de partida e dos acelerogramas resultantes, na tentativa de se obter um sismo de projeto com características consistentes com os terremotos esperados na região. Não se trata de tarefa simples pois muitas vezes os sismos apresentam aparência correta e real no domínio do tempo mas são irreais no domínio da frequência, da mesma forma que registros de aceleração assim gerados, quando integrados no tempo, podem resultar em histórias de velocidade ou de deslocamento incoerentes.

Os métodos de geração de sismos artificiais agrupam-se em quatro categorias principais:

1. Normalização de registros sísmicos existentes: é o procedimento mais simples, pois utiliza parâmetros máximos, como aceleração de pico (PGA) ou a velocidade (PGV) para escalar os registros, convertendo-os para níveis superiores ou inferiores (Figura 5.8). Este fator de escala é a relação entre a amplitude do registro final e a amplitude do registro de partida que deve ser o mais próximo possível de 1,0 e sempre situado na faixa entre 0,25 até 4,0 . Para problemas que implicam potencial de liquefação a faixa recomendável situa-se entre 0,5 e 2,0.

O sismo gerado com este procedimento naturalmente apresentará características do movimento (conteúdo de frequência, duração) herdadas do sismo de partida, razão pela qual se se recomenda uma escolha cuidadosa do acelerograma inicial. 


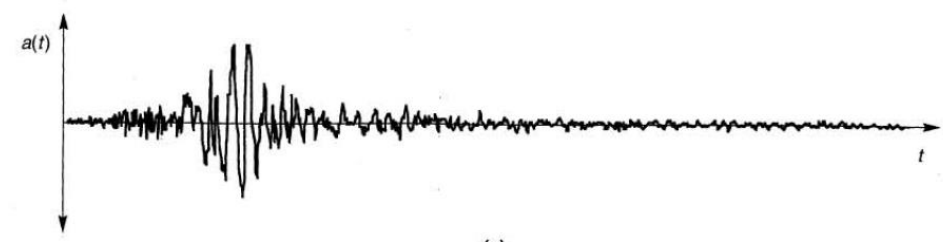

(a)

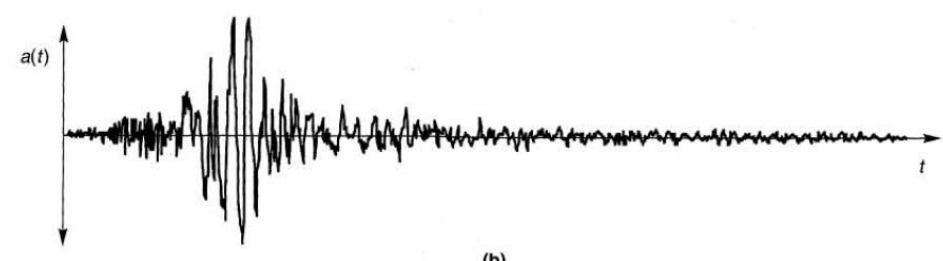

(b)

Figura 5.8 - Geração de sismos artificiais por normalização de registros: a) acelerograma inicial; b) acelerograma modificado na escala 1,5 (Kramer, 1996).

2. Geração no domínio do tempo: a semelhança de registros sísmicos no domínio do tempo com processos transientes estocásticos faz com que muitos métodos para geração de acelerogramas artificiais sejam feitos através de processos estocásticos. A abordagem geral implica na multiplicação de um sinal de ruído branco (white noise), estacionário e filtrado, por uma função envoltória não estacionária que descreve as etapas da amplitude do movimento do terreno (Shinozuka \& Deodatis, 1988), conforme representação na Figura 5.9. Sharma e Shah (1986) também incorporaram uma condição não estacionária para a amplitude do movimento e para as frequências.

(a)

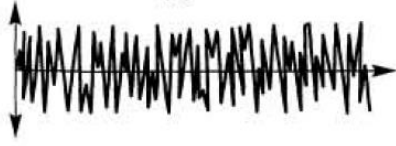

(b)

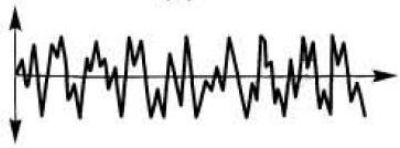

(c)

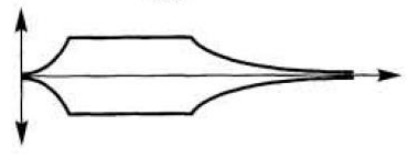

(d)

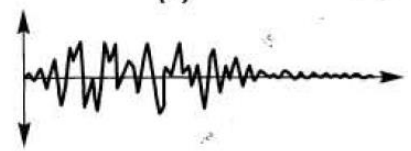

Figura 5.9 - Geração de sismos artificiais no domínio do tempo: a) função de ruído branco é filtrada para produzir; b) função ruído branco filtrada no domínio do tempo; c) função envoltória; d) sismo artificial no domínio do tempo (Kramer, 1996).

3. Geração no domínio da frequência: constitui-se o método mais frequentemente utilizado. Para a produção do sismo artificial combinam-se o espectro de amplitude de Fourier FAS (Figura 5.10d) com o espectro de 
fase de Fourier (FPS) (Figura 5.10c). O espectro de amplitude (FAS) deve ser gerado a partir do espectro do sismo original ou sob forma de uma função de densidade do espectro de potência (Power Spectral Density Function, PSDF); o espectro de fase também se obtém do sismo original mas, alternativamente, também pode ser determinado a partir de um registro de acelerações no tempo produzido pelo produto de um sinal de ruído branco com uma função envoltória (Figura 5.10a,b).

Este procedimento é recomendado particularmente quando se pretende gerar um movimento ajustado a um espectro de resposta de projeto específico. Alguns softwares desenvolvidos para esta finalidade (SeismoArtif, SeismoSoft, 2016) partem dos espectros de amplitude e fase de Fourier, e mediante processo iterativo ajustam o espectro de amplitude até se aproximar o máximo possível do espectro de resposta alvo de projeto.

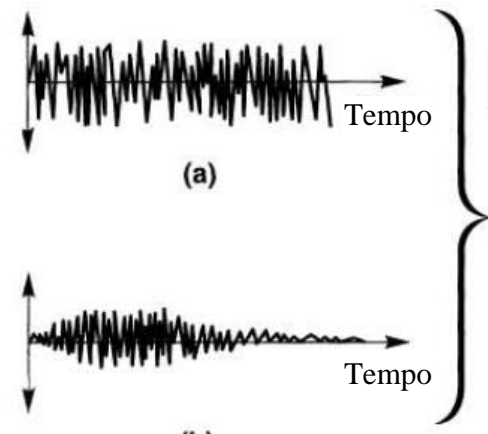

(b)

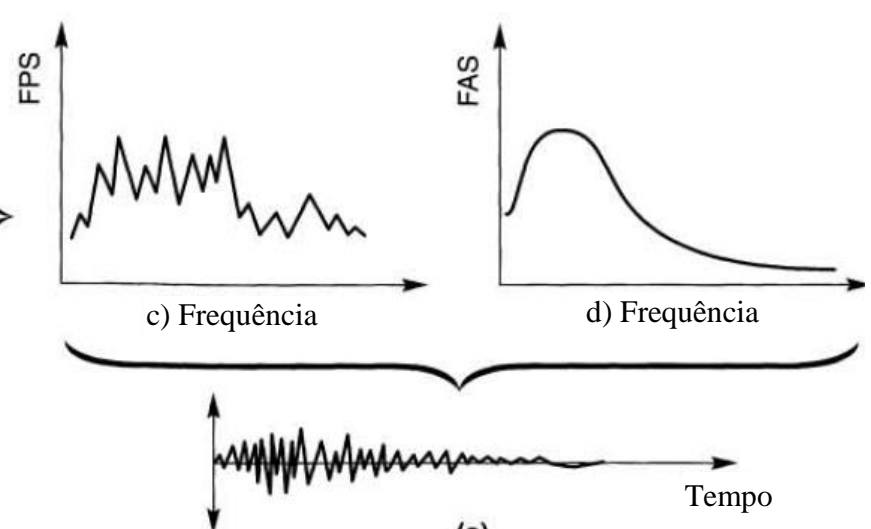

(e)

Figura 5.10 - Geração de sismos no domínio da frequência: a) função de ruído branco ajustada à envoltória; b) função de ruído branco no domínio do tempo; c) espectro de fase de Fourier; d) espectro de amplitude de Fourier; e) acelerograma artificial no domínio do tempo (Kramer, 1996).

4. Procedimentos baseados em função de Green: fundamentam-se no fato de que o movimento em uma região é composto pela soma dos movimentos decorrentes de rupturas individuais de pequenos trechos ao longo de uma falha. Frequentemente se determina a área da fonte sísmica dividindo-a em um número determinado de trechos e a ordem em que estes se rompem, atribuindo uma função de deslizamento que relaciona o deslocamento com o tempo para cada trecho. A função de Green descreve o movimento na região analisada devido a um deslizamento unitário na 
fonte (Figura 5.11). Com a combinação das funções de deslizamento e a função de Green obtêm-se então o movimento no local de interesse provocado por uma ruptura individual de cada trecho da fonte.

Segundo Kramer (1996) esta metodologia é de particular interesse para gerar movimentos em regiões próximas a falhas. Na Figura 5.11 representa-se uma falha subdividida em $N$ trechos, com uma função de Green definida para cada trecho, que se diferenciam entre si devido a parâmetros como distância focal, distância epicentral e estrutura geológica entre o trecho da falha e o local de interesse na análise. Uma vez determinadas as funções de Green (parte de maior complexidade) diferentes padrões de movimento no local podem ser simulados para diversos modelos de ruptura de falha e funções de deslizamento.

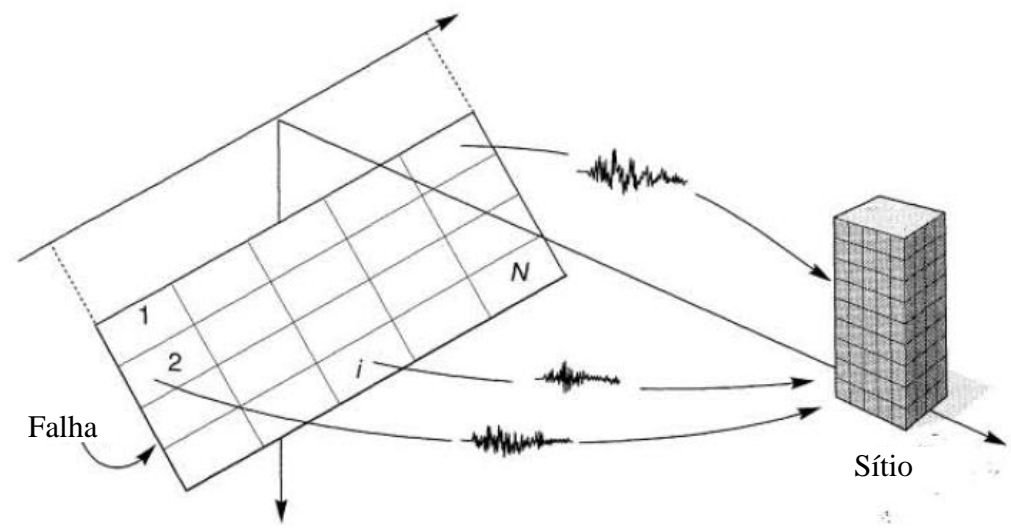

Figura 5.11 - Geração de movimentos mediante funções de Green (Kramer, 1996).

\subsection{2.}

\section{Espectros de Fourier, de potência e de resposta}

Três tipos de espectros são utilizados para análise da resposta dinâmica de geoestruturas:

a) Espectro de Fourier:

Uma série de Fourier é a soma de funções harmônicas de diferentes frequências, amplitudes e fases. Qualquer função periódica pode ser expressa como uma série de Fourier, matematicamente escrita como:

$$
x(t)=c_{o}+\sum_{n=1}^{\infty} c_{n} \sin \left(w_{n} t+\emptyset_{n}\right)
$$


onde $c_{n}$ e $\phi_{\mathrm{n}}$ são a amplitude e o ângulo de fase da função harmónica, respetivamente, e $w_{n}$ representa a frequência de vibração no modo $n$.

$\mathrm{O}$ espectro de amplitudes de Fourier mostra a forma com que a amplitude se distribui com respeito à frequência ou períodos de um terremoto, dele observa-se claramente o conteúdo de frequências de um sismo.

\section{b) Espectro de potência:}

O conteúdo de frequências com respeito à energia do terremoto é expresso mediante a Função Densidade Espectro de Potência $G(w)$ (Power Spectral Density Function PSDF). Esta função tem aplicações na estimativa de propriedades estatísticas da distribuição de frequências do sismo, sendo determinada como:

$$
\sum_{n=1}^{\infty} P\left(w_{n}\right)=\frac{1}{2} \int_{0}^{w_{n}} c_{n}^{2} d w
$$

Onde $w_{n}$ representa a frequência de vibração e $c_{n}$ amplitude da função harmônica.

A partir do espectro de potência pode-se determinar a frequência dominante no sistema. Na Figura 5.12 observa-se uma estreita distribuição do espectro de potência, indicando uma frequência dominante de aproximadamente $1,0 \mathrm{~Hz}$; verifica-se também que o sismo é mais forte para baixas frequências, que a maior frequência é de $15 \mathrm{~Hz}$ e que a maior parte da energia do terremoto é produzida por frequências de até $10 \mathrm{~Hz}$.

c) Espectro de resposta

Um espectro de resposta descreve a máxima resposta (em aceleração, velocidade ou deslocamento) de um sistema com um grau de liberdade quando submetido a um movimento, sendo função da frequência natural do sistema e do amortecimento. Fornece informações sobre as frequências onde as acelerações, velocidades e deslocamentos espectrais atingem seus valores máximos.

O espectro de resposta constitui uma importante ferramenta para estimar os potenciais efeitos de terremotos em geoestruturas. 


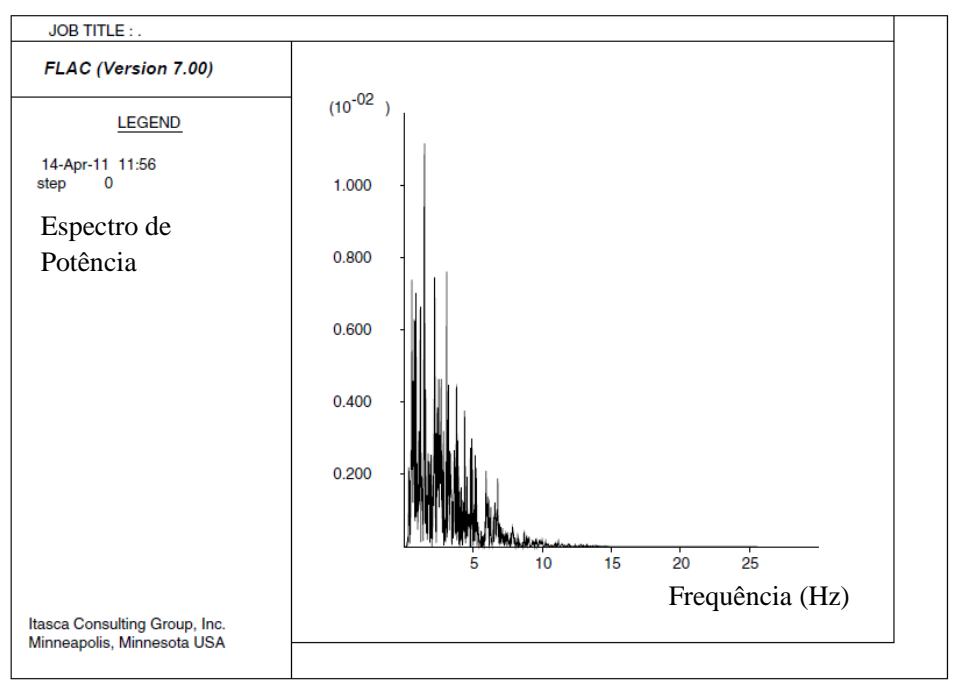

Figura 5.12 - Espectro de potência do registro de velocidades (modificado de Flac v.8 User's manual). 


\section{6 \\ Exemplos analisados}

\section{1.}

\section{Talude natural ao sul do Equador}

A estrada federal E35 atravessa o Equador de sul a norte, iniciando na província de Loja (fronteira sul com o Perú) e chegando até a província de Carchi (fronteira norte com a Colombia), com uma extensão total de 781 km (Figura 6.1). É mais conhecida como estrada Panamericana por se prolongar por alguns países da costa do Pacifico na América Latina. Ao longo desta via, existe grande variedade de formações geológicas, com materiais desde rochas vulcânicas de alta resistência (andesitos, basaltos) até solos residuais de baixa capacidade.

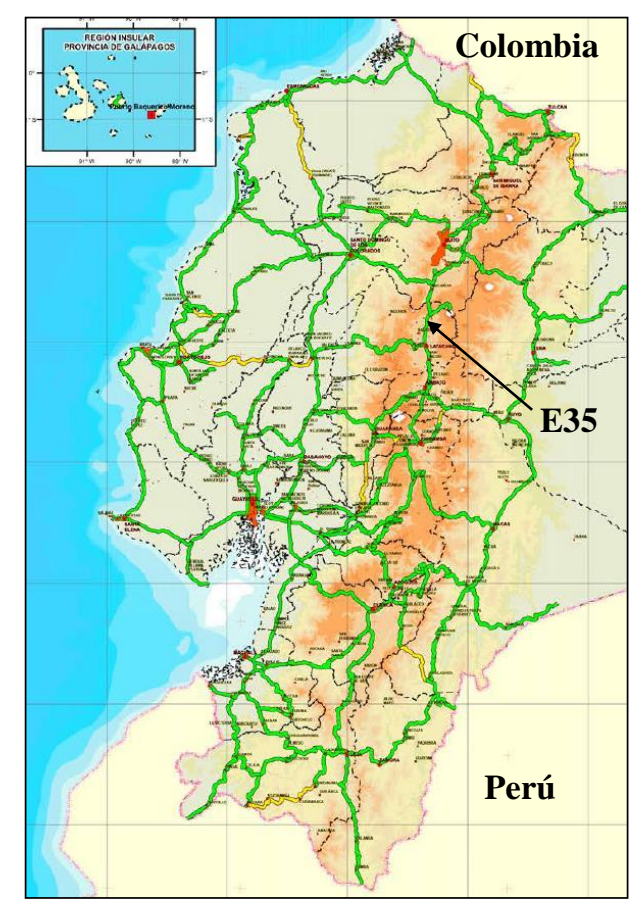

Figura 6.1 - Rede rodoviária federal do Equador (Ministério de Transporte e Obras Públicas Equador).

No ano de 2014 foi empreendida pelo governo federal uma completa reabilitação desta estrada, particularmente nos trechos onde apresentava significativos problemas, principalmente de estabilidade de taludes em trechos 
situados nas províncias de Azuay e Canar, localizados no sul do país. Como o Equador está situado em uma zona de alta sismicidade, com ocorrência frequente de terremotos como recentemente em 16 de abril de 2016, é importante executar estudos de resposta sísmica nos taludes de grande altura ao longo da estrada federal E35.

Neste capitulo são feitas as análises estática, pseudoestática e dinâmica de uma encosta situada no limite entre as províncias de Azuay e Canar (Figura 6.2), com 77 m de altura, formado por solo coluvionar pertencente à formação Loyola.
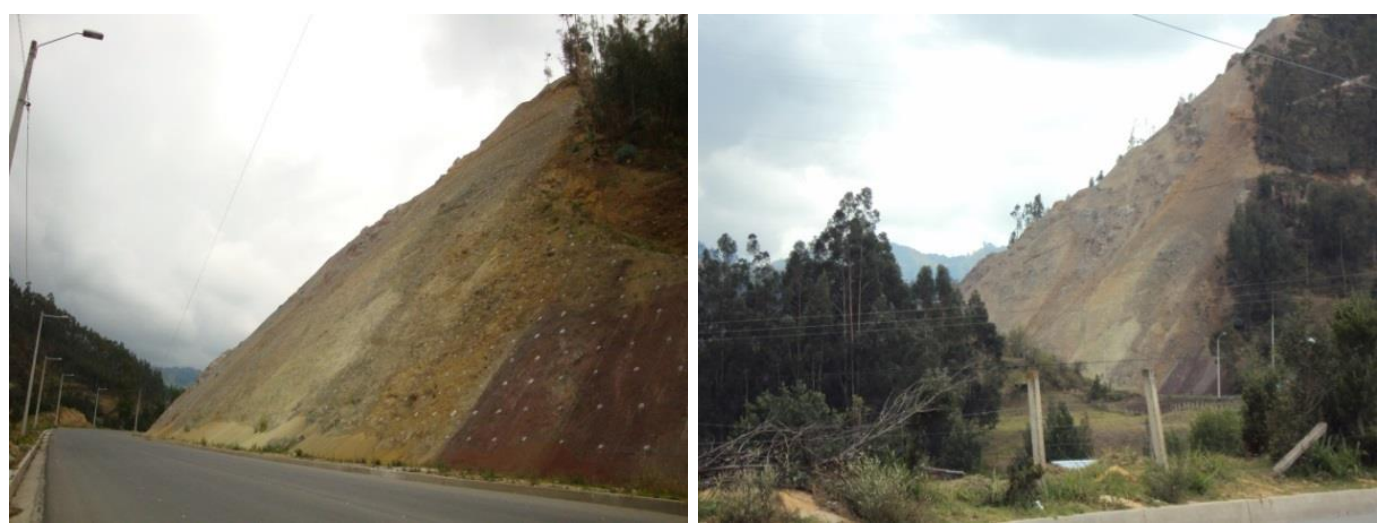

Figura 6.2 - Talude natural na abscissa 4+990.

\subsection{1. \\ Propriedades dos materiais}

A partir de ensaios em campo (SPT), determinou-se que o estrato de solo é composto por um solo coluvial, que abrange todo o talude, seguido por uma camada de areia siltosa friável e o substrato rochoso. A geologia local da zona esta composta pela formação Loyola que apresenta solos residuais arenosos de resistência media; assim como depósitos coluviais de matriz arenosa, consistência firme e baixa permeabilidade.

As simulações numéricas, tanto estáticas quanto dinâmicas foram executadas no estado plano de deformação utilizando o modelo constitutivo elasto-plástico de Mohr Coulomb para aproximar o comportamento tensão x deformação da areia siltosa e do solo coluvial, cujos parâmetros (Tabela 6.1) foram determinados em ensaios triaxiais e de cisalhamento direto, bem como em ensaios geofísicos de campo (Figura 6.3). Para o substrato rochoso, a pesar de que os parâmetros de resistência do modelo de Mohr Coulomb são apresentados na 
Tabela 6.1, em todas as simulações numéricas foi utilizado o modelo constitutivo elástico linear para representar o comportamento deste material, e cujos parâmetros estão também detalhados na Tabela 6.1.

Tabela 6.1 - Propriedades geotécnicas dos materiais da encosta (Ministério de Obras Públicas Equador).

\begin{tabular}{|c|c|c|c|}
\hline Propriedades & Coluvial & Areia siltosa & Estrato rochoso \\
\hline $\begin{array}{l}\text { Massa específica } \\
\rho\left(\mathrm{kg} / \mathrm{m}^{3}\right)\end{array}$ & 1886 & 2035 & 2385 \\
\hline $\begin{array}{l}\text { Peso especifico sat } \\
\gamma_{\text {sat }}\left(\mathrm{kN} / \mathrm{m}^{3}\right)\end{array}$ & 18,5 & 20 & 23,4 \\
\hline $\begin{array}{l}\text { Peso específico } \\
\gamma_{\mathrm{d}}\left(\mathrm{kN} / \mathrm{m}^{3}\right)\end{array}$ & 15,5 & 17,5 & 18 \\
\hline $\begin{array}{l}\text { Módulo Cisalhante } \\
\mathrm{G}_{\max }(\mathrm{MPa})\end{array}$ & 348,7 & 598,9 & 7727,4 \\
\hline $\begin{array}{l}\text { Módulo Young } \\
\mathrm{E}_{\max }(\mathrm{MPa})\end{array}$ & 906,6 & 1557,1 & 20091 \\
\hline $\begin{array}{l}\text { Módulo Cisalhante } \\
\text { G (MPa) }\end{array}$ & 110 & 117 & 3100 \\
\hline $\begin{array}{l}\text { Modulo Deformação } \\
\text { Volumétrica } \\
\mathrm{K}(\mathrm{MPa})\end{array}$ & 238 & 254 & 2066 \\
\hline Coeficiente Poisson $v$ & 0,3 & 0,3 & 0,3 \\
\hline $\begin{array}{l}\text { Velocidade onda } S \\
V_{s}(\mathrm{~m} / \mathrm{s})\end{array}$ & 430 & 542 & 1800 \\
\hline Coesão c (kPa) & 40 & 20 & 103 \\
\hline Ângulo atrito & $36^{\circ}$ & $27^{\circ}$ & $36^{\circ}$ \\
\hline
\end{tabular}

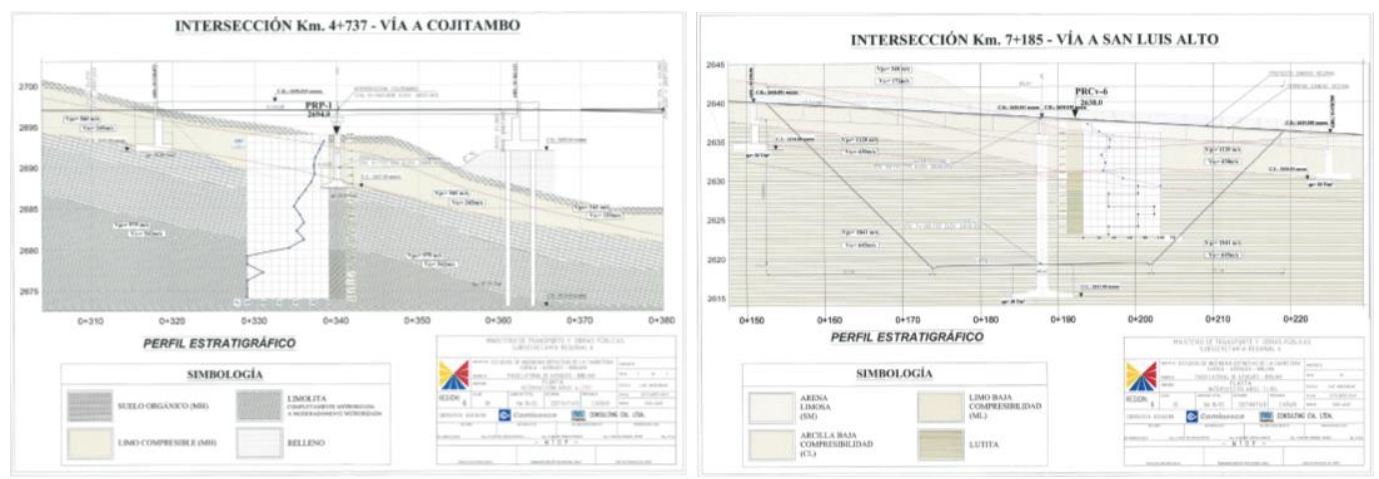

Figura 6.3 - Ensaios geofísicos de propagação de ondas de cisalhamento nas vizinhanças do talude (Ministério de Transporte e Obras Públicas - Equador). 
Com base na velocidade de propagação da onda cisalhante $V_{s}$, o código americano de construção (IBC-2009) da ASCE (American Society of Civil Engineering) estabelece uma classificação aproximada dos solos, conforme a Tabela 6.2.

Tabela 6.2 - Classificação de solos em função da velocidade de propagação da onda cisalhante $\left(V_{s}\right)$ - International Building Code (IBC, 2009) - American Society Civil Engineering (ASCE 7 - 10).

\begin{tabular}{|c|c|c|c|c|}
\hline \multirow{2}{*}{$\begin{array}{c}\text { TIPO } \\
\text { DE } \\
\text { SOLO }\end{array}$} & \multirow[b]{2}{*}{ CLASSIFICAÇÃO } & \multicolumn{3}{|c|}{ PROPRIEDADES MÉDIAS NOS 30 PRIMEIROS METROS } \\
\hline & & $\begin{array}{l}\text { Velocidade de onda cisalhante, } \\
\qquad \bar{v}_{S(\mathrm{~m} / \mathrm{s})}\end{array}$ & $\begin{array}{c}\text { Resistência à penetração } \\
\text { padrão } \bar{N}\end{array}$ & $\begin{array}{c}\text { Resistência ao cisalhamento não } \\
\text { drenado, } \bar{S}_{u} \text { (psf) }\end{array}$ \\
\hline A & Rocha sã & $\bar{v}_{s}>1,500$ & N/A & N/A \\
\hline B & Rocha dura & $760<\bar{v}_{s} \leq 1,500$ & N/A & N/A \\
\hline $\mathrm{C}$ & $\begin{array}{c}\text { Solo rijo ou rocha } \\
\text { branda }\end{array}$ & $360<\bar{v}_{s} \leq 760$ & $\bar{N}>50$ & $\bar{S}_{u \geq 2,000}$ \\
\hline $\mathrm{D}$ & Solo médio & $180 \leq \overline{\boldsymbol{v}}_{s} \leq 360$ & $15 \leq \bar{N} \leq 50$ & $1,000 \leq \bar{S}_{u} \leq 2,000$ \\
\hline $\mathrm{E}$ & Solo mole & $\bar{v}_{S}<180$ & $\bar{N}<15$ & $\bar{s}_{u}<1,000$ \\
\hline $\mathrm{E}$ & - & $\begin{array}{l}\text { Qualquer perfil de solo com } \\
\text { características: } \\
\text { 1. Índice de plastici } \\
\text { 2. Teor de umidade } \\
\text { 3. Resistência ao cis }\end{array}$ & $\begin{array}{l}\text { ais de } 3 \mathrm{~m} \text { de espessura } \\
\text { e(IP) }>20 \\
\geq 40 \% \\
\text { amento não drenado } \bar{S}\end{array}$ & $\begin{array}{l}\text { possua as seguintes } \\
000 \mathrm{psf}\end{array}$ \\
\hline $\mathrm{F}$ & - & 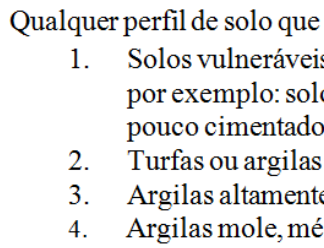 & $\begin{array}{l}\text { sua uma ou mais das se } \\
\text { Ima possível ruptura ou } \\
\text { uscetíveis à liquefação, } \\
\text { mente orgânicas }(\mathrm{H}>3 \\
\text { ásticas }(\mathrm{H}>7.6 \mathrm{~m} \text { com } \\
\text { ou rija muito espessas }\end{array}$ & $\begin{array}{l}\text { ntes características: } \\
\text { apso devido ao efeito sísmico, } \\
\text { ilas altamente sensíveis e solos } \\
\mathrm{H}=\text { espessura da camada } \\
\text { ce de plasticidade } \mathrm{IP}>75 \text { ) } \\
36 \mathrm{~m}) \operatorname{com} \mathrm{S}_{\mathrm{u}}<50 \mathrm{kPa}\end{array}$ \\
\hline
\end{tabular}

\subsection{2.}

\section{Sismos de projeto}

As características de sismicidade (acelerações máximas, profundidades focais, magnitudes, conteúdo de frequências do terremoto, duração significativa, etc.) devem ser analisadas de forma específica para o local do projeto. No presente trabalho se dispunham dos acelerogramas de três sismos ocorridos em território equatoriano registrados pela Rede Sísmica del Austro (Universidade de Cuenca):

- o primeiro deles corresponde ao evento de 15 de novembro de 2015 , com magnitude de momento $M_{w}=5.6$, profundidade $87 \mathrm{~km}$ e epicentro próximo da cidade de La Troncal (Figura 6.4a), PGA = 0,18g.

- o segundo sismo com data de 25 de março de 2014 com magnitude de momento $M_{w}=4.5$ e profundidade de $10 \mathrm{~km}$ com epicentro próximo à cidade de Bucay (Figura 6.4b), PGA =0,12g. 
- o terceiro terremoto corresponde ao registrado em 04 de agosto de 1998, com epicentro na cidade de Bahia de Caraquez e magnitude de momento $M_{w}=7.1$, profundidade focal de $33 \mathrm{~km}$, PGA =0,22g (Figura 6.4c).
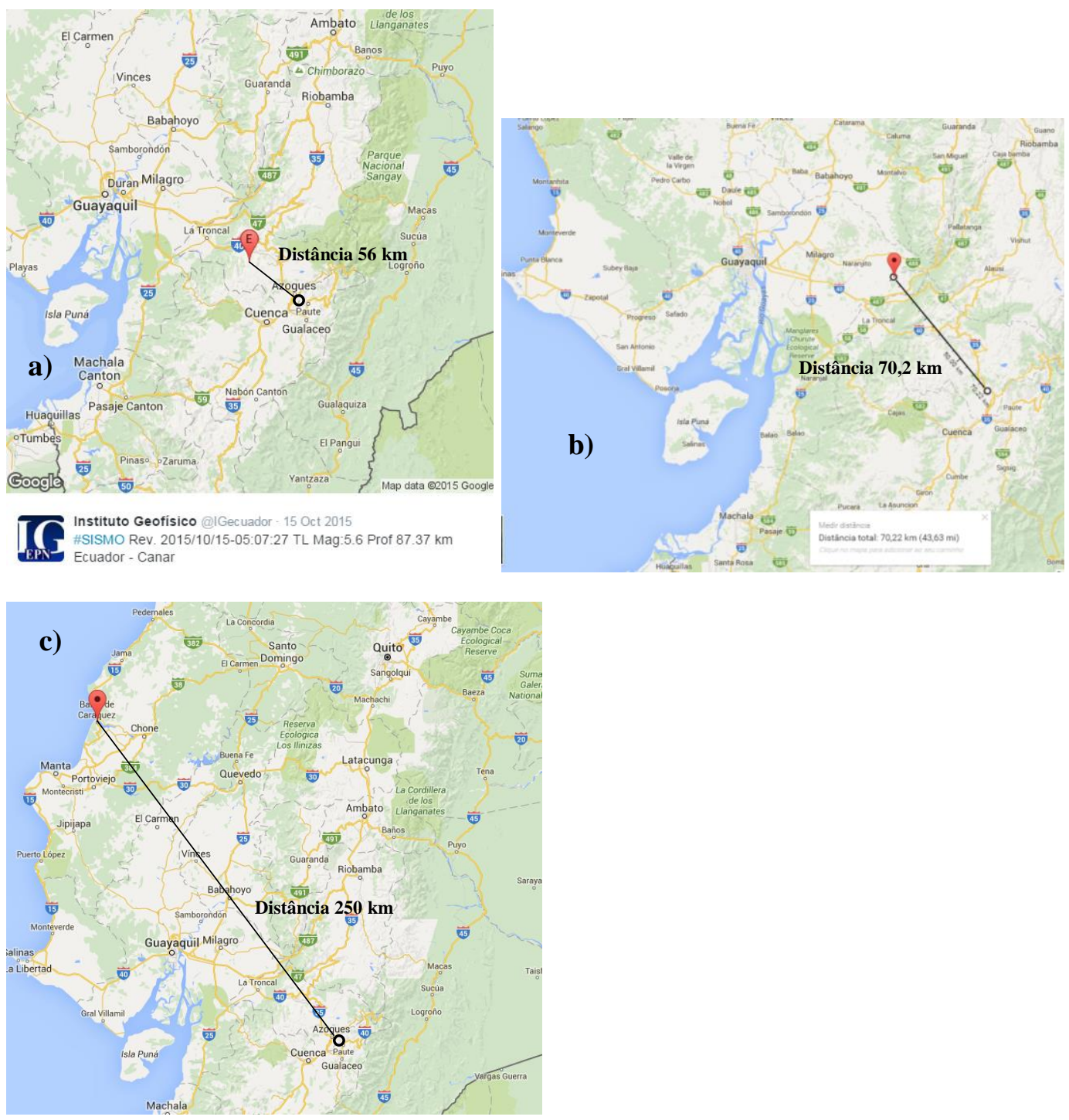

Figura 6.4 - Localização de epicentros dos sismos: a) cidade de La Troncal 15/11/2015; b) cidade de Bucay 25/03/2014; c) cidade de Bahia de Caraquez 4/08/1998 (Red Sísmica del Austro, Instituto Geofísico Ecuador).

As razões principais da escolha destes três sismos devem-se à proximidade do talude analisado (distâncias epicentrais de $56 \mathrm{~km}$ e $70 \mathrm{~km}$ para o primeiro e segundo sismo respectivamente) e pelo fato do terceiro sismo ser o segundo de maior magnitude já registrado no país. Como informação, o terremoto ocorrido no Equador em 16 de abril de 2016 na cidade costeira de Pedernales se constitui no maior evento sísmico registrado no Equador, com magnitude de momento $M_{w}=$ 7.8 , profundidade de $22 \mathrm{~km}$, produzindo PGA reportadas tão altas quanto $1,4 \mathrm{~g}$ nas 
proximidades do epicentro. Apesar das tentativas junto ao Instituto Geofísico do Ecuador, não foi possível obter os acelerogramas deste evento para inclusão neste trabalho.

A etapa seguinte foi definir os sismos de projeto a partir dos acelerogramas dos três sismos anteriormente citados. Neste procedimento, optou-se pelo ajuste espectral no domínio da frequência (Capítulo 5) realizado com o software SeismoMatch (SeismoSoft Ltd, 2014).

Como ilustrado na Figura 6.11 a uma profundidade de $15 \mathrm{~m}$ do pé do talude encontrou-se o estrato rochoso com velocidade de propagação da onda cisalhante $\left(V_{s}=1800 \mathrm{~m} / \mathrm{s}\right)$. Considerando a classificação do material de acordo com a Norma Equatoriana da Construção (NEC, 2014), (Tabela 5.1, Capítulo 5) trata-se de uma rocha competente do tipo A $\left(V_{s} \geq 1500 \mathrm{~m} / \mathrm{s}\right)$, com os atributos estabelecidos na Tabela 6.3 para construção do espectro de resposta elástico em acelerações, apresentado na Figura 6.5.

Tabela 6.3 - Parâmetros do terreno na região de estudo (NEC, 2014) utilizados para gerar o espectro de resposta.

\begin{tabular}{|c|c|l|}
\hline Parâmetro & valor & \multicolumn{1}{|c|}{ Descrição } \\
\hline$z$ & 0,25 & $\begin{array}{l}\text { Aceleração máxima na rocha para o sismo de projeto } \\
\text { segundo o mapa de zoneamento sísmico (Figura 5.2) }\end{array}$ \\
\hline$\eta$ & 2,48 & $\begin{array}{l}\text { Relação de amplificação espectral, para probabilidade } \\
\text { de excedência de 10\% em 50 anos (período de retorno } \\
475 \text { anos). Varia em função da região do país. }\end{array}$ \\
\hline Fa & 0,9 & $\begin{array}{l}\text { Coeficiente de amplificação do solo na zona } \\
\text { de períodos curtos (Tabela 5.2) }\end{array}$ \\
\hline Fd & 0,9 & $\begin{array}{l}\text { Coeficiente de amplificação espectral em } \\
\text { deslocamentos (Tabela 5.2) }\end{array}$ \\
\hline Fs & 0,75 & $\begin{array}{l}\text { Coeficiente de amplificação devido ao } \\
\text { comportamento não linear do solo (Tabela 5.2) }\end{array}$ \\
\hline
\end{tabular}




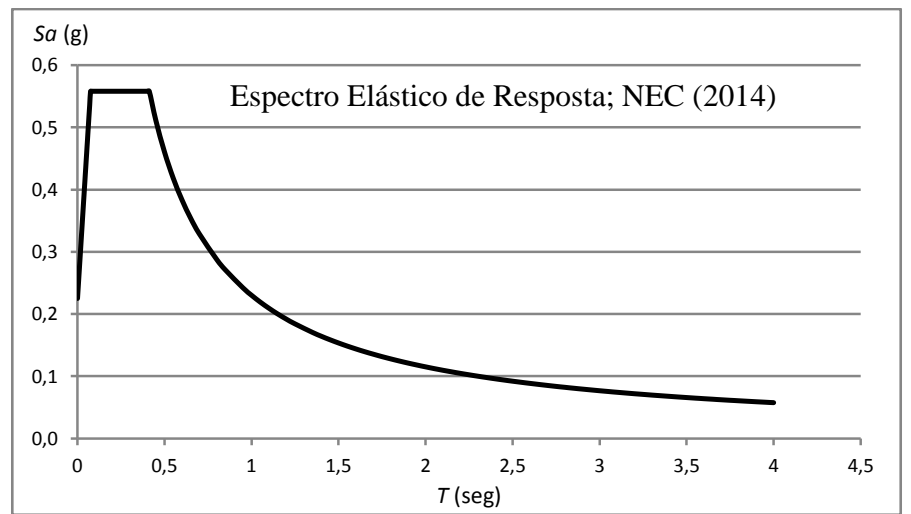

Figura 6.5 - Espectro elástico de resposta em acelerações de acordo com a Norma Equatoriana da Construção (NEC, 2014).

\subsubsection{1.}

\section{Ajuste ao espectro de acelerações}

Com a finalidade de se obter registros sísmicos em concordância com a aceleração de pico especificada na Norma Equatoriana da Construção (NEC 2014) para região do projeto $(\mathrm{PGA}=0,25 \mathrm{~g})$, determinada mediante estudo de ameaça sísmica para uma probabilidade de excedência de 10\% em 50 anos (tempo de recorrência 475 anos) considerado como sismo severo na NEC 2014 (indicado para este tipo de estruturas), os acelerogramas dos três sismos escolhidos foram normalizados em relação ao valor da aceleração PGA. Em seguida, foi realizado o ajuste do espectro elástico no domínio do tempo com o software SeismoMatch (SeismoSoft Ltd, 2013), obtendo-se os resultados mostrados nas Figuras 6.6 a 6.8.

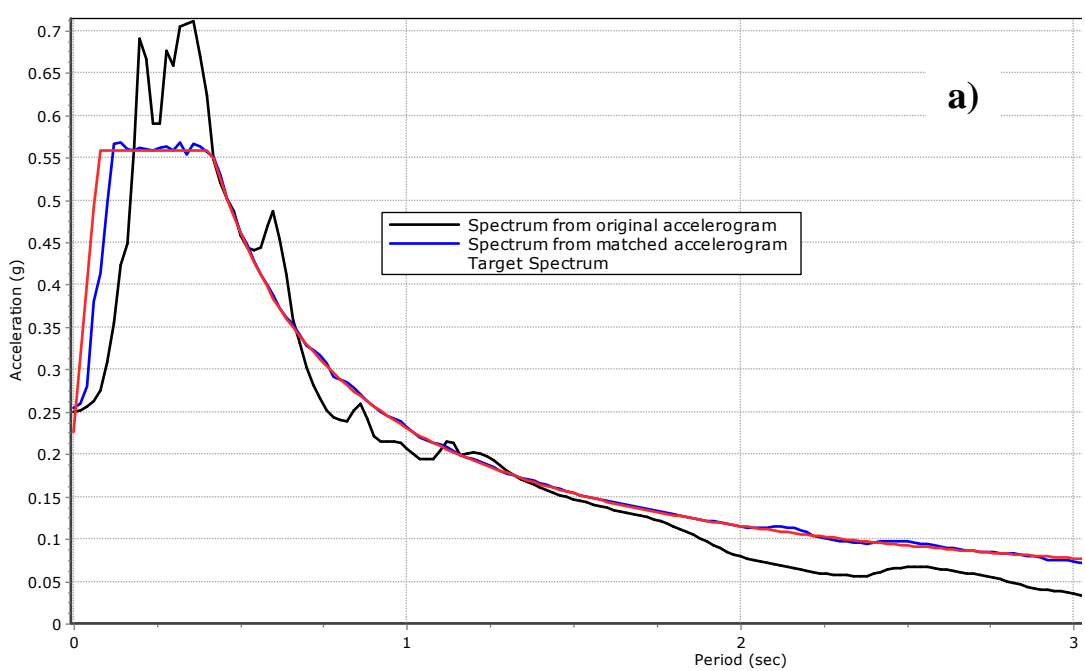




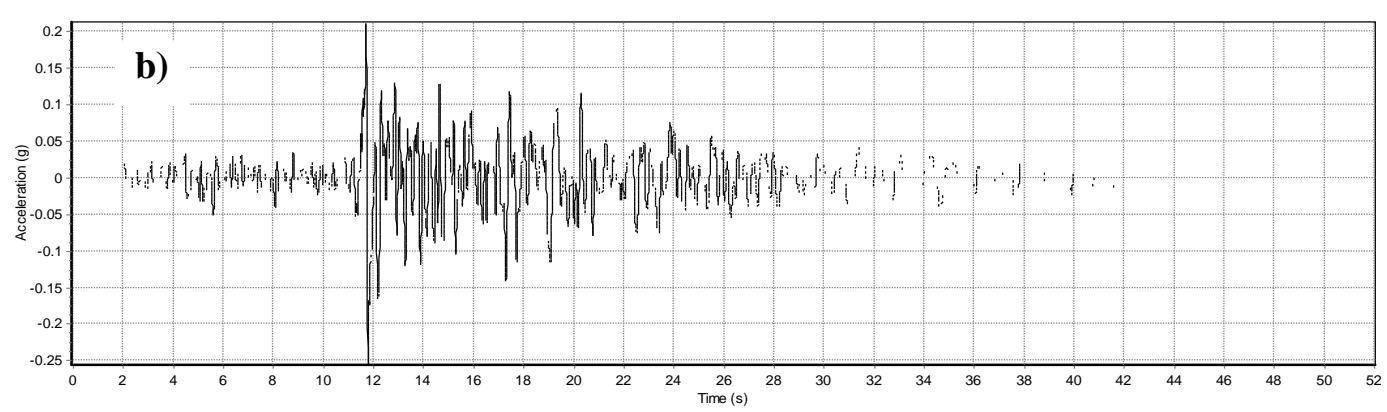

Figura 6.6 - Sismo de La Troncal: a) ajuste ao espectro elástico de resposta da norma NEC (2014); b) registro acelerográfico de projeto.

Observa-se que o espectro obtido com o acelerograma original encontra-se levemente acima da envoltória do espectro da norma NEC (2014), mas após a execução do ajuste espectral a concordância entre ambos os registros é aceitável.
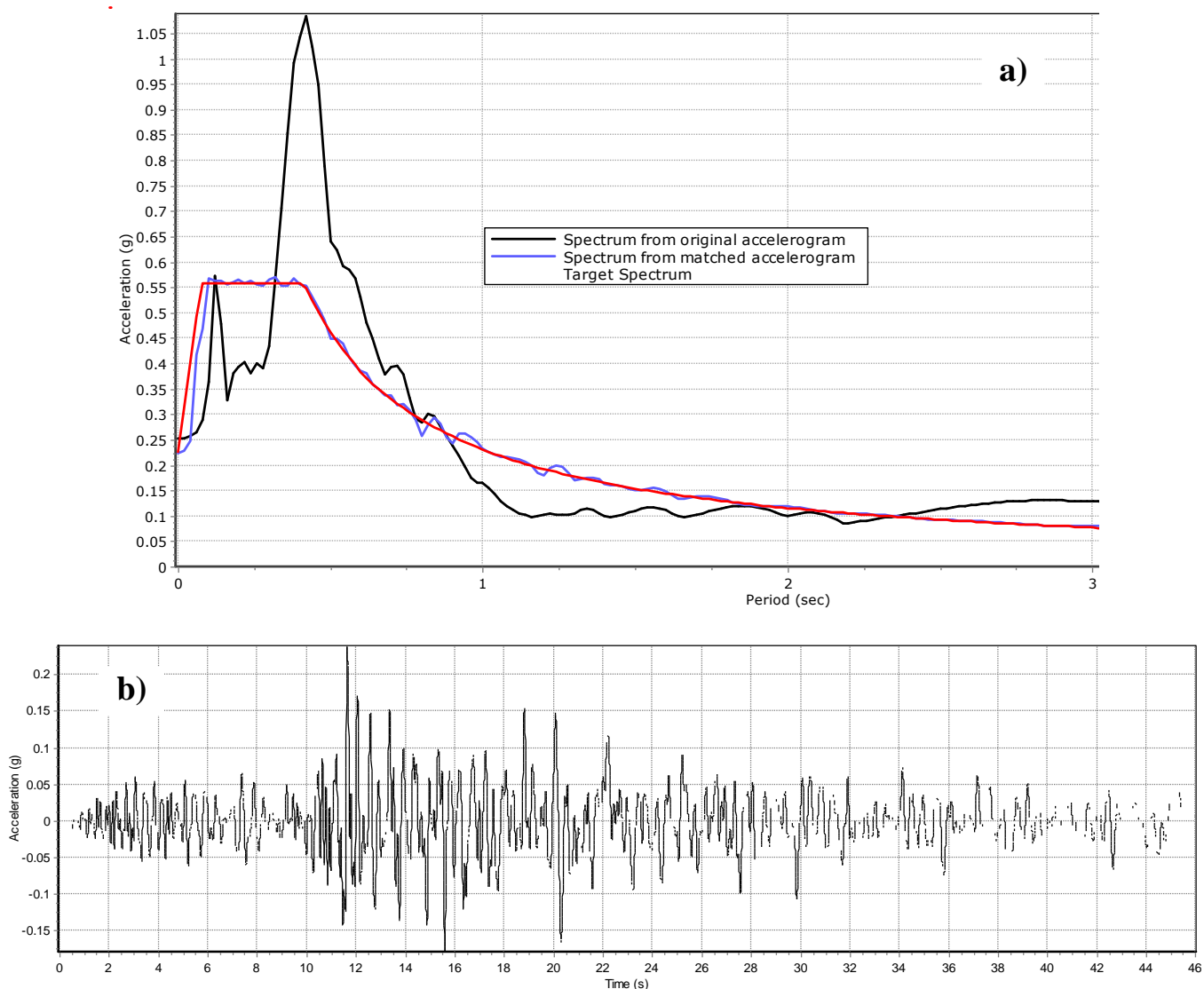

Figura 6.7 - Sismo de Bucay: a) ajuste ao espectro elástico de resposta da norma NEC (2014); b) registro acelerográfico de projeto.

Neste caso também se percebe que o acelerograma original apresenta uma distribuição de acelerações muito acima do espectro-alvo para períodos curtos. 

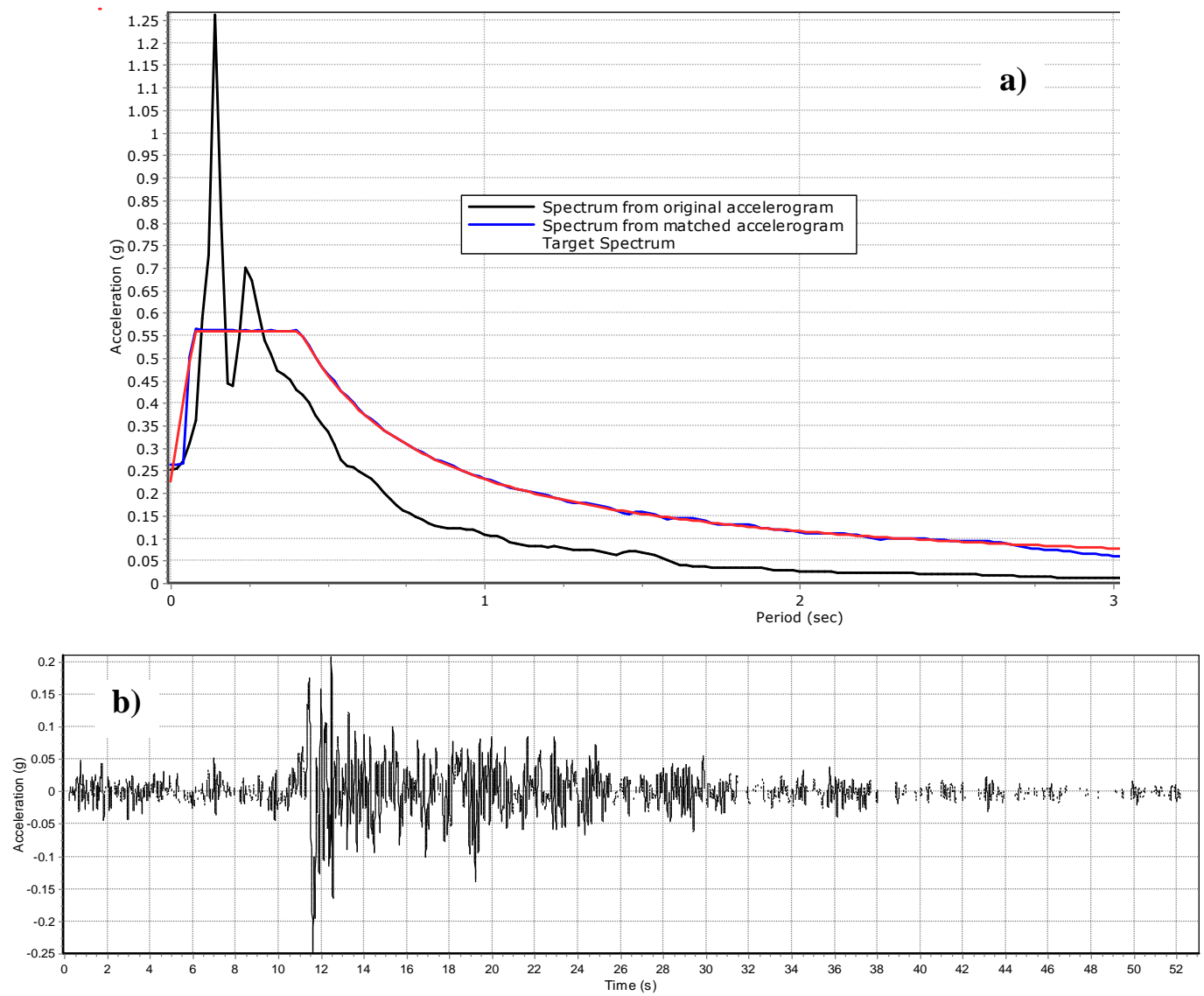

Figura 6.8 - Sismo de Bahia de Caraquez: a) ajuste ao espectro elástico de resposta da norma NEC (2014); b) registro acelerográfico de projeto.

Na Figura 6.8a também se observa que o acelerograma original apresenta uma distribuição de acelerações bastante acima da envoltória recomendada pela NEC (2014) para períodos curtos. O acelerograma ajustado (Figura 6.8b) mostra marcada predominância de altas frequências.

Considerando o espectro elástico de resposta (Figura 6.5) sugerido na Norma Equatoriana da Construção (NEC, 2014) para a região onde se localiza o talude deste estudo, e a maneira de uma verificação deste espectro, foi gerado um acelerograma artificial com auxílio do programa SeismoArtif (SeismoSoft, 2016) incluindo uma razão de amortecimento do material de 5\%. A Figura 6.9 mostra o ajuste em relação ao espectro de acelerações da Norma Equatoriana de Construção e a respectiva história de acelerações para o sismo artificial (sismo 1). 


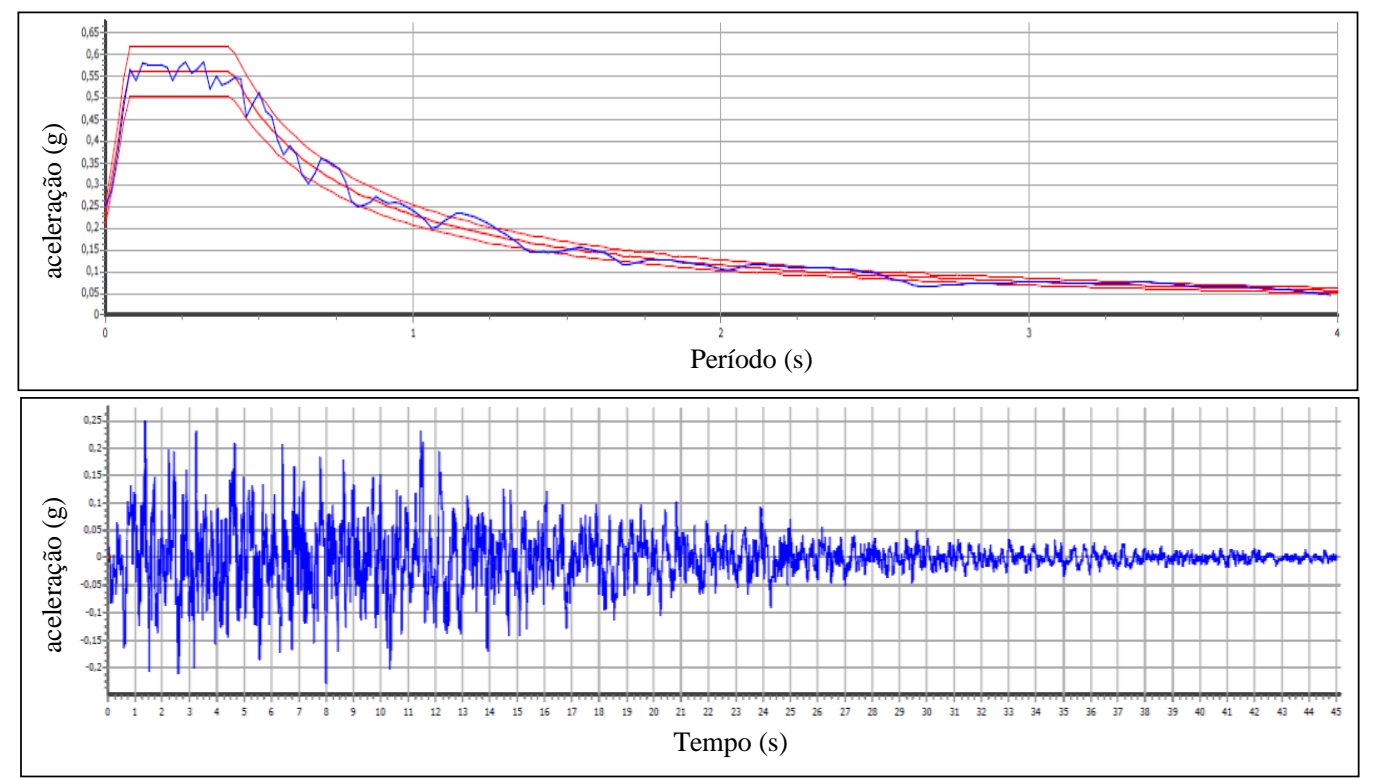

Figura 6.9 - Ajuste ao espectro elástico da norma NEC (2014) e história de acelerações sismo artificial sismo 1.

Observa-se da Figura 6.9 que em função do espectro da norma NEC-2014, com maior distribuição de acelerações em períodos curtos, foi gerada uma historia de aceleração com conteúdos de alta frequência. A duração significativa para este sismo artificial situa-se na faixa $\mathrm{D}_{5-95}$ de 22 a 23 segundos; da mesma forma, a PGA é semelhante com os sismos de projeto com valor de $0,25 \mathrm{~g}$.

\subsubsection{2.}

\section{Filtragem de frequências e correção da linha base}

Para os sismos de projeto procedeu-se a filtragem de altas e baixas frequências e correções de desvio da linha base, utilizando o software de processamento de sinais sísmicas SeismoSignal (SeismoSoft Ltd, 2016).

Para os três sismos de projeto (La Troncal, Bucay e Bahia de Caraquez) foi aplicada a filtragem das frequências contidas nos respectivos sinais, utilizando um filtro tipo Butterworth com limites de $0,1 \mathrm{~Hz}$ e $12 \mathrm{~Hz}$ para baixas e altas frequências, respetivamente, enquanto que para a correção da linha base foi utilizado um polinômio de terceira ordem. A Figura 6.10 mostra os acelerogramas finais obtidos com as correções. 

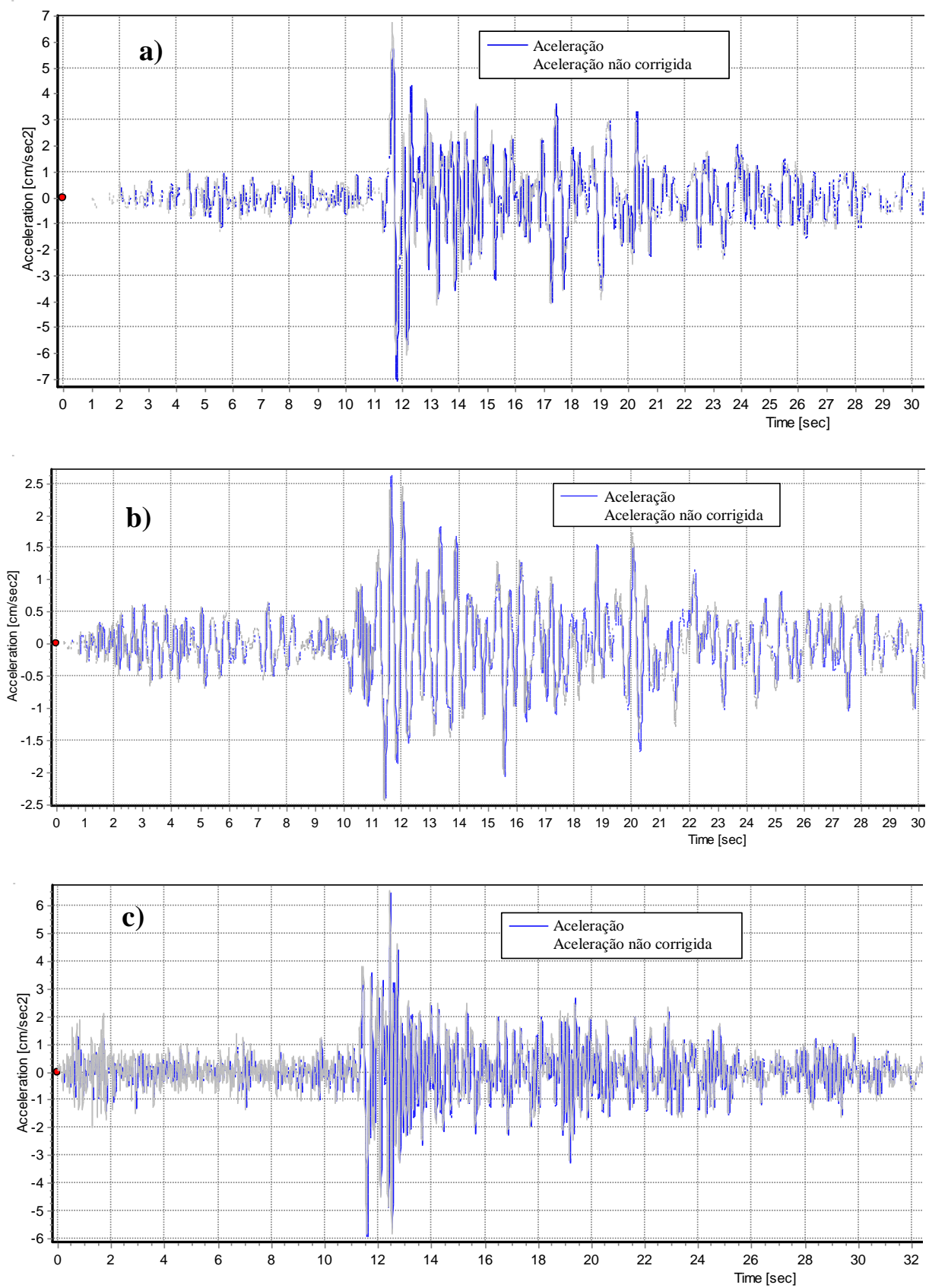

Figura 6.10 - Comparação dos acelerogramas após filtragem de frequências e correção da linha base no intervalo inicial dos registros de 0 a 30 segundos: a) sismo de La Troncal; b) sismo de Bucay; c) sismo de Bahia de Caraquez.

Na Figura 6.10 o intervalo de tempo mostrado (0 a 30 s) é o trecho do registro onde se concentra a maior intensidade do terremoto para todos os sismos. Observa-se que o terremoto de Bahia de Caraquez apresenta o maior conteúdo de altas frequências em comparação com os dois outros terremotos de projeto. Da mesma forma o registro correspondente a terremoto de Bucay apresenta períodos mais longos do que os outros 2 sismos considerados no presente estudo. Cabe aclarar que na Figura 6.10 unicamente mostra-se este intervalo de tempo ( 0 a $30 \mathrm{~s}$ ) 
dos registros sísmicos devido à escala do gráfico, sendo que com a finalidade de evitar perdas da potencia dos terremotos não se efetuaram cortes nos registros sísmicos.

Em quanto à energia dos terremotos, a Tabela 6.4 estabelece um comparativo deste parâmetro para cada um dos sismos de projeto. Aprecia-se que a Intensidade de Arias $\left(I_{a}\right)$ para os sismos de Bahia de Caraquez e La Troncal apresenta valores similares, enquanto que para o terremoto de Bucay o valor da $I_{a}$ é marcadamente superior, isto se explica na forma de determinação da intensidade de Arias, já que a $I_{a}$ considera o acelerograma inteiro do terremoto (equação 6.1).

$$
I_{a}=\frac{\pi}{2 g} \int_{0}^{\infty}[a(t)]^{2} d t
$$

Onde $a(t)$ é a historia completa de acelerações no tempo para cada terremoto.

Devido à integração ser executada na totalidade da historia de acelerações (duração total do terremoto) os múltiplos picos de aceleração com amplitude considerável que apresenta o terremoto de Bucay (Figura 6.10b) em comparação com os outros sismos de projeto tem evidente influência no maior valor determinado da intensidade de Arias $\left(I_{a}\right)$ para este sismo de projeto.

Da Tabela 6.4 observa-se também que para o outro parâmetro de energia adotado (intensidade característica $I_{c}$ ) os valores para os três sismos de projeto apresentam maior similitude desde parâmetro. Isto se explica na forma em que $I_{c}$ é determinada (equação 6.2).

$$
I_{c}=a_{r m s}^{1,5} T_{d}^{0,5}
$$

Onde, $T_{d}$ é a duração significativa do terremoto (geralmente determinada mediante $\mathrm{D}_{5-95}$ ) e a aceleração $a_{r m s}$ é determinada mediante a seguinte equação:

$$
a_{r m s}=\sqrt{\frac{1}{T_{d}} \int_{0}^{T_{d}}[a(t)]^{2} d t}
$$


Segundo Kramer (1996) devido a que a integral na equação 6.3 não é fortemente influenciada por grandes acelerações de alta frequência (que ocorrem unicamente sob um pequeno período de tempo) e devido a que é influenciada sim pela duração significativa do movimento do terreno, a aceleração $a_{r m s}$ pode ser de muita utilidade para propósitos da engenharia. Seu valor, por outra parte, recebe influência do método utilizado para determinar a duração significativa do terremoto. No caso dos três sismos de projeto utilizados a duração significativa apresenta valores similares $\left(D_{5-95 \%} \approx 25 \mathrm{~s}\right)$, razão pela qual a intensidade característica $I_{c}$ exibe maior proximidade no seu valor entre todos os terremotos.

Tabela 6.4 - Sismos de projeto, Intensidade de Arias $\left(I_{a}\right)$, intensidade característica $\left(I_{c}\right)$.

\begin{tabular}{|lcc|}
\hline Sismo de projeto & Intensidade Arias $I_{a}(\mathrm{~m} / \mathrm{s})$ & Intensidade característica $\left(I_{\mathrm{c}}\right)$ \\
\hline Bahia de Caraquez & 0,70 & 0,035 \\
Bucay & 1,16 & 0,050 \\
La Troncal & 0,74 & 0,038 \\
\hline
\end{tabular}

\subsection{3.}

\section{Tamanho máximo do elemento na malha}

Considerando um limite superior de frequência (cutoff frequency) que contenha no mínimo $99 \%$ da energia do terremoto, determinou-se para os três sismos de projeto a frequência de corte $f_{c}=12 \mathrm{~Hz}$ com base nos espectros de potência (Figura 6.11) obtidos com os registros de aceleração dos diferentes sismos considerados neste trabalho.

Uma vez estimada a frequência de corte, e utilizando as velocidades de propagação da onda cisalhante $V_{s}$ nos diferentes materiais (Tabela 6.1), determinou-se o máximo comprimento do elemento na direção vertical de propagação das ondas. Dos materiais presentes nesta análise o de menor velocidade de propagação de onda $\mathrm{S}$ é o solo coluvial com $V_{s}=430 \mathrm{~m} / \mathrm{s}$. Com base na recomendação de Kuhlemeyer e Lysmer (1973), com o objetivo de reduzir tempos computacionais, foram considerados para o modelo numérico elementos de tamanho máximo de $2 \mathrm{~m}$, que corresponde à máxima frequência provável de transmissão $f_{\text {max }}$ :

$$
f_{\max }=\frac{V_{S}}{10 \Delta_{l}}=21 \mathrm{~Hz}
$$

Valor superior ao da frequência de corte estabelecido anteriormente. 

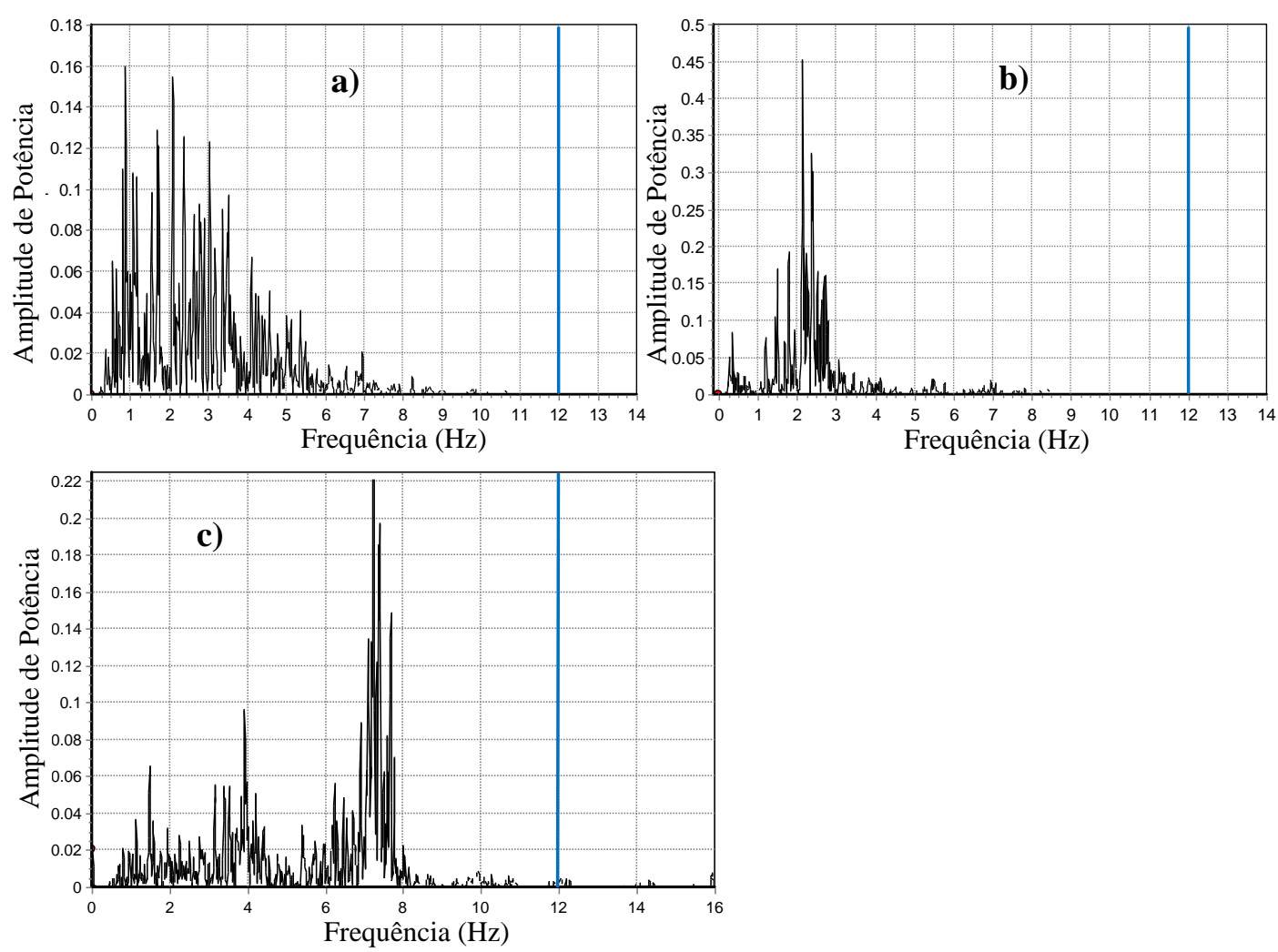

Figura 6.11 - Frequências de corte $\left(f_{c}=12 \mathrm{~Hz}\right)$ estimadas a partir dos espectros de potência: a) sismo de La Troncal; b) sismo de Bucay; c) sismo de Bahia de Caraquez.

\subsection{4.}

\section{Analise estática da estabilidade do talude}

Antes do estudo da resposta dinâmica do talude é necessário verificar a estabilidade na condição de carregamento estático.

O modelo numérico bidimensional de diferenças finitas que será utilizado em todas as análises deste capítulo possui $325 \mathrm{~m}$ de comprimento e $112 \mathrm{~m}$ de altura, conforme Figura 6.13. Sobrejacente ao substrato rochoso, representado com $5 \mathrm{~m}$ de espessura encontra-se uma camada de areia siltosa com espessura aproximada de $25 \mathrm{~m}$, e acima desta o solo coluvial que forma o talude (Figura 6.12).

Levando em conta o critério de tamanho máximo do elemento, a discretização é formada por 10500 elementos quadrangulares, ilustrada na Figura 6.13. As condições de contorno estáticas foram de restrição de deslocamento na base em ambas as direções e impedimento do deslocamento horizontal nos contornos laterais. 


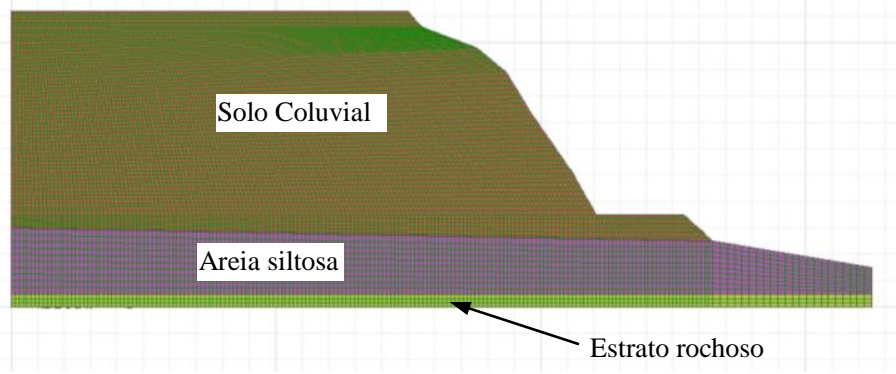

Figura 6.12 - Estratos de solo presentes na análise de estabilidade do talude.

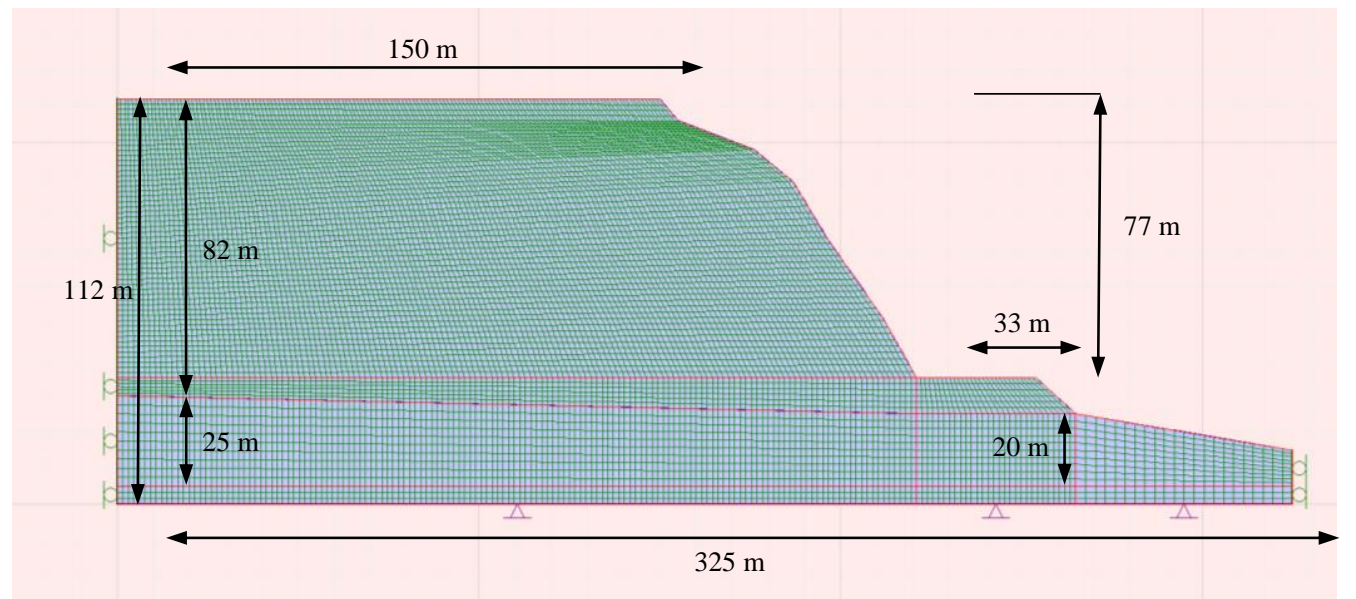

Figura 6.13 - Malha de diferenças finitas e condições de contorno para a análise estática.

\subsubsection{1.}

\section{Fator de segurança estático}

Para determinação do fator de segurança estático foram utilizados os programas computacionais Flac 2D, que utiliza o método de redução dos parâmetros de resistência considerando as relações tensão x deformação dos materiais, e Slide 6.0 (Rocscience, 2010), baseado no método de equilíbrio limite (método das fatias) que simula os materiais como rígido-perfeitamente plásticos.

A vantagem de utilizar um método numérico (Flac 2D) na determinação do fator de segurança vem do fato que as potenciais superfícies de deslizamento não precisam ser previamente definidas, pois são determinadas durante o processo de solução. É importante verificar a consistência dos resultados obtidos, uma vez que os resultados podem se referir a colapsos locais principalmente no caso de taludes com existência de bermas. No presente estudo, sempre que rupturas consideradas locais ou de falhamento superficial foram observadas optou-se por incrementar o valor da coesão $\left(c=1 \times 10^{6} \mathrm{~Pa}\right)$ dos materiais contidos nos elementos afetados pela ruptura. 
Na Figura 6.14 constata-se uma boa concordância na posição das superfícies locais de deslizamento obtidas mediante a técnica de redução dos parâmetros de resistência (Flac 2D v7) e o método das fatias de Spencer (Slide 6.0), com fatores de segurança contra ruptura estática calculados respectivamente como $\mathrm{FS}=0,94 \mathrm{e}$ $\mathrm{FS}=1,02$.

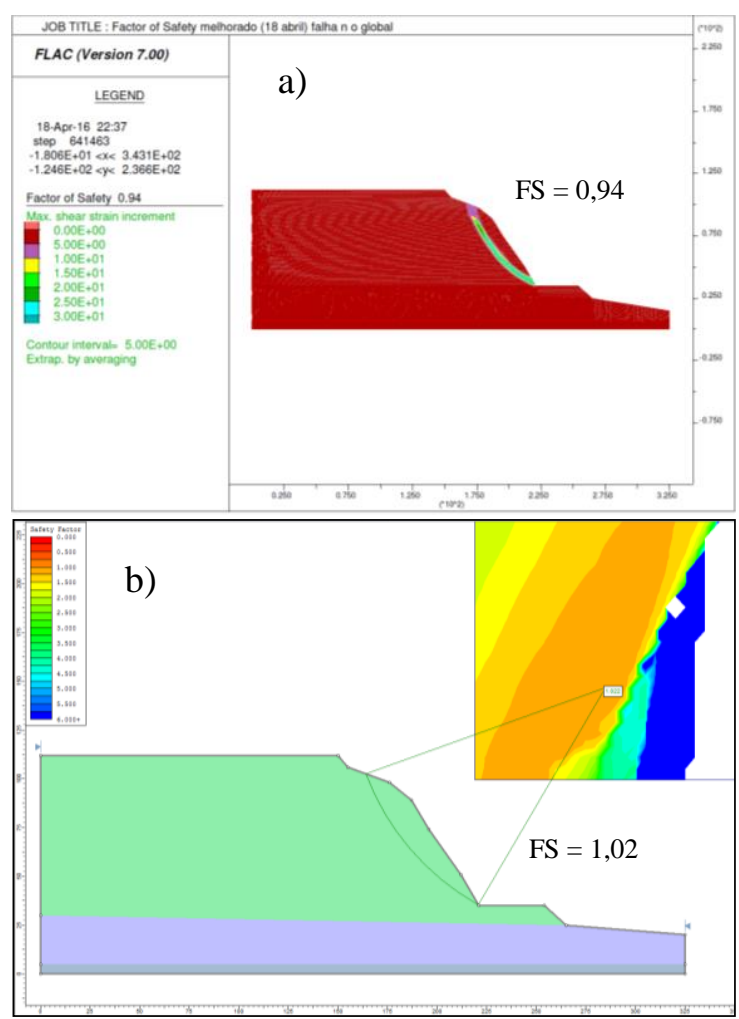

Figura 6.14 - Fator de segurança estático em potenciais superfícies locais de ruptura: a) método de redução dos parâmetros de resistência (Flac 2D) $F S=0,94 ; b)$ método das fatias de Spencer (Slide 6.0) FS = 1,02.

Com base nestes resultados, é evidente a necessidade de um mecanismo de estabilização para a estrutura contra a ocorrência de rupturas superficiais. Segundo a empresa consultora do projeto (CAMINOSCA S.A.) a utilização de ancoragem (rockbolts) na massa superficial instável constitui-se na solução mais conveniente, que atualmente esta sendo executada ao longo dos taludes da estrada federal E35.

A Figura 6.15a ilustra o projeto de estabilização em uma seção típica do talude com utilização de ancoragens com diâmetro de 2,54 cm, espaçamento de 1,0 m e profundidade de penetração variável. A malha metálica colocada na superfície do talude (Figura 6.15b) tem a finalidade de prevenir desprendimentos menores que possam causar acidentes na estrada, não sendo concebida para funcionar como um elemento estrutural de suporte. 

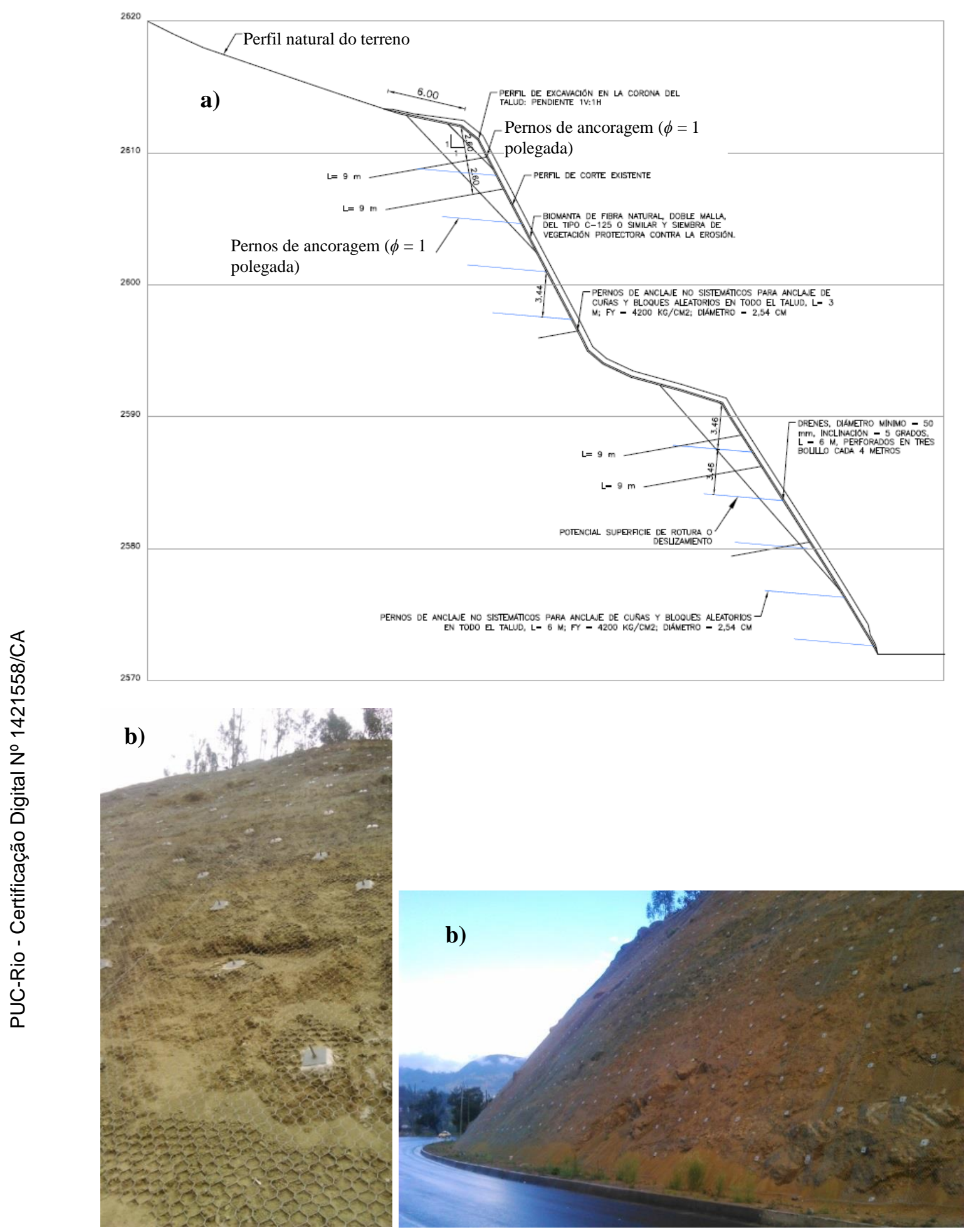

Figura 6.15 - Estudo de estabilidade na abscissa 4+990: a) seção típica de reforço estrutural; b) ancoragens executadas no talude (Caminosca S.A.).

Nos softwares Flac 2D v7 e Slide 6.0 as estruturas de ancoragem foram modeladas como rockbolts como diâmetro de 1,0 polegada, tensão admissível de 2,1E6 Pa e espaçamento fora do plano de 1,0 m. 
Adotando estas medidas de estabilização da geoestrutura, foram determinados os coeficientes de segurança contra a ruptura global do talude na Figura 6.16, obtendo-se os valores FS = 1,16 (método da redução dos parâmetros de resistência), FS = 1,4 (método das fatias considerando superfície de ruptura circular) e FS = 1,2 (método das fatias considerando superfície de ruptura planar). De acordo com Hynes-Griffin e Franklin (1984) uma análise pseudo-estática é recomendada caso o fator de segurança estático seja inferior a 1,7, o que é o caso do presente talude.
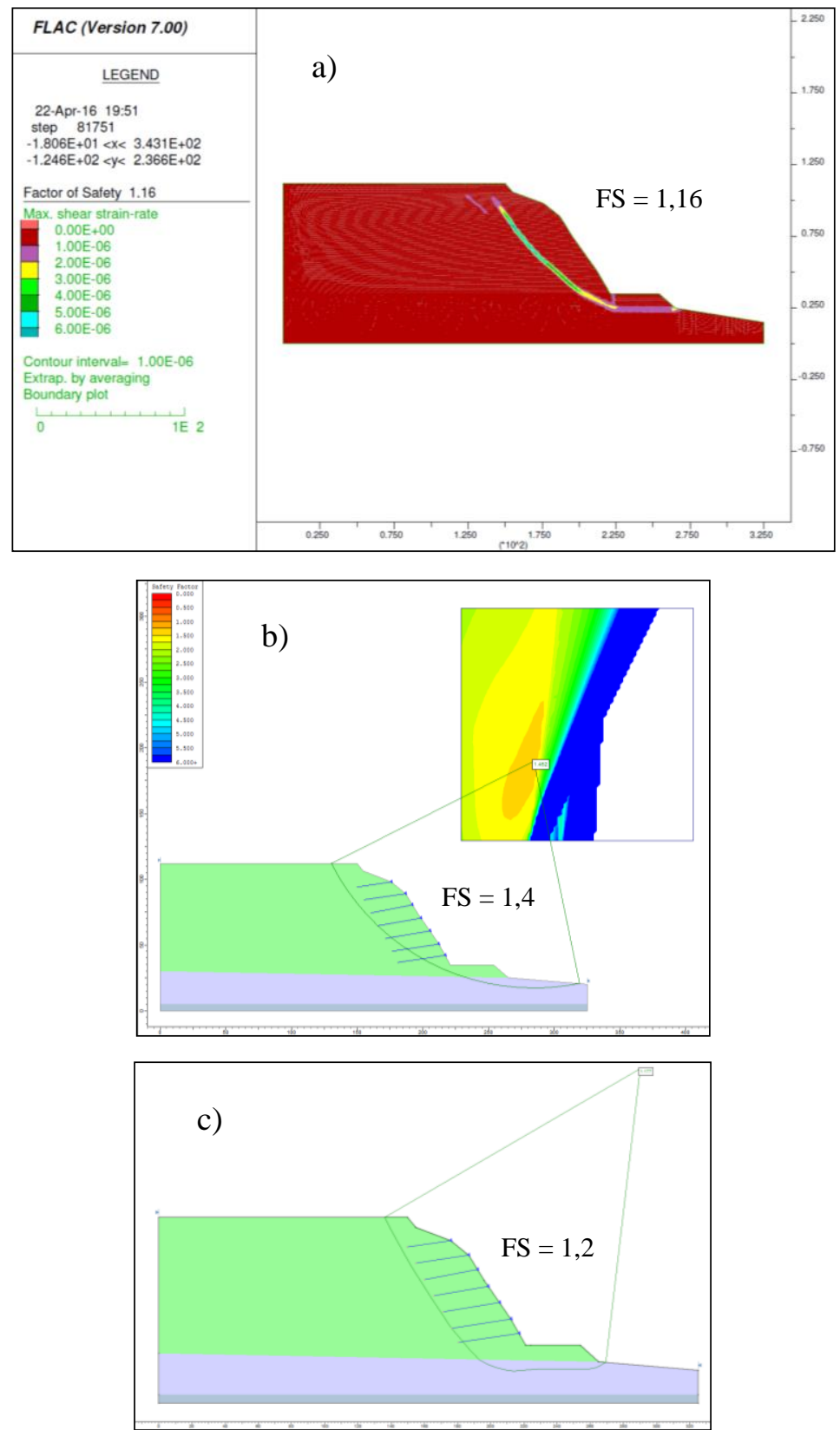

Figura 6.16 - Fator de segurança talude com reforço: a) método de redução da resistência FS = 1,16 b) equilíbrio limite com superfície de ruptura circular $F S=1,4$. c) equilíbrio limite com superfície de ruptura poligonal FS = 1,2. 


\subsection{5.}

\section{Análise de estabilidade pseudo-estática}

Diversas são as referências bibliográficas quanto ao valor do coeficiente sísmico horizontal $k_{h}$ a ser incluído nas análises pseudo-estáticas de estabilidade de taludes, mas no presente trabalho foi adotada a recomendação de Hynes-Griffin \& Franklin (1984) que considera um valor equivalente a $50 \%$ da máxima aceleração horizontal em rocha $\left(\mathrm{PHA}_{\mathrm{rock}}\right)$, normalizada em relação à aceleração da gravidade.

De acordo com o estudo de ameaça sísmica na região do projeto, a aceleração de pico $\mathrm{PGA}_{\text {rock }}=0,25 \mathrm{~g}$ resulta portanto em um coeficiente sísmico horizontal $k_{h}=0,12$.

Na Figura 6.17 apresentam-se os fatores de segurança pseudo-estático do talude, calculados por método de equilíbrio limite (software Slide 6.0), considerando os métodos de equilíbrio limite de Bishop Simplificado e de Spencer. Estes resultados são também comparados com o fator de segurança pseudo-estático determinado pelo programa computacional Flac 2D, com base no método da redução dos parâmetros de resistência de Mohr-Coulomb (Figura $6.18)$.

Um resumo dos fatores de segurança na condição pseudo-estática é apresentado na Tabela 6.5 , de onde se observa boa concordância entre os resultados computados.
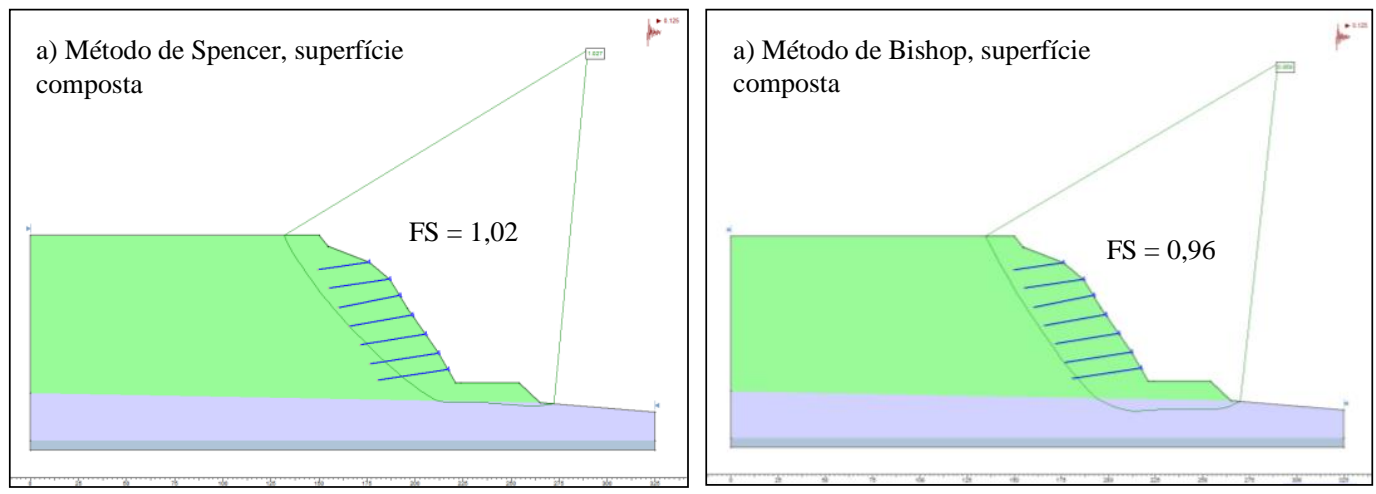

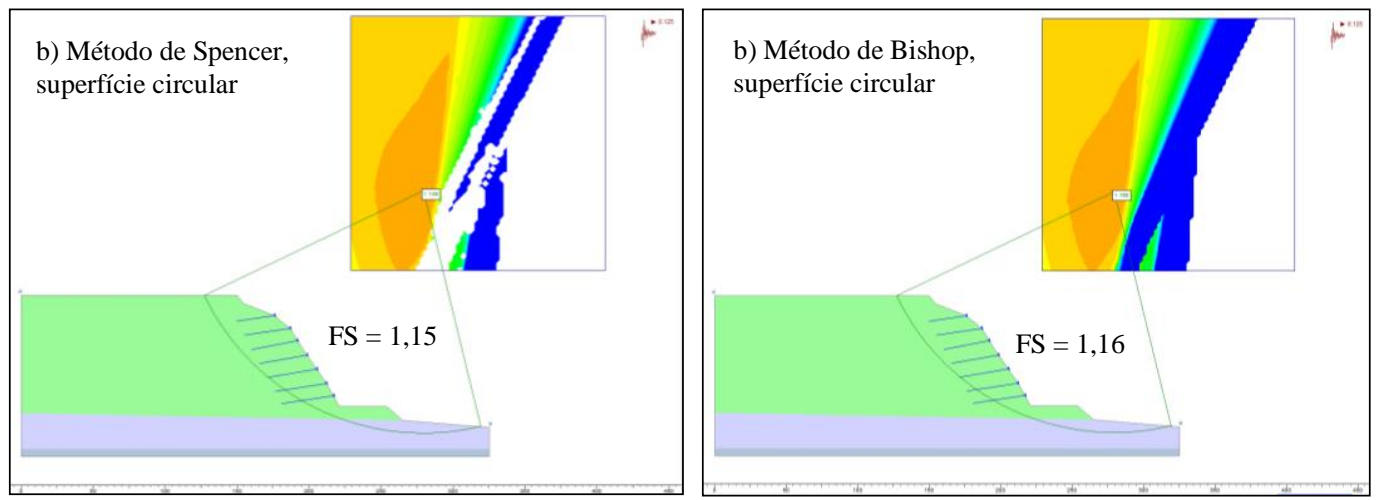

Figura 6.17 - Fator de segurança pseudo-estático talude com reforço estrutural pelos métodos de equilíbrio limite (Slide 6.0) de Spencer e Bishop simplificado considerando: a) superfície planar; b) superfície circular.

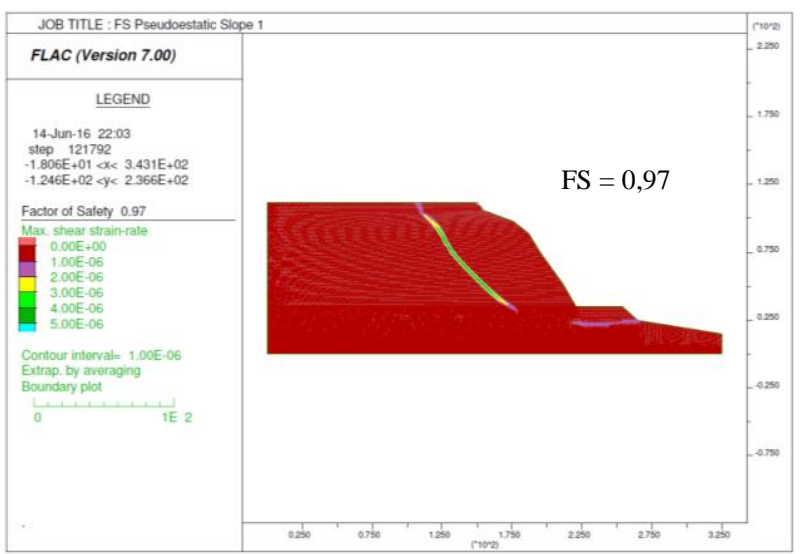

Figura 6.18 - Fator de segurança pseudo-estático do talude com reforço estrutural pelo método de redução dos parâmetros de resistência (Flac 2D v 7.0).

Tabela 6.5 - Fatores de segurança determinados nas análises pseudo-estáticas do talude utilizando estruturas de reforço.

\begin{tabular}{|l|l|l|c|}
\hline \multicolumn{2}{|c|}{ Método } & FS pseudo-estático \\
\hline \multirow{2}{*}{ Equilíbrio Limite } & \multirow{2}{*}{ Superfície de falha planar } & Spencer & 1,02 \\
\cline { 3 - 4 } & & Bishop simplificado & 0,96 \\
\hline \multirow{2}{*}{ Equilíbrio Limite } & \multirow{2}{*}{ Superfície de falha circular } & Spencer & 1,15 \\
\cline { 3 - 4 } & & Bishop simplificado & 1,16 \\
\hline Redução dos parâmetros de resistência do solo & Flac v7.0 & 0,97 \\
\hline
\end{tabular}

Conclui-se que o fator de segurança pseudo-estático encontra-se na maioria dos casos analisados abaixo do valor mínimo recomendado $\left(\mathrm{FS}_{\text {pseudo-estático }}=1,1\right)$, o que pode induzir deslocamentos permanentes que comprometam a servicibilidade do talude. Neste caso, a análise do comportamento do talude carregado por excitação sísmica deve prosseguir considerando uma análise dinâmica, por método analítico simplificado ou método numérico. 


\subsection{6. \\ Métodos simplificados para estimativa de deslocamentos permanentes}

Conforme abordado no Capítulo 3, a aceleração de escoamento $a_{\mathrm{y}}$ é necessária para a estimativa de deslocamentos permanentes nos métodos simplificados de Newmark (1965), Bray e Travasarou (2007) e Rathje e Saygili (2011), tendo sido determinada com base no coeficiente sísmico horizontal $k_{y}$ que provoca um fator de segurança pseudo-estático $\mathrm{FS}_{\text {pseudo-estático }}=1$, resultando no valor $a_{\mathrm{y}}=k_{y} \mathrm{~g}=0,12 \mathrm{~g}$.

\subsubsection{1.}

\section{Método simplificado de Newmark}

O método de Newmark (1965) baseado na analogia do bloco rígido deslizante sobre plano inclinado utiliza a história de acelerações para estimar os deslocamentos permanentes mediante a dupla integração no tempo deste registro sempre que as amplitudes superarem o valor da aceleração de escoamento $\left(a_{\mathrm{y}}\right)$.

Para o talude analisado, a distribuição das acelerações ao longo da potencial superfície de ruptura foram calculadas com o programa de propagação de ondas 1D SHAKE2000 (Ordõnez, 2015). Como tentativa de aproximação dos efeitos da amplificação topográfica ( de solo foi subdividida em várias colunas (Figura 6.19), de diferentes alturas, admitindo em cada uma delas a propagação 1D de ondas de cisalhamento.

Com base neste conjunto de acelerações, os deslocamentos permanentes do talude foram obtidos mediante o método de Newmark convencional. Os valores computados estão mostrados na Tabela 6.6 e na Figura 6.20.

O registro sísmico artificial apresenta marcada diferença na distribuição de acelerações no tempo (amplitudes das acelerações) em comparação com os sismos de projeto inicialmente utilizados, por esta razão é interessante se avaliar os efeitos na estimativa dos deslocamentos permanentes mediante métodos simplificados. Para isto, foram utilizados os mesmos parâmetros do movimento das análises anteriores com os sismos de projeto; de forma análoga, três colunas de solo foram estudadas com o programa SHAKE2000 e modelo linear equivalente (Figura 6.19). O deslocamento permanente calculado esta indicado na Figura 6.20d e na Tabela 6.6. 


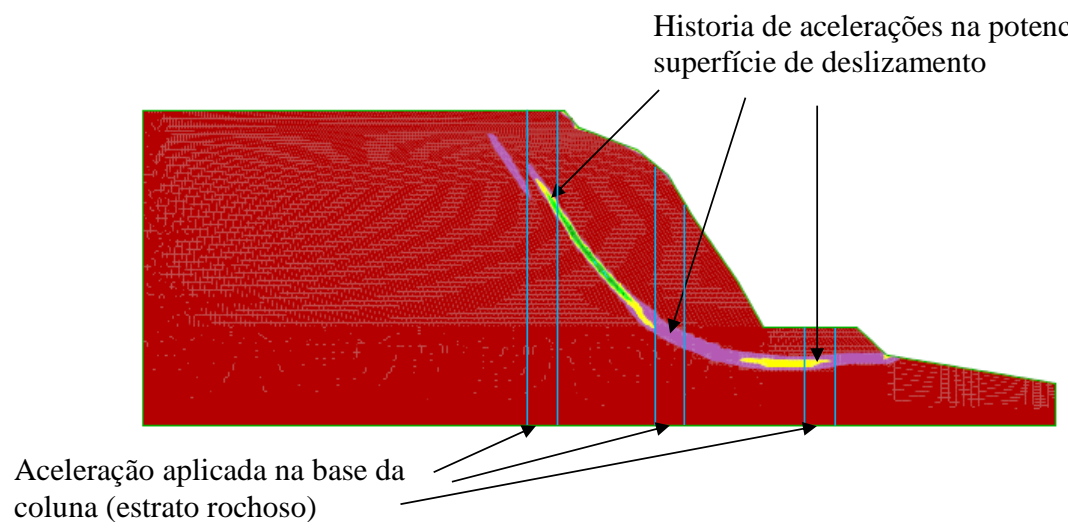

Figura 6.19 - Colunas de solo para estimativa da história de acelerações em pontos da potencial superfície de deslizamento determinada na análise de estabilidade pseudo-estática.

Tabela 6.6 - Deslocamentos permanentes estimados pelo método de Newmark (1965) com o programa computacional SHAKE 2000.

\begin{tabular}{|l|c|c|}
\hline \multicolumn{1}{|c|}{ Sismo de projeto } & $\begin{array}{c}a_{\mathrm{y}} \\
(\mathrm{g})\end{array}$ & $\begin{array}{c}\text { Deslocamento permanente } \\
(\mathrm{cm})\end{array}$ \\
\hline Bahia de Caraquez & 0,12 & 7,0 \\
Bucay & 0,12 & 5,4 \\
La Troncal & 0,12 & 3,8 \\
sismo 1 & 0,12 & 5,0 \\
\hline
\end{tabular}
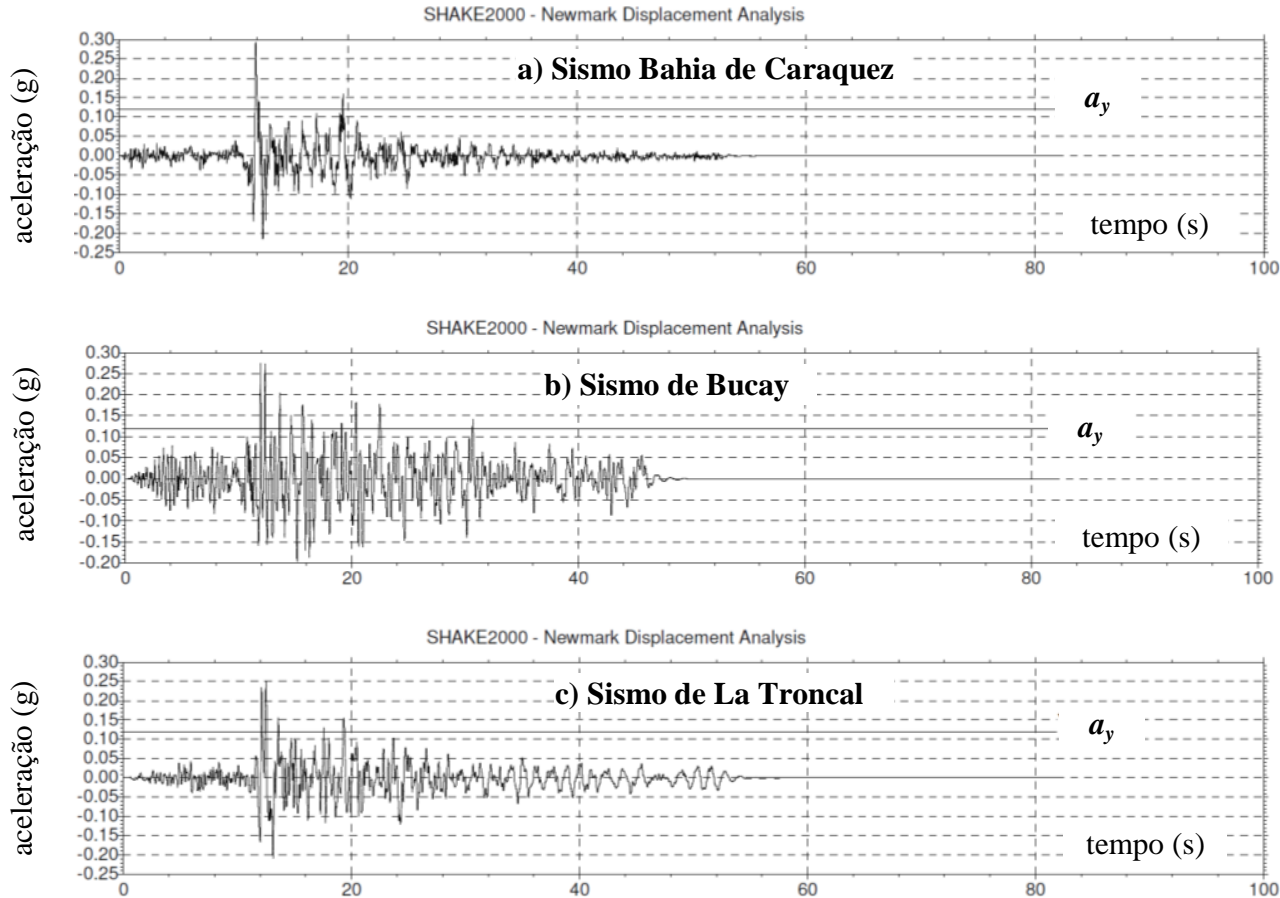


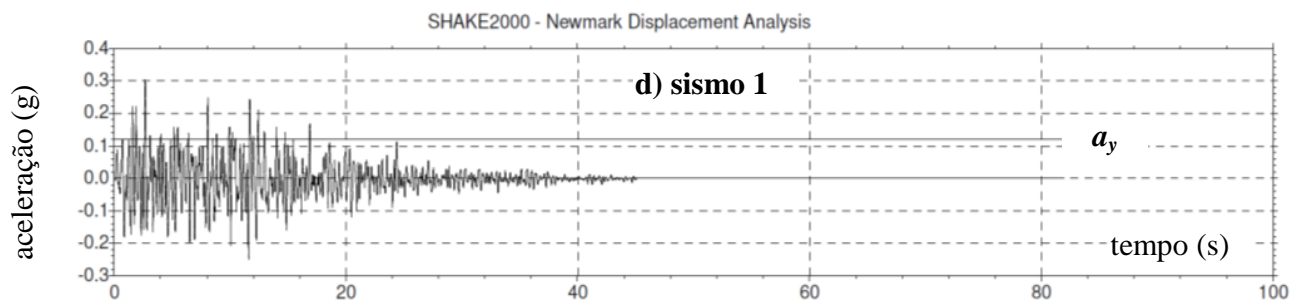

Figura 6.20 - Deslocamentos permanentes pelo método de Newmark (1965) considerando os sismos de projeto: a) Bahia de Caraquez; b) Bucay; c) La Troncal; d) sismo 1.

Observa-se que para todos os sismos de projeto assim como para o registro artificial (sismo 1) o método de Newmark resulta em deslocamentos permanentes pequenos que, na prática da engenharia, poderiam ser considerados desprezíveis. A história de acelerações registrada em pontos situados ao longo da superfície de deslizamento causada pelo registro sísmico de Bahia de Caraquez produziu um valor de deslocamento permanente $(\mathrm{D}=7,0 \mathrm{~cm})$ consideravelmente maior do que os resultados correspondentes estimados para os outros três sismos. Isto pode ser explicado quando se observa que no instante de tempo $t=12 \mathrm{~s}$ existe um aumento brusco da aceleração até um valor próximo de $0,30 \mathrm{~g}$, conforme Figura 6.20a, ultrapassando fortemente a aceleração de escoamento $a_{y}=0,12 \mathrm{~g}$.

Para verificação dos resultados obtidos, foi utilizado o programa computacional Slide v7.0 (Rockscience, 2016) para estimativa dos deslocamentos permanentes, listados na Tabela 6.7 e ilustrado na Figura 6.21.

Tabela 6.7 - Deslocamentos máximos permanentes pelo método de Newmark calculados pelo programa computacional Slide $\mathbf{v} 7.0$.

\begin{tabular}{|lcc|}
\hline Sismo de Projeto & $\begin{array}{c}a_{y} \\
(\mathrm{~g})\end{array}$ & $\begin{array}{c}\text { Deslocamento máximo } \\
(\mathrm{cm})\end{array}$ \\
\hline Bahia de Caraquez & 0,12 & 5,5 \\
Bucay & 0,12 & 4,9 \\
La Troncal & 0,12 & 2,3 \\
\hline
\end{tabular}

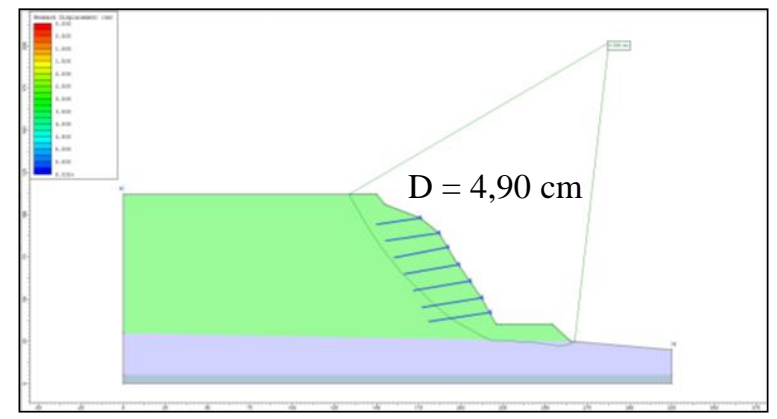

Figura 6.21 - Deslocamento permanente pelo método de Newmark para o sismo de Bucay estimado no programa Slide $v 7.0$ 


\subsubsection{1. \\ Método de Newmark - versão de Houston et al. (1987)}

Como descrito no Capítulo 3, Houston et al. (1987) apresentaram uma versão do método de Newmark visando a assegurar que a massa de solo potencialmente instável seja admitida rígida, conforme a hipótese básica do método (bloco rígido). Assim, considerou-se a existência de uma camada de solo mole ao longo da potencial superfície de ruptura determinada na análise pseudoestática (Figura 6.22).

No programa de análise linear equivalente SHAKE2000 (Ordoñez, 2015) efetuou-se novamente o cálculo da resposta dinâmica unidimensional de colunas de solo, variando-se a velocidade de propagação da onda cisalhante $\left(V_{s}\right)$ na camada intermediária mole até se atingir acelerações máximas médias próximas da aceleração de escoamento $\left(a_{y}=0,12 \mathrm{~g}\right)$ nos pontos $\mathrm{B}_{1}, \mathrm{~B}_{2}$ e $\mathrm{B}_{3}$ (Figura 6.22). Este processo foi repetido para os três perfis de solo $(1,2,3)$ mostrados na Figura 6.22: próximo à crista do talude, próximo ao pé do talude e na distância intermediária entre estes perfis.

A história de acelerações registrada no ponto $\mathrm{A}$, imediatamente inferior à camada de solo mole, é duplamente integrada no tempo para produzir os deslocamentos permanentes das colunas. Os resultados finais de deslocamento permanente, para as histórias de aceleração do ponto A obtidas nos sismos de Bahia de Caraquez, Bucay, La Troncal e sismo artificial estão representadas na Figura 6.23 e seus respetivos valores listados na Tabela 6.8 .

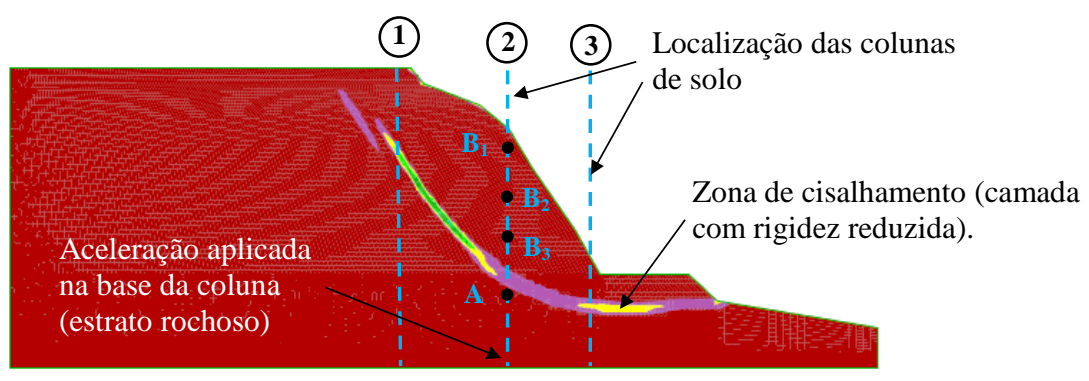

Figura 6.22 - Método de Newmark na versão proposta por Houston et al (1987).

Segundo Houston et al. (1987), provavelmente a estimativa mais acertada do deslocamento permanente no talude é a média dos valores registrados em cada coluna de solo; não obstante, o valor máximo obtido também deve ser reportado. 
No talude analisado, todos os deslocamentos permanentes máximos foram registrados na coluna de solo 1 .
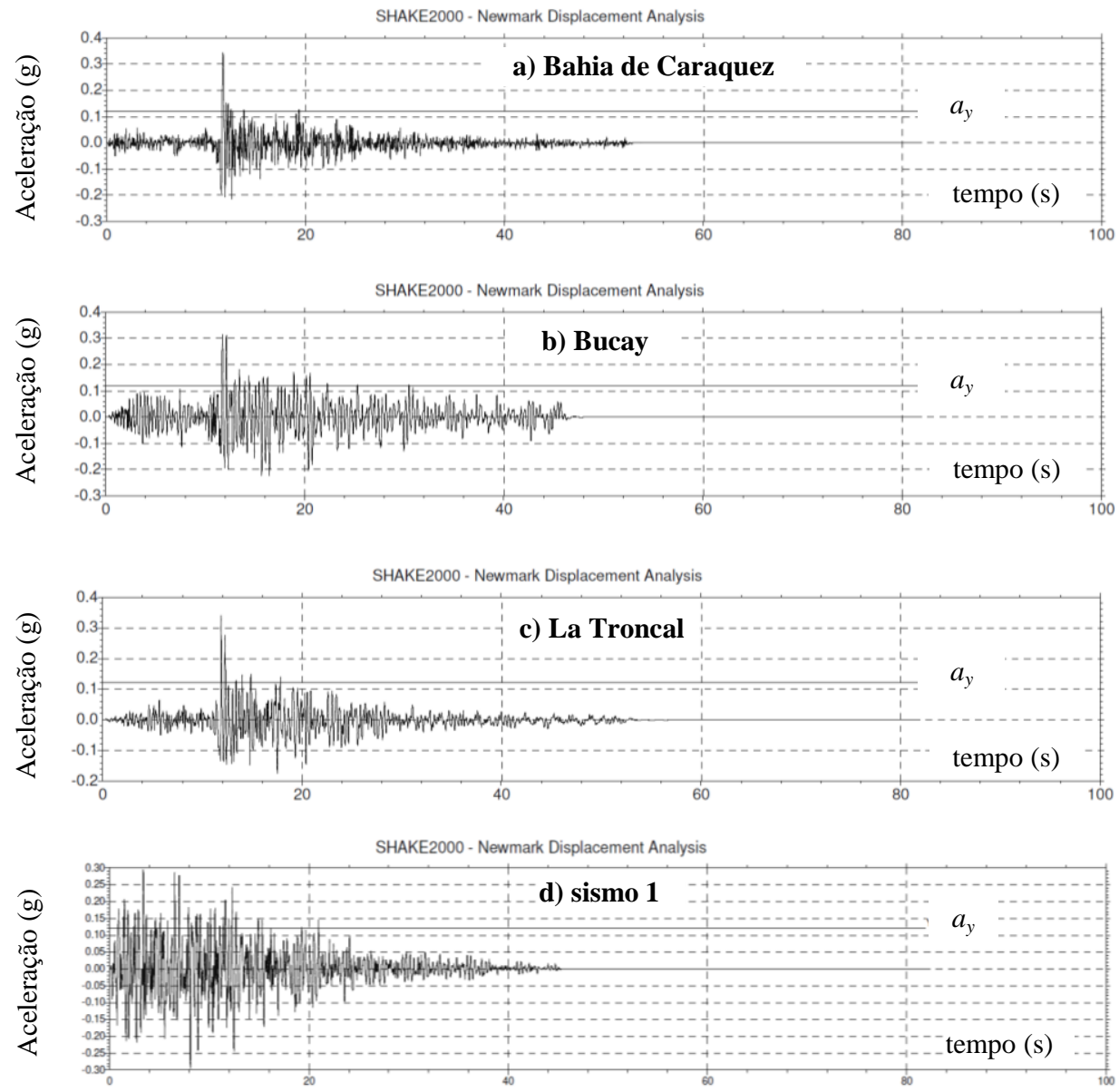

Figura 6.23 - Método de Newmark, versão de Houston et al (1987): a) sismo de Bahia de Caraquez; b) sismo de Bucay; c) sismo de La Troncal; d) sismo artificial 1.

Tabela 6.8 - Deslocamentos permanentes computados no método de Newmark, versão de Houston et al. (1987).

\begin{tabular}{|l|c|c|c|}
\hline Sismo de projeto & $\begin{array}{c}a_{y} \\
(\mathrm{~g})\end{array}$ & $\begin{array}{c}\text { Deslocamento permanente } \\
\text { médio }(\mathrm{cm})\end{array}$ & $\begin{array}{c}\text { Deslocamento permanente } \\
\text { máximo }(\mathrm{cm})\end{array}$ \\
\hline Bahia de Caraquez & 0,12 & 2,4 & 3,4 \\
Bucay & 0,12 & 2,6 & 3,7 \\
La Troncal & 0,12 & 2,9 & 3,5 \\
sismo 1 & 0,12 & 2,9 & 6,0 \\
\hline
\end{tabular}

Observa-se em geral que os deslocamentos permanentes máximos estimados mediante os sismos de projeto (Bahia de Caraquez, Bucay e La Troncal) podem ser considerados desprezíveis, da ordem de poucos centímetros para um talude de $77 \mathrm{~m}$ de altura; adicionalmente estes valores não apresentam significativa diferença entre eles. 
No caso do sismo artificial (sismo 1) vê-se evidente diferença na amplitude do deslocamento permanente calculado mediante este método simplificado em comparação com os sismos de projeto, atingindo este valor quase o dobro dos calculados inicialmente para os sismos de Bahia de Caraquez, Bucay e La Troncal.

\subsubsection{2.}

\section{Método simplificado de Bray e Travasarou (2007)}

O método simplificado de Bray e Travasarou (2007) para estimativa de deslocamentos permanentes em taludes utiliza o coeficiente de escoamento $\left(k_{\mathrm{y}}=\right.$ 0,12) proveniente da análise de estabilidade pseudo-estática para fator de segurança $\mathrm{FS}=1$. Adicionalmente, outros parâmetros relativos à geometria do talude e ao sismo de projeto são necessários para execução dos cálculos:

- período inicial fundamental da massa instável $\left(T_{\mathrm{s}}=0,72 \mathrm{~s}\right)$ que, em função da geometria do talude, é estimado mediante a equação aproximada (equação 6.5), assumindo uma superfície de ruptura circular:

$$
T_{S}=\frac{4 \mathrm{H}}{V_{S}}
$$

onde $\mathrm{H}$ representa altura média da massa potencialmente instável e $V_{s}$ a velocidade de propagação da onda cisalhante $\left(V_{s}=430 \mathrm{~m} / \mathrm{s}\right)$;

- aceleração espectral do sismo de projeto no período de 1,5 vezes o período inicial fundamental $S_{\mathrm{a}}\left(1,5 T_{\mathrm{s}}\right)$, que apresenta diferentes valores para cada sismo de projeto, variando na faixa entre $0,20 \mathrm{~g}$ a $0,25 \mathrm{~g}$;

- magnitude do terremoto: o método foi desenvolvido utilizando registros sísmicos com magnitude de momento máxima $M_{w}=7.6$, mas esta variável é necessária ser especificada pois a aceleração espectral $\left(\mathrm{S}_{\mathrm{a}}\right)$ não reflete adequadamente a influência da magnitude e duração do terremoto. No presente estudo foram consideradas magnitudes entre $M_{w}=7.0$ a 7.5.

Trata-se de um método probabilístico que envolve duas etapas de cálculo: a primeira determina a probabilidade de serem gerados deslocamentos permanentes desprezíveis ( $\mathrm{D} \leq 1 \mathrm{~cm})$, enquanto que a segunda etapa estima a amplitude do deslocamento permanente de acordo com a equação 3.29 (Capítulo 3). 
As estimativas de deslocamento permanente foram auxiliadas pelo programa computacional SHAKE2000 (Ordoñez, 2015). Os resultados obtidos estão mostrados na Figura 6.24 e na Tabela 6.9 onde D se refere ao deslocamento permanente médio e $\mathrm{D} \pm \sigma$ aos valores afastados da média de um desvio padrão $\sigma$.

Tabela 6.9 - Deslocamentos permanentes pelo método de Bray e Travasarou (2007).

\begin{tabular}{|lccc|}
\hline \multirow{2}{*}{ Registro sísmico } & \multicolumn{3}{c|}{ Deslocamento permanente D $(\mathrm{cm})$} \\
& $\mathrm{D}-\sigma$ & $\mathrm{D}$ & $\mathrm{D}+\sigma$ \\
\hline Bahia de Caraquez & $<1,0$ & 2,4 & 6,0 \\
Bucay & $<1,0$ & $<1,0$ & 3,3 \\
La Troncal & $<1,0$ & 2,3 & 5,8 \\
\hline
\end{tabular}

Verifica-se que para os registros sísmicos de Bahia de Caraquez e de $\mathrm{La}$ Troncal os valores dos deslocamentos permanentes são muito próximos, o que é explicado pelo fato dos seus respectivos espectros de aceleração apresentarem valores similares no período correspondente a 1,5 vezes o período fundamental inicial da massa instável.
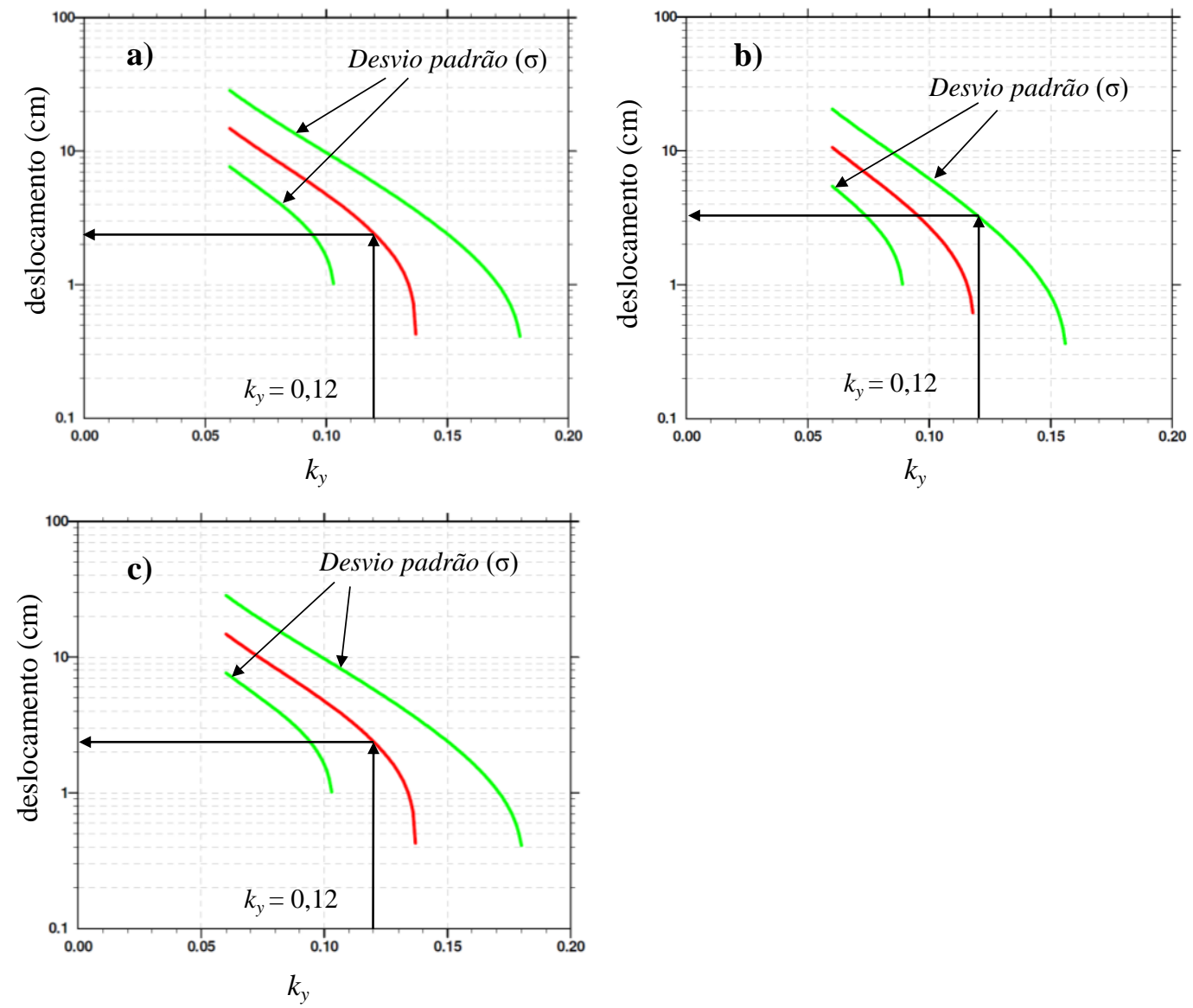

Figura 6.24 - Deslocamentos permanentes estimados pelo método de Bray e Travasarou (2007): a) sismo de Bahia de Caraquez; b) sismo de Bucay; c) sismo de La Troncal. 


\subsubsection{3. \\ Método simplificado de Rathje e Saygili (2011)}

Este método simplificado apresenta duas abordagens de desenvolvimento em função dos parâmetros utilizados:

- no modelo escalar a aceleração máxima esperada no terreno foi determinada a partir das isozonas de ameaça sísmica (Figura 5.2) no Estado de Canar com um valor da PGA $=0,25 \mathrm{~g}$; a magnitude de momento do terremoto foi assumida como $M_{w}=7.5$;

- no modelo vetorial, que leva em conta unicamente os parâmetros de movimento do terreno, foram utilizadas PGA $=0,25 \mathrm{~g}$ e velocidade de pico no terreno (PGV) determinada mediante a equação 3.24 proposta por Alarcon et al. (2006), função da aceleração espectral $S_{a}$ para um período de vibração da geoestrutura de $\mathrm{T}=0,5 \mathrm{~s}$. $\mathrm{O}$ valor calculado foi $\mathrm{PGV}=$ $22,58 \mathrm{~cm} / \mathrm{s}$.

Os resultados listados na Tabela 6.10 mostram o deslocamento permanente médio e relativos a $\mathrm{D}+/$ - um desvio padrão $(\sigma)$, como recomendado por Rathje e Saygili (2011). Em ambas as abordagens (escalar e vetorial) o coeficiente de escoamento considerado foi $k_{y}=0,12$. Os resultados da abordagem vetorial, por incorporarem dois parâmetros do movimento (PGA, PGV), são os recomendados pelos autores do método. Devido a que todos os sismos de projeto foram ajustados ao espectro da norma NEC-2014, estes apresentaram idênticos valores dos parâmetros de movimento (PGA, PGV) assim como $M_{w}$, razão pela qual obteve-se mediante este método simplificado um valor comum de deslocamento permanente para todos os sismos de projeto. A Figura 6.25 mostra a variação dos deslocamentos permanentes médio $\mathrm{D}$ e $\mathrm{D}+/-\sigma$ em função do coeficiente de escoamento pseudoestático $k_{y}$, determinados com auxilio do programa computacional SHAKE 2000.

Tabela 6.10 - Deslocamentos permanentes $(\mathrm{cm})$ pelo método de Rathje e Saygili (2011).

\begin{tabular}{|ccc|}
\hline \multicolumn{3}{|c|}{ Modelo Escalar: PGA $=0,25 \mathrm{~g}, M_{w}=7.5$} \\
\hline $\mathrm{D}-\sigma(\mathrm{cm})$ & $\mathrm{D}(\mathrm{cm})$ & $\mathrm{D}+\sigma(\mathrm{cm})$ \\
\hline 1,7 & 4,6 & 12,4 \\
\hline
\end{tabular}

\begin{tabular}{|ccc|}
\hline \multicolumn{3}{|c|}{ Modelo Vetorial: $\mathrm{PGA}=0,25 \mathrm{~g}, \mathrm{PGV}=22,58 \mathrm{~cm} / \mathrm{s}$} \\
\hline $\mathrm{D}-\sigma(\mathrm{cm})$ & $\mathrm{D}(\mathrm{cm})$ & $\mathrm{D}+\sigma(\mathrm{cm})$ \\
\hline 0,8 & 1,6 & 3,1 \\
\hline
\end{tabular}




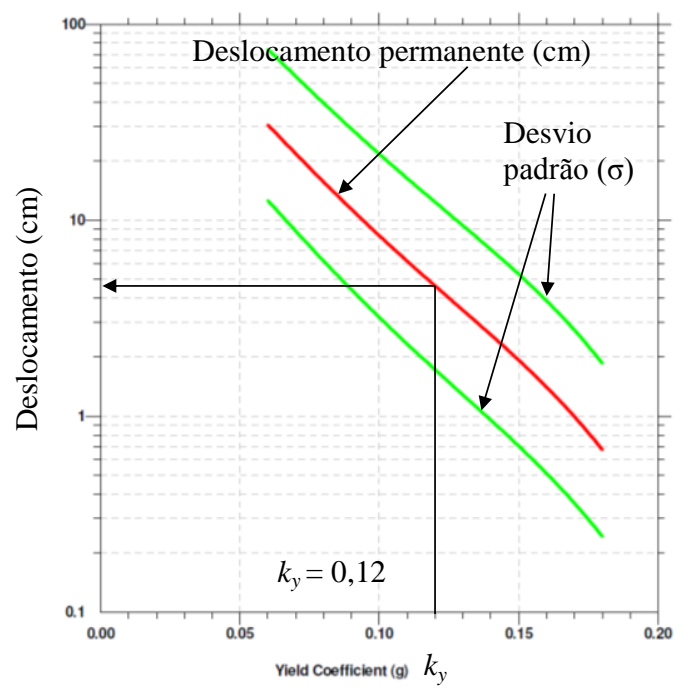

Figura 6.25 - Deslocamento permanente médio $D$ e $D+/-\sigma$ pelo método de Rathje e Saygili (2011).

\subsubsection{4.}

\section{Resumo dos deslocamentos permanentes obtidos por métodos} simplificados

A Tabela 6.11 apresenta um resumo dos resultados de deslocamento permanente do talude obtidos pelos métodos simplificados anteriormente descritos com ajuda do programa computacional SHAKE2000 (Ordoñez, 2015).

Observa-se que os deslocamentos permanentes do talude são da ordem de poucos centímetros. Há uma boa concordância entre os resultados da abordagem escalar do método de Rathje e Saygili (2011) e do método de Newmark (1965). De forma análoga, a abordagem vetorial do método de Rathje e Saygili (2011) tende a se aproximar dos resultados obtidos com o método simplificado de Bray e Travasarou (2007).

Com o método de Newmark, versão de Houston et al. (1987), foram determinados valores marcadamente inferiores em relação àqueles obtidos com o método de Newmark original, pois neste último se considera a deformabilidade da massa de solo instável enquanto que no primeiro foi introduzida a rigidez da massa de solo deslizante (bloco rígido na formulação original de Newmark), pela inclusão de uma camada de solo mole, de pequena espessura, ao longo da potencial superfície de ruptura. Os efeitos destas hipóteses (massa de solo rígido ou deformável) na variação das acelerações com a profundidade estão mostrados na Figura 6.26. 
Tabela 6.11 - Resumo dos deslocamentos permanentes (cm).

\begin{tabular}{|l|ccc|}
\hline \multirow{2}{*}{\multicolumn{1}{|c|}{ Método simplificado }} & \multicolumn{3}{c|}{ Sismo de projeto } \\
\cline { 2 - 4 } & Bahia de Caraquez & Bucay & La Troncal \\
\hline Newmark (1965) & 7,0 & 5,4 & 3,3 \\
\hline Newmark - Houston et al. (1987) & 3,4 & 3,7 & 3,5 \\
\hline Bray e Travasarou (2007) & 2,4 & $<1,0$ & 2,3 \\
\hline Rathje e Saygili (2011) - modelo escalar & & 4,6 & \\
\hline Rathje e Saygili (2011) - modelo vetorial & \multicolumn{3}{|c|}{1,6} \\
\hline
\end{tabular}
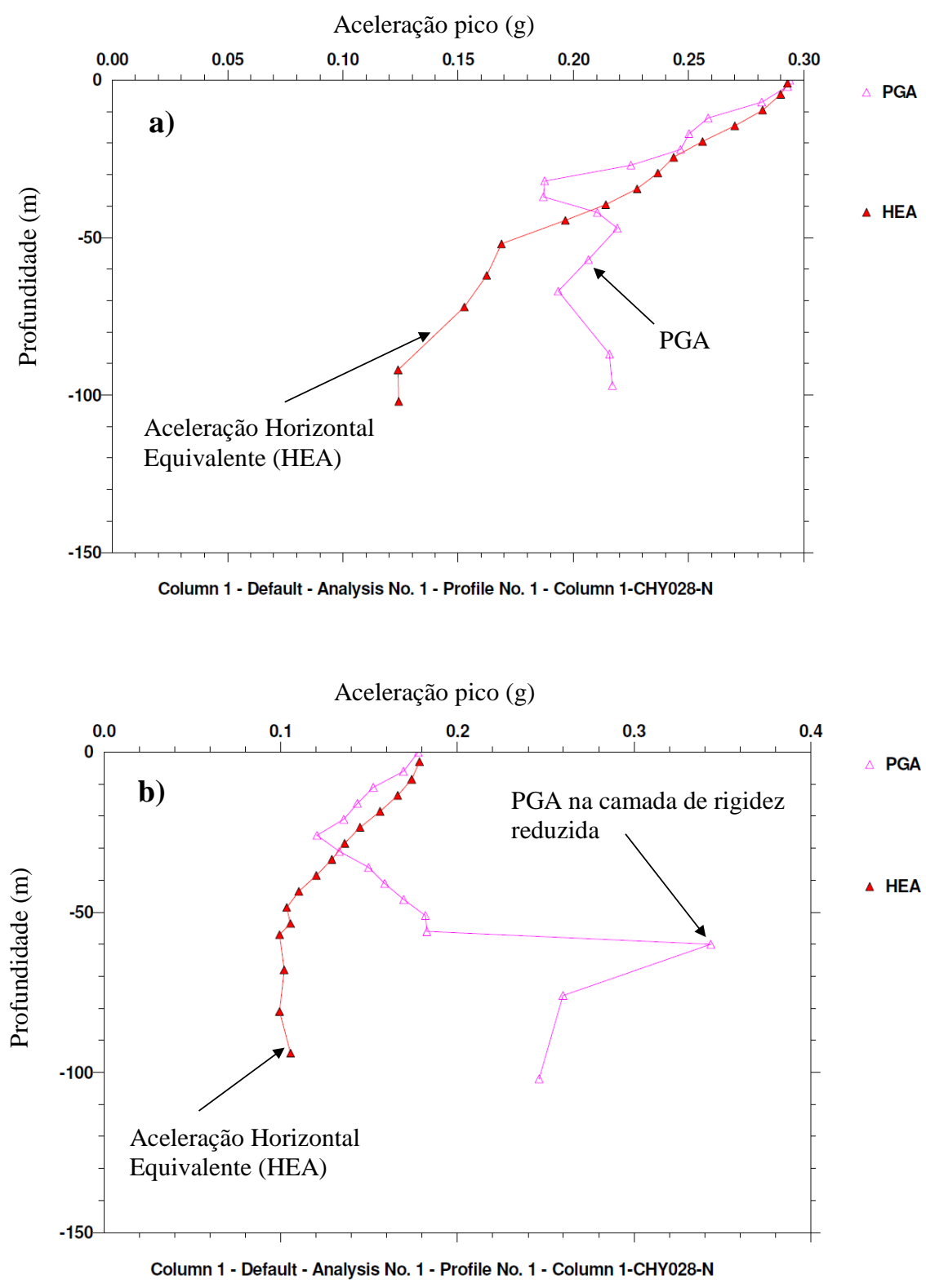

Figura 6.26 - Comparação da variação com a profundidade da aceleração máxima na coluna de solo: a) método de Newmark; b) método de Newmark - versão Houston et al (1987). 


\subsection{7. \\ Análise dinâmica}

\subsubsection{1. Análise dinâmica considerando comportamento elástico linear não amortecido}

A consideração de um modelo elástico linear, não amortecido, aparentemente irreal para simulação do comportamento cíclico de solos, é necessária para a averiguação de 3 fatores de grande importância em estudos de análise dinâmica não linear de geoestruturas:

1. Verificação das condições de contorno: ao serem introduzidos contornos laterais de campo livre e a base do modelo como contorno absorvente (Figura 6.27), existe a possibilidade de uma diferença significativa entre a velocidade calculada pelo programa computacional Flac 2D próximo à base do modelo e a velocidade de entrada proveniente da integração no tempo das acelerações do registro sísmico. Assim para evitar este inconveniente ambas as histórias de velocidade são comparadas (Figura $6.28)$.

O carregamento sísmico é aplicado na base do modelo sob forma de tensões cisalhantes $\tau_{x y}$ estimadas de acordo com a equação 6.6,

$$
\tau_{x y}=f\left(\rho V_{s}\right) V_{r s}
$$

onde $\rho$ e $V_{s}$ são a massa específica e velocidade de propagação da onda cisalhante, respectivamente, do material existente na base do modelo e $V_{r s}$ é o registro de velocidades no tempo determinado a partir da integração do acelerograma. O fator de calibração adimensional $f$ (discutido no Capítulo 4) é inicialmente admitido igual a 2 devido ao fato de que a tensão cisalhante aplicada deveria ser o dobro daquela observada em um meio infinito, pois metade da energia é absorvida pelo contorno viscoso (Joyner $\&$ Chen, 1975). O valor apropriado deste coeficiente é determinado em um processo de tentativa e erro, ajustando o máximo possível as histórias de velocidade calculadas pelo programa computacional e proveniente da integração no tempo do registro sísmico correspondentes à base do 
modelo. Na presente análise, depois de algumas tentativas, foi adotado um fator $f=1,1$ (Figura 6.28).

A razão de que um valor $f=1,1$ resulta mais adequado do que $f=2$, deve-se ao fato de que a base do modelo está dentro do alcance do efeito chamado de duplicação da velocidade (velocity doubling), causado pela reflexão das ondas na superfície livre do modelo (Graff, 1991).

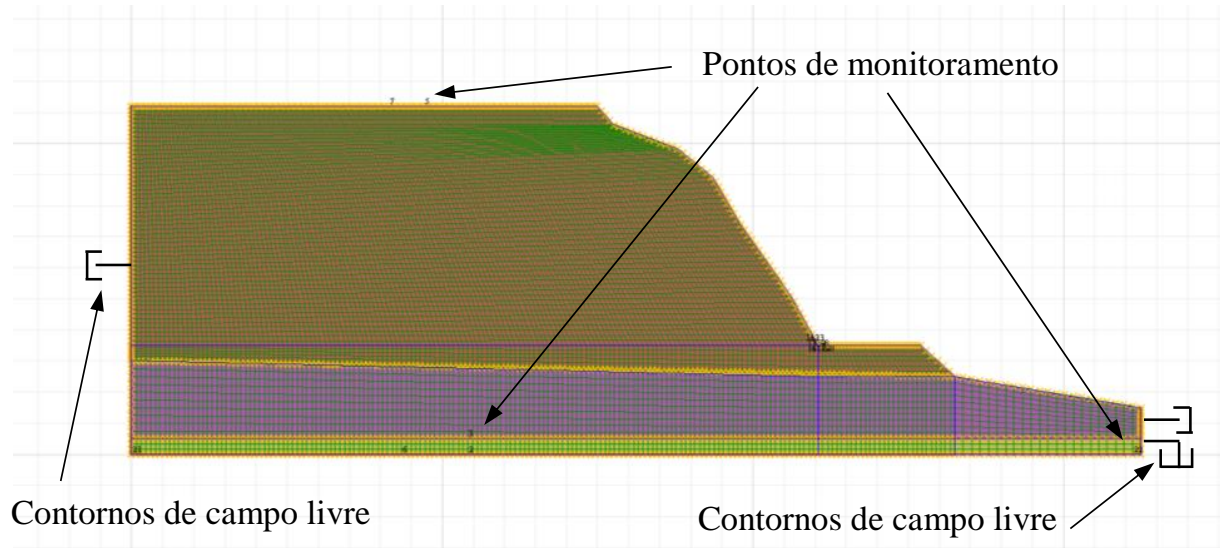

Figura 6.27 - Condições de contorno na simulação do comportamento dinâmico do talude.

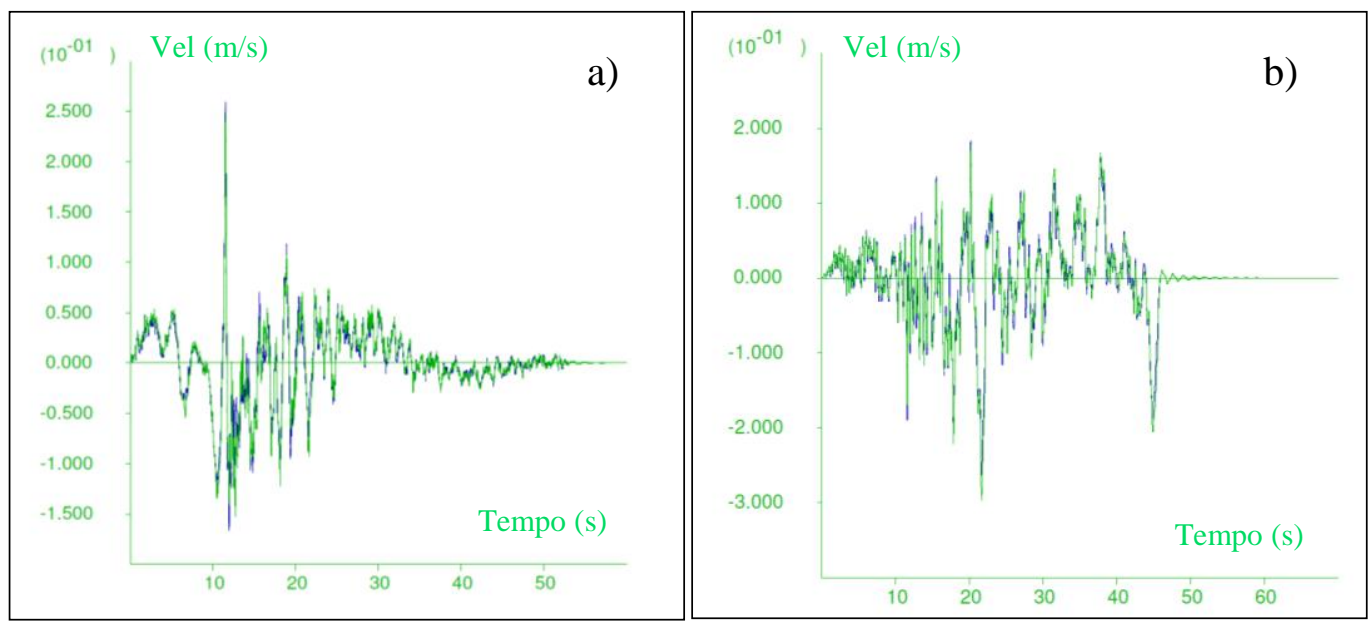

Velocidade calculada na base do modelo (Flac v7)

Velocidade aplicada (a partir da integração do acelerograma) 


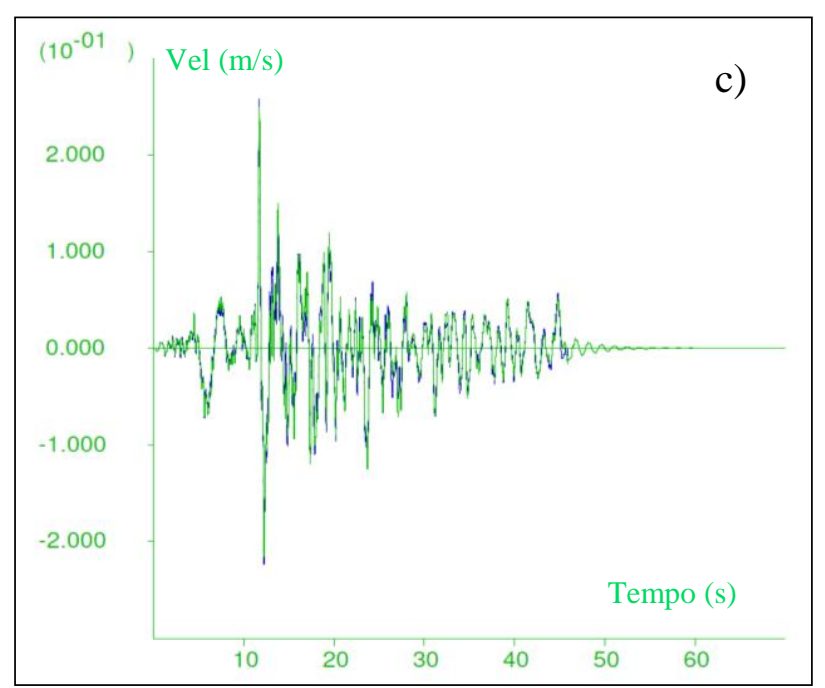

Figura 6.28 - Comparação entre velocidades de entrada (registro sísmico) e na base do modelo calculada pelo programa Flac 2D, em simulação elástica linear, não amortecida: a) sismo de Bahia de Caraquez; b) sismo de Bucay; c) sismo de La Troncal.

2. Frequência natural do modelo: para determinação da frequência natural não amortecida do modelo foram gerados os espectros de potência a partir das velocidades em pontos representativos dos materiais componentes do sistema. A Figura 6.29 mostra os espectros de potencia correspondentes aos três sismos de projeto. Na Figura 6.29a observa-se um pico máximo na frequência $0,1 \mathrm{~Hz}$ que foi descartado por representar um período aproximado $T=10$ s que não corresponde ao período natural esperado. Devido à posterior aplicação do amortecimento de Rayleigh, a ser utilizado nas simulações amortecidas conjuntamente com o amortecimento do tipo histerético, que requer uma faixa de frequências aproximadamente constante, decidiu-se considerar o pico intermediário no espectro como a frequência natural não amortecida do sistema (aproximadamente $1 \mathrm{~Hz}$ ).

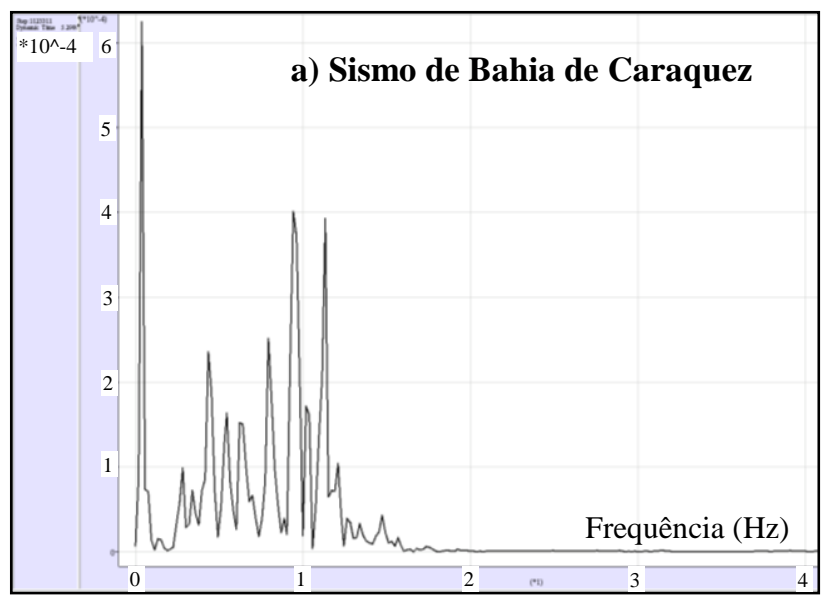




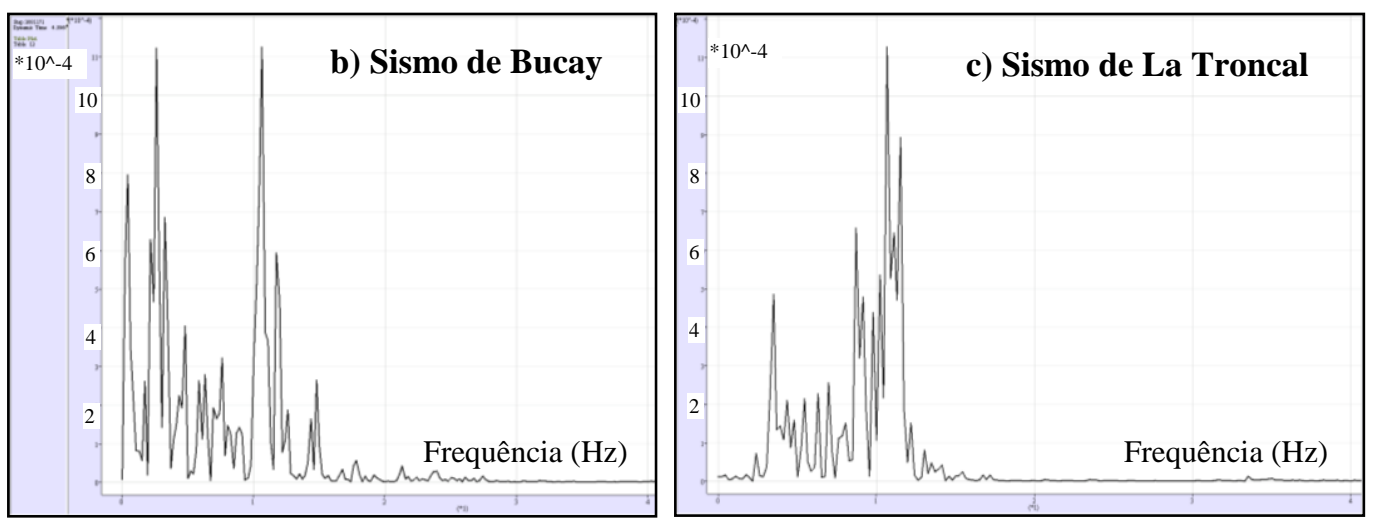

Figura 6.29 - Espectro de potência das velocidades na hipótese de material elástico linear não amortecido: a) sismo de Bahia de Caraquez; b) sismo de Bucay; c) sismo de La Troncal.

3. Máximas deformações cisalhantes cíclicas: a determinação das máximas deformações cisalhantes no solo como material elástico linear, não amortecido, é útil para efeitos de implementação do amortecimento histerético, pois como abordado no Capítulo 4 ele depende do nível de deformação cisalhante. Quando esta se tornar excessiva deve-se considerar um amortecimento adicional no sistema (amortecimento de Rayleigh).

$\mathrm{Na}$ Figura 6.30 são apresentadas as distribuições das máximas deformações cisalhantes para cada sismo de projeto, estas deformações foram atingidas de forma momentânea em pequenos intervalos de tempo, os tempos dinâmicos a partir do inicio do movimento do terreno em que se observaram estes valores de pico foram: $\mathrm{t}=12 \mathrm{~s} ; \mathrm{t}=15,7 \mathrm{~s}$ e $\mathrm{t}=12,4 \mathrm{~s}$ para os terremotos de Bahia de Caraquez, Bucay e La Troncal respetivamente. Pode-se verificar que existe uma semelhança no comportamento das deformações cisalhantes cíclicas nos três casos de carregamento sísmico, atingindo valores máximos entre $0,05 \%$ a $0,10 \%$ na maior parte da área do modelo. Maiores deformações (até 0,2\%) foram encontradas nas vizinhanças do pé do talude; de modo geral, considerou-se adequado o nível de deformações cisalhantes cíclicas máximas para incorporação do modelo histerético nas análises dinâmicas amortecidas, não lineares. 

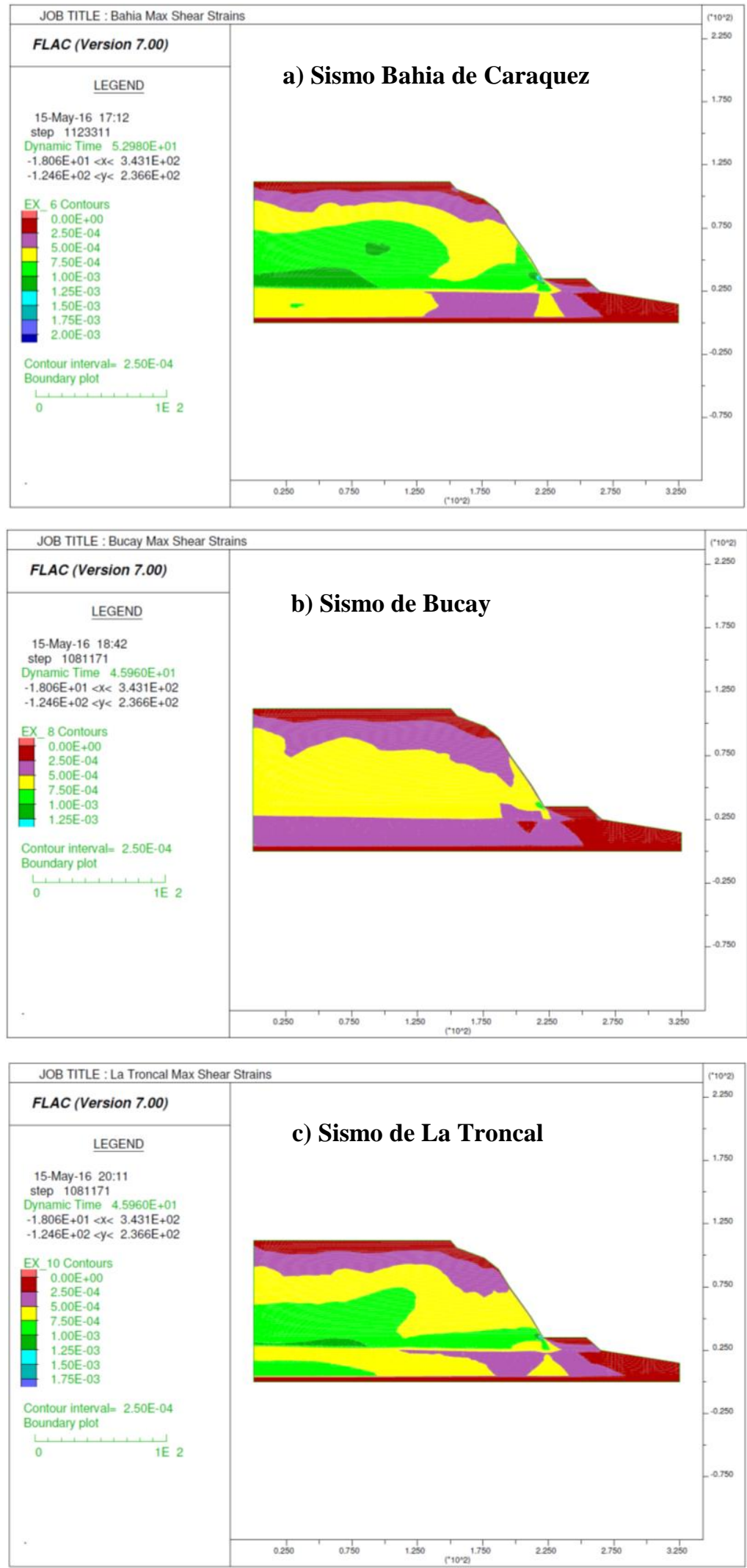

Figura 6.30 - Contornos de máximas deformações cisalhantes: a) sismo de Bahia de Caraquez; b) sismo de Bucay; c) sismo de La Troncal. 


\subsubsection{2. Análise dinâmica considerando comportamento não linear e não
amortecido}

Nesta análise considerou-se o solo como material elasto-plástico governado pelo modelo constitutivo de Mohr-Coulomb, simulando o carregamento sísmico aplicado na base do modelo sob forma de tensões cisalhantes, condições de contorno laterais em termos de campo livre e na base do modelo em termos de amortecedores absorventes.

A Figura 6.31a apresenta os deslocamentos verticais nos extremos inferiores esquerdo e direito do modelo, podendo-se observar que a partir do tempo $t=2 \mathrm{~s}$, aproximadamente, ocorre uma rotação da base. Este fato pode acontecer quando a profundidade do modelo varia muito entre os contornos laterais, como no caso de taludes e barragens.

Segundo Itasca (2011), para resolver este problema é necessário fazer a atualização das reações (forças normal e tangencial) ao longo dos contornos laterais de campo livre em cada passo de cálculo, a fim de garantir a condição de equilíbrio global do sistema para forças e momentos originados pelas tensões redistribuídas durante uma analise dinâmica. No programa computacional Flac v.7 isto é executado mediante um comando específico (corr_ffrot). Na Figura 6.31b apresentam-se os deslocamentos verticais nos extremos inferiores após execução deste processo de correção, notando-se que a diferença relativa entre os deslocamentos nos extremos da base do modelo foi reduzida consideravelmente. Segundo Itasca (2011) a rotação da base não tem consequências no comportamento geral do modelo, mas se aconselha efetuar sua correção.
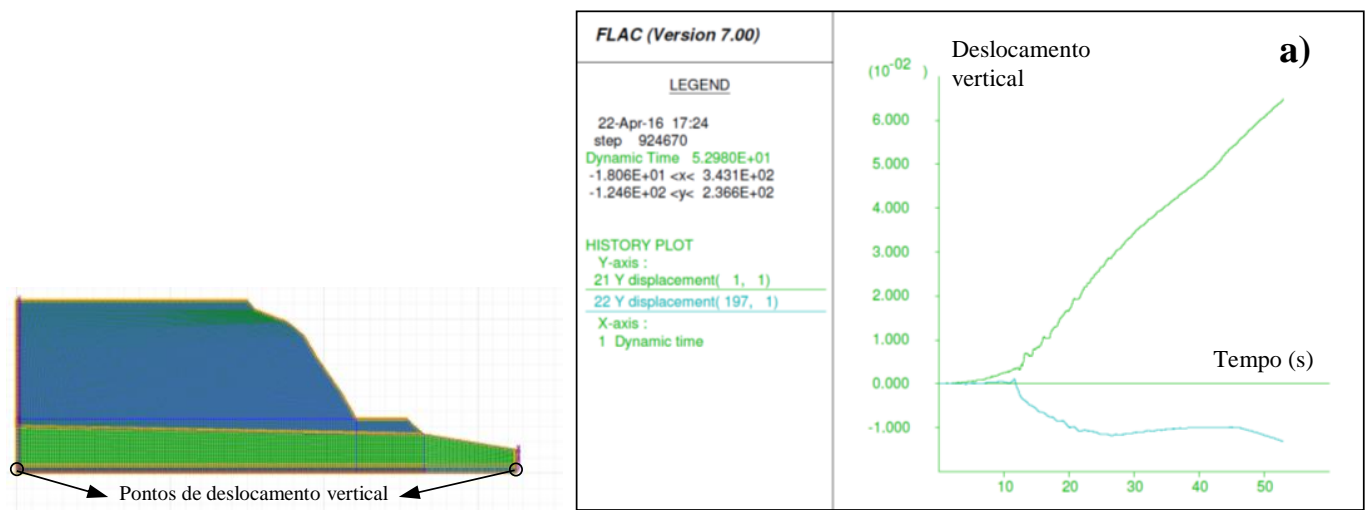


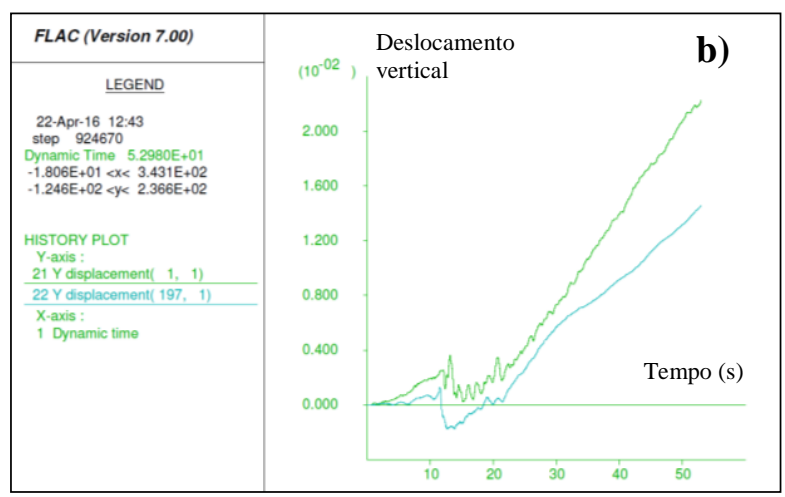

Figura 6.31 - Rotação da base do modelo: a) sem aplicação da correção; b) com aplicação de correção no programa Flac 2D v7.0.

\subsubsection{3.}

\section{Consideração do amortecimento histerético}

Existem várias formulações na literatura para incorporação do amortecimento histerético no comportamento dinâmico de solos, expressos pelas curvas de degradação do módulo cisalhante $\left(G / G_{\max }\right)$ e do aumento da razão de amortecimento com o nível de distorção cisalhante do material. No programa Flac 2D as curvas para os diferentes modelos de degradação do módulo de cisalhamento são representadas geralmente pelo modelo Sig3 (Itasca, 2011), que utiliza três constantes $\left(a, b, x_{\mathrm{o}}\right)$ para sua completa definição, definidas em função de ensaios de laboratório de carregamento cíclico.

Neste trabalho, devido à inexistência de resultados de ensaios de laboratório executados nos solos que compõem a geometria do modelo numérico, foram adotadas formulações disponíveis na literatura, dependentes do tipo de material. Especificamente, consideraram-se as seguintes propostas sugeridas por:

- Darendeli, M. (2001) para o solo coluvionar não plástico que forma o talude;

- Seed, H. B. e Idriss, I M. (1970) para a camada de areia;

- Schnabel (1973) para o substrato rochoso.

Os parâmetros do modelo Sig3, conforme equação de degradação do módulo cisalhante $G / G_{\max }$ apresentada no Capítulo 3, foram então calculados por ajuste pelo método dos mínimos quadrados e listados na Tabela 6.12. 
Tabela 6.12 - Parâmetros do modelo Sig3 (Flac 2D) para ajuste das funções de degradação do módulo cisalhante propostas na literatura.

\begin{tabular}{|lccc|}
\hline \multicolumn{1}{|c}{ Referência } & $a$ & $b$ & $x_{o}$ \\
\hline Normalizado IP = 0\%, Darendeli (2001) & 1,014 & $-0,4792$ & $-1,1$ \\
\hline Areia, Seed H. B. \& Idriss I. M. (1970) & 1,014 & $-0,4792$ & $-1,249$ \\
\hline Rocha, Schnabel (1973) & 1,014 & $-1,01$ & $-0,05$ \\
\hline
\end{tabular}

Na Figura 6.32 observa-se uma adequada concordância entre as curvas $G / G_{\max }$ experimentais apresentadas pelos autores citados e o modelo Sig3 (Itasca, 2011). Por outro lado, as curvas de aumento da razão de amortecimento, principalmente para a areia, exibiram maior diferença em virtude de comparação com a formulação teórica implementada no programa Flac 2D que determina o valor deste parâmetro em função da degradação do módulo de cisalhamento e não em relação a curvas experimentais de laboratório da variação da razão de amortecimento. Nos resultados de ajuste em relação às curvas sugeridas por Seed e I. M. Idriss (1970) para areias, tanto para redução do módulo cisalhante $\left(G / G_{\max }\right)$ quanto para aumento da razão de amortecimento $(\lambda)$, há uma concordância razoável na faixa de deformação cisalhante entre $0,001 \%$ a $0,3 \%$. No presente trabalho, como já mencionado, a deformação cisalhante máxima atinge o valor aproximado de $0,15 \%$.

Este ajuste obrigatório das curvas de amortecimento histerético é sem dúvida uma limitação importante do software Flac 2D v.7, principalmente em relação à variação da razão de amortecimento, quando comparado com o programa de análise linear equivalente SHAKE2000 (Ordoñez, 2015) que dispõe de um extenso banco de dados de curvas de redução do módulo cisalhante e do aumento da razão de amortecimento, sugeridas por vários autores e para diferentes tipos de solos, em função do índice de plasticidade, densidade relativa, tensão de confinamento, etc. 

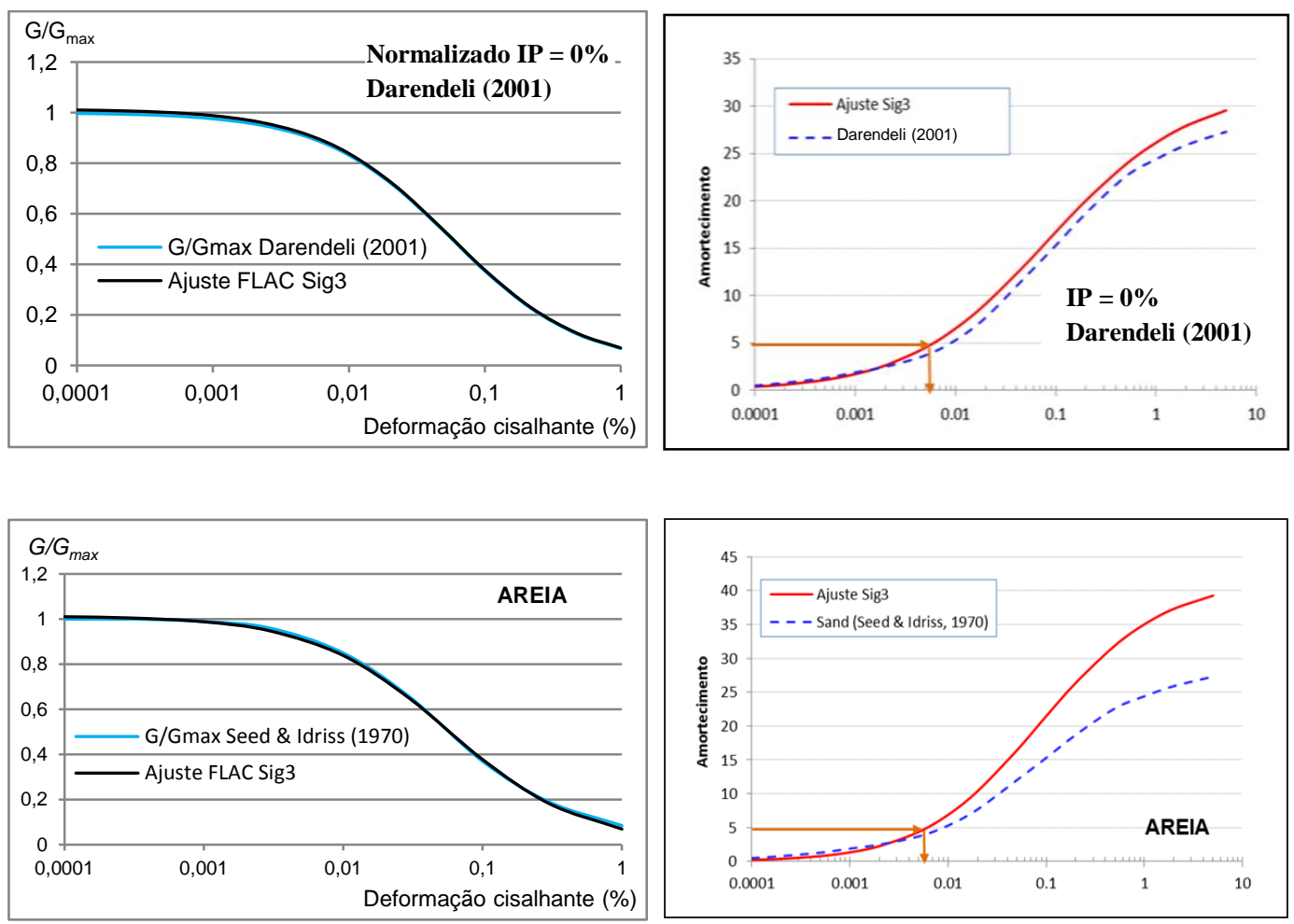

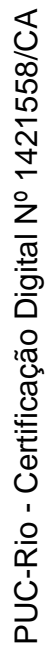
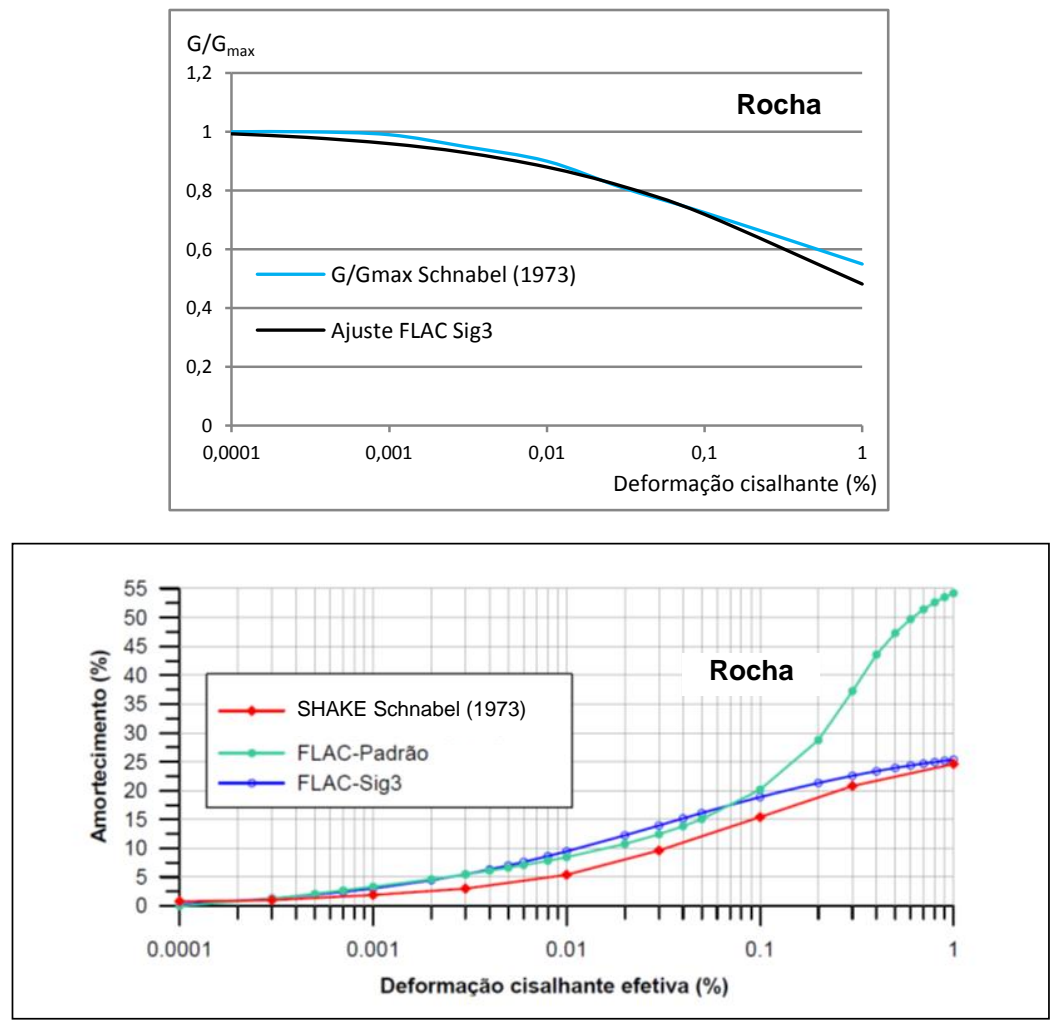

Figura 6.32 - Comparação de funções de degradação do módulo de cisalhamento publicadas na literatura e ajustadas no programa Flac 2D no modelo Sig3.

Em adição ao amortecimento histerético foi também aplicada uma parcela de amortecimento de Rayleigh de $0,5 \%$, proporcional unicamente à rigidez, com 
objetivo de absorver vibrações provocadas por altas frequências no sistema de conformidade com as recomendações de Itasca (2011).

\subsubsection{4.}

Comparação com o programa SHAKE 2000

O programa computacional SHAKE2000 (Ordoñez, 2015) é frequentemente utilizado em análises da resposta de solos submetidos a carregamentos dinâmicos. Este software simula a propagação unidimensional de ondas SV verticais em colunas de solo compostas por camadas horizontais visco-elásticas com módulo de cisalhamento e razão de amortecimento dependentes do nível de deformação cisalhante cíclica (modelo linear equivalente).

Assim, com o objetivo de avaliar o desempenho do amortecimento histerético incorporado no programa computacional Flac 2D, foi modelada uma coluna de solo (Figura 6.33) ao longo do talude, comparando-se os valores de aceleração horizontal máxima $\left(a_{\max }\right)$ e de tensão cisalhante cíclica máxima determinadas por ambos os programas.

$\mathrm{Na}$ Figura 6.34a observa-se que as opções consideradas forneceram resultados com boa concordância na distribuição da aceleração horizontal máxima com a profundidade, à exceção do caso onde o amortecimento de Rayleigh não foi adicionado (unicamente amortecimento histerético, linha tracejada), quando a aceleração foi fortemente majorada até atingir $a_{\max }=0,45 \mathrm{~g}$ na crista do talude.

Em vista destes resultados, decidiu-se utilizar nas análises dinâmicas posteriores o amortecimento histerético ajustado pelo modelo Sig3 (Itasca, 2011) com adição de $0,5 \%$ de amortecimento de Rayleigh, proporcional à rigidez. A inclusão desta parcela de amortecimento de Rayleigh, apesar de incrementar os tempos computacionais, é um procedimento comum adotado no amortecimento dos efeitos das altas frequências.

No que se refere à variação da tensão cisalhante máxima com a profundidade na coluna de solo (Figura 6.34b) não se verifica grandes diferenças entre as opções analisadas mas, similarmente à distribuição com a profundidade da aceleração máxima, os resultados computados pelos programas Flac 2D e SHAKE2000 são mais próximos entre si quando o amortecimento histerético é incorporado com parcela adicional de $0,5 \%$ de amortecimento de Rayleigh, proporcional à rigidez. 


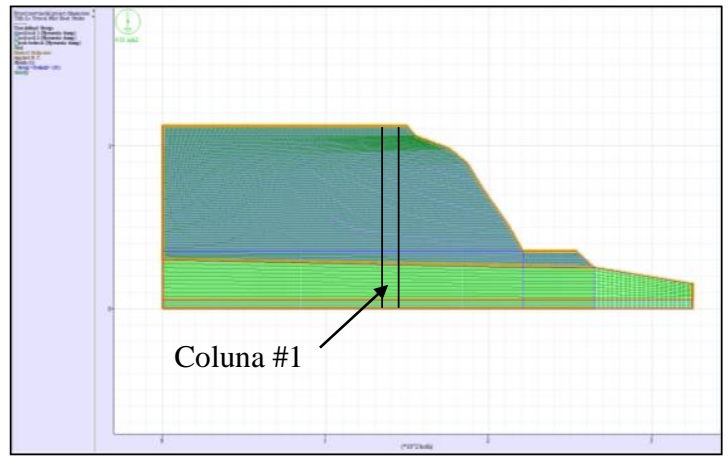

Figura 6.33 - Coluna de solo simulada no programa SHAKE 2000.
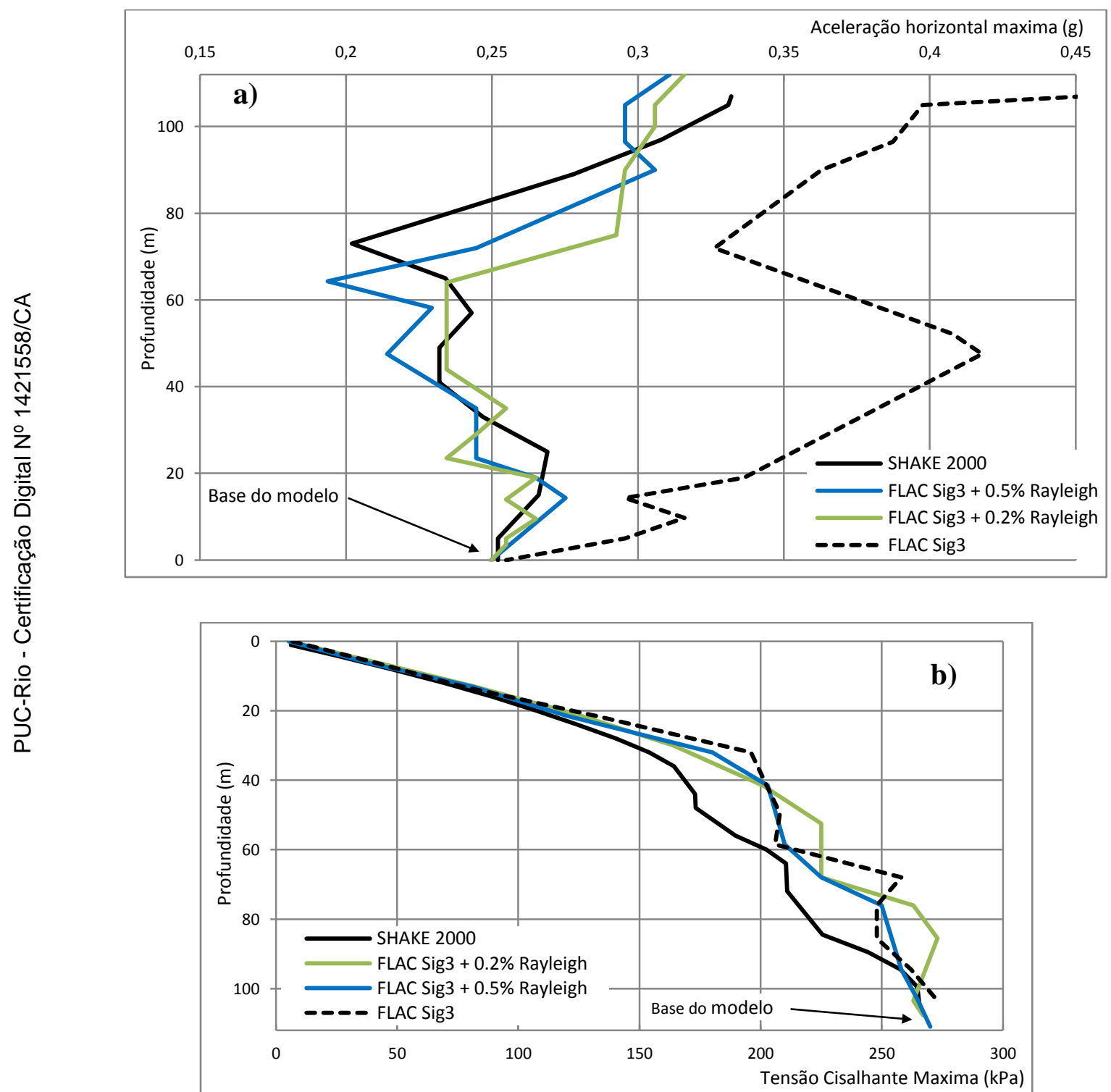

Figura 6.34 - Comparação da resposta dinâmica entre os programas SHAKE2000 e FLAC 2D v7: a) aceleração horizontal máxima; b) tensão cisalhante cíclica máxima. 


\subsubsection{5.}

\section{Análise dinâmica com amortecimento histerético}

As análises dinâmicas com amortecimento histerético e parcela de $0,5 \%$ de amortecimento de Rayleigh proporcional da rigidez foram executadas no programa de diferenças finitas Flac 2D v.7, utilizando para cada material componente do talude as curvas de degradação do módulo cisalhante e de aumento da razão de amortecimento apresentadas na Figura 6.32. No software Flac 2D as estruturas de reforço na face do talude foram modeladas como elementos estruturais de ancoragem rockbolts com diâmetro de 1,0 polegada, tensão admissível de 2,1E6 Pa e espaçamento fora do plano de 1,0 $\mathrm{m}$ de forma idêntica à especificada no estudo de estabilização realizado pela empresa Caminosca (Figura 6.15)

Nas Figuras 6.35 a 6.37 se apresentam os resultados em termos de contornos de deslocamentos permanentes, horizontais e verticais, causados por cada sismo de projeto. A Figura 6.38 mostra os contornos de deslocamentos horizontais e verticais produzidos pelo registro sísmico artificial considerado de maneira adicional nesta análise de comportamento dinâmico do talude.

Nas Figuras 6.39 e 6.40 mostram-se as historias de acelerações horizontais e deslocamentos (horizontais e verticais) para um ponto situado na crista do talude para cada sismo de projeto.

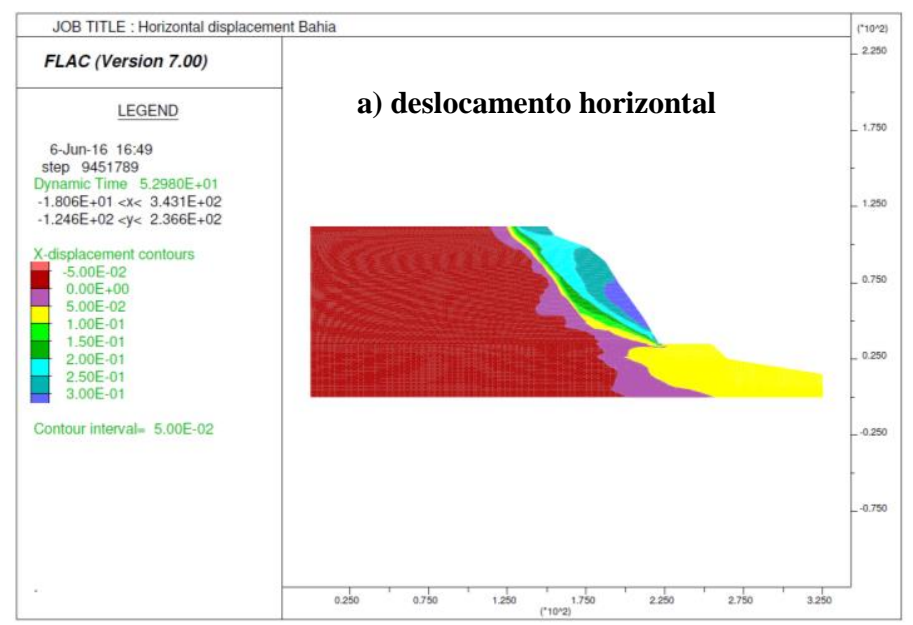




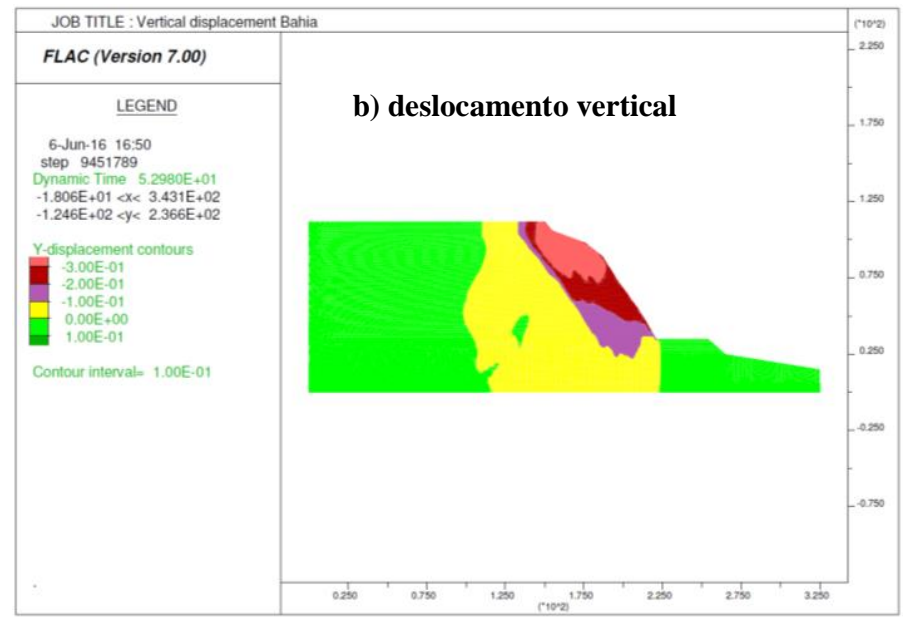

Figura 6.35 - Contornos de deslocamentos permanentes causados pelo terremoto de Bahia de Caraquez: a) deslocamentos horizontais; b) deslocamentos verticais.
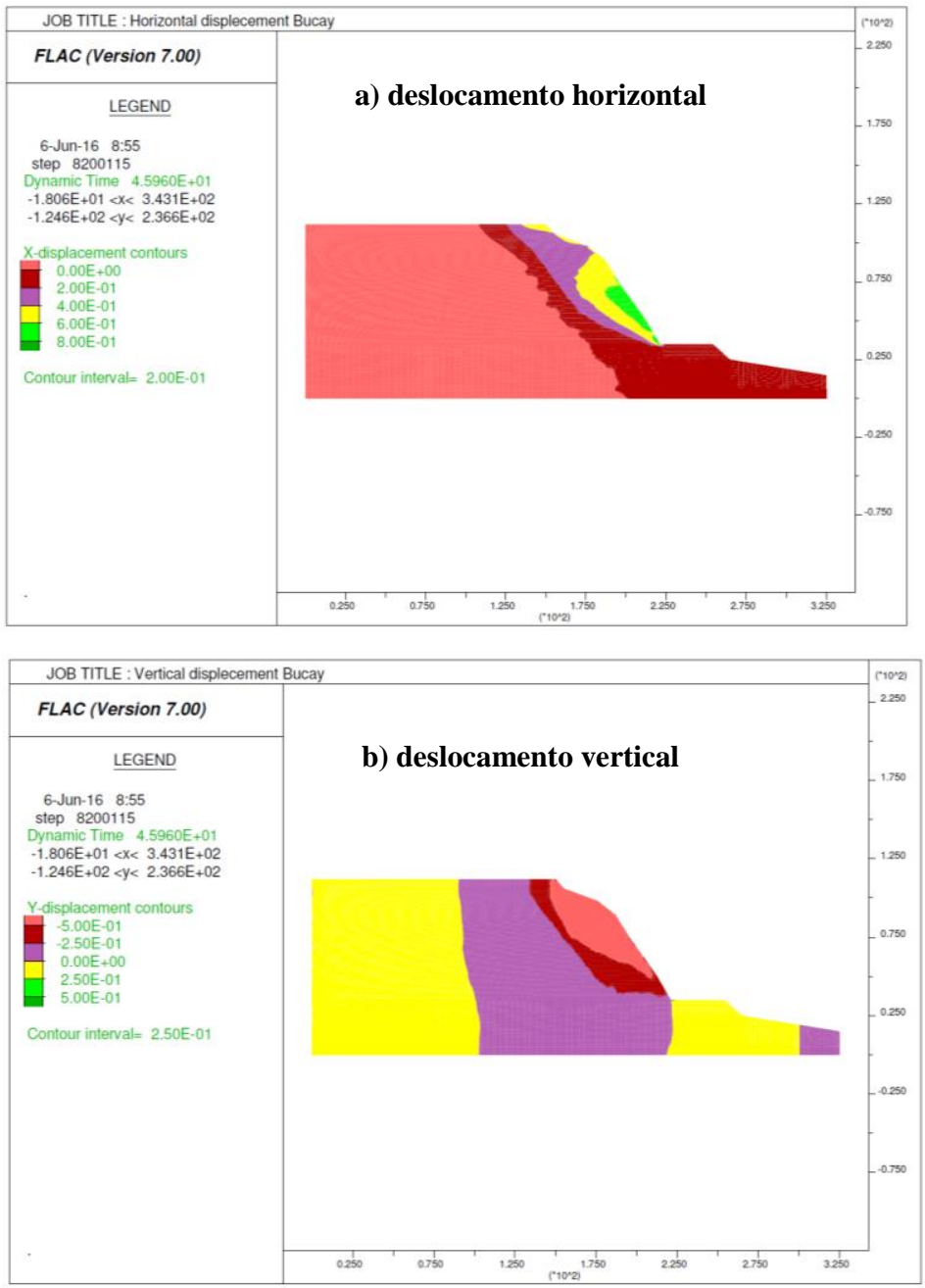

Figura 6.36 - Contornos de deslocamentos permanentes causados pelo sismo de Bucay: a) deslocamentos horizontais; b) deslocamentos verticais. 

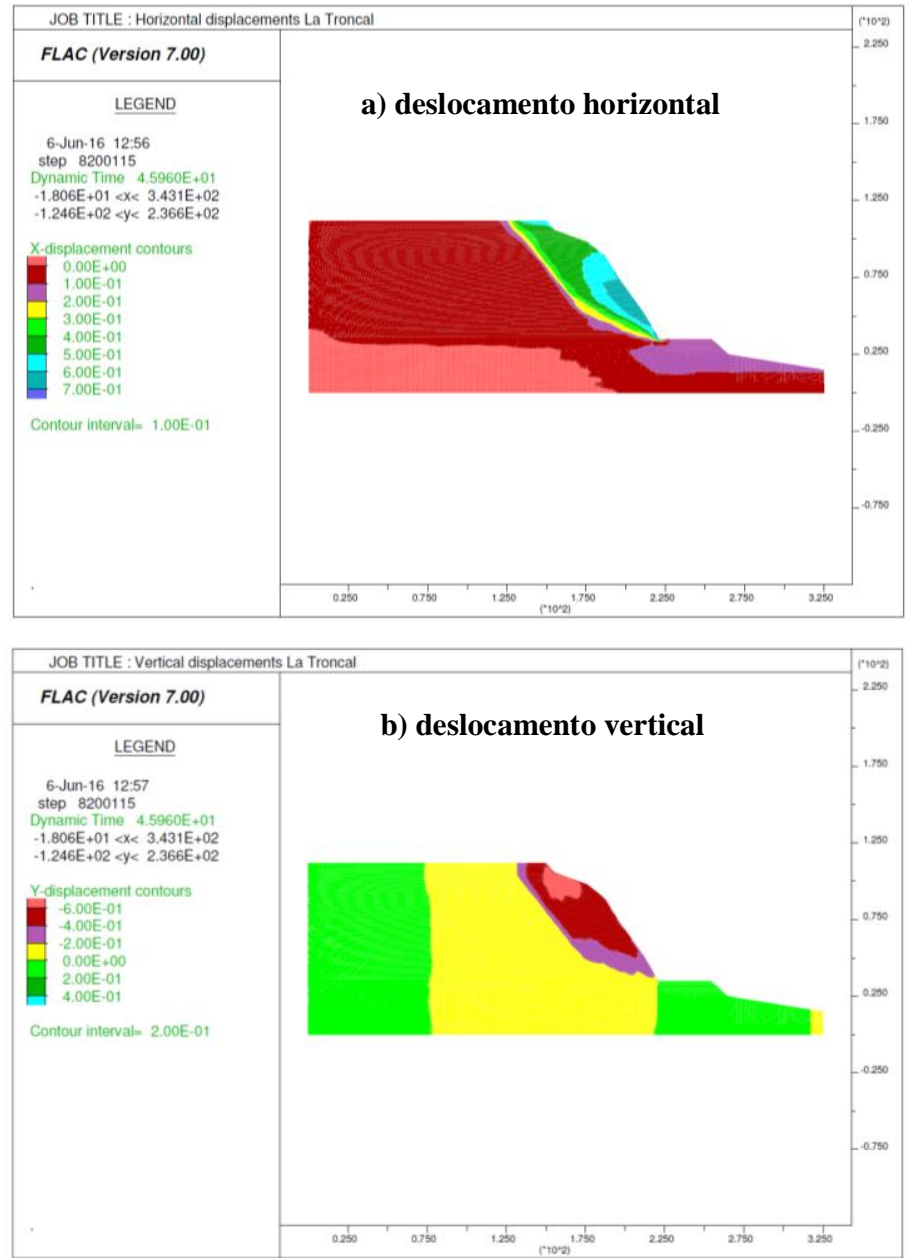

Figura 6.37 - Contornos de deslocamentos permanentes causados pelo sismo de La Troncal: a) deslocamentos horizontais; b) deslocamentos verticais.

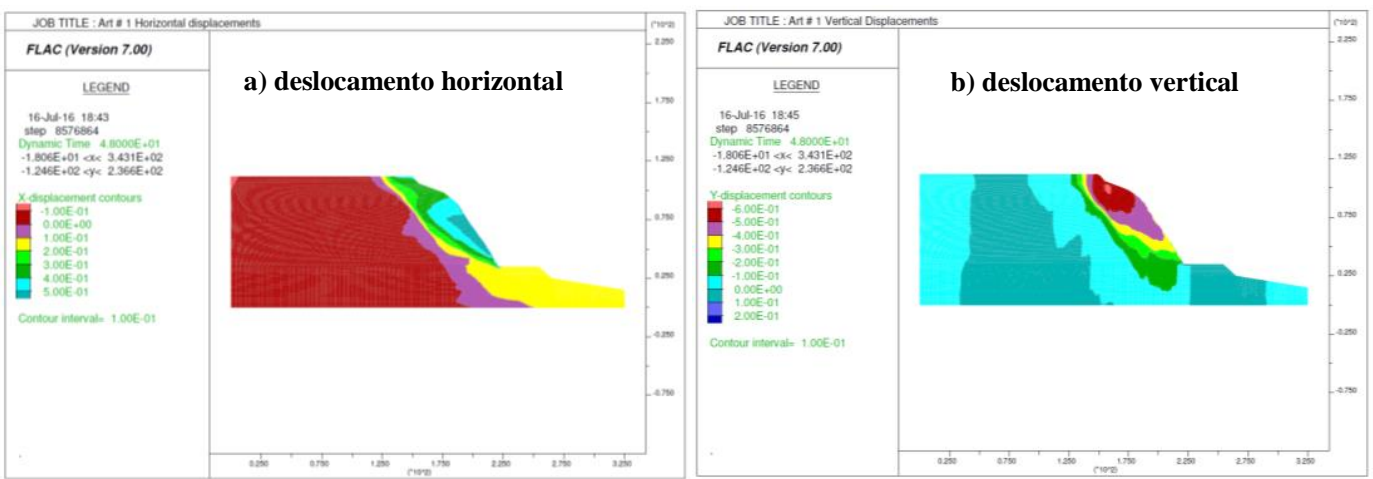

Figura 6.38 - Contornos de deslocamentos permanentes causados pelo sismo artificial sismo 1: a) deslocamentos horizontais; b) deslocamentos verticais. 

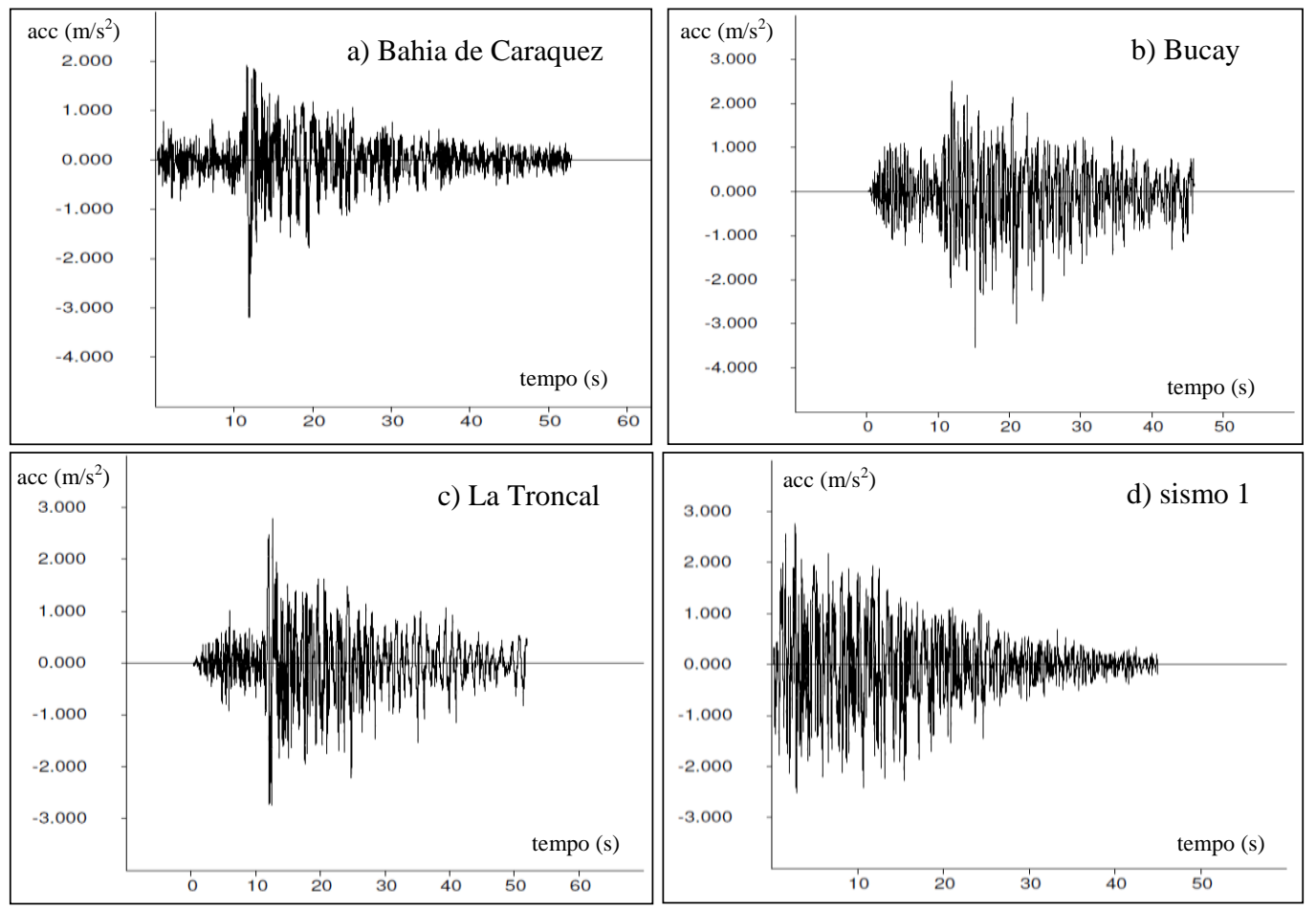

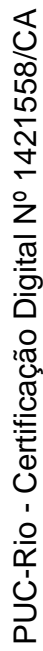

Figura 6.39 - Historia de acelerações horizontais na crista do talude: a) sismo de Bahia de Caraquez; b) sismo de Bucay; c) sismo de La Troncal; d) sismo 1.

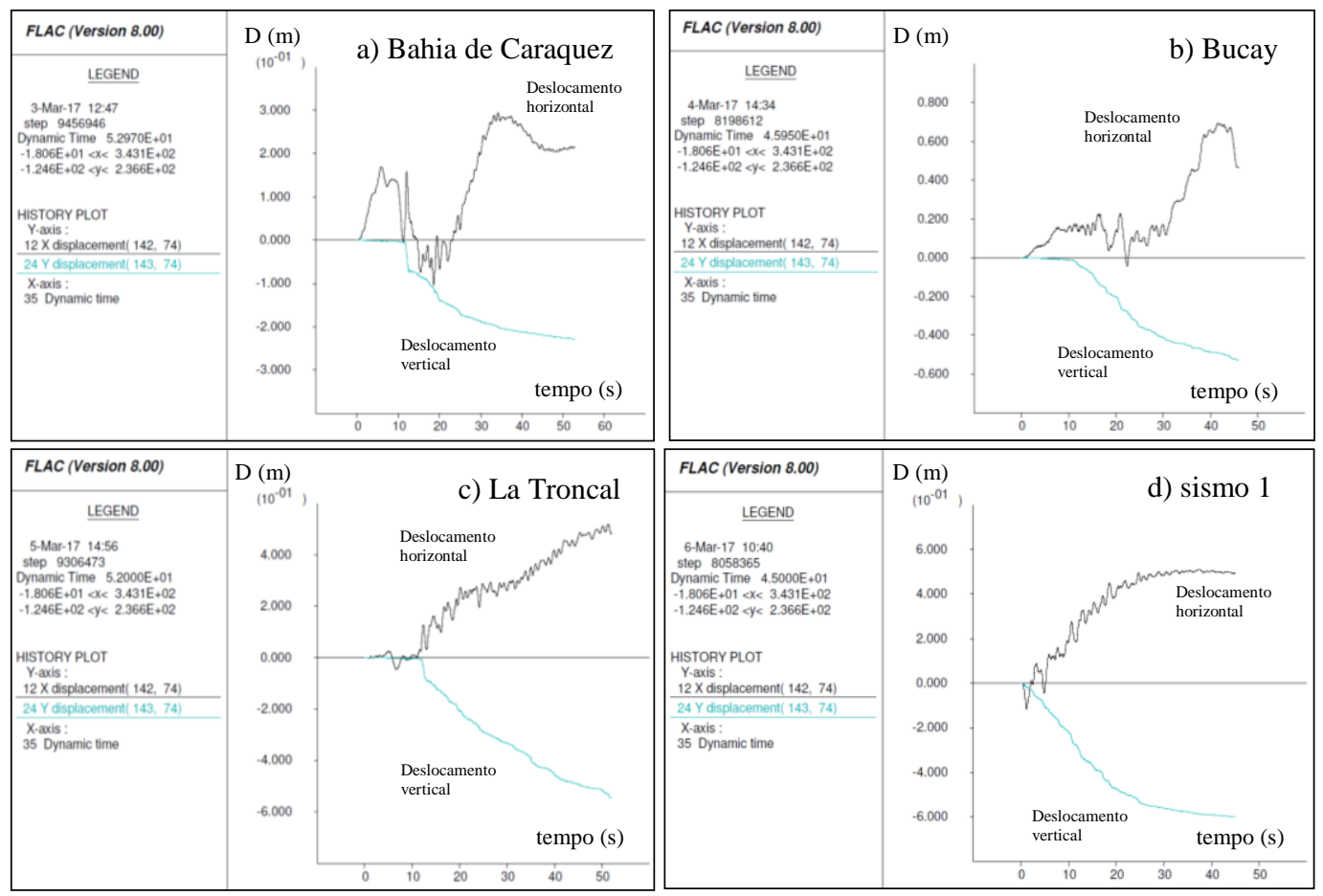

Figura 6.40 - Historia de deslocamentos horizontal e vertical na crista do talude: a) sismo de Bahia de Caraquez; b) sismo de Bucay; c) sismo de La Troncal; d) sismo 1.

Observa-se que os terremotos de Bucay e La Troncal produzem deslocamentos permanentes aproximadamente da mesma magnitude na face do 
talude, mas superiores àqueles obtidos com o terremoto de Bahia de Caraquez (Figura 6.35). A Tabela 6.13 lista os valores computados.

No caso do registro artificial (Figura 6.38), observa-se similar comportamento ao estimado anteriormente com os três sismos de projeto, com deslocamentos permanentes máximos ocorrendo na crista e no pé do talude.

No caso do sismo artificial vê-se da Figura 6.40d que os deslocamentos no talude incrementam-se até um tempo aproximado de 25 segundos, após esta duração do movimento, os deslocamentos mostram tendência a se manter constantes sem incremento significativo de amplitude, isto se explica em função das características da historia de acelerações (Figura 6.9), onde se aprecia a concentração da maior energia do terremoto nos primeiros 25 segundos do acelerograma, após este tempo o movimento é de relativa baixa intensidade.

$\mathrm{Na}$ Figura 6.41 apresentam-se os espectros de resposta em aceleração horizontal na crista do talude para verificação da máxima resposta em aceleração em determinados períodos de interesse da excitação sísmica para os três sismos de projeto assim como para o registro artificial (sismo 1).

Tabela 6.13 - Deslocamentos permanentes (m) na simulação dinâmica não linear, amortecida.

\begin{tabular}{|l|c|c|c|c|}
\hline \multirow{2}{*}{ Sismo de projeto } & \multicolumn{2}{|c|}{ Deslocamento crista do talude $(\mathrm{m})$} & \multicolumn{2}{c|}{ Deslocamento pé do talude $(\mathrm{m})$} \\
\cline { 2 - 5 } & Horizontal & Vertical & Horizontal & Vertical \\
\hline Bahia de Caraquez & 0,22 & 0,24 & 0,25 & 0,11 \\
Bucay & 0,47 & 0,54 & 0,90 & 0,20 \\
La Troncal & 0,48 & 0,57 & 0,70 & 0,34 \\
sismo 1 & 0,49 & 0,63 & 0,56 & 0,29 \\
\hline
\end{tabular}

Finalmente, na Figura 6.42 apresentam-se os perfis de deslocamento permanente (horizontal e vertical) após a ocorrência de cada terremoto de projeto, esta distribuição de deslocamentos foi registrada ao longo da altura máxima do talude. 


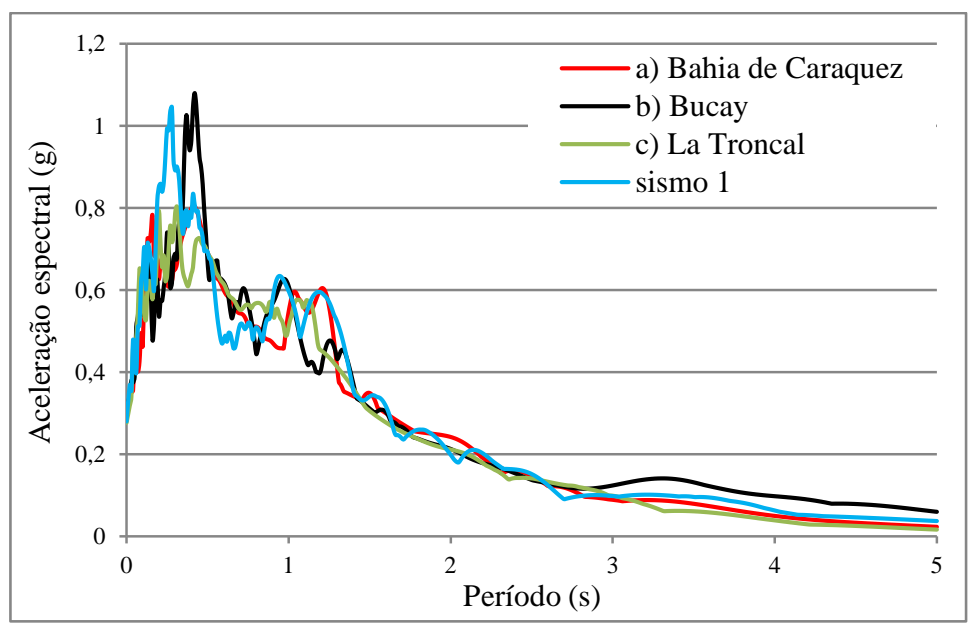

Figura 6.41 - Espectro de resposta em aceleração horizontal na crista do talude para os terremotos Bahia de Caraquez, Bucay, La Troncal e sismo artificial 1.
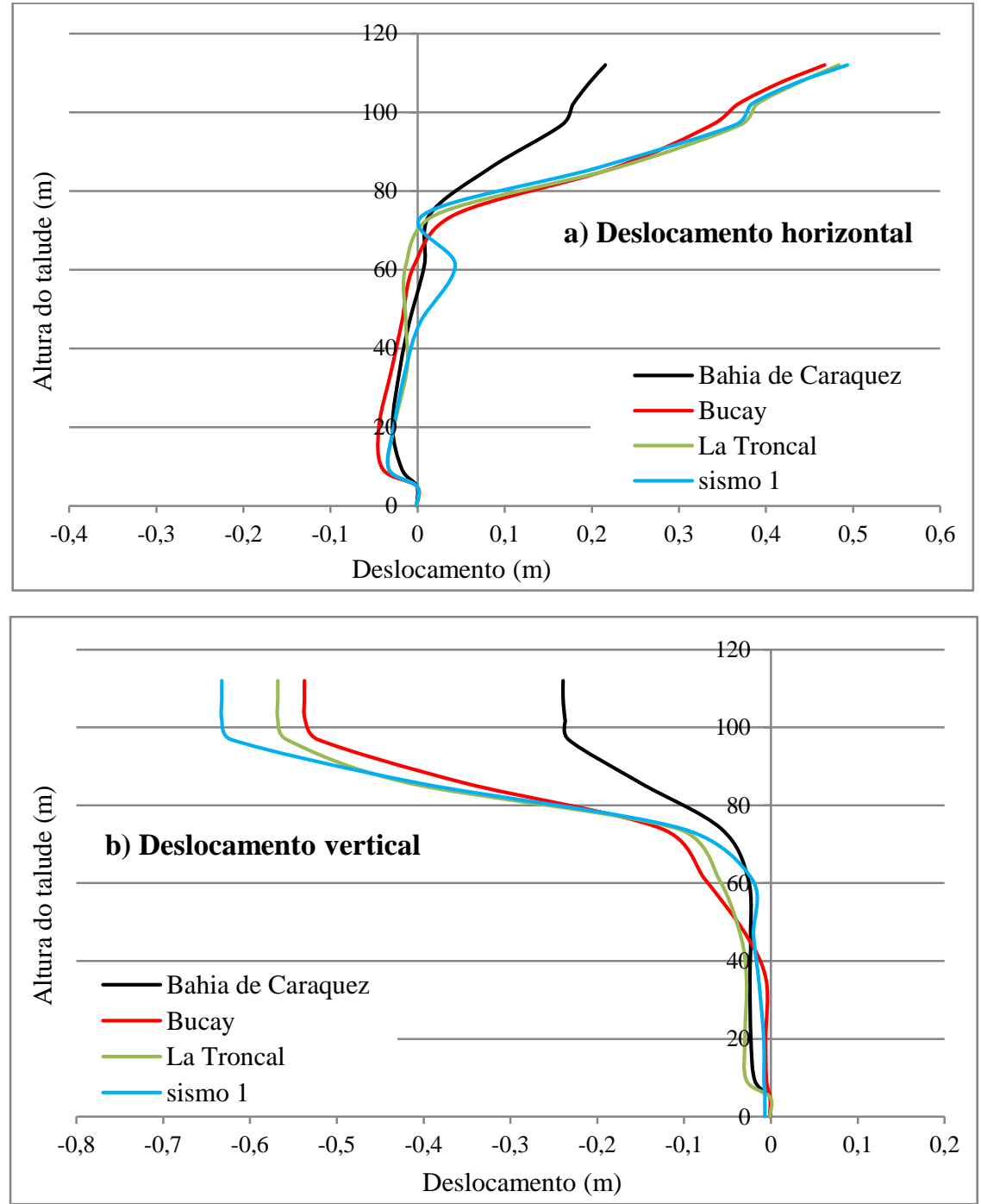

Figura 6.42 - Distribuição de deslocamentos permanentes causados pelos sismos de projeto: a) deslocamento horizontal; b) deslocamento vertical. 
Em relação ao acelerograma artificial (sismo 1), o valor de deslocamento permanente não foram muito discordante daqueles calculados com os sismos de Bucay e La Troncal (Tabela 6.13), sendo a principal diferença para o caso do terremoto de Bahia de Caraquez que resultou em valores de deslocamentos consideravelmente menores. Estes resultados seriam esperados porque tanto os sismos de projeto quanto o sismo artificial foram ajustados ao espectro de acelerações da Norma Equatoriana de Construção (NEC-2014).

Em relação aos deslocamentos permanentes estimados mediante os métodos simplificados resumidos na Tabela 6.11, pode-se concluir que há diferenças evidentes em comparação com os valores computados da análise dinâmica acoplada. Nos métodos simplificados a maior amplitude de deslocamento permanente $(\mathrm{D}=0,07 \mathrm{~m}$ ) foi obtida para o sismo de Bahia de Caraquez com o método de Newmark, enquanto que no método numérico a menor amplitude $\mathrm{D}=$ 0,22 m foi obtida para o sismo de Bahia de Caraquez.

Sem dúvida estas diferenças reforçam as hipóteses embutidas em cada método. Enquanto que a formulação numérica é acoplada, determinando simultaneamente acelerações e deslocamentos, os métodos simplificados são geralmente de natureza desacoplada, necessitando do cálculo antecipado de acelerações horizontais máximas (PGA), velocidades horizontais máximas (PGV), etc. O método de Newmark, por exemplo, que depende do valor da PGA é fortemente influenciado por valores extremos de aceleração (como ocorrido no terremoto de Bahia de Caraquez) enquanto que no método numérico, que depende do inteiro registro de acelerações, tais valores extremos (ocorrendo em pequenos intervalos de tempo) tem uma influência muito menor na previsão do comportamento da geoestrutura.

Finalmente, o tamanho máximo do elemento que depende da velocidade de propagação da onda cisalhante, e que por sua vez é função do módulo de cisalhamento que experimenta degradação com a deformação cisalhante (Figura 6.32), a questão é comprovar se os elementos ainda satisfazem o critério da $f_{\max }$ (equação 6.4). Conclui-se que a frequência de cutoff $\left(f_{c}=12 \mathrm{~Hz}\right)$ foi garantida de ser propagada no modelo com os níveis de deformação observados. Isto explica o efetuado na seção 6.1 .3 onde se escolheu um elemento de tamanho máximo $\Delta_{l}=2$ m que por um lado representa tempos computacionais maiores, mas por outro lado garante a correta propagação da $f_{c}$ durante toda a duração do terremoto. 


\section{7 \\ Exemplo 2 - Barragem de enrocamento de Mazar - Equador}

\section{1. Descrição da barragem de Mazar}

A barragem de enrocamento com face de concreto (Concrete Faced Rockfill Dam CFRD) de Mazar está localizada no limite entre as províncias de Canar e Azuay na parte sudeste do Equador. A geologia local apresenta uma cobertura de material vulcânico do Terciário chamada de formação Tarqui assim como depósitos quaternários, aluviares e coluviares recentes, e depósitos glaciares. $\mathrm{Na}$ zona de construção da barragem Mazar esta composta por rochas de natureza meta-vulcânica e sedimentar que contem xistos quartzíticos, cloríticos, grafíticos, mármores, e rochas andesitas (Arevalo, 2014).

O desvio do rio Paute, para iniciar a construção da barragem, foi efetuado em dezembro de 2006, entrando a barragem em operação no ano 2010. A barragem de Mazar tem $166 \mathrm{~m}$ de altura final (até o parapeito), comprimento total de $452 \mathrm{~m}$, comprimento de crista de $340 \mathrm{~m}$ e taludes de montante e jusante com inclinação horizontal/vertical de 1,4:1 e 1,25:1, respectivamente. Os materiais rochosos, em volume aproximado de $5.10^{6} \mathrm{~m}^{3}$, utilizados na execução do enrocamento foram xistos quartzíticos, cloríticos e sericíticos (Cruz, 2014). A Figura 7.1 ilustra a distribuição das zonas na barragem, enquanto que a Tabela 7.1 relaciona os diversos materiais que compõem a geoestrutura.

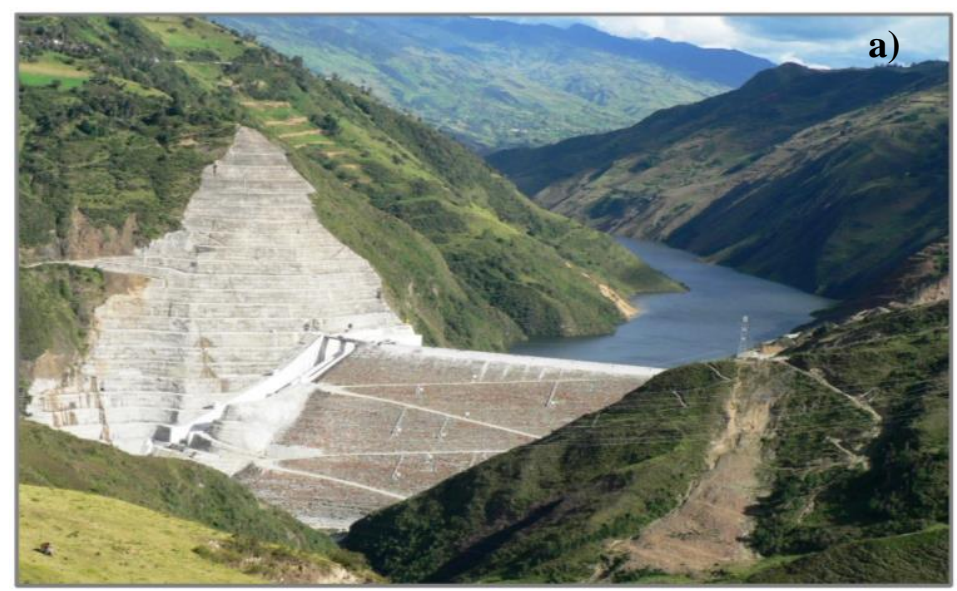



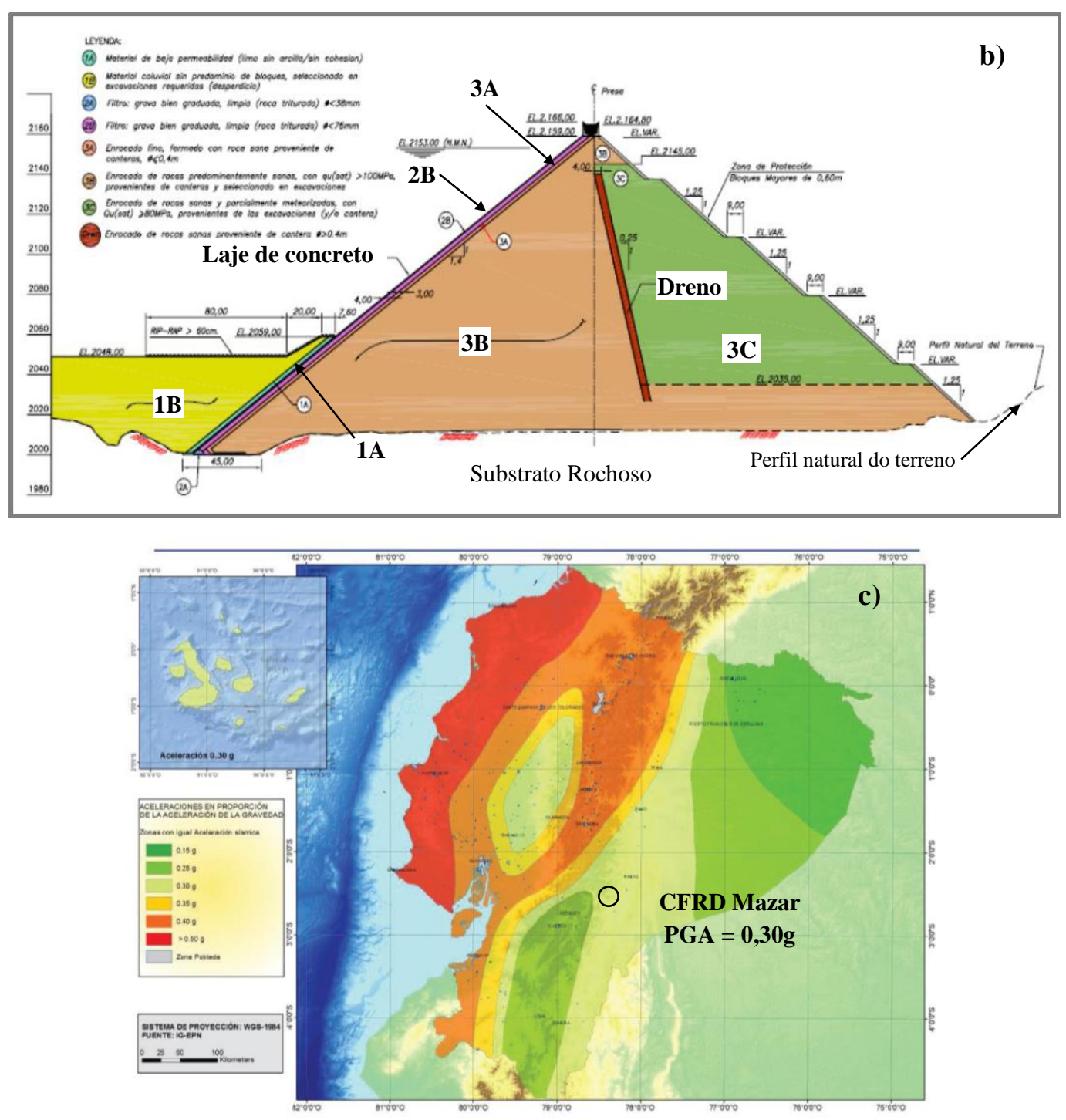

Figura 7.1 - CFRD Mazar - Equador: a) vista geral do projeto; b) seção máxima (Toledo, 2009); c) localização no mapa de isozonas sísmicas (NEC-2014).

Tabela 7.1 - Materiais e método construtivo da CFRD Mazar (Cruz, 2014).

\begin{tabular}{lcll}
\hline Designação & Zona & Colocação & Compactação \\
\hline Silte & 1A & Camadas de $0,30 \mathrm{~m}$ & Equipamento de construção \\
\hline Material selecionado & 1B & Camadas de $0,60 \mathrm{~m}$ & Equipamento de construção \\
\hline Transição fina, $\mathrm{D}_{\max } 30 \mathrm{~mm}$ & 2A & Camadas de $0,40 \mathrm{~m}$ & Rolo vibratório \\
\hline $\begin{array}{l}\text { Seixo processados } \\
\mathrm{D}_{\max } 75 \mathrm{~mm} \text {, bem graduado }\end{array}$ & 2B & Camadas de $0,50 \mathrm{~m}$ & Rolo vibratório $10 \mathrm{t}, 6$ passadas \\
\hline $\begin{array}{l}\text { Transição de enrocamento } \\
\mathrm{D}_{\max } 0,40 \mathrm{~m}\end{array}$ & 3A & Camadas de $0,50 \mathrm{~m}$ & Rolo vibratório $10 \mathrm{t}, 6$ passadas \\
\hline Enrocamento da pedreira & 3B & Camadas de $0,50 \mathrm{~m}$ & $\begin{array}{l}\text { Rolo vibratório } 13.6 \mathrm{t}, 6 \text { passadas, água } \\
3001 / \mathrm{m}^{3}\end{array}$ \\
\hline Enrocamento das escavações & 3C & Camadas de $0,80 \mathrm{~m}$ & $\begin{array}{l}\text { Rolo vibratório } 13.6 \mathrm{t}, 6 \text { passadas, água } \\
3001 / \mathrm{m}^{3}\end{array}$ \\
\hline
\end{tabular}




\subsection{1.}

\section{Propriedades dos materiais}

As simulações numéricas, tanto estáticas quanto dinâmicas na barragem de Mazar, foram executadas no estado plano de deformação utilizando o modelo constitutivo elástico linear para a rocha de fundação e o modelo elasto-plástico de Mohr Coulomb para os materiais componentes da barragem (enrocamentos 3B e 3C, dreno e material da região 1B). Na Tabela 7.2 apresentam-se as propriedades para cada material.

Tabela 7.2 - Propriedades dos materiais da fundação e corpo da barragem de Mazar (Hidropaute, 2011).

\begin{tabular}{|l|c|cccc|}
\hline \multirow{2}{*}{\multicolumn{1}{|c|}{ Parâmetros }} & Fundação & \multicolumn{4}{c|}{ Corpo da barragem } \\
\cline { 2 - 6 } & Rocha & Enrocamento 3B & Enrocamento 3C & Dreno & Região 1B \\
\hline Peso especifico $\gamma\left(\mathrm{kN} / \mathrm{m}^{3}\right)$ & 25 & 21 & 19 & 17 & 21,5 \\
Módulo de Young E $(\mathrm{MPa})$ & 6288 & 120 & 90 & 100 & 120 \\
Coeficiente de Poisson $v$ & 0,28 & 0,3 & 0,3 & 0,3 & 0,25 \\
Módulo de cisalhamento G (MPa) & 2456 & 46,15 & 34,62 & 38,46 & 48 \\
Coesão c $(\mathrm{kPa})$ & 294 & 0 & 0 & 0 & 40 \\
Ângulo de atrito $\left({ }^{\circ}\right)$ & 35 & Figura 7.2 & Figura 7.2 & 45 & 36 \\
Velocidade onda cisalhante $(\mathrm{m} / \mathrm{s})$ & 1850 & 387 & 406 & 400 & 350 \\
Massa específica $\left(\mathrm{kg} / \mathrm{m}^{3}\right)$ & 2550 & 2140 & 1937 & 1733 & 2192 \\
\hline
\end{tabular}

Da Tabela 7.2 nota-se que os ângulos de atrito do modelo de MohrCoulomb para os enrocamentos 3B e 3C encontram-se explicitados na Figura 7.2, pois o modelo numérico considera uma variação do ângulo de atrito em função da tensão vertical atuante, conforme recomendação de Leps (1970). Na barragem de Mazar os ângulos de atrito nos enrocamentos apresentaram variação na faixa de $37^{\circ}$ a $46^{\circ}$. 


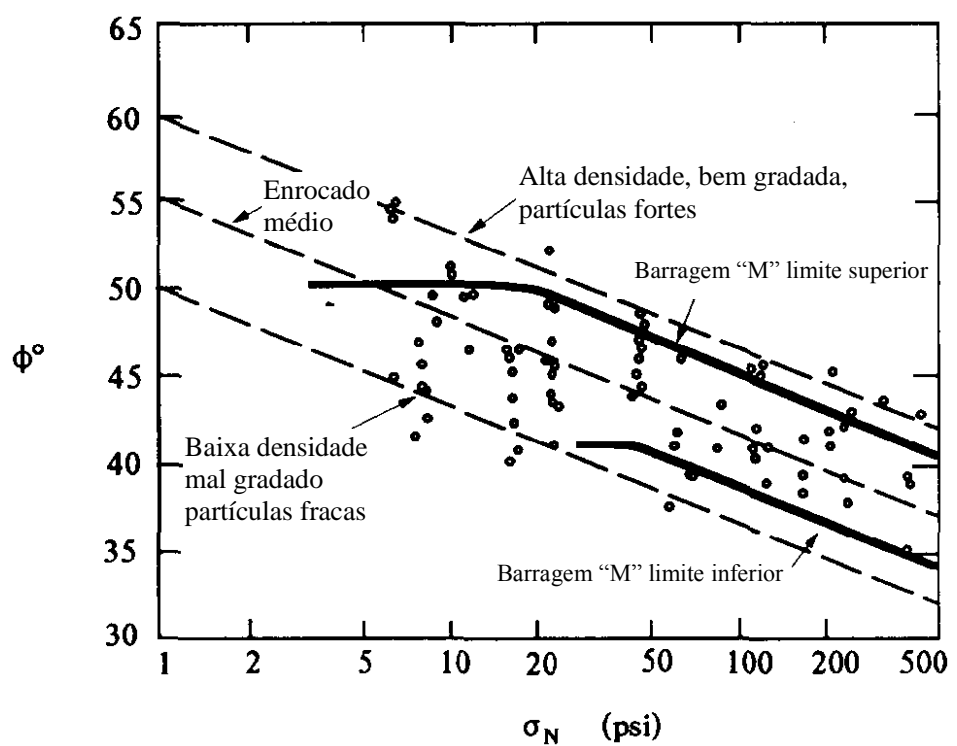

Figura 7.2 - Variação do ângulo de atrito de enrocamento em função da tensão vertical atuante (Adaptado de Leps, 1970).

\subsection{2. \\ Sismos de projeto}

Devido à importância da estrutura, e de acordo com as recomendações da Norma Equatoriana da Construção (NEC, 2014), deve-se verificar o desempenho sísmico da geoestrutura para duas modalidades de terremotos de projeto:

- terremoto operacional OBE (Operating Basis Earthquake), com um período de recorrência de 475 anos.

- máximo terremoto provável MCE (Maximum Credible Earthquake) com um período de recorrência de 2500 anos.

De acordo com estas recomendações, estabeleceram-se 3 registros sísmicos reais, com características diferentes em relação a profundidades focais, mas com epicentros próximos da área de projeto (Figura 7.3 e Tabela 7.3). Estes acelerogramas reais foram ajustados no domínio da frequência com os espectros elásticos representativos do MCE e OBE (Norma Equatoriana da Construção NEC 2014) indicados na Figura 7.4. Foram também efetuadas correções de desvio da linha base e filtragem de frequências nos limites entre $0,1 \mathrm{~Hz}$ e $12 \mathrm{~Hz}$. As Figuras 7.5 e Figura 7.6 mostram os resultados. 
Tabela 7.3 - Terremotos de projeto (OBE, MCE) para a barragem de enrocamento de Mazar.

\begin{tabular}{|lcccc|}
\hline Sismo & Data & $M_{\mathrm{w}}$ & $\begin{array}{c}\text { Profundidade } \\
(\mathrm{km})\end{array}$ & $\begin{array}{c}\text { Distância } \\
\text { epicentral }(\mathrm{km})\end{array}$ \\
\hline La Troncal & $15 / \mathrm{nov} / 15$ & 5.6 & 87 & 75 \\
Paute Base 1 & 29/mar/12 & 4.7 & 59,9 & 58 \\
Paute Base 3 & $16 / \mathrm{nov} / 13$ & 4 & 116 & 20,7 \\
\hline
\end{tabular}
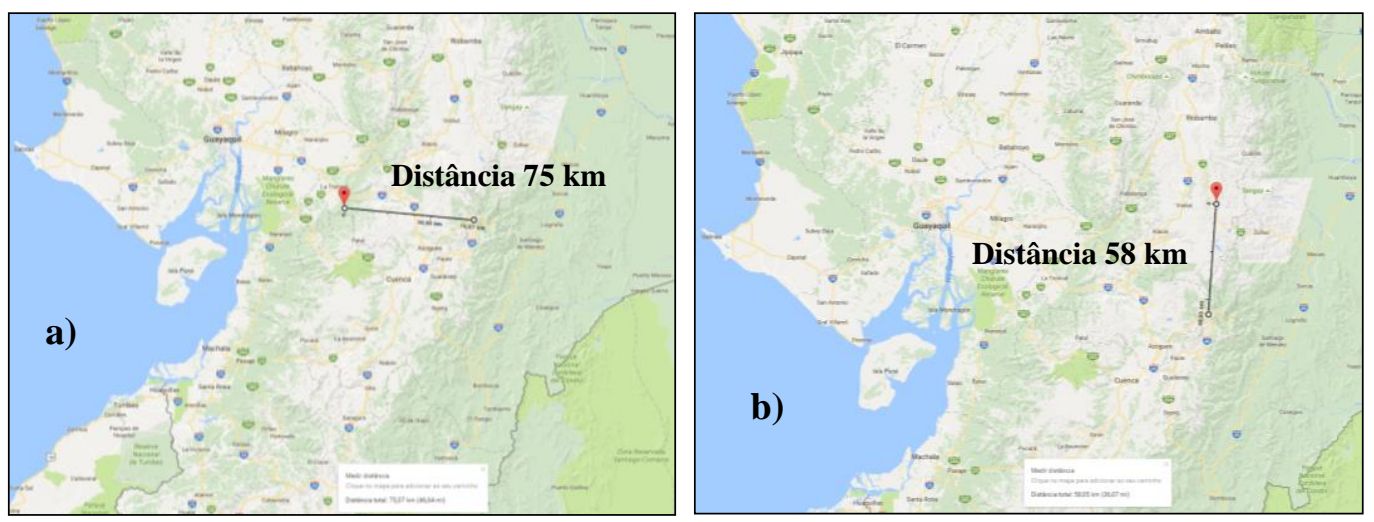

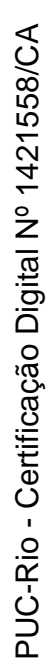

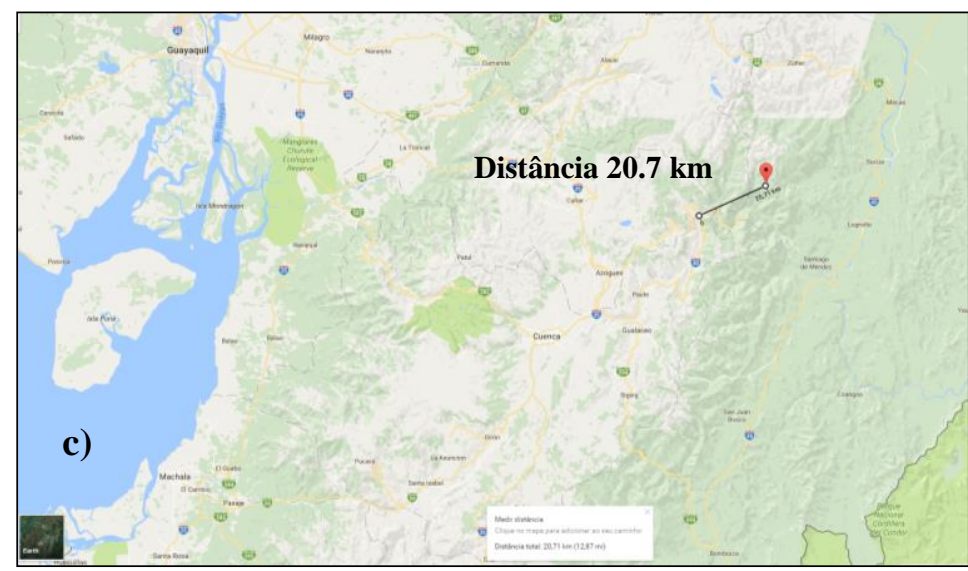

Figura 7.3 - Distâncias epicentrais da CFRD Mazar aos sismos de projeto: a) La Troncal; b) Paute Base 1; c) Paute Base 3.

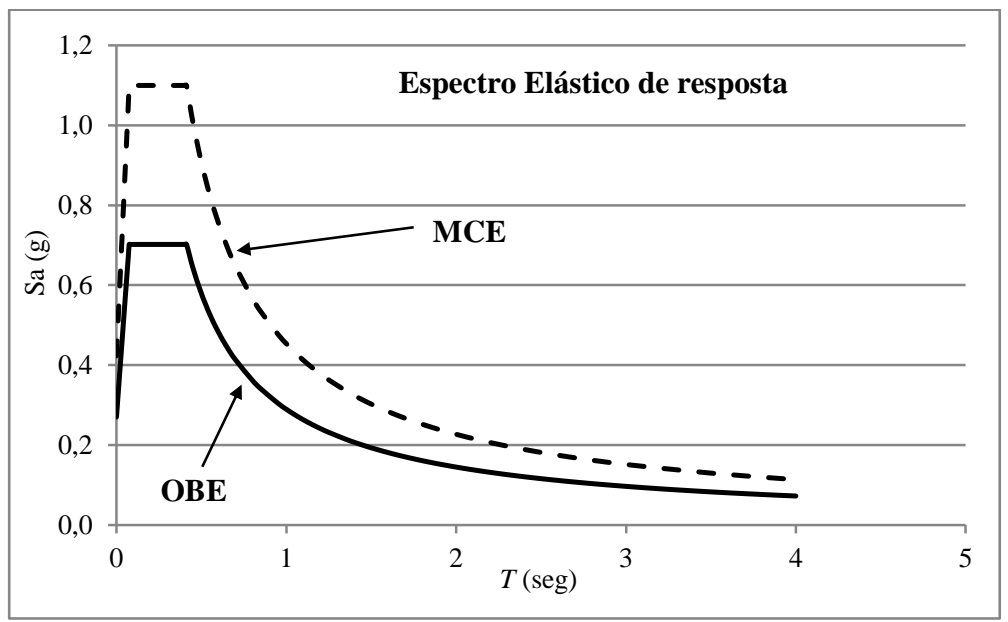

Figura 7.4 - Espectros elásticos OBE, MCE (Norma Equatoriana da Construção NEC, 2014). 

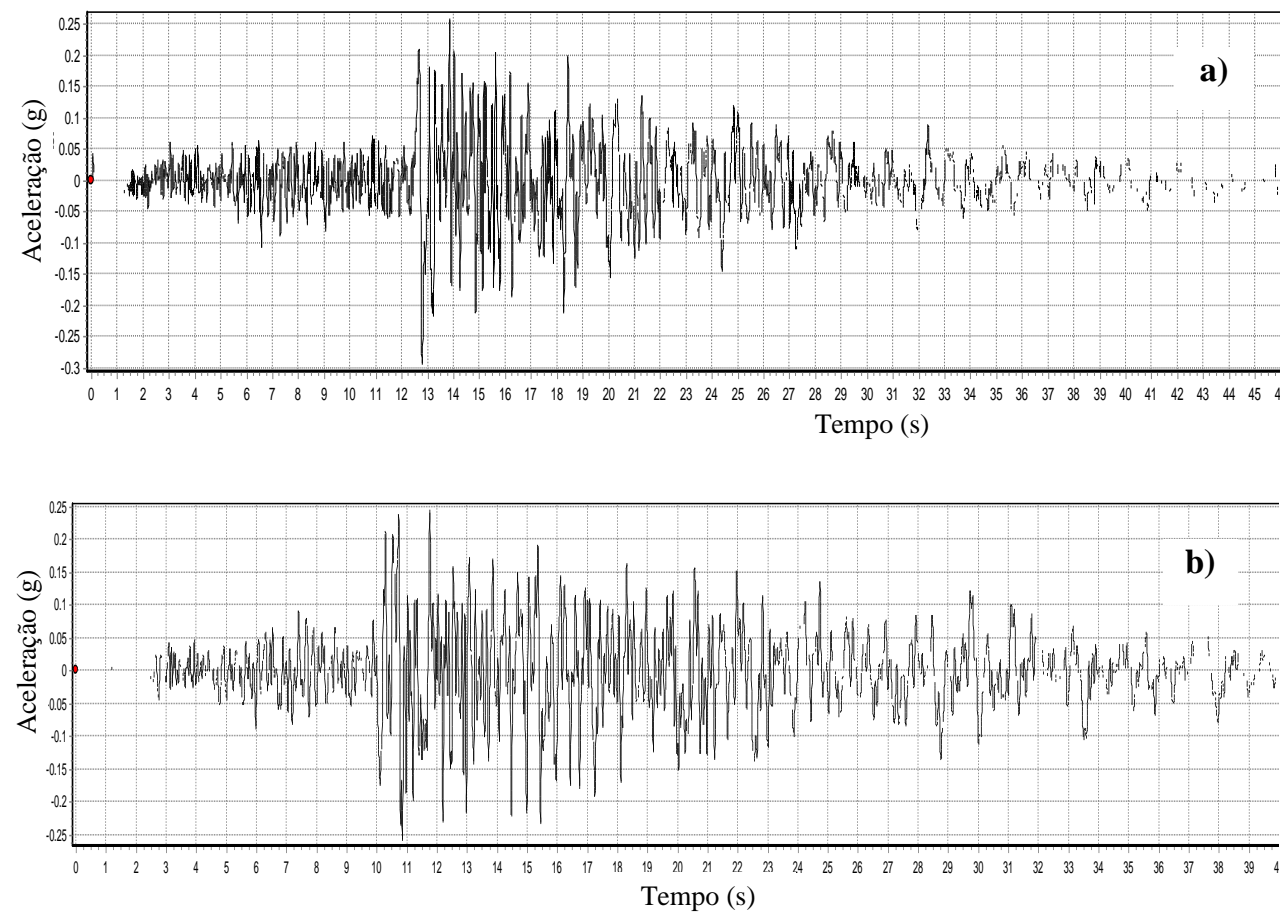

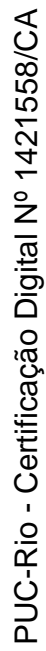

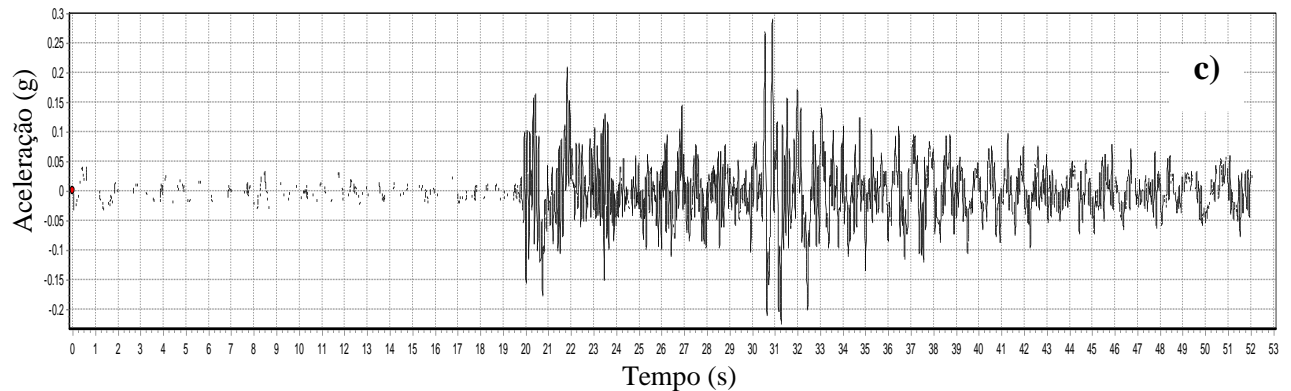

Figura 7.5 - Sismos de projeto (OBE), após ajuste ao espectro elástico, correção da linha base e filtragem de frequências $(0,1-12 \mathrm{~Hz})$ : a) La Troncal; b) Paute Base 1; c) Paute Base 3.
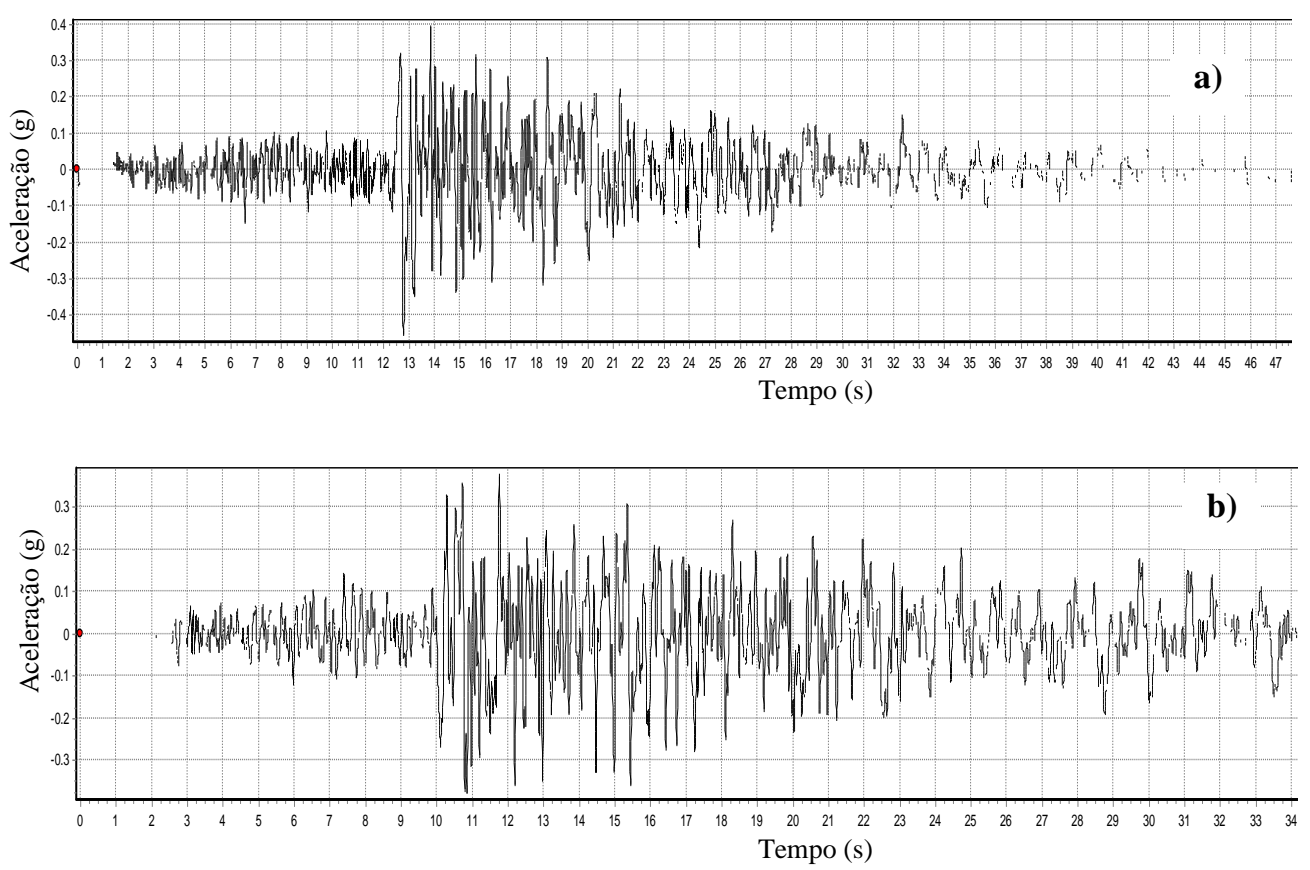


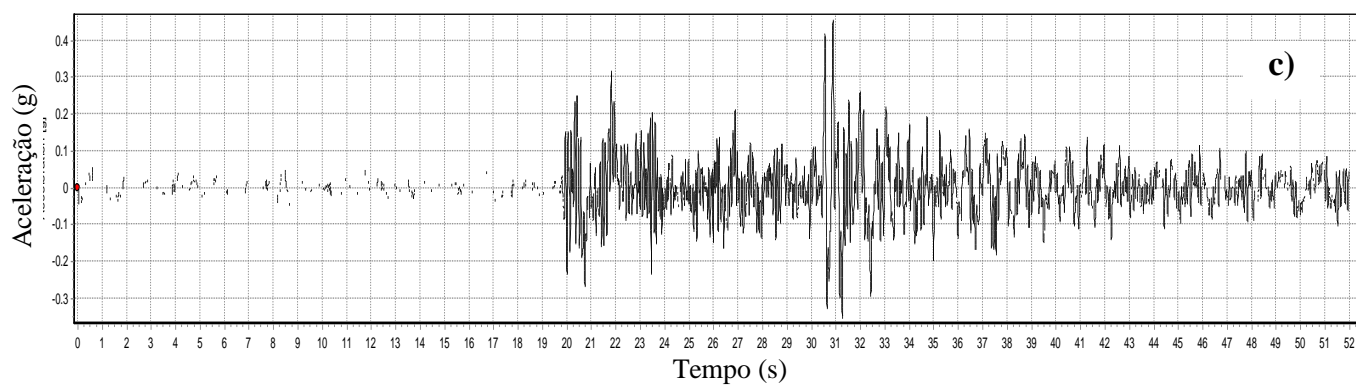

Figura 7.6 - Sismos de projeto (MCE), após ajuste ao espectro elástico de projeto, correção da linha base e filtragem de frequências $(0,1-12 \mathrm{~Hz})$ : a) La Troncal; b) Paute Base 1; c) Paute Base 3.

A Tabela 7.4 apresenta uma comparação da energia dos sismos de projeto em função da Intensidade de Arias $\left(I_{a}\right)$ e a intensidade característica $\left(I_{c}\right)$. Como mencionado anteriormente no Capitulo 6 , a intensidade característica do terremoto $I_{c}$ é determinada levando em conta a duração significativa fato pelo qual vê-se maior uniformidade destes valores tanto para o OBE quanto para o MCE. Por outro lado a intensidade de Arias é obtida pela integração sob a inteira duração do acelerograma, razão pela qual apresenta maior diferença em seus valores.

Tabela 7.4 - Sismos de projeto CFRD Mazar, Intensidade de Arias $I_{a}$, intensidade característica $I_{c}$.

\begin{tabular}{|lcc|}
\hline Sismo de projeto & Intensidade Arias $I_{a}(\mathrm{~m} / \mathrm{s})$ & Intensidade característica $\left(I_{c}\right)$ \\
\hline La Troncal MCE & 4,12 & 0,134 \\
Paute Base 1 MCE & 4,3 & 0,153 \\
Paute Base 3 MCE & 3,0 & 0,109 \\
\hline La Troncal OBE & 1,72 & 0,069 \\
Paute Base 1 OBE & 1,90 & 0,084 \\
Paute Base 3 OBE & 1,34 & 0,059 \\
\hline
\end{tabular}

\subsection{3.}

\section{Tamanho máximo do elemento no modelo numérico}

As frequências de corte $\left(f_{c}\right)$ para os diferentes registros de aceleração foram determinadas com o espectro de potência das acelerações, conservando-se no mínimo $99 \%$ da potência original do sismo. Assim foi fixado o valor $f_{c}=12 \mathrm{~Hz}$ para todos os sismos de projeto. As Figuras 7.7 e Figura 7.8 apresentam os respectivos espectros de potência.

Uma vez fixada uma frequência de corte determinou-se em seguida o máximo comprimento do elemento na direção (vertical) de propagação das ondas. Dos solos presentes na estrutura o de menor velocidade de propagação da onda 
cisalhante é o Material 1B $\left(V_{s}=350 \mathrm{~m} / \mathrm{s}\right)$. Utilizando a recomendação de Kuhlemeyer e Lysmer (1973), com o objetivo de reduzir o tamanho da malha e tempos computacionais, foram considerados nas regiões críticas do modelo elementos com tamanho máximo $2,5 \mathrm{~m}$. A máxima frequência transmitida nesta região será aproximadamente de:

$$
f_{\max }=\frac{V_{s}}{10 \Delta_{l}}=14 \mathrm{~Hz}
$$

superior à frequência de corte $f_{c}=12 \mathrm{~Hz}$ anteriormente estabelecida.
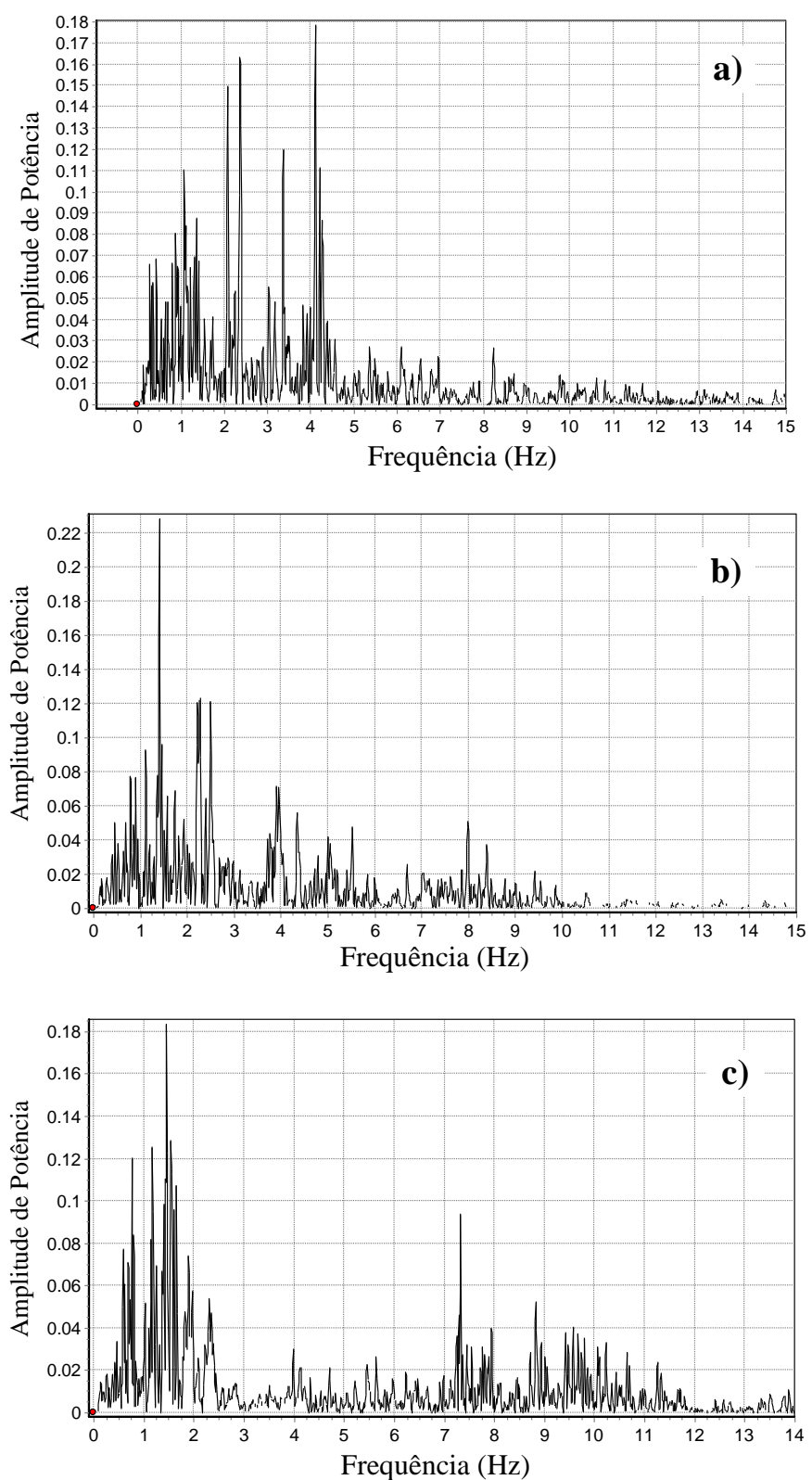

Figura 7.7 - Frequências de corte determinadas dos espectros de potência dos sismos de projeto OBE: a) La Troncal; b) Paute Base 1; c) Paute Base 3. 

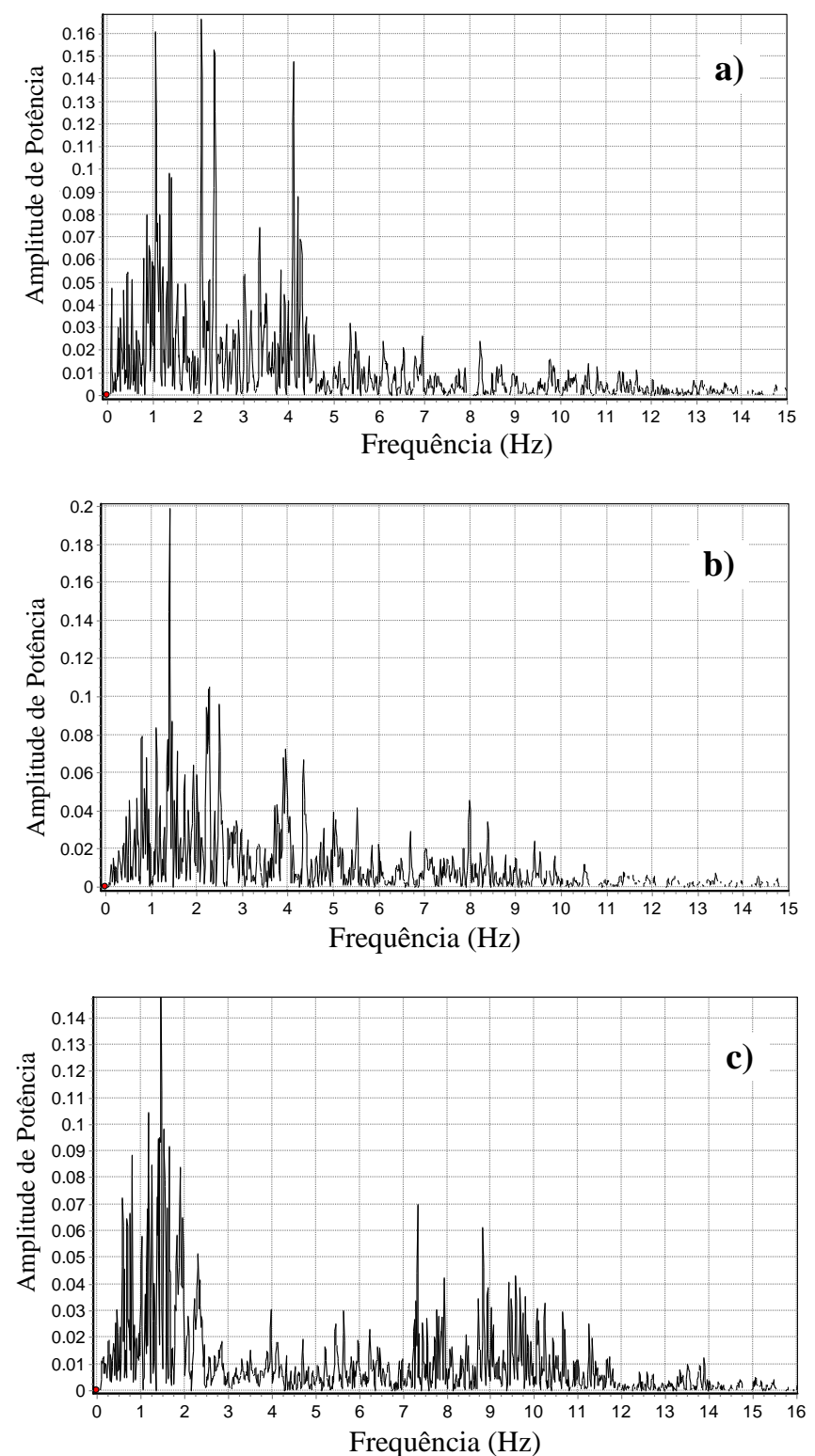

Figura 7.8 - Frequências de corte determinadas dos espectros de potência dos sismos de projeto MCE: a) La Troncal; b) Paute Base 1; c) Paute Base 3.

\section{2.}

\section{Análise de estabilidade estática}

Como requisito prévio à análise da resposta dinâmica da barragem, foram verificadas as condições de estabilidade estática dos taludes, determinando-se fatores de segurança para os casos de reservatório vazio e reservatório cheio na capacidade máxima de armazenamento de água.

O modelo numérico bidimensional construído com o programa de diferenças finitas Flac 2D v8.0 possui $169 \mathrm{~m}$ de altura e $1220 \mathrm{~m}$ de comprimento (Figura 7.9), com o subsolo representado por uma camada única de rocha inalterada de $20 \mathrm{~m}$ de espessura. 
Cabe destacar que os materiais incluídos nesta modelagem foram os enrocamentos denominados $3 \mathrm{~B}$ e $3 \mathrm{C}$, material $1 \mathrm{~B}$, filtro, substrato rochoso e laje de concreto na face de montante.

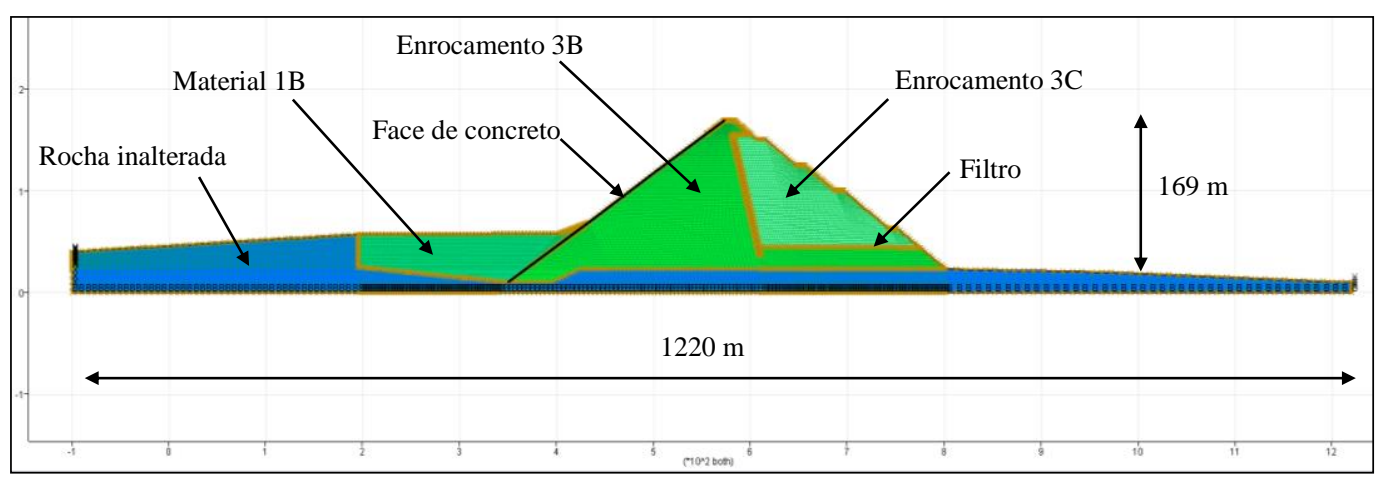

Figura 7.9 - Geometria da barragem de Mazar.

Quando se utiliza um método numérico deve ser verificado se a superfície de ruptura obtida representa verdadeiramente uma instabilidade global da estrutura; caso negativo, o solo da região local potencialmente instável deve ter sua resistência majorada, geralmente incrementando-se o valor da coesão (Figura 7.10). Os fatores de segurança estáticos, nos casos de reservatório vazio e reservatório cheio, foram determinados pelo programa Flac 2D v.8, pelo método da redução dos parâmetros de resistência (Figura 7.11), e pelo programa computacional Slide 6, pelo método das fatias de Spencer (Figura 7.12).

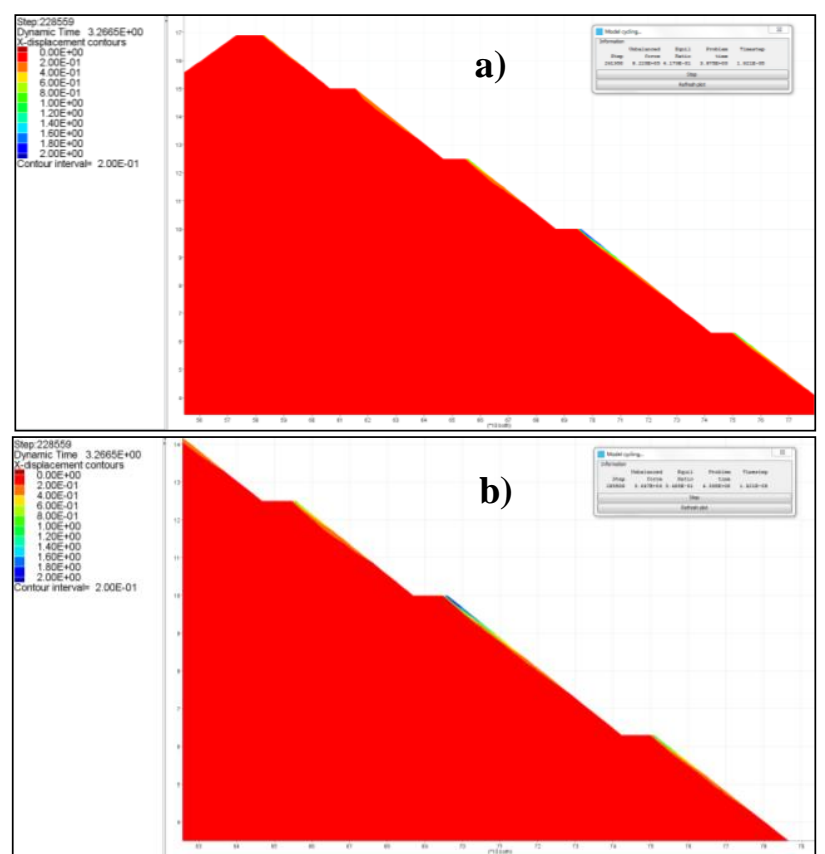

Figura 7.10 - Superfícies de ruptura locais com reservatório na máxima capacidade: a) FS = 1,3; b) $\mathrm{FS}=1,35$. 

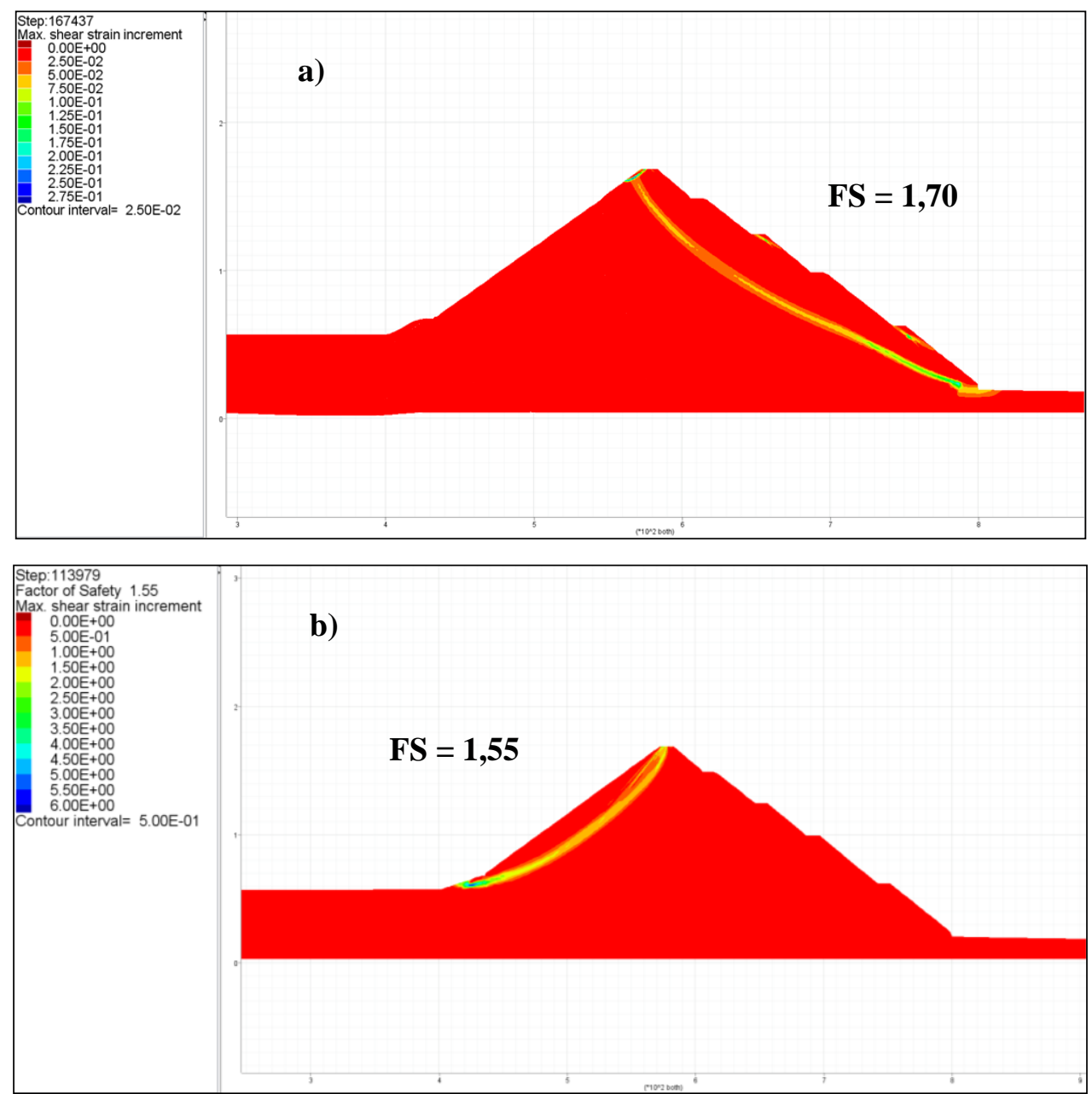

Figura 7.11 - Fatores de segurança para superfícies de ruptura globais na barragem de Mazar: a) reservatório na máxima capacidade $\mathrm{FS}=1,70 ; \mathrm{b}$ ) reservatório vazio $\mathrm{FS}=1,55$.

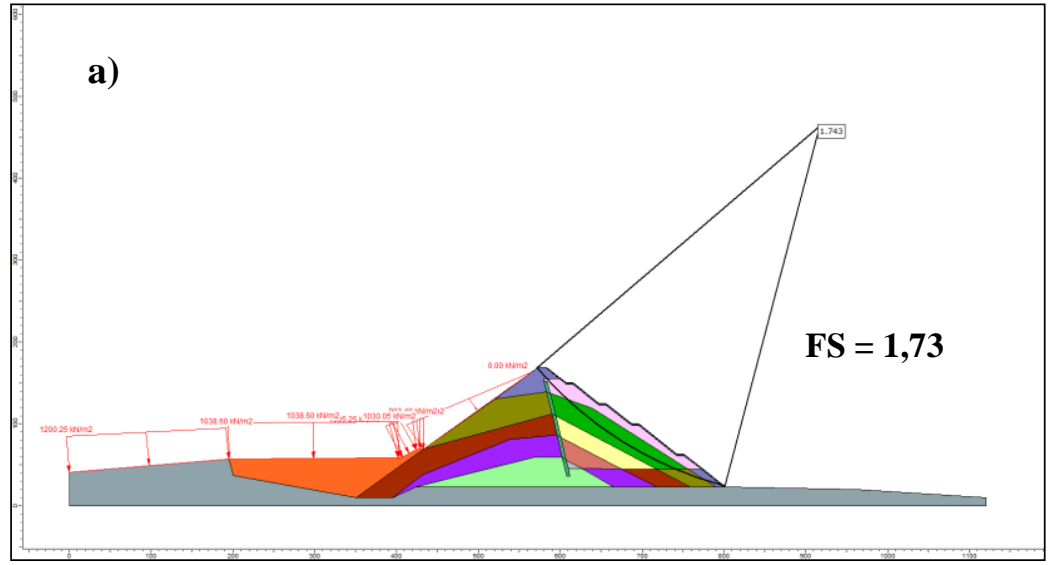




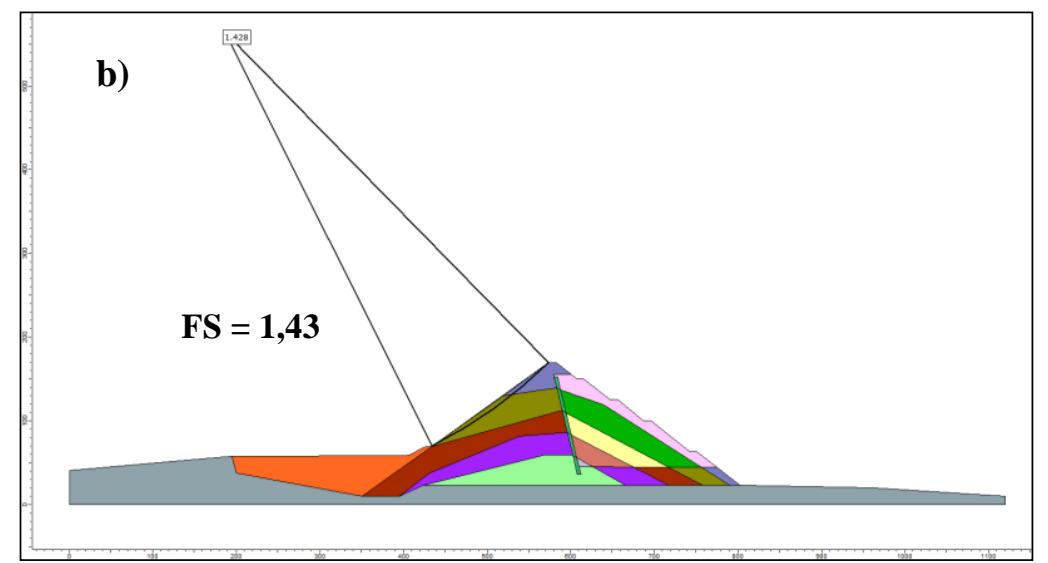

Figura 7.12 - Fatores de segurança calculados com método das fatias (método de Spencer) na barragem de Mazar: a) reservatório na máxima capacidade $\mathrm{FS}=1,73$; b) reservatório vazio $\mathrm{FS}=$ 1,43 .

\section{3.}

\section{Análise de estabilidade pseudo-estático}

Os efeitos do movimento sísmico serão simulados mediante aplicação de uma força de amplitude constante no sentido horizontal, representativa da força de inércia. Para este fim, foi adotado um coeficiente sísmico horizontal $k_{h}$ equivalente a 50\% da máxima aceleração horizontal em rocha, como recomendado por Hynes-Griffin e Franklin (1984). Sendo PGA $_{r o c k}=0,30 \mathrm{~g}$ para o caso de terremoto operacional $(\mathrm{OBE})$ e $\mathrm{PGA}_{\text {rock }}=0,46 \mathrm{~g}$ para o máximo terremoto provável (MCE), os coeficientes sísmicos horizontais aplicados serão $k_{h}=0,15 \mathrm{e}$ $k_{h}=0,23$, respetivamente. As Figuras 7.13 e 7.14 apresentam os fatores de segurança para os taludes da barragem de Mazar determinados mediante equilíbrio limite com o programa computacional Slide 7.0. A Figura 7.15 mostra o

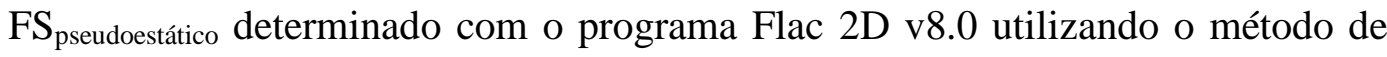
redução dos parâmetros de resistência dos materiais. A Tabela 7.5 apresenta um resumo dos resultados obtidos para as condições de reservatório analisadas.

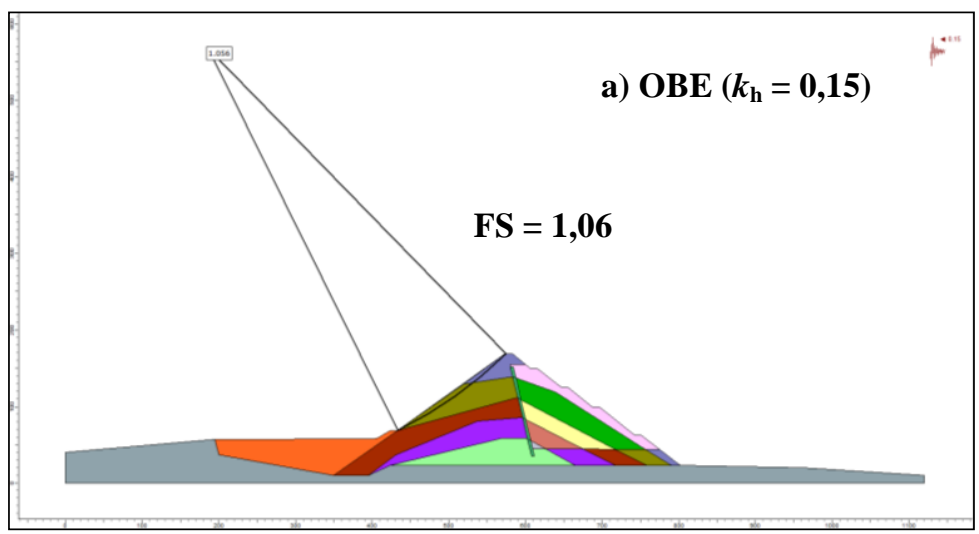




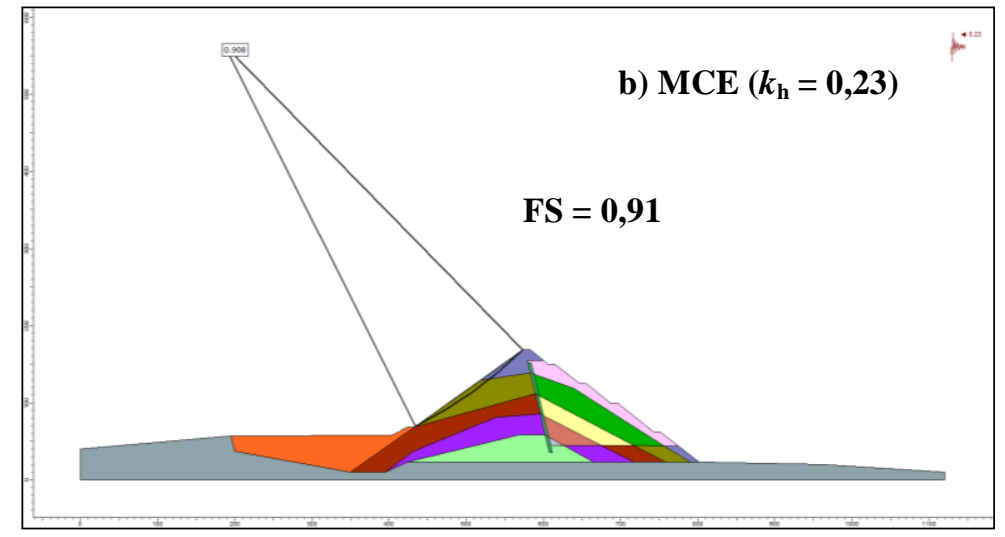

Figura 7.13 - Fator de segurança pseudoestático no caso de reservatório vazio com o método das fatias de Spencer: a) OBE FS = 1,06; b) MCE FS = 0,91.

a) OBE $\left(k_{\mathrm{h}}=\mathbf{0 , 1 5}\right)$
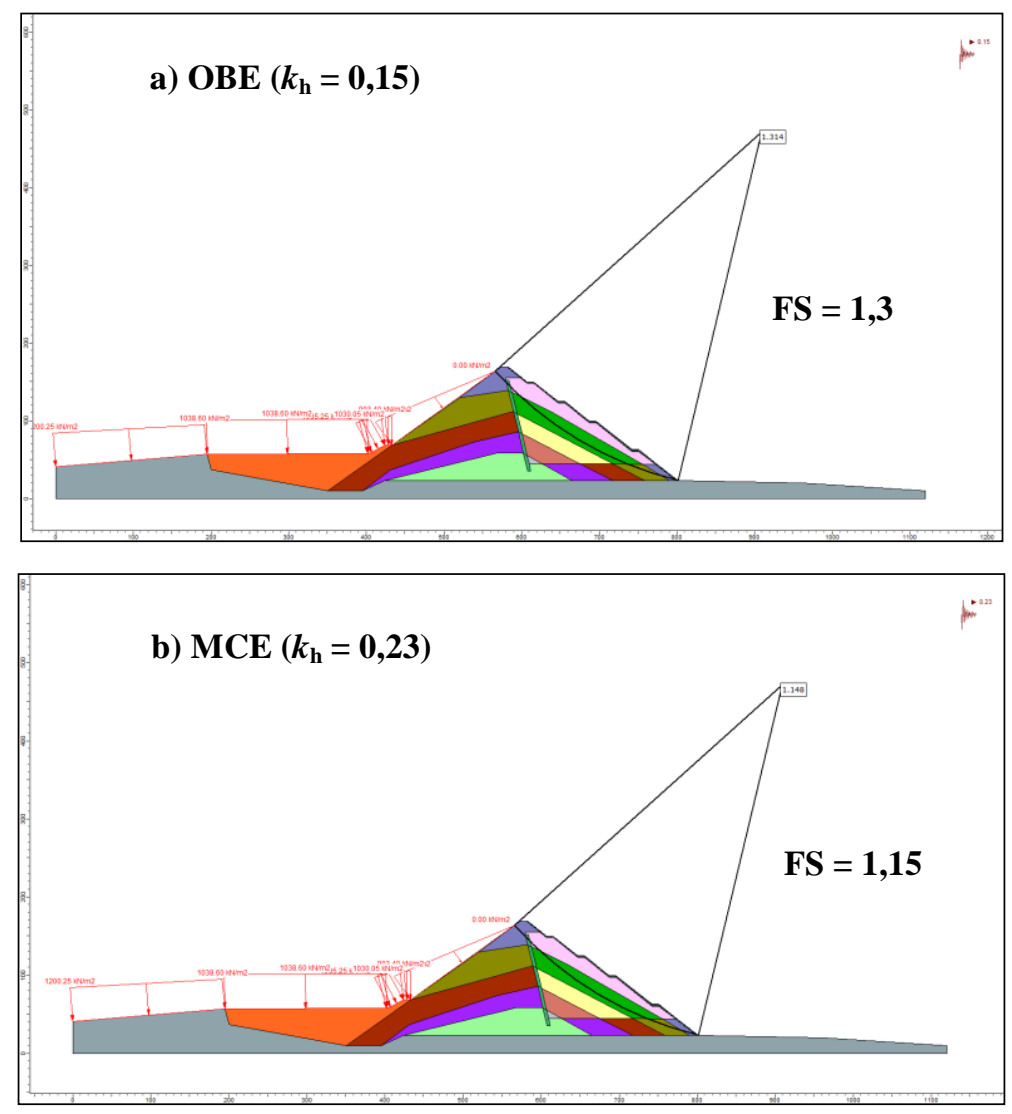

Figura 7.14 - Fator de segurança pseudo-estático no caso de reservatório cheio com o método das fatias de Spencer a) OBE FS = 1,3; b) MCE FS = 1,15. 

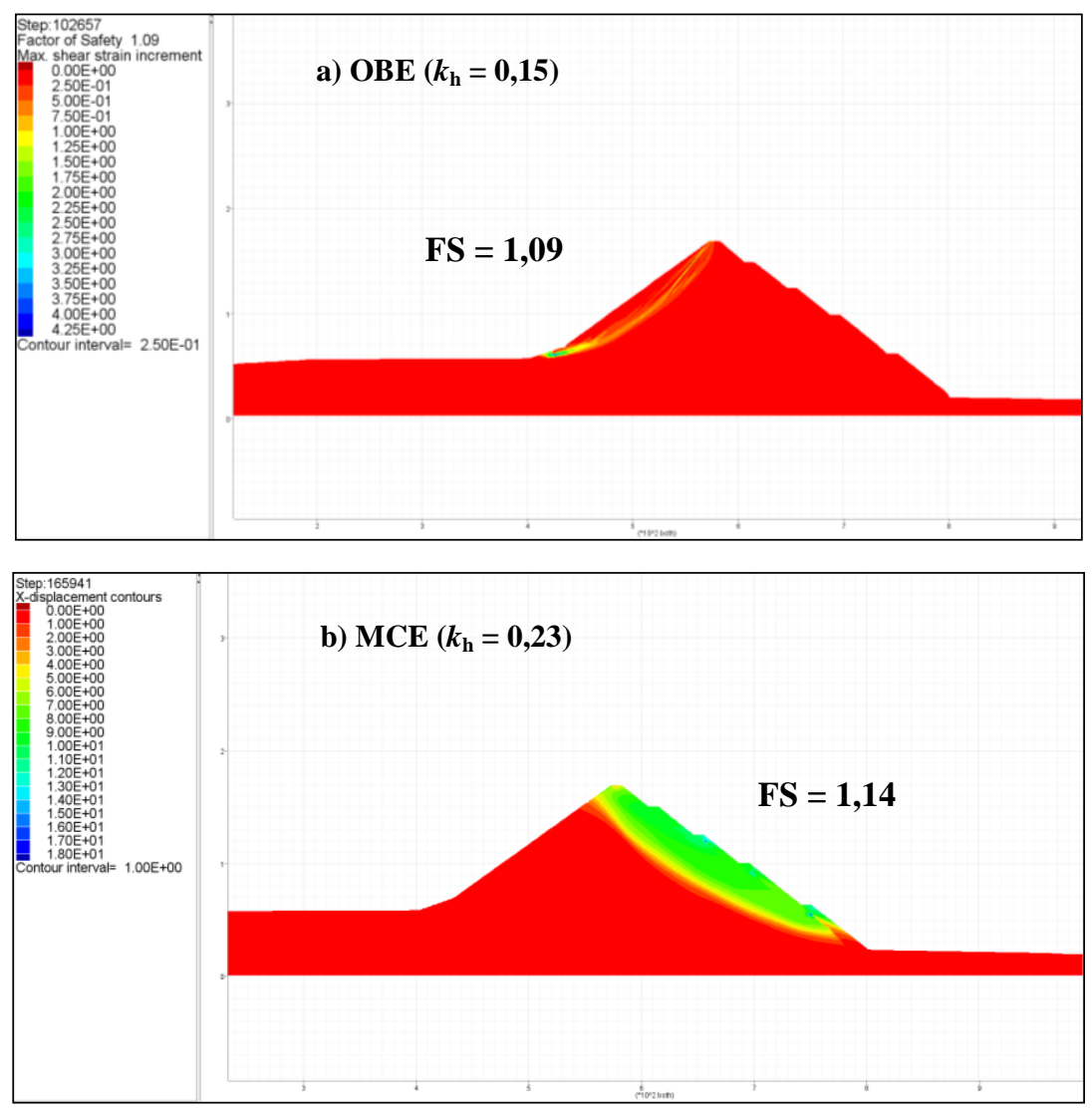

Figura 7.15 - Fator de segurança pseudoestático pelo método de redução dos parâmetros de resistência (software Flac $2 \mathrm{D}$ v8.0); a) reservatório vazio $\mathrm{OBE} F \mathrm{FS}=1,09$; b) reservatório cheio MCE FS $=1,14$.

Tabela 7.5 - Resumo dos fatores de segurança obtidos da análise pseudo-estática da barragem de Mazar.

\begin{tabular}{|l|c|cc|}
\hline \multirow{2}{*}{ Método } & \multirow{2}{*}{ Sismo de projeto } & \multicolumn{2}{c|}{ Condição do reservatório } \\
\cline { 3 - 4 } & & Vazio & Máximo nível \\
\hline Equilíbrio limite (Slide v7) & OBE & 1,06 & 1,30 \\
Equilíbrio limite (Slide v7) & MCE & 0,91 & 1,15 \\
\hline Redução dos parâmetros & OBE & 1,09 & 1,36 \\
de resistência do material (Flac v8.0) & MCE & $<1,0$ & 1,14 \\
\hline
\end{tabular}

Conclui-se que a condição mais desfavorável de estabilidade é a de reservatório vazio com aplicação do terremoto máximo provável (MCE). Como os valores dos fatores de segurança pseudo-estático resultaram inferiores a 1,1 então é recomendável a execução de uma análise dinâmica para verificação da amplitude dos deslocamentos permanentes causados pelos sismos de projeto que possam comprometer a servicibilidade pós-terremoto da barragem de Mazar. 


\section{4. \\ Métodos simplificados para estimativa de deslocamentos permanentes}

Para estimativa de deslocamentos permanentes mediante métodos simplificados disponíveis na literatura é necessário a determinação da aceleração de escoamento que induz um fator de segurança $\mathrm{FS}_{\text {pseudo-estático }}=1$ nos taludes da barragem de Mazar. Com auxílio do método das fatias de Spencer foram determinados $a_{y}=0,31 \mathrm{~g}$ para o talude de jusante no caso de reservatório cheio e $a_{y}=0,18 \mathrm{~g}$ no talude de montante, na condição mais desfavorável de reservatório vazio.

\subsection{1.}

\section{Métodos baseados no bloco rígido deslizante}

Os métodos simplificados baseados na analogia do deslizamento de bloco rígido em plano inclinado de Newmark (1965) requerem dupla integração no tempo das histórias de aceleração registradas em pontos situados na superfície potencial de deslizamento. Com este objetivo foram consideradas colunas de solo com as propriedades dos enrocamentos 3B e 3C no programa de propagação de ondas 1D SHAKE 2000, mas as acelerações de pico observadas em pontos da superfície potencial de deslizamento foram inferiores à aceleração de escoamento $\left(a_{y}\right)$, indicando deslocamentos permanentes nulos. Este resultado deve-se também ao fato de que o programa SHAKE2000 (método linear equivalente) assume camadas horizontais de extensão lateral infinita (análise 1D) sendo impossível incorporar os efeitos de amplificação topográfica que ocorrem devido à geometria da barragem.

Por outro lado, mediante as funções analíticas propostas por Cai e Bathurst (1996) apresentadas no Capítulo 3, considerando-se os valores de $k_{y}=\mathrm{a}_{y} / \mathrm{g}$, PGA e PGV, obtiveram-se os deslocamentos permanentes listados na Tabela 7.6. Observa-se, como era esperado, que o máximo deslocamento horizontal permanente $(\mathrm{D}=20$ $\mathrm{cm}$ ) ocorre na condição de reservatório vazio com o terremoto de projeto MCE. Para os demais casos, os deslocamentos são relativamente pequenos. 
Tabela 7.6 - Deslocamentos permanentes mediante as funções analíticas propostas por Cai e Bathurst (1996).

\begin{tabular}{|lcccccc|}
\hline Reservatório & Sismo de projeto & $k_{y}$ & PGA $(\mathrm{g})$ & PGV $(\mathrm{m} / \mathrm{s})$ & $k_{y} / \mathrm{PGA}$ & $\mathrm{D}(\mathrm{m})$ \\
\hline Máxima & MCE & 0,31 & 0,45 & 0,526 & 0,69 & 0,07 \\
capacidade & OBE & 0,31 & 0,30 & 0,335 & 1,03 & 0,02 \\
\hline \multirow{2}{*}{ Vazio } & MCE & 0,18 & 0,45 & 0,526 & 0,4 & 0,20 \\
& OBE & 0,18 & 0,30 & 0,335 & 0,6 & 0,05 \\
\hline
\end{tabular}

\subsection{2.}

\section{Método de Bray e Travasarou (2007)}

Para a execução deste método simplificado são necessários os parâmetros que representam o movimento sísmico e as características da resistência dinâmica do material:

- Coeficiente de escoamento $\left(k_{y}\right)$ : calculado como $k_{y}=a_{y} / \mathrm{g}$, que para o caso da barragem de Mazar apresentou valores $k_{y}=0,31$ no caso de reservatório cheio, e $k_{y}=0,18$ no caso de reservatório vazio.

- Período inicial fundamental da massa deslizante $\left(T_{s}\right)$ : segundo Bray e Travasarou (2007) para o caso de massas deslizantes que obedecem a um comportamento marcadamente bidimensional, tem sido observados deslizamentos de forma triangular em barragens de terra e aterros de resíduos sólidos (Capítulo 3). Neste caso aqueles autores sugerem a equação 7.2 para cálculo do período fundamental inicial da massa instável:

$$
T_{s}=\frac{2,6 \mathrm{H}}{V_{s}}=0,95 s
$$

com a superfície de deslizamento iniciando na crista da barragem e se prolongando até o pé do talude de jusante $(\mathrm{H}=146 \mathrm{~m})$ e $V_{s}$ a velocidade de propagação da onda cisalhante no material de enrocamento.

- O terceiro parâmetro representativo dos efeitos do movimento do terreno é a aceleração espectral no período degradado da estrutura $S_{a}\left(1,5 T_{s}\right)$. Nos sismos de projeto (MCE e OBE), ajustados ao espectro elástico da norma NEC-2014, obtiveram-se os valores $S_{a}\left(1,5 T_{s}\right)=0,32 \mathrm{~g}$ e $S_{a}\left(1,5 T_{s}\right)=0,21 \mathrm{~g}$ para os terremotos MCE e OBE, respectivamente. 
- A magnitude de momento do terremoto foi estabelecida como $M_{\mathrm{w}}=7.6$, devido que a formulação do método considerou uma faixa de magnitudes sísmicas entre $5.5 \leq M_{\mathrm{w}} \leq 7.6$.

A análise simplificada foi executada utilizando o programa SHAKE2000

(Ordoñez, 2015) com os resultados apresentados nas Figuras 7.16 e Figura 7.17.
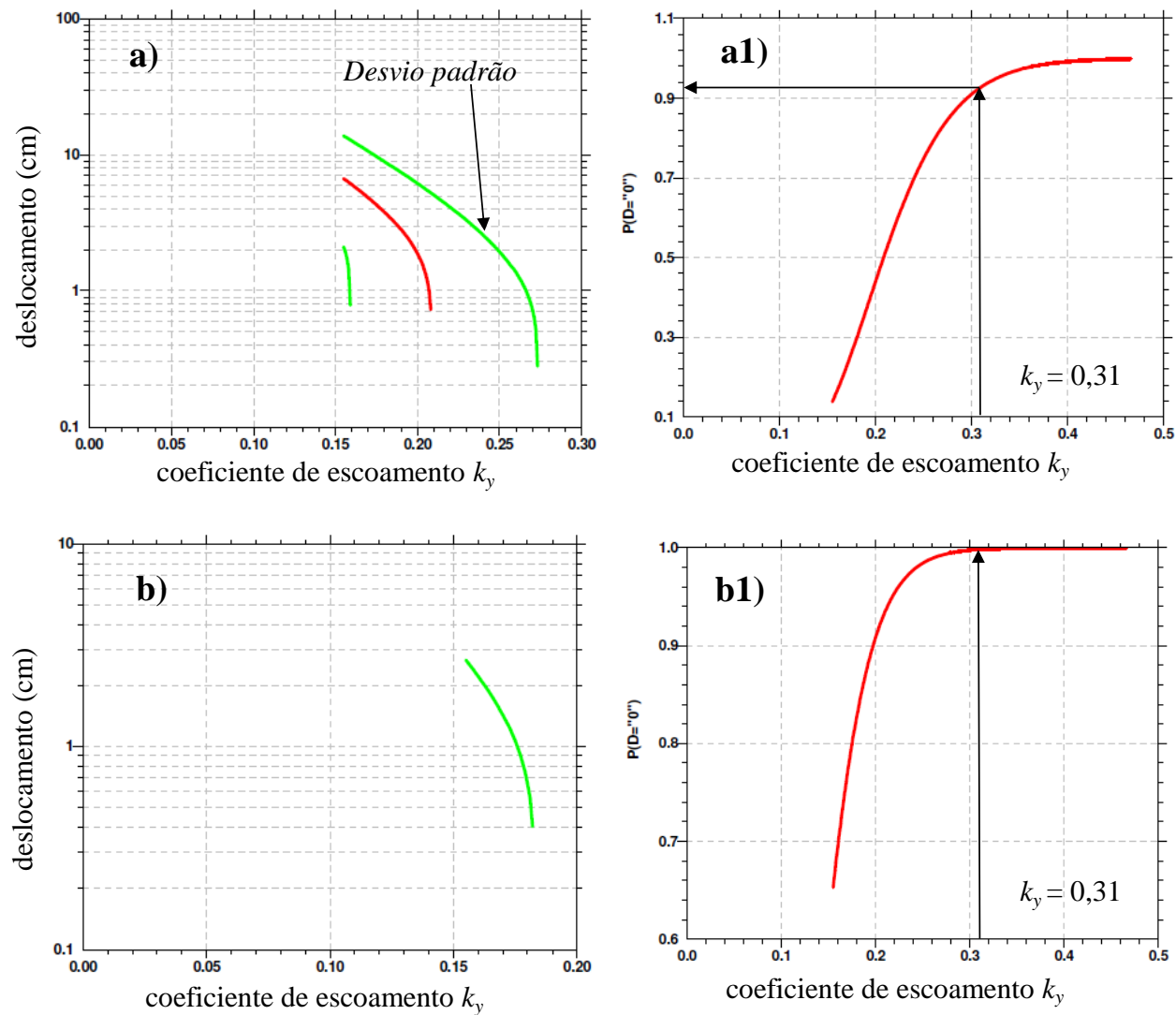

Figura 7.16 - Deslocamentos permanentes na barragem de Mazar com reservatório cheio pelo método de Bray e Travasarou: a) MCE; b) OBE.
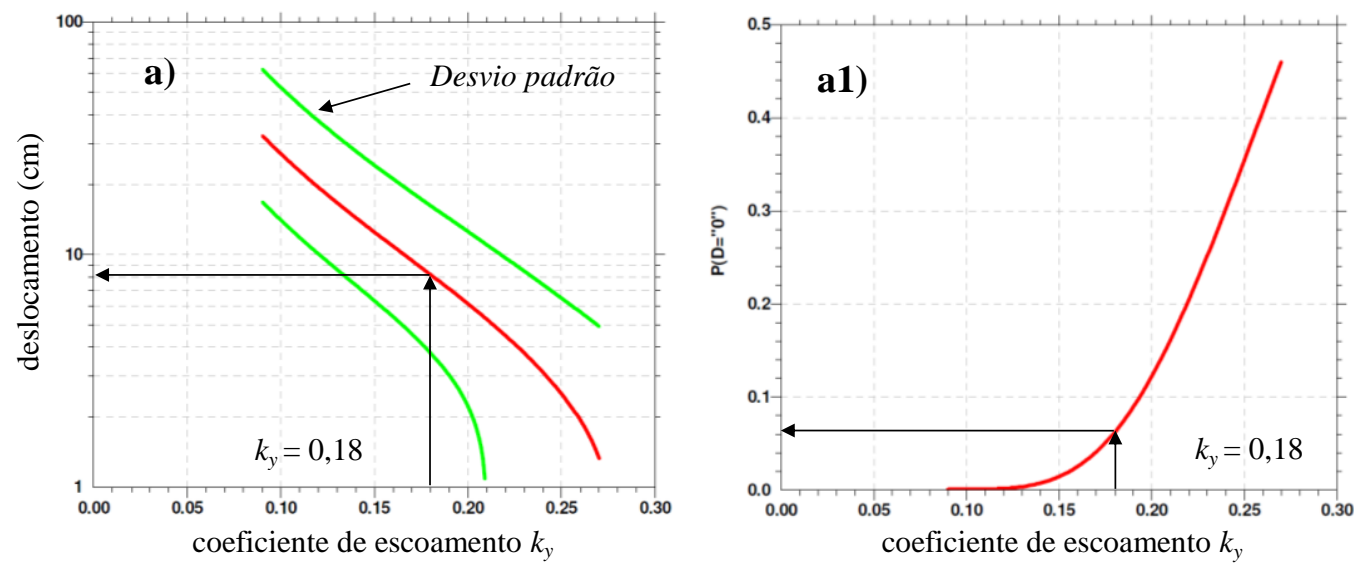

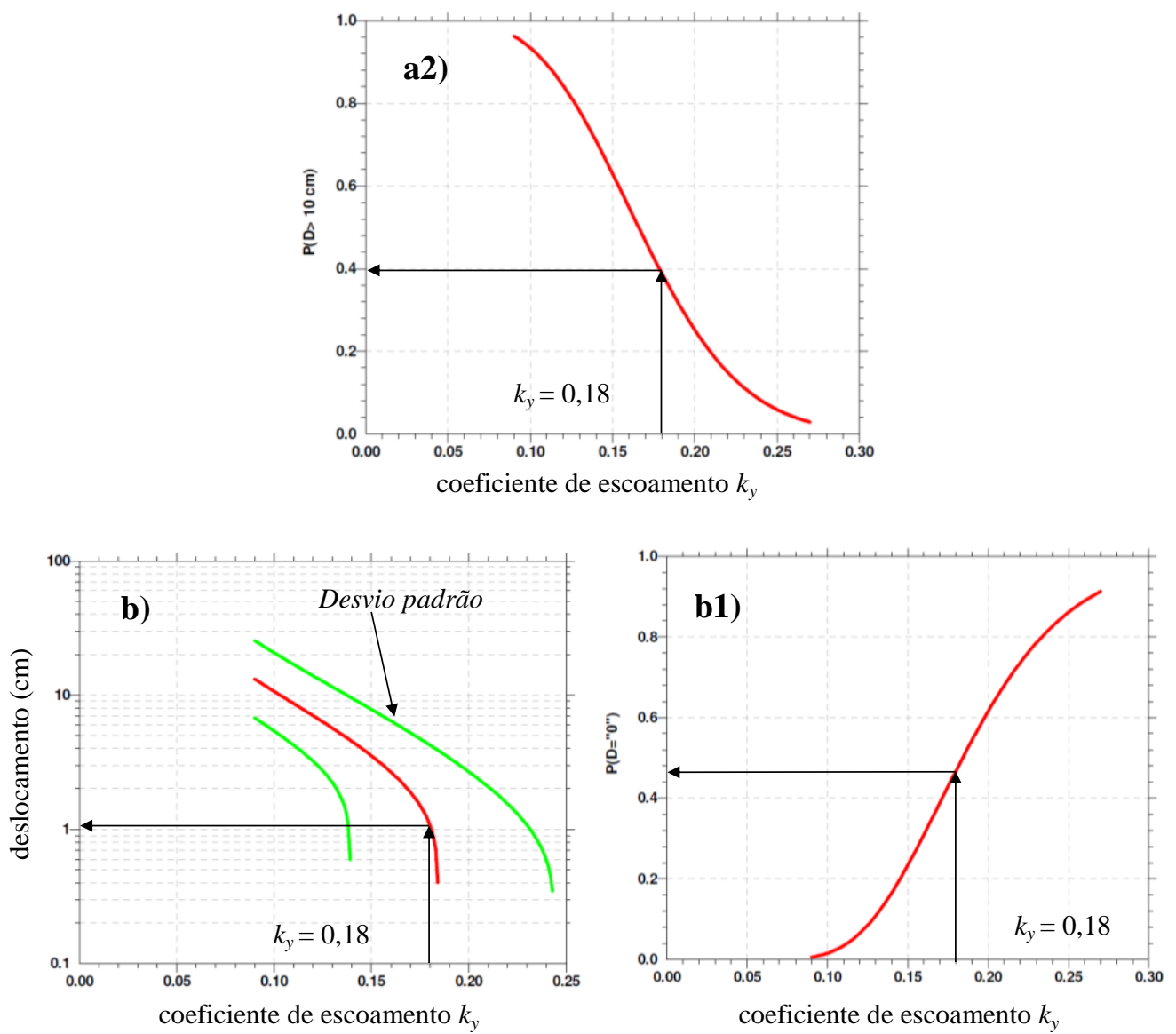

Figura 7.17 - Deslocamentos permanentes na barragem de Mazar com reservatório vazio pelo método de Bray e Travasarou: a) MCE; b) OBE.

Tratando-se de uma abordagem probabilística, o método de Bray e Travasarou (2007) determina na primeira etapa de cálculo a probabilidade de serem gerados deslocamentos permanentes desprezíveis $(\mathrm{D} \leq 1 \mathrm{~cm})$. Neste caso verifica-se da Figura 7.16 para o coeficiente de escoamento $k_{y}=0,31$ que não ocorrem deslocamentos permanentes, nem considerando as curvas afastadas de um desvio padrão do valor médio; a probabilidade de deslocamentos nulos $\mathrm{P}(\mathrm{D}=0)$ atinge um valor muito próximo a 1 .

Estes resultados se justificam também na Figura 7.18, onde Bray e Travasarou (2007) apresentam a dependência da probabilidade de deslocamento nulo em função do coeficiente de escoamento $k_{y}$, período inicial fundamental $T_{s} \mathrm{e}$ aceleração espectral no período degradado da massa instável; como se constata, para o valor $k_{y}=0,31$ a probabilidade de deslocamento nulo é muito próxima da unidade. 


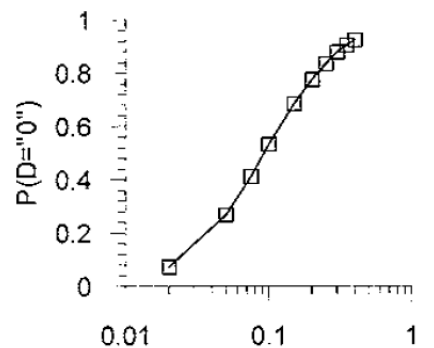

(a)

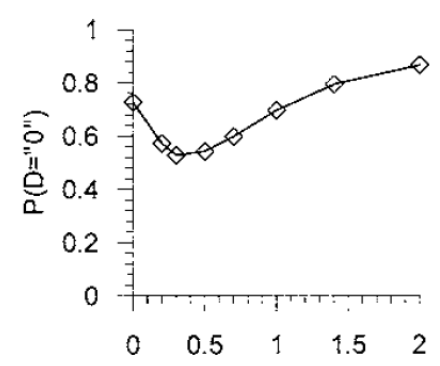

(b)

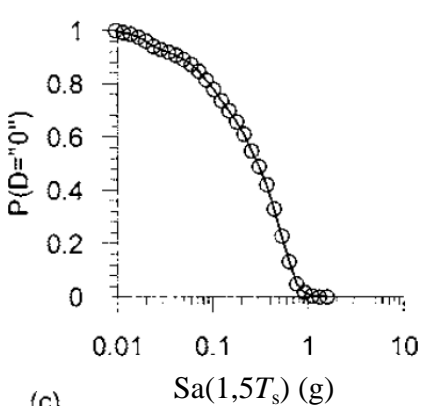

(c)

Figura 7.18 - Dependência da probabilidade de deslocamento nulo em função de: a) coeficiente de escoamento; b) período fundamental inicial; c) aceleração espectral em 1,5 vezes o período fundamental inicial (Bray and Travasarou, 2007).

Para reservatório vazio, levando em consideração que representa a condição mais desfavorável de estabilidade da barragem de Mazar, verifica-se na Figura 7.17 que o deslocamento permanente médio $\mathrm{D}=1,07 \mathrm{~cm}$ e $\mathrm{D}=8,2 \mathrm{~cm}$ para os terremotos OBE e MCE, respectivamente. Da Figura 7.17a2 para o terremoto MCE com $k_{y}=0,18$ verifica-se que a probabilidade de ocorrência de deslocamentos permanentes superiores a $10 \mathrm{~cm}$ é de $40 \%$.

\subsection{3.}

\section{Método de Makdisi e Seed (1978)}

O método de Makdisi e Seed (1978) aplica-se para estimativa de deslocamentos permanentes sismicamente induzidos em aterros e barragens de terra, visto que o procedimento utiliza soluções com base em analogia de cisalhamento de viga triangular, razão pela qual a geoestrutura deve apresentar uma geometria aproximadamente triangular e um eixo vertical de simetria. Para aplicação do método de Makdisi e Seed (1978) foram necessários os seguintes parâmetros para o caso mais desfavorável (reservatório vazio) de análise:

- relação entre altura da barragem e profundidade da superfície instável: $\mathrm{y} / \mathrm{H}=0,7$.

- aceleração máxima na crista da barragem: $a_{\max }=0,6 \mathrm{~g}$.

- resistência dinâmica da estrutura, representada pela aceleração de escoamento $a_{y}=0,18 \mathrm{~g}$.

- período inicial fundamental da barragem: $T_{\mathrm{o}}=0,9 \mathrm{~s}$. 
Da Figura 3.8, utilizando a relação y/H e $a_{\max }$ acima especificados, foram determinados o coeficiente sísmico máximo $\left(k_{\max }\right)$, que reflete a média das acelerações máximas ao longo da potencial superfície de deslizamento. Para o passo seguinte foi utilizada a Figura 3.9, que juntamente com o período inicial fundamental $T_{o}$ e aceleração de escoamento $a_{y}$, possibilitou a determinação do deslocamento permanente máximo na barragem, que para o caso do reservatório vazio resultou em $\mathrm{D}=0,29 \mathrm{~m}$.

Para o caso do reservatório cheio a relação entre aceleração de escoamento ( $\left.a_{y}=0,31 \mathrm{~g}\right)$ e a média das máximas acelerações produzidas na superfície de deslizamento da massa instável $\left(k_{\max }=0,288\right)$ resultou em valor superior a 1 $\left(a_{y} / k_{\max }=1,08\right)$, situado acima do limite superior $\left(a_{y} / k_{\max } \approx 0,9\right)$ mostrado na Figura 3.9; isto é interpretado como deslocamento permanente nulo pois a aceleração de escoamento apresenta um valor superior à aceleração máxima média da potencial massa de solo instável.

\subsection{4. \\ Método de Rathje e Saygili (2011)}

Foram estimados os deslocamentos permanentes mediante as abordagens escalar e vetorial da formulação deste método simplificado. Os seguintes parâmetros do movimento e da resistência dinâmica da estrutura são necessários:

a) Reservatório cheio: coeficiente de escoamento $k_{y}=0,31$; PGA $=0,45 \mathrm{~g}$ e 0,30g para MCE e OBE, respectivamente; $M_{w}=7.6$.

b) Reservatório vazio: coeficiente de escoamento $k_{y}=0,18$; PGA $=0,45 \mathrm{~g}$ e 0,30g para MCE e OBE, respectivamente; $M_{w}=7.6$.

Para o modelo vetorial necessita-se também da velocidade de pico PGV, determinada com base na aceleração espectral para um período de $0,5 \mathrm{~s} S_{a}(T=0,5 \mathrm{~s})$, conforme equação proposta por Alarcon et al (2006) apresentada no Capitulo 3 (equação 3.24).

A Figura 7.19 apresenta parte dos resultados para a condição mais desfavorável (reservatório vazio, MCE) e a Tabela 7.7 resume os resultados obtidos. Na condição mais desfavorável os deslocamentos permanentes se situam na faixa de 3 a $12 \mathrm{~cm}$ para a abordagem vetorial, de maior confiabilidade segundo seus autores. 

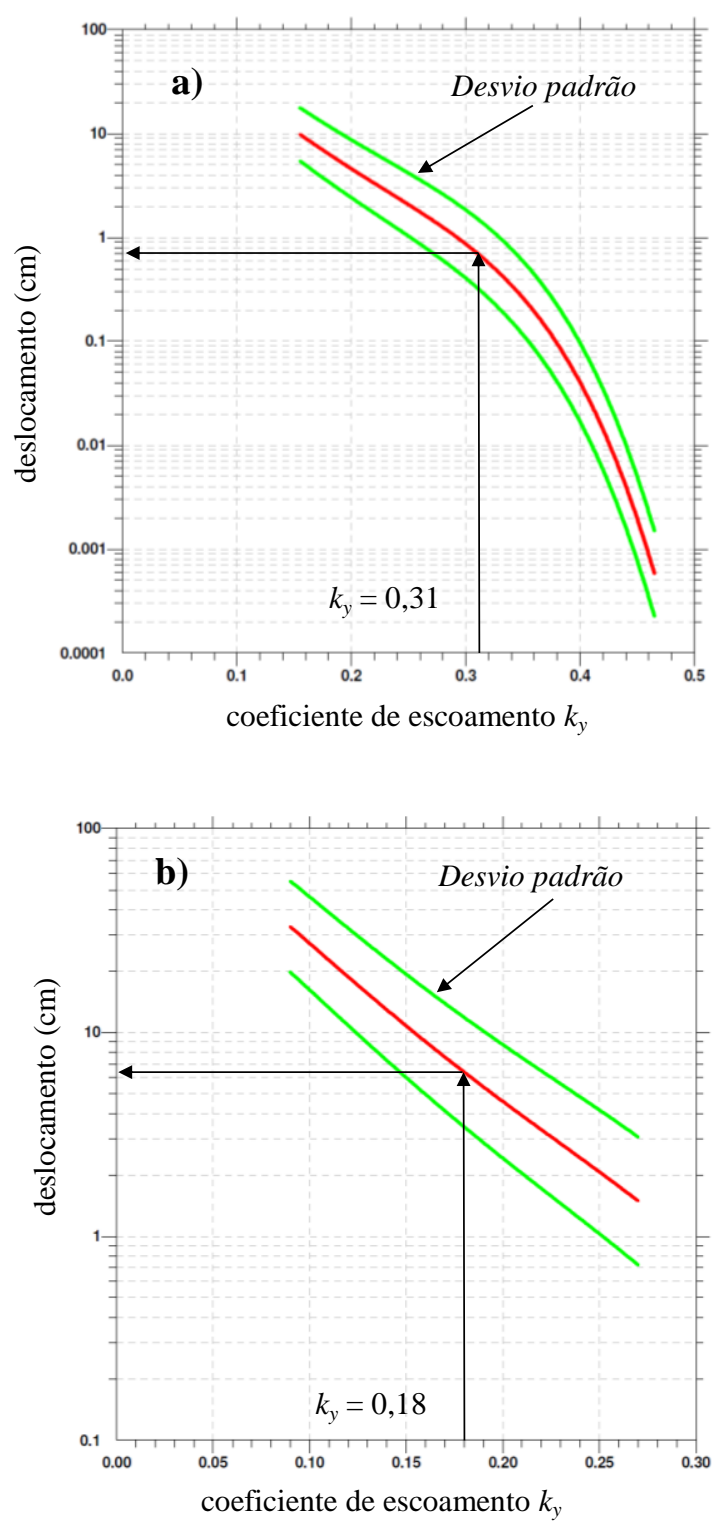

Figura 7.19 - Deslocamentos permanentes médio e afastados (+/-) de um desvio padrão, pelo método de Rathje e Saygili: a) MCE, reservatório cheio; b) MCE, reservatório vazio.

Tabela 7.7 - Deslocamentos permanentes $(\mathrm{cm})$ pelo método simplificado de Rathje e Saygili (2011).

\begin{tabular}{|c|c|ccc|ccc|}
\hline \multirow{2}{*}{ Reservatório } & \multirow{2}{*}{ Sismo de projeto } & \multicolumn{3}{|c|}{ Abordagem Escalar $(\mathrm{cm})$} & \multicolumn{4}{|c|}{ Abordagem Vetorial $(\mathrm{cm})$} \\
& & $\mathrm{D}-\sigma$ & $\mathrm{D}$ & $\mathrm{D}+\sigma$ & $\mathrm{D}-\sigma$ & $\mathrm{D}$ & $\mathrm{D}+\sigma$ \\
\hline \multirow{2}{*}{ Cheio } & MCE & 0,55 & 1,52 & 4,22 & 0,32 & 0,7 & 1,52 \\
& OBE & & 0 & & & 0 & \\
\hline \multirow{2}{*}{ Vazio } & MCE & 5,32 & 13,9 & 36,29 & 3,44 & 6,38 & 11,84 \\
& OBE & 0,87 & 2,4 & 6,6 & 0,46 & 0,96 & 1,98 \\
\hline
\end{tabular}

Observa-se como era de ser esperar que na condição mais desfavorável os deslocamentos permanentes que podem se apresentar estão na faixa de 3 até 12 cm para o modelo vetorial de maior confiabilidade segundo Rathje e Saygili (2011). 


\subsection{5.}

\section{Resumo dos deslocamentos permanentes calculados com métodos simplificados}

A Tabela 7.8 apresenta um resumo geral dos deslocamentos permanentes estimados mediante os métodos simplificados, na condição de reservatório vazio, pois na condição de reservatório cheio os deslocamentos permanentes resultaram praticamente nulos $(\mathrm{D} \leq 1 \mathrm{~cm})$, à exceção do método de Cai e Bathurst onde $\mathrm{D}=7$ $\mathrm{cm}$ para MCE.

Tabela 7.8 - Resumo de deslocamentos permanentes, reservatório vazio, métodos simplificados.

\begin{tabular}{|l|cc|}
\hline Condição do reservatório e & \multicolumn{2}{|c|}{ Deslocamento permanente (cm) } \\
\cline { 2 - 3 } sismo de Projeto & Bray e Travasarou (2007) & Makdisi e Seed (1978) \\
\hline Reservatório vazio (OBE) & 1,1 & 4,3 \\
Reservatório vazio (MCE) & 8,2 & 29 \\
\hline
\end{tabular}

\begin{tabular}{|lcc|}
\hline Condição do reservatório e & \multicolumn{2}{|c|}{ Deslocamento permanente (cm) } \\
sismo de Projeto & Rathje e Saygili (2011) & Cai e Bathurst (1996) \\
\hline Reservatório vazio (OBE) & 0,96 & 5 \\
Reservatório vazio (MCE) & 6,38 & 20 \\
\hline
\end{tabular}

Observa-se da Tabela 7.8 que o método de Makdisi e Seed (1978) estimou os maiores deslocamentos permanentes para o sismo de projeto MCE, seguido de valores muito próximos determinados mediante a formulação analítica de Cai e Bathurst (1996).

\section{5.}

\section{Análise dinâmica}

\subsection{1.}

\section{Determinação das frequências naturais e deformações cisalhantes} cíclicas máximas

Inicialmente, considerando a barragem formada por um material elástico linear não amortecido, são calculadas as frequências naturais de vibração do sistema e as amplitudes das deformações cisalhantes cíclicas máximas:

1. Verificação das condições de contorno: os contornos laterais foram estabelecidos como de campo livre e a base do modelo como contorno absorvente. Como já mencionado anteriormente, no programa de diferenças 
finitas Flac 2D o carregamento dinâmico é aplicado sob forma de tensões cisalhantes (equação 6.3) na base do modelo na condição de base flexível. O fator de calibração adimensional $f$ é determinado por tentativa e erro, normalmente entre os valores 1,0 a 2,0, procurando-se ajustar a história de velocidades calculada na base do modelo com aquela obtida pela integração do registro de acelerações. Nesta pesquisa, depois de algumas tentativas, foi selecionado o valor $f=1,0$ para todos os sismos de projeto, devido ao bom ajuste verificado entre ambas as histórias de velocidade (Figura 7.20).
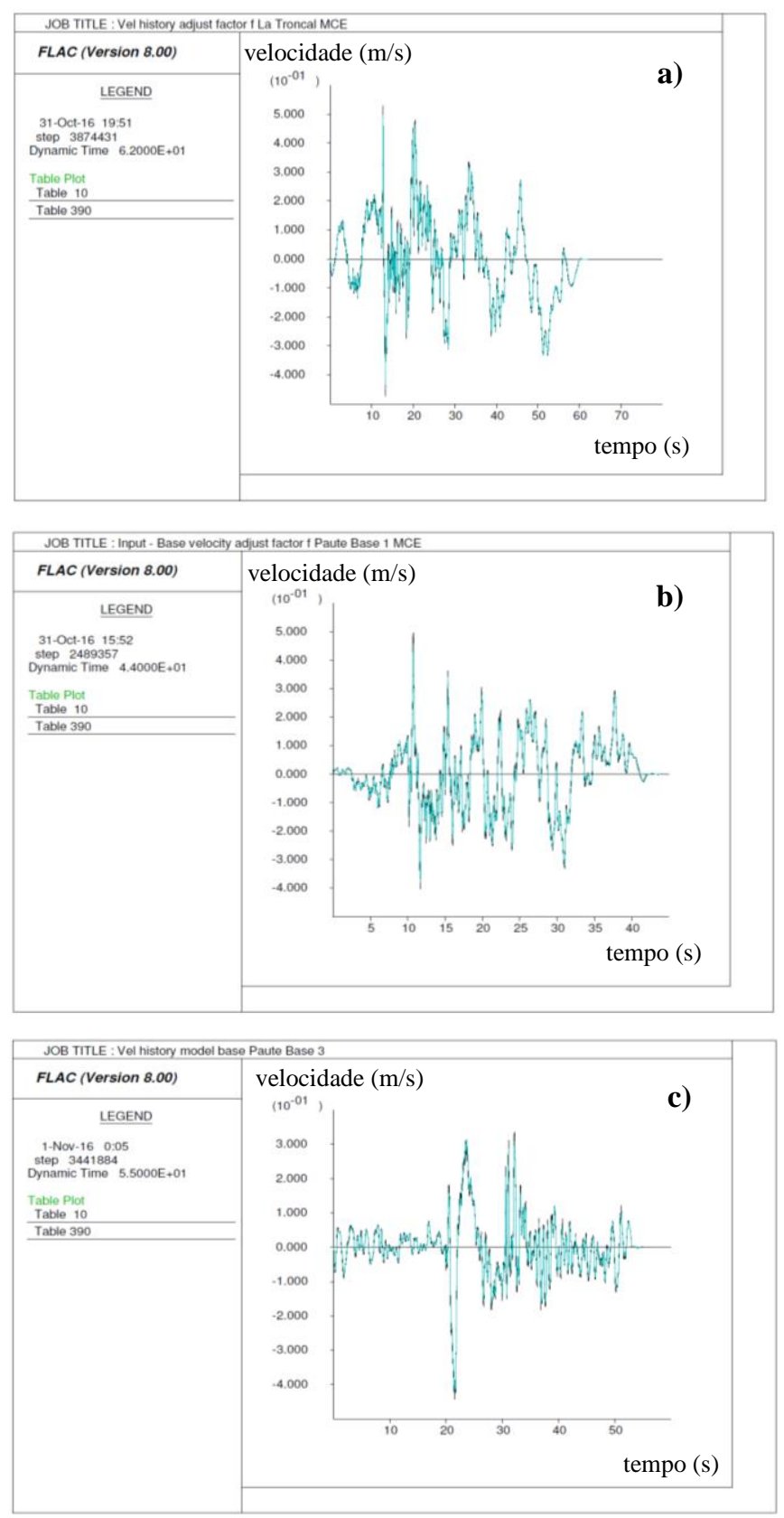

Figura 7.20 - Comparação das histórias de velocidade de entrada (registro sísmico) e calculada na base do modelo (Flac 2D v8) na simulação elástica linear não amortecida: a) sismo La Troncal; b) sismo Paute Base 1; c) sismo Paute Base 3. 
2. Frequência natural do modelo: a partir dos espectros de potencia determinaram-se as frequências fundamentais da geoestrutura que será de utilidade para definição da fração de amortecimento de Rayleigh na análise dinâmica amortecida. Levando em consideração que a barragem de Mazar esta formada por dois enrocamentos principais (enrocamentos 3B e 3C) foram utilizados pontos de controle nestas duas regiões do modelo. De acordo com resultados da Figura 7.21 foi considerada uma frequência fundamental de $0,8 \mathrm{~Hz}$.
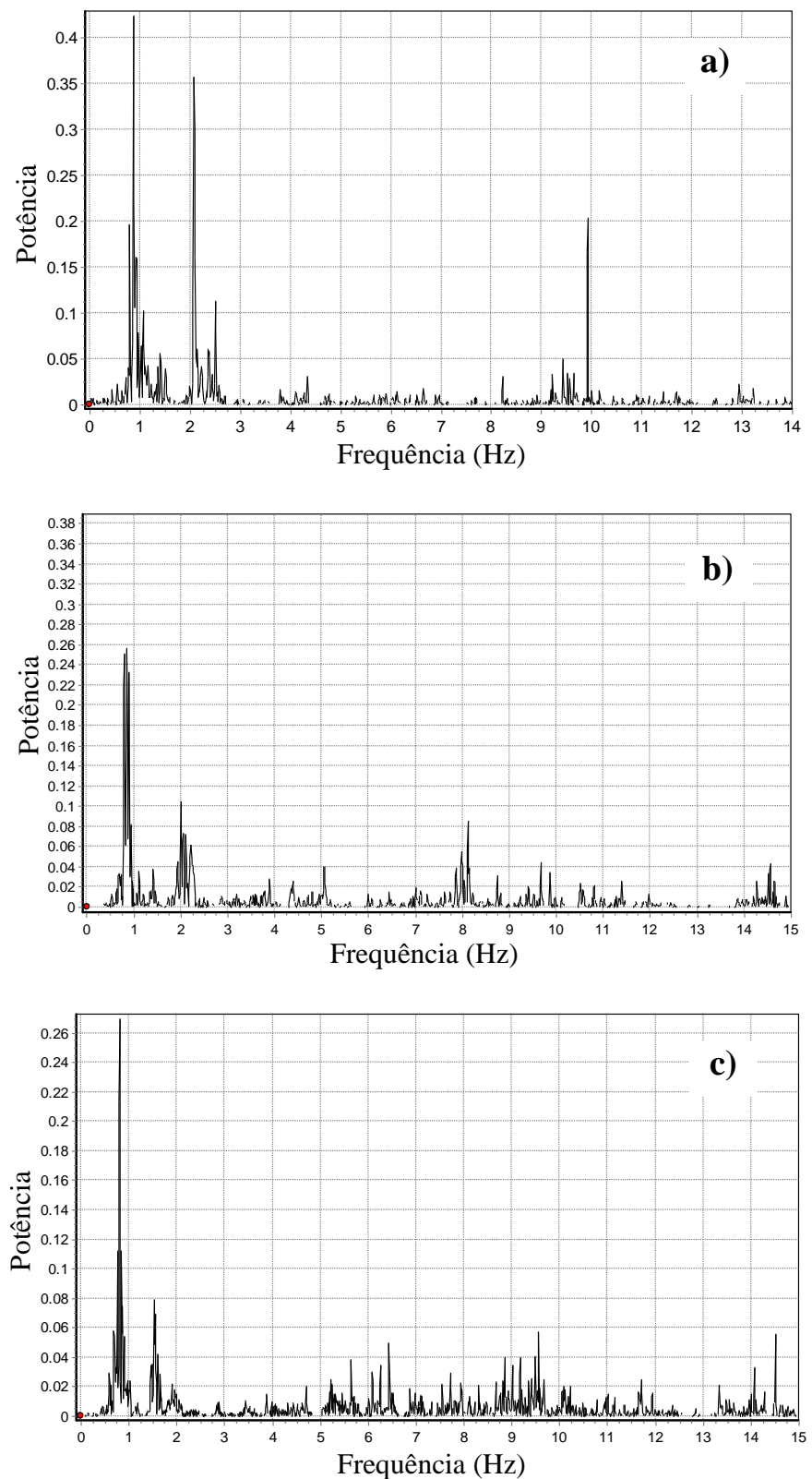

Figura 7.21 - Determinação da frequência fundamental da Barragem de Mazar; a) sismo La Troncal; b) sismo Paute Base 1; c) sismo Paute Base 3. 
3. Deformações cisalhantes cíclicas máximas: para efeitos de verificação da validade de utilização de amortecimento histerético no modelo constitutivo linear equivalente foram determinadas as deformações cisalhantes cíclicas máximas assumindo comportamento elástico linear não amortecido dos materiais que formam o sistema. Na Figura 7.22 apresentam-se os contornos de deformações cisalhantes máximas (máximo valor momentaneamente gerado no modelo) para cada sismo de projeto, os tempos dinâmicos a partir do inicio do movimento do terreno em que se observaram estes valores de pico foram: $\mathrm{t}=29,5 \mathrm{~s} ; \mathrm{t}=34,2 \mathrm{~s} ; \mathrm{t}=37 \mathrm{~s}$ para os sismos de La Troncal, Paute Base 1 e Paute Base 3 respetivamente.

Pode-se observar uma semelhança de comportamento para todos os sismos considerados atingido valores que variam entre $0,06 \%$ a $0,2 \%$ na maior parte do modelo. De maneira geral, a partir dos valores de deformações cisalhantes cíclicas máximas computadas, considera-se aceitável a aplicação do modelo histérico para amortecimento de solos.
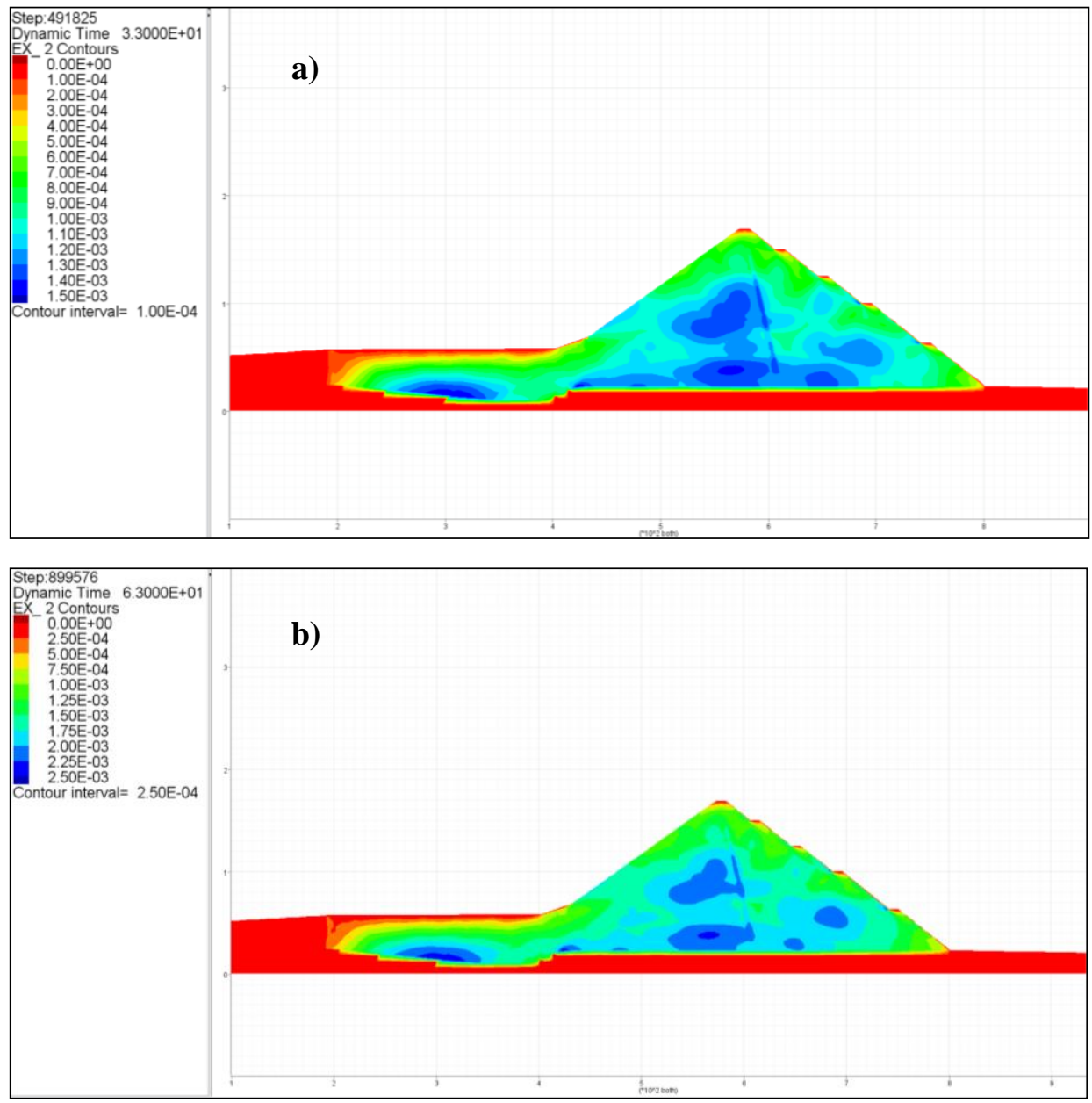

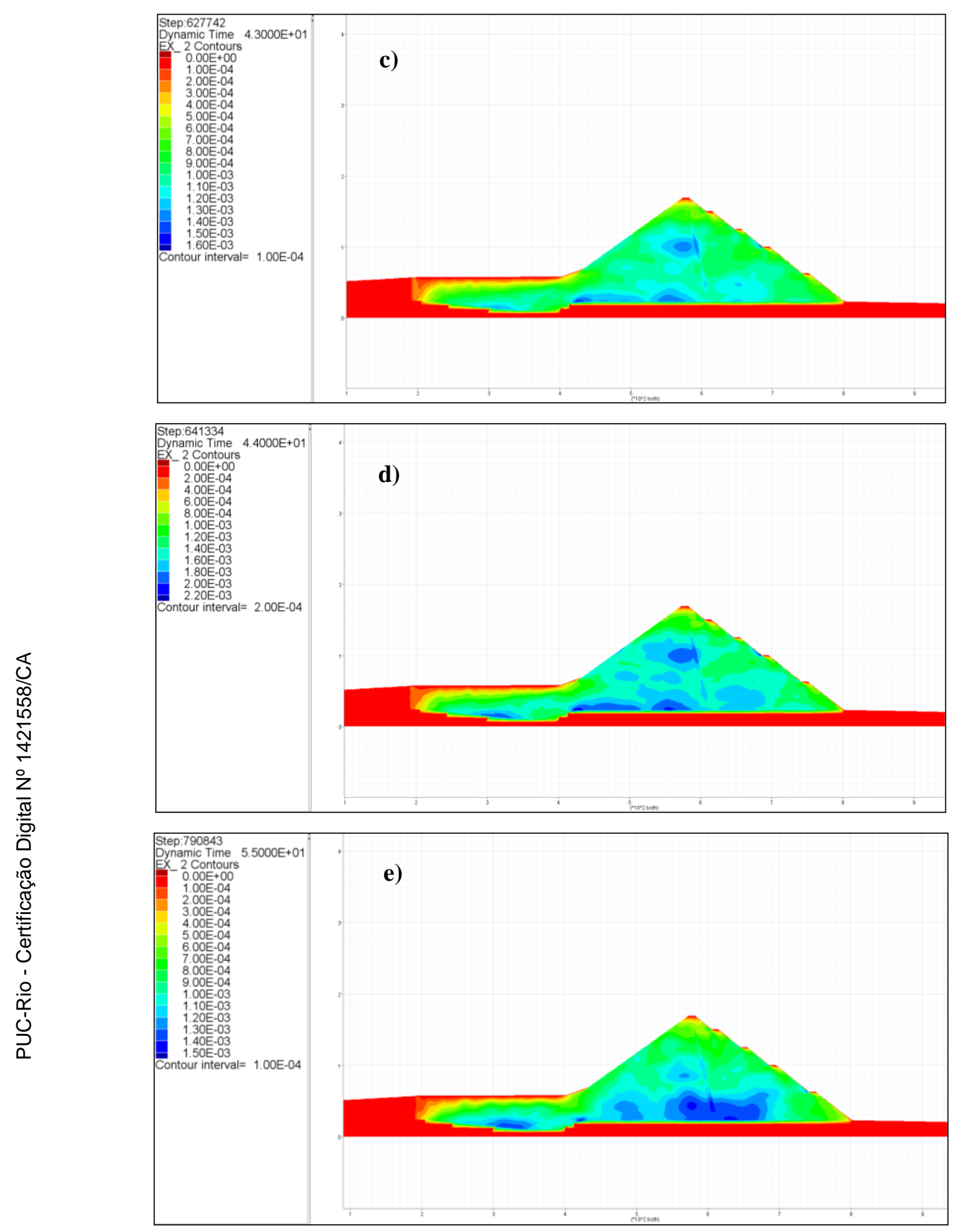


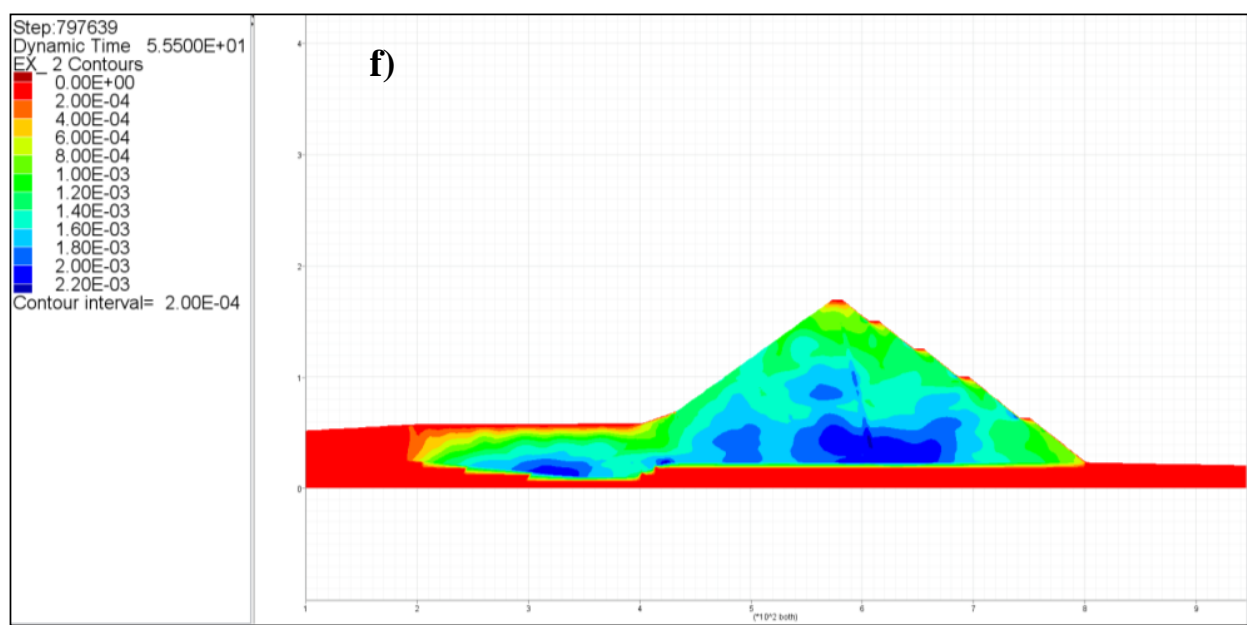

Figura 7.22 - Contornos de máximas deformações cisalhantes cíclicas: a) sismo de La Troncal OBE; b) Sismo de La Troncal MCE; c) Sismo Paute Base 1 OBE; d) Sismo Paute Base 1 MCE; e) Sismo Paute Base 3 OBE; f) Sismo Paute Base 3 MCE.

O passo seguinte foi a análise dinâmica da barragem considerando o modelo constitutivo elasto-plástico de Mohr-Coulomb associado ao amortecimento histerético (modelo linear equivalente) para predominantemente amortecer a componente de deformação elástica. Na primeira etapa foi analisada a resposta do que se presumiu a condição mais desfavorável com reservatório cheio para os três sismos escolhidos: La Troncal, Paute Base 1 e Paute Base 3, agrupados em duas categorias de terremoto de projeto: Máximo Terremoto Provável (MCE) e Terremoto Básico Operacional (OBE). Em seguidas, as análises foram repetidas para a condição de reservatório vazio.

Para aproximação da variação do ângulo de atrito do enrocamento com a tensão vertical no corpo da barragem (Leps, 1970) foi considerada a recomendação de Gazetas e Dakoulas (1992) apresentada na Figura 7.23.

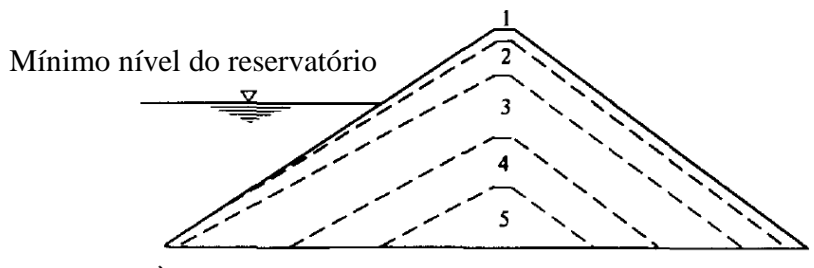

Máximo nível do reservatório

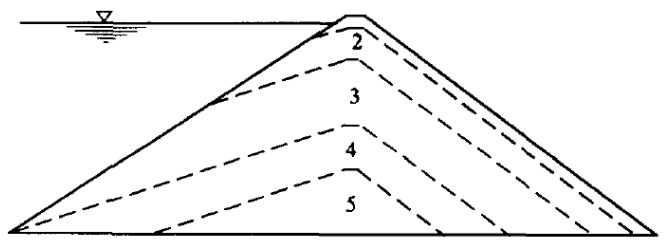

Figura 7.23 - Zonas na barragem com diferentes ângulos de atrito (Gazetas and Dakoulas, 1992). 


\subsection{2.}

\section{Análise dinâmica considerando comportamento elasto-plástico e amortecimento histerético}

De forma idêntica ao efetuado para o primeiro exemplo analisado, o ajuste no programa Flac v8.0 mediante o modelo Sig3 (Itasca, 2011) foi executado na base de funções de degradação do módulo de cisalhamento e razão de amortecimento apresentadas pelos seguintes autores:

- Enrocamentos 3B e 3C: funções de Gazetas e Dakoulas (1992).

- Dreno: modelo de Seed et al. (1986).

- Material 1B: modelo de Seed e Idriss (1970).

- Embasamento rochoso: amortecimento para rocha Schnabel (1973).

As constantes de ajuste (Sig3) para cada material foram as seguintes (Tabela 7.9).

Tabela 7.9 - Constantes de ajuste modelo Sig3 CFRD Mazar

\begin{tabular}{|lccc|}
\hline \multicolumn{1}{|c}{ Referência } & $a$ & $b$ & $x_{o}$ \\
\hline Enrocamentos 3B e 3C; Gazetas \& Dakoulas (1992) & 1,065 & $-0,695$ & $-1,995$ \\
Dreno; Seed et al. (1986) & 1,03 & $-0,65$ & $-1,9$ \\
Material 1B; Seed e Idriss (1970) & 0,98 & $-0,5$ & $-1,5$ \\
Rocha; Schnabel (1973) & 1,014 & $-1,01$ & $-0,05$ \\
\hline
\end{tabular}

Na Figura 7.24 observam-se as funções de degradação do modulo de cisalhamento e razão de amortecimento para os diferentes materiais da barragem.

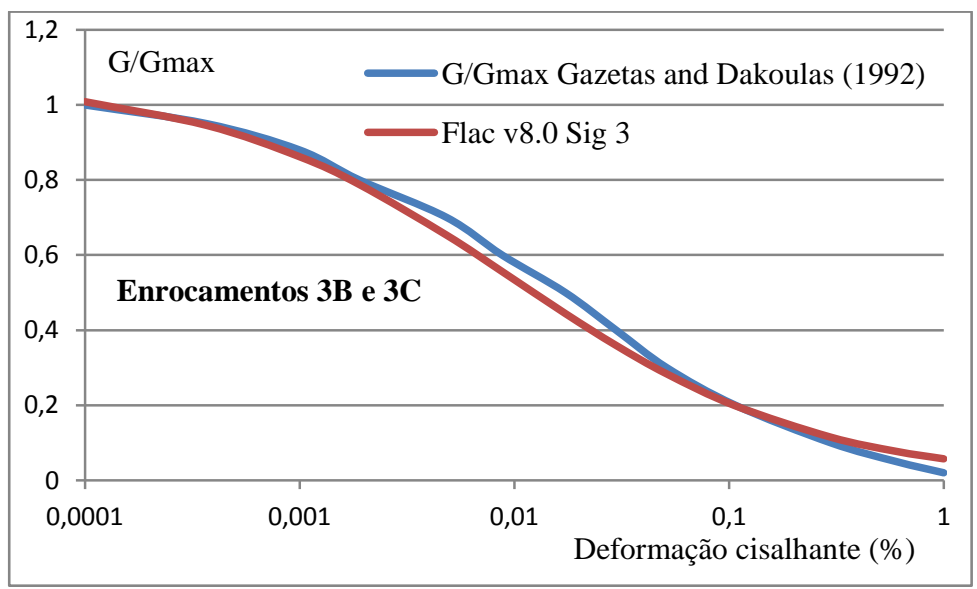



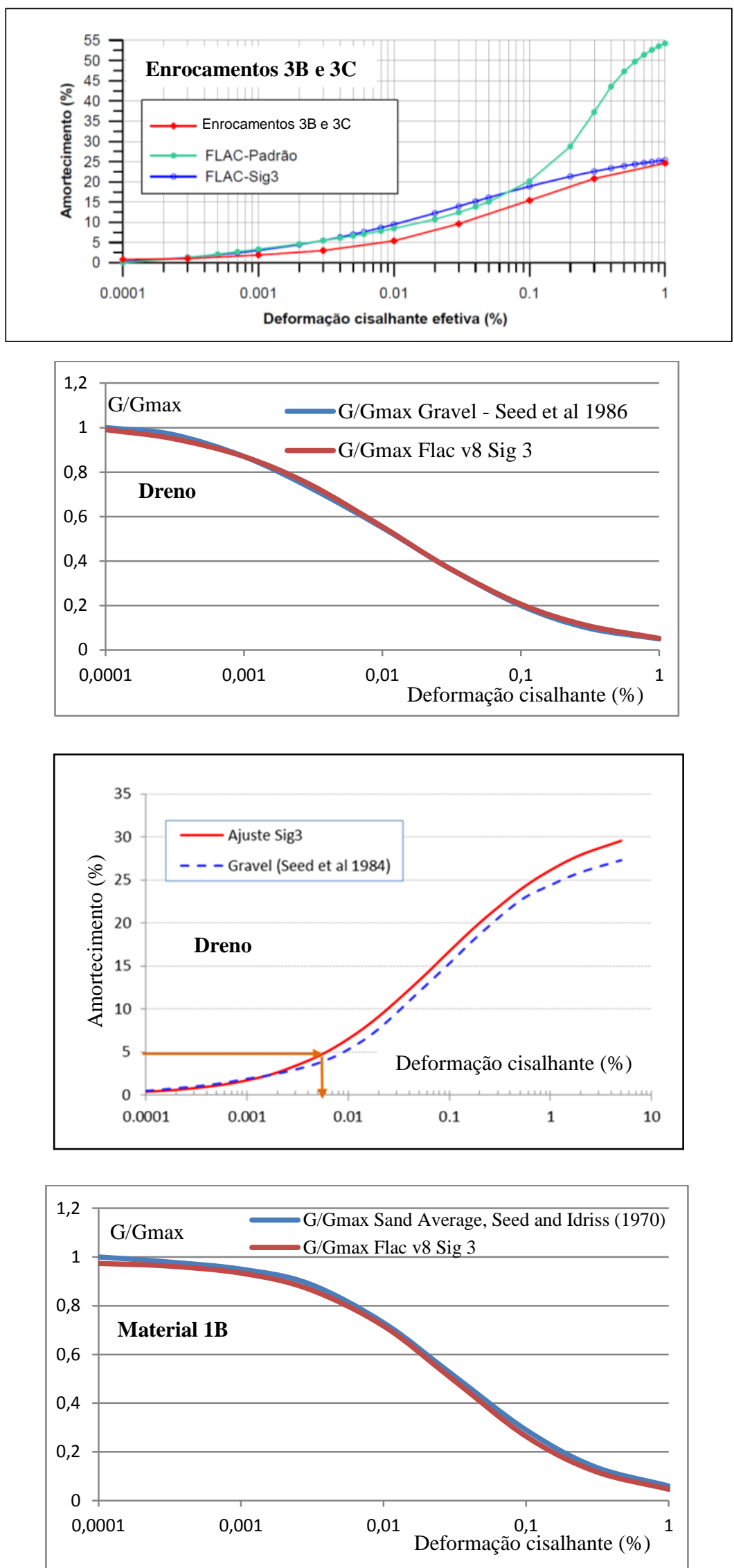


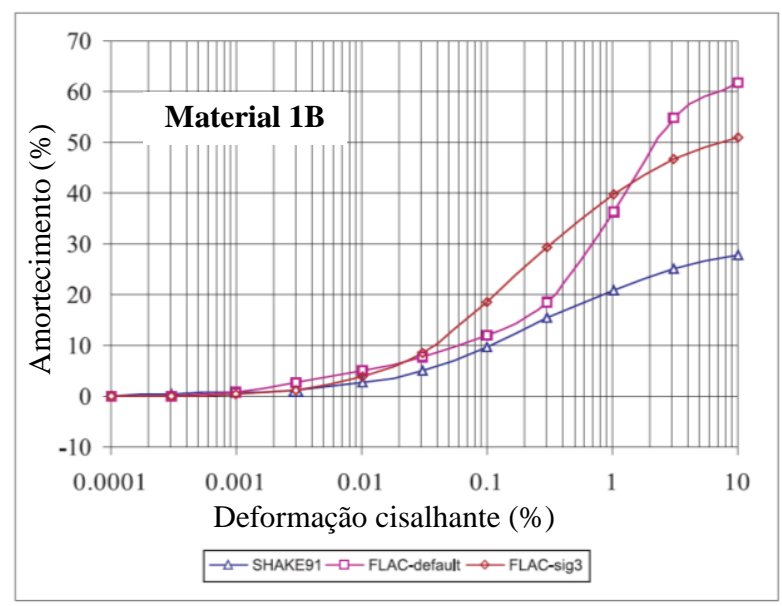

Figura 7.24 - Curvas de degradação do modulo cisalhante e aumento da razão de amortecimento para os materiais componentes da CFRD Mazar.

\subsubsection{1}

\section{Reservatório cheio}

O reservatório da barragem de Mazar atinge sua máxima capacidade operacional na elevação $2153 \mathrm{msnm}$, isto é $6 \mathrm{~m}$ abaixo da crista (elevação 2159 $\mathrm{msnm})$. Adicionalmente é especificado no projeto um muro de parapeito que atinge uma elevação final de coroamento de $2166 \mathrm{msnm}$.

\section{- Sismo de La Troncal}

A Figura 7.25 mostra a resposta de aceleração horizontal prevista para um ponto situado na crista no eixo central da barragem. Para o terremoto MCE foi calculada uma aceleração de pico de $0,28 \mathrm{~g}$ e para o terremoto OBE a aceleração horizontal de pico prevista foi $0,17 \mathrm{~g}$. Estes valores refletem uma de amplificação de 0,8 e 0,6, respectivamente, em relação à aceleração horizontal máxima aplicada no embasamento rochoso.

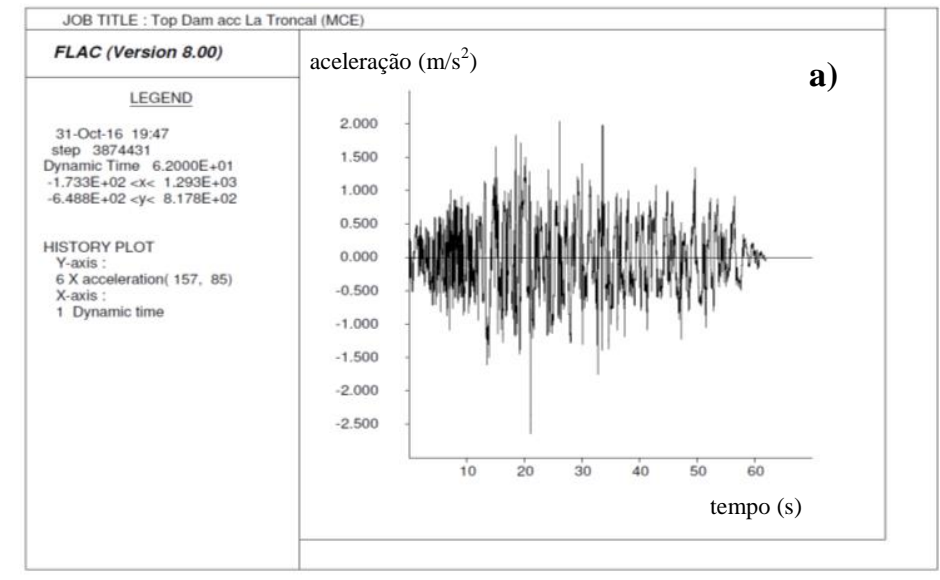




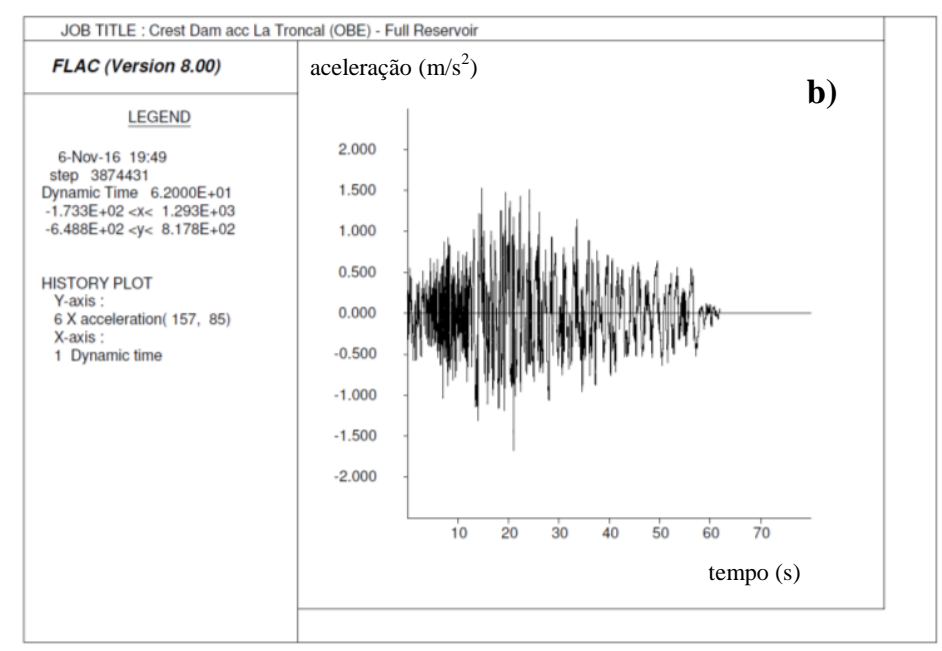

Figura 7.25 - Resposta em aceleração horizontal na crista da barragem para o sismo La Troncal: a) MCE; b) OBE.

Os deslocamentos horizontais permanentes máximos na barragem ocorreram no talude de jusante: para o terremoto MCE atingiu o valor de $1,10 \mathrm{~m}$ (Figura 7.26a) e para o terremoto OBE resultou no valor 0,50m (Figura 7.26b). Comportamento similar foi constatado em relação aos deslocamentos verticais permanentes: $0,80 \mathrm{~m}$ para o terremoto $\mathrm{MCE}$ e $0,45 \mathrm{~m}$ para o terremoto $\mathrm{OBE}$ (Figura 7.27). A Figura 7.28 apresenta a história dos deslocamentos verticais e horizontais para um ponto situado no eixo central da crista da barragem, observando-se que a partir do instante de tempo $t=60 \mathrm{~s}$ estes se tornam permanentes, atingindo $0,40 \mathrm{~m}$ na componente horizontal e $0,10 \mathrm{~m}$ na componente vertical para o terremoto MCE. Por outro lado, para o terremoto OBE os deslocamentos permanentes esperados são de menor amplitude, mas também tornam-se constantes após o tempo aproximado de $\mathrm{t}=60 \mathrm{~s}$, com valores de $0,15 \mathrm{~m}$ na componente horizontal e 0,07 m na componente vertical.

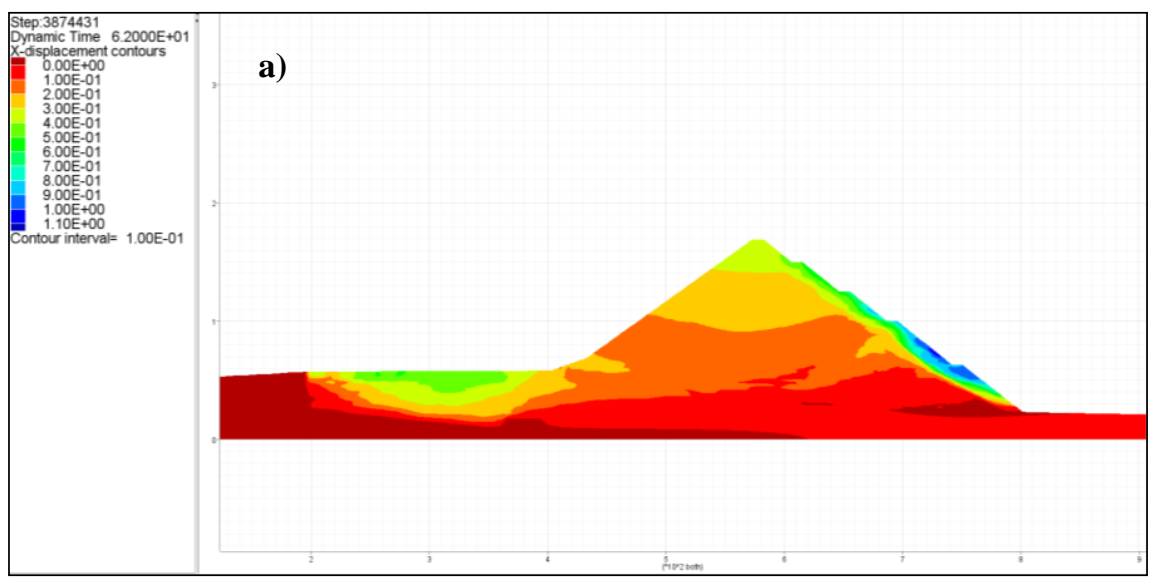




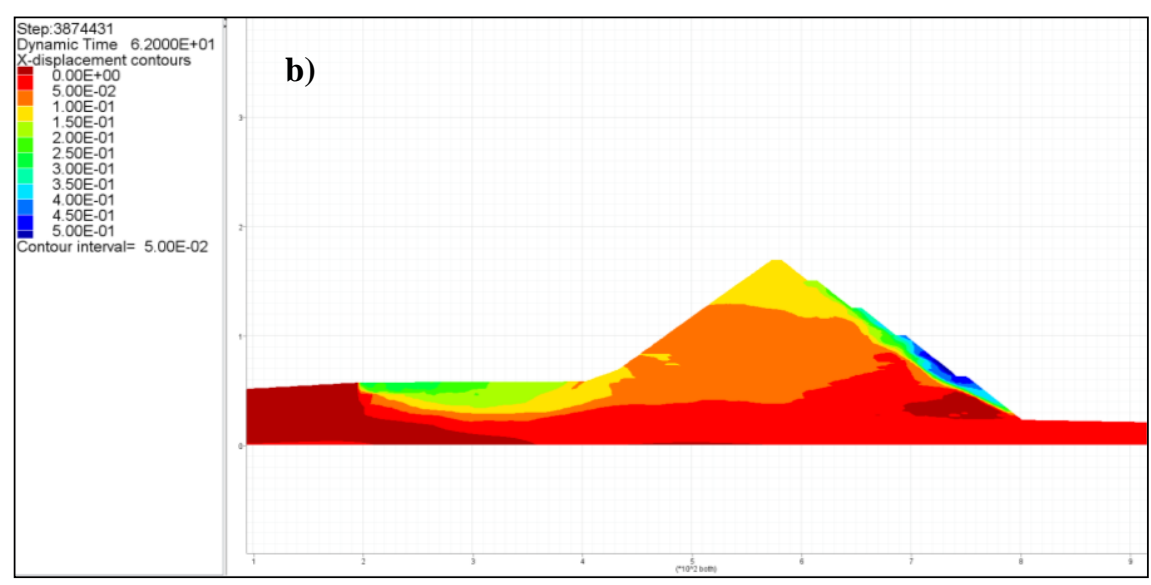

Figura 7.26 - Deslocamentos horizontais causados pelo sismo La Troncal: a) MCE; b) OBE.

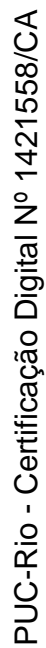
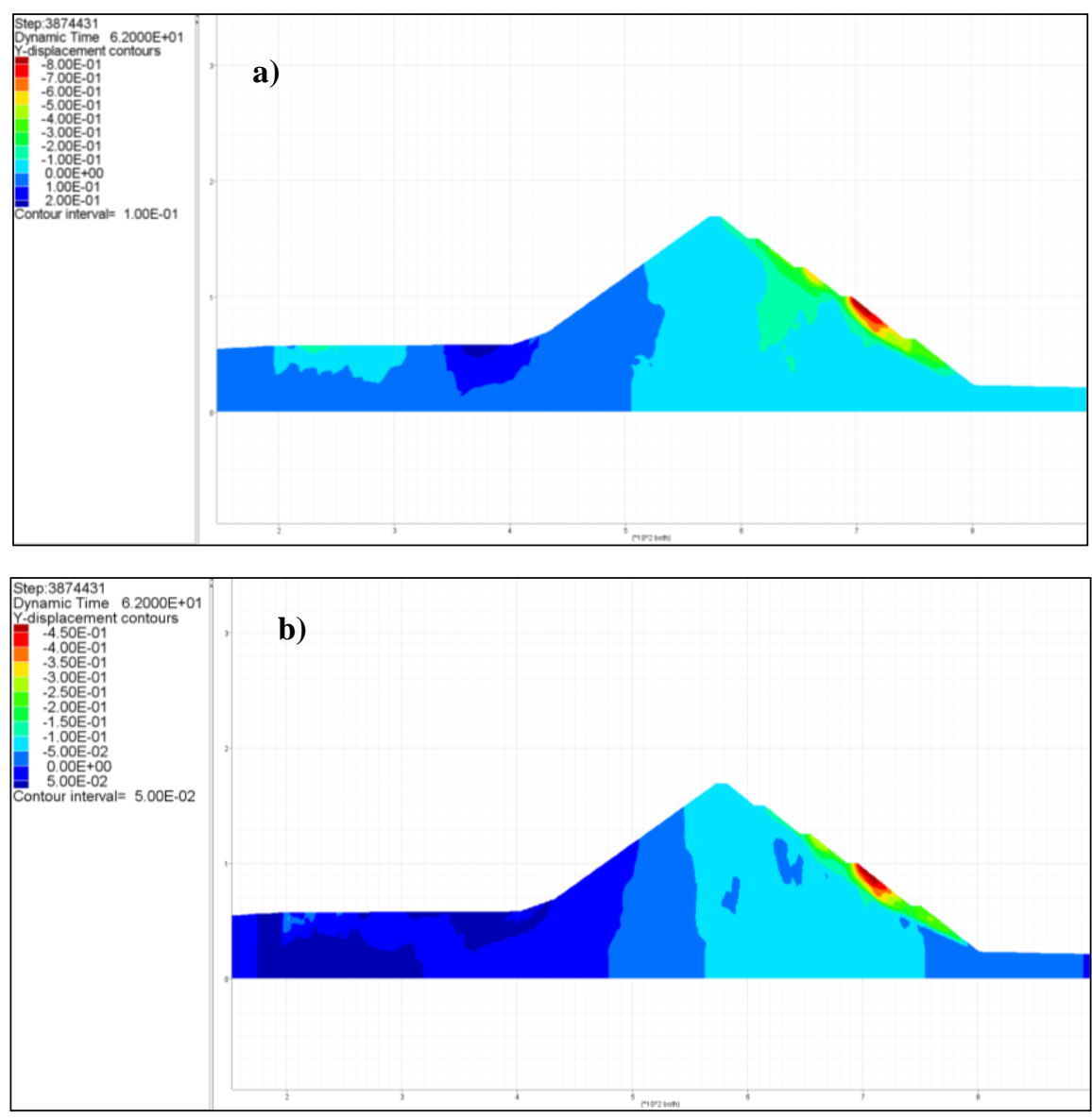

Figura 7.27 - Deslocamentos verticais causados pelo sismo La Troncal: a) MCE; b) OBE. 

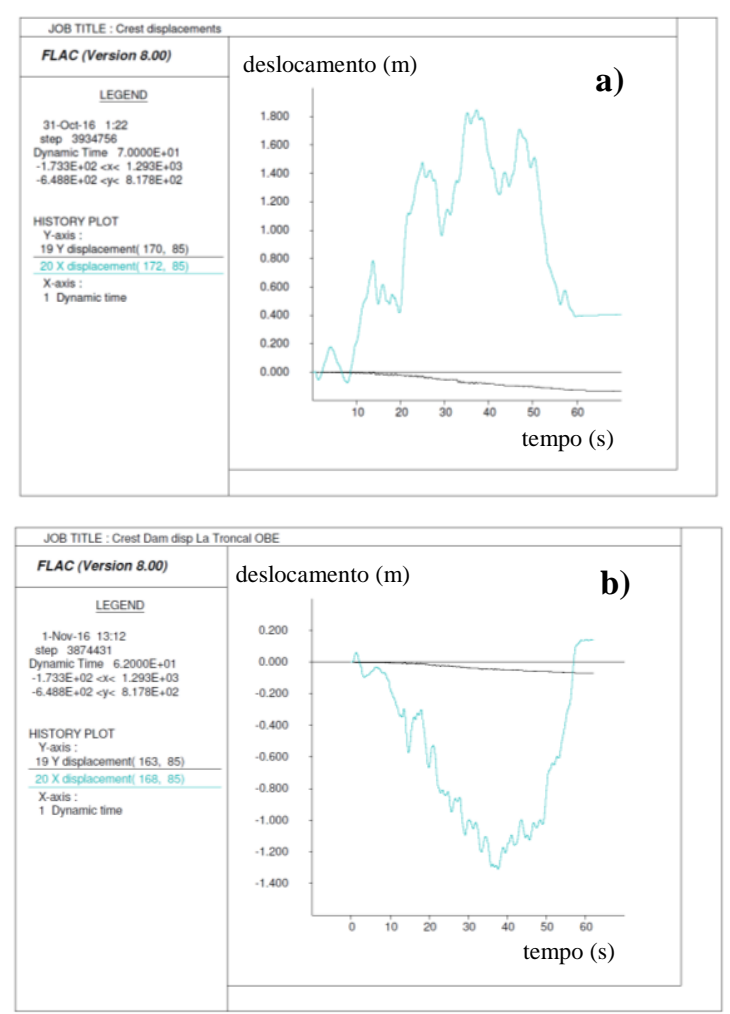

Figura 7.28 - Histórias de deslocamentos horizontal e vertical no ponto central da crista da barragem no sismo La Troncal: a) MCE; b) OBE.

Na Figura 7.29 apresentam-se os espectros de resposta em aceleração horizontal na crista da barragem para verificação da resposta máxima em determinados períodos de interesse da excitação sísmica.
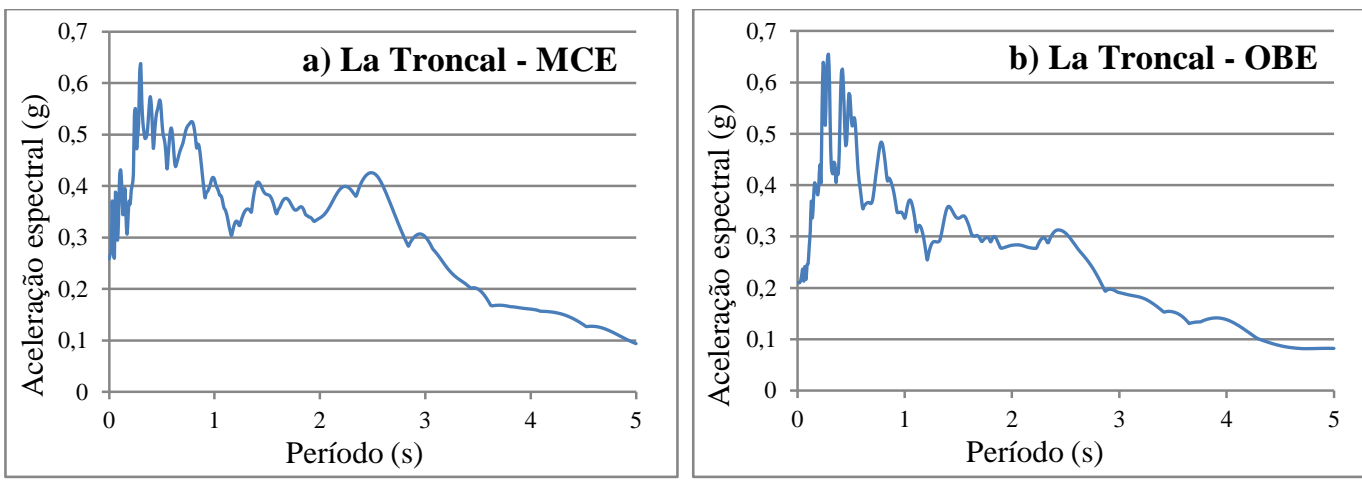

Figura 7.29 - Espectro de resposta em aceleração horizontal na crista da barragem, reservatório máxima capacidade, sismo de La Troncal: a) MCE; b) OBE.

\section{- Sismo Paute Base 1:}

Similarmente, a Figura 7.30 apresenta a resposta em termos de aceleração horizontal para um ponto situado no centro da crista da barragem. Para o terremoto MCE foi prevista uma aceleração horizontal de pico de $0,22 \mathrm{~g}$ 
correspondente a uma de amplificação de 0,6 em relação à aceleração horizontal máxima do registro sísmico implicitamente aplicado na base do modelo numérico.

Deslocamentos horizontais permanentes máximos foram verificados no talude de jusante com amplitudes de 1,10 m (terremoto MCE, Figura 7.31a) e 0,55 m (terremoto OBE, Figura 7.31b). Os deslocamentos verticais máximos atingiram os valores $0,55 \mathrm{~m}$ e $0,35 \mathrm{~m}$ para os terremotos MCE e OBE, respectivamente, conforme ilustração da Figura 7.32.

A Figura 7.33 apresenta a história dos deslocamentos horizontais e verticais para um ponto situado no eixo central da crista da barragem, constatando-se que os mesmos se tornam permanentes a partir do tempo aproximado $\mathrm{t}=40 \mathrm{~s}$, atingindo os valores $0,70 \mathrm{~m}$ (componente horizontal) e $0,20 \mathrm{~m}$ (componente vertical) no terremoto MCE e 0,30 m (componente horizontal) e 0,10 m (componente vertical) no terremoto OBE.
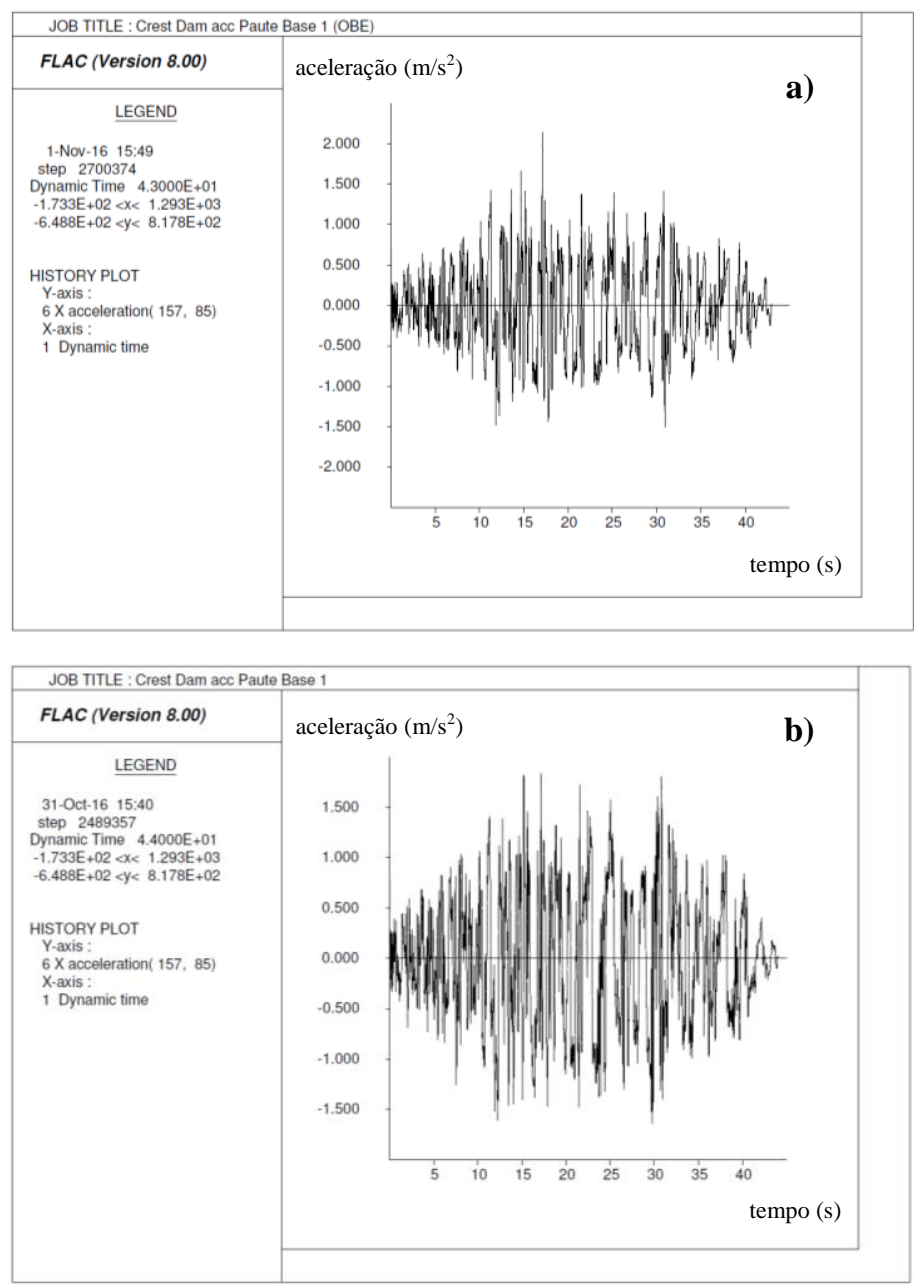

Figura 7.30 - Resposta em aceleração horizontal na crista da barragem, terremoto Paute Base 1: a) MCE; b) OBE. 

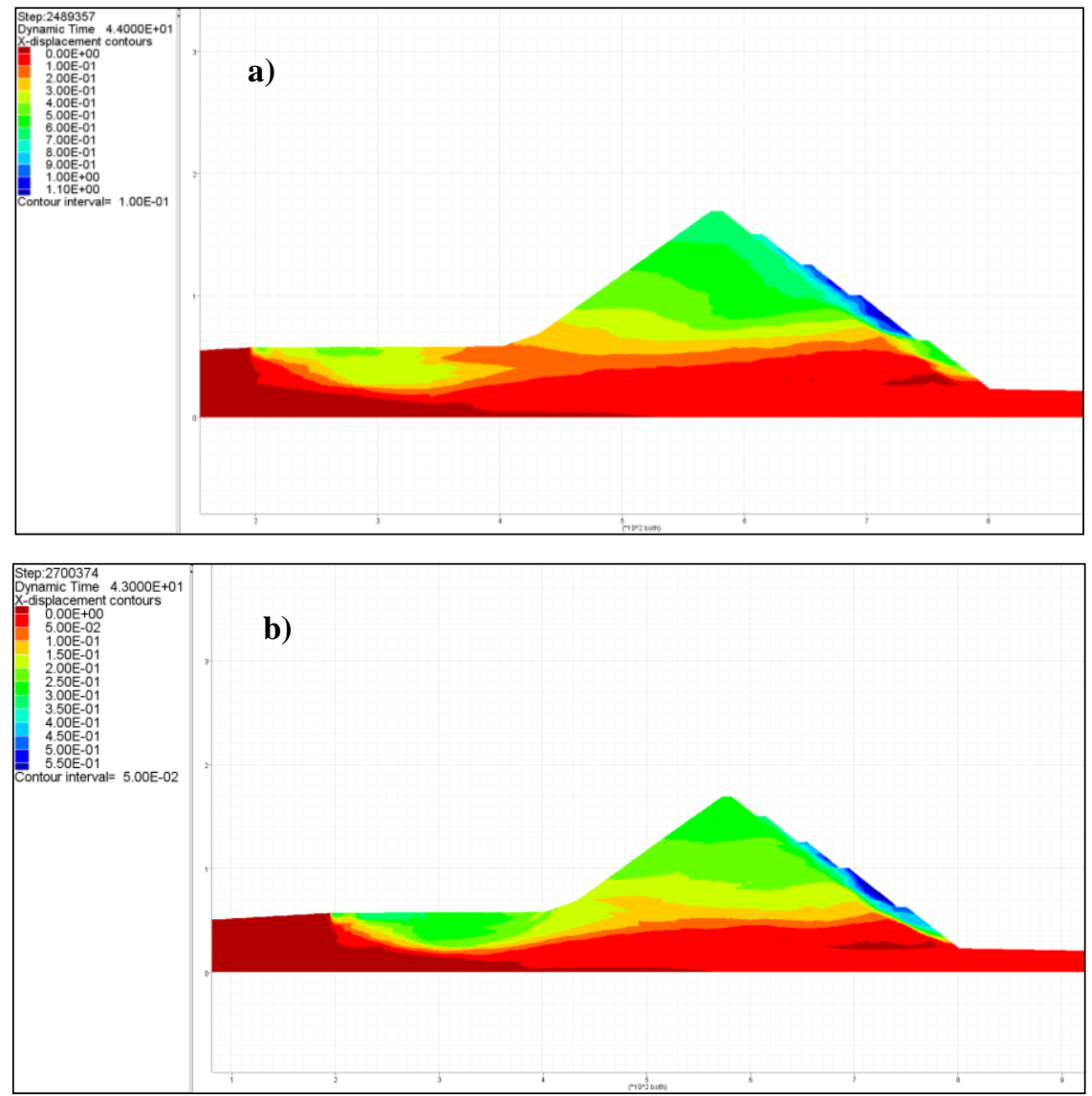

Figura 7.31 - Deslocamentos horizontais causados pelo sismo Paute Base 1: a) MCE; b) OBE.

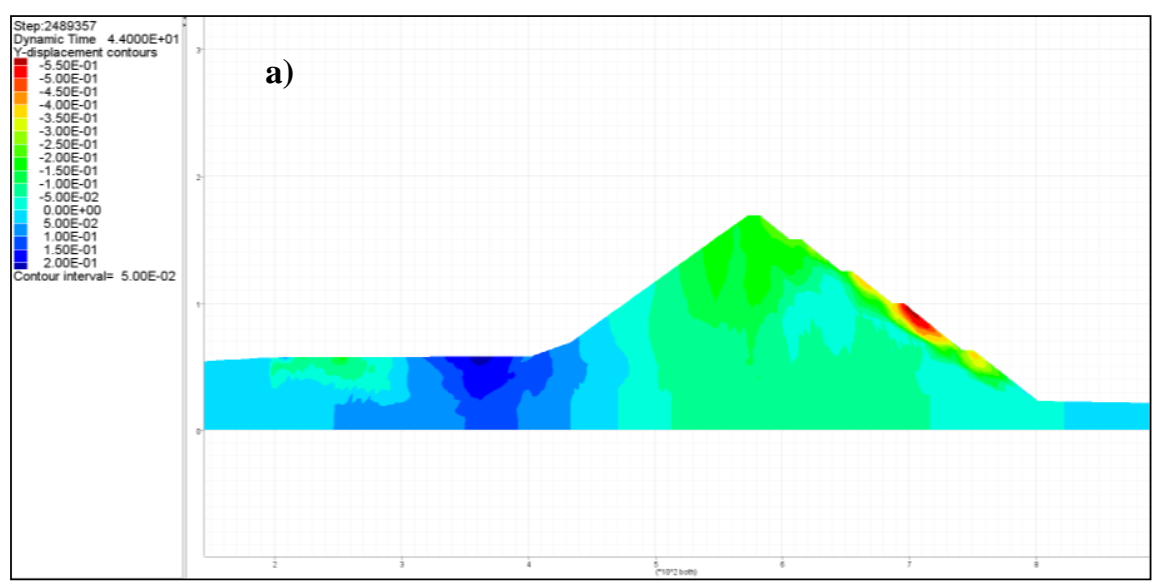




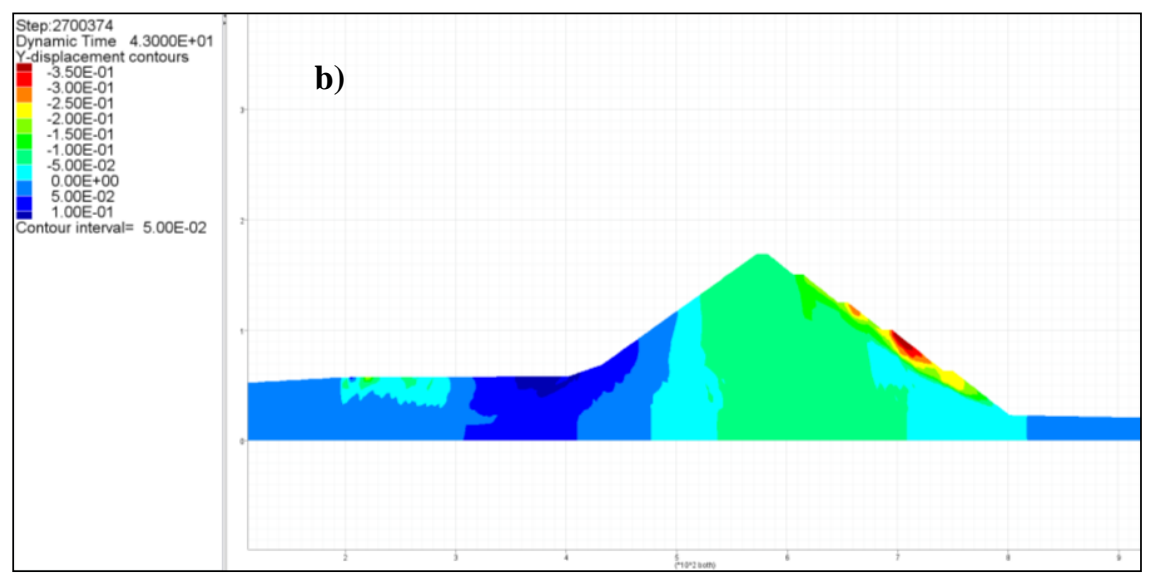

Figura 7.32 - Deslocamentos verticais causados pelo sismo Paute Base 1: a) MCE; b) OBE.
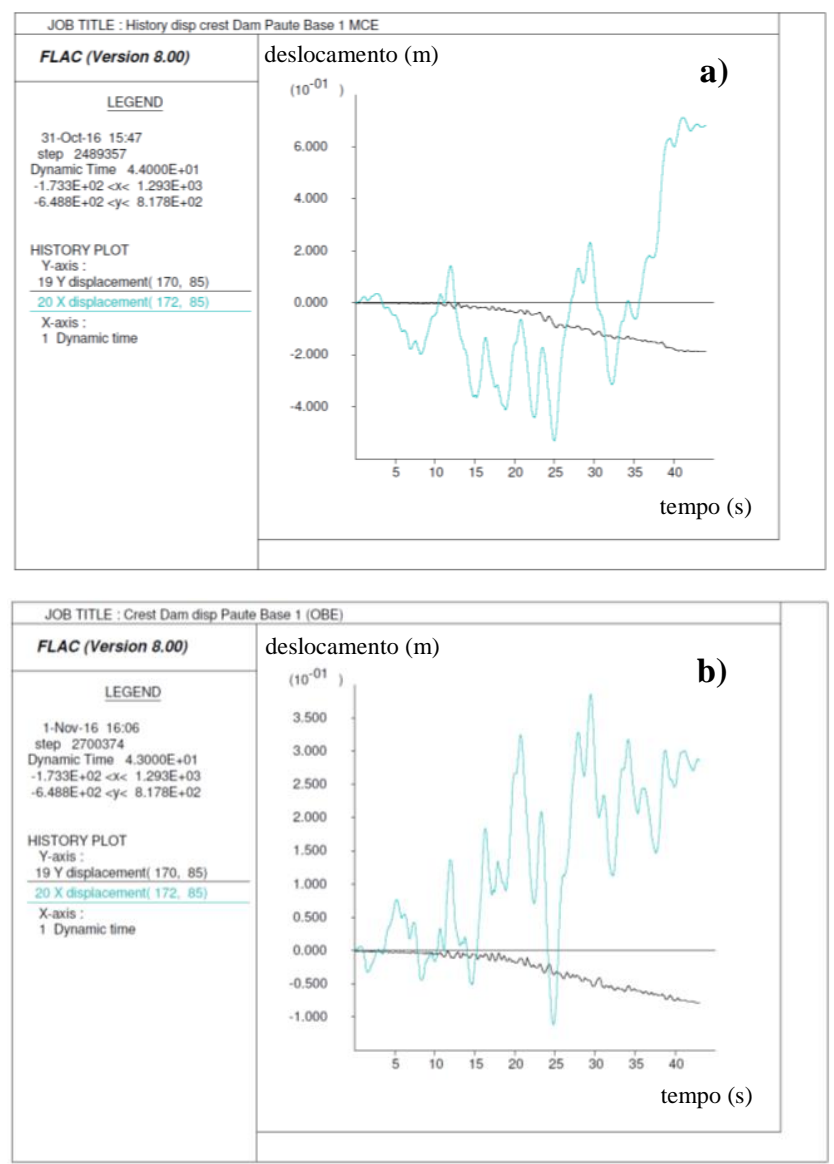

Figura 7.33 - Histórias de deslocamentos horizontal e vertical no ponto central da crista da barragem, terremoto Paute Base 1: a) MCE; b) OBE.

Na Figura 7.34 apresentam-se os espectros de resposta em aceleração horizontal na crista da barragem para verificação da resposta máxima em determinados períodos de interesse da excitação sísmica. 

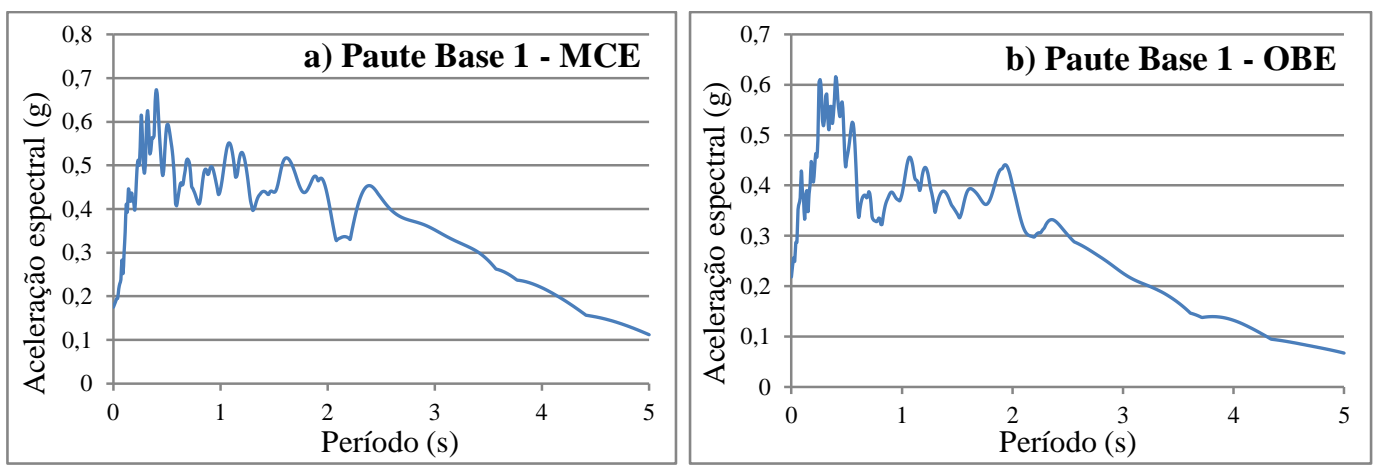

Figura 7.34 - Espectro de resposta em aceleração horizontal na crista da barragem, reservatório máxima capacidade, sismo de La Troncal: a) MCE; b) OBE.

\section{- Sismo Paute Base 3:}

A Figura 7.35 mostra a resposta em termos de aceleração horizontal para um ponto situado na crista no eixo central da barragem. Para o terremoto MCE a aceleração de pico prevista foi $0,21 \mathrm{~g}$ e para o terremoto OBE atingiu $0,18 \mathrm{~g}$, correspondente a uma de amplificação de 0,6 com respeito à aceleração máxima do registro sísmico de entrada.

Deslocamentos horizontais permanentes máximos na barragem apresentaram-se no talude de jusante, atingiram 0,75m (terremoto MCE, Figura 7.36a) e 0,30m (terremoto OBE, Figura 7.36b). Comportamento semelhante foi observado em relação aos deslocamentos verticais permanentes, que atingiram a amplitude 0,60 m (terremoto MCE, Figura 7.37a) e 0,35 m (terremoto OBE, Figura 7.37b).

A Figura 7.38a apresenta as histórias de deslocamentos verticais e horizontais para um ponto no eixo central da crista da barragem, observando-se que ao final do sismo os valores permanentes atingem $0,13 \mathrm{~m}$ (componente horizontal) e $0,10 \mathrm{~m}$ (componente vertical) para o terremoto MCE. Para o terremoto OBE os valores correspondentes são 0,04 m e 0,06 m, respectivamente (Figura 7.38b). 

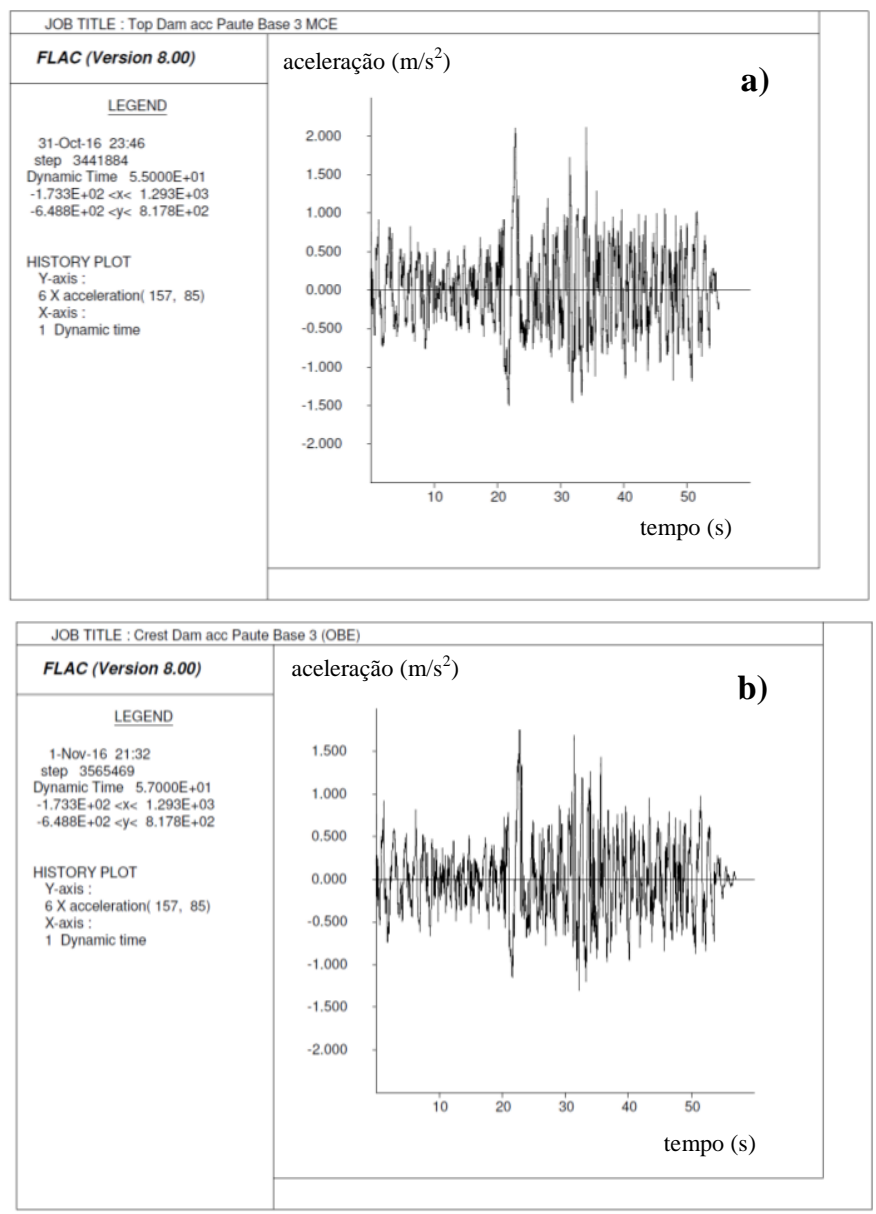

Figura 7.35 - Resposta em aceleração horizontal na crista da barragem, terremoto Paute Base 3: a) MCE; b) OBE.

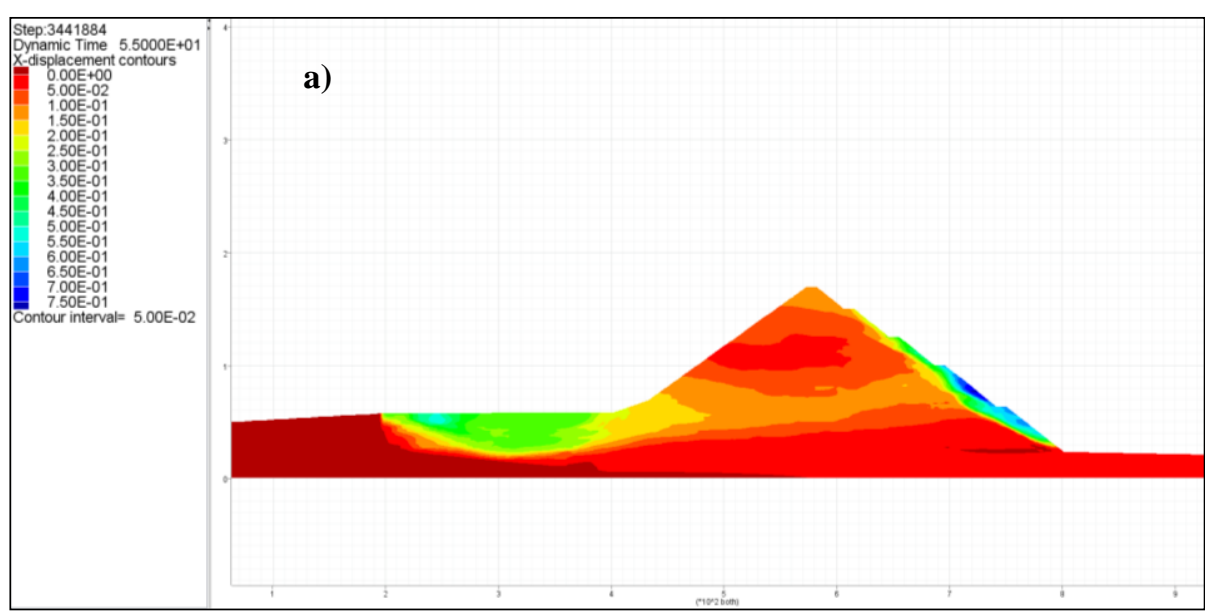




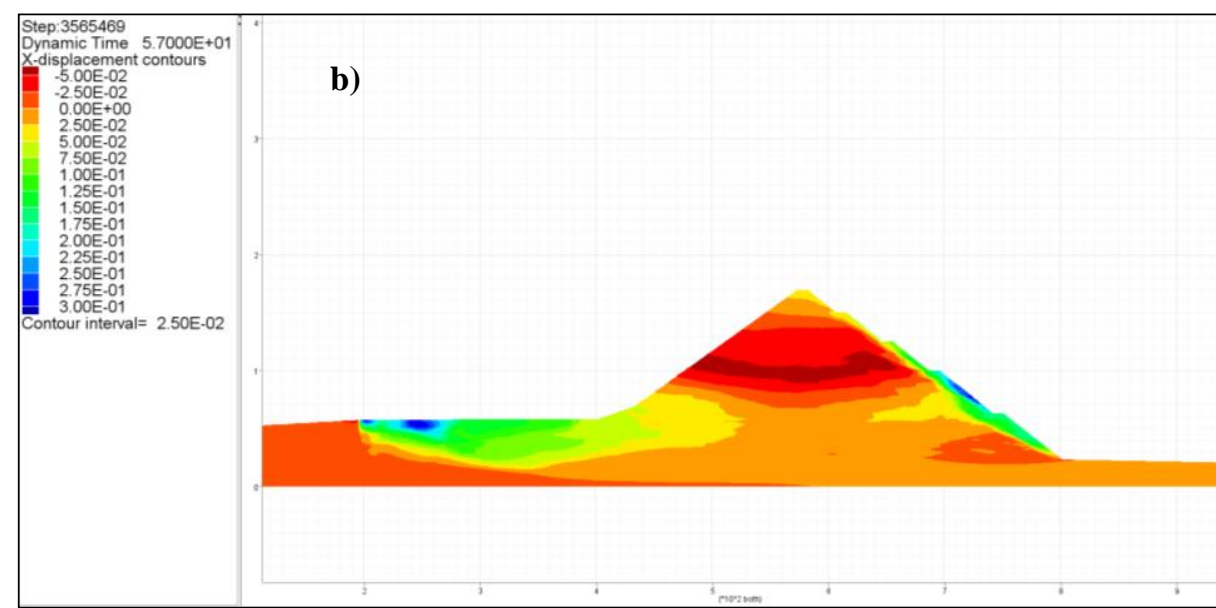

Figura 7.36 - Contornos de deslocamentos horizontais causados pelo sismo Paute Base 3: a) MCE; b) OBE.
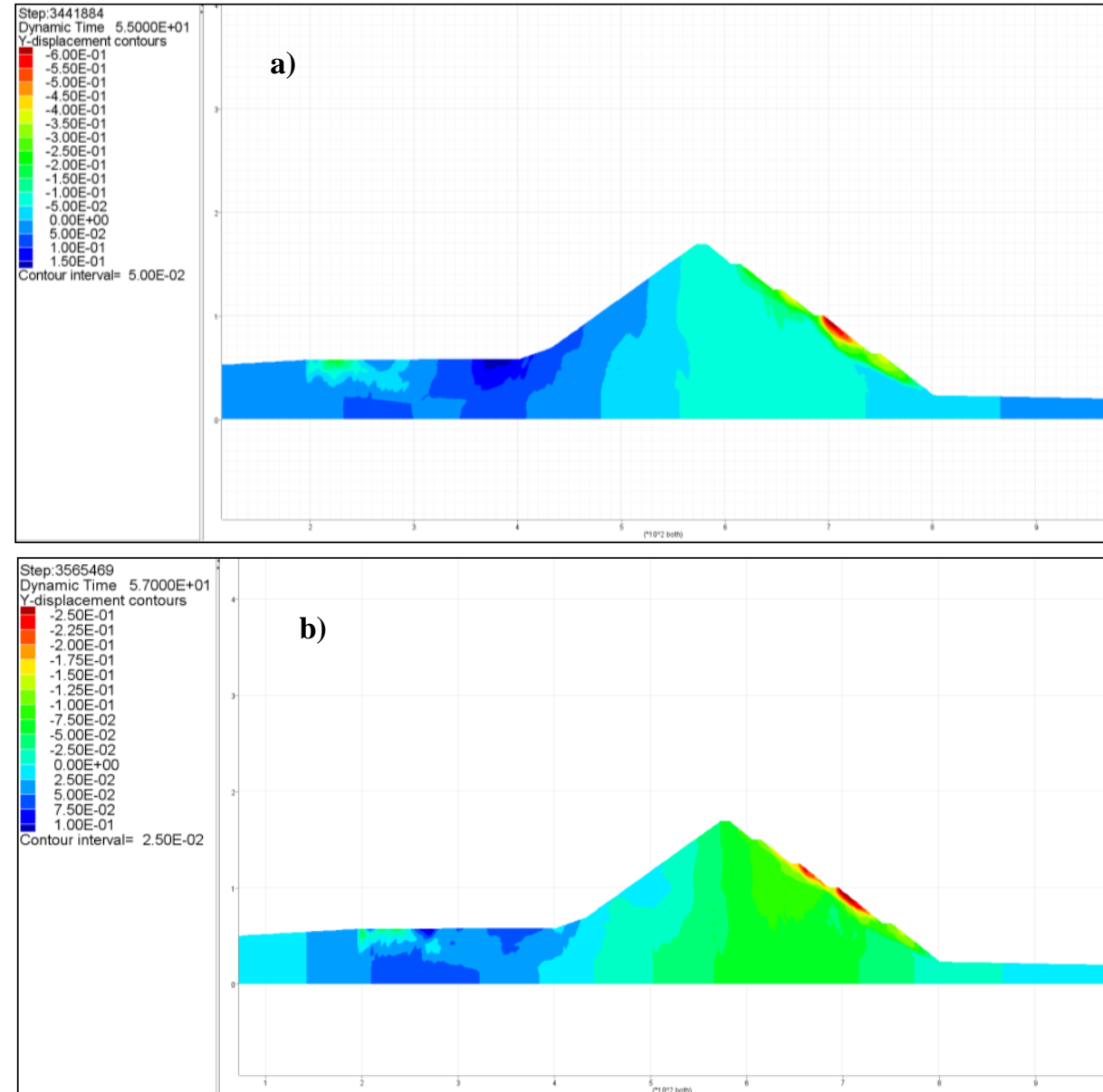

Figura 7.37 - Contornos de deslocamentos verticais causados pelo sismo Paute Base 3: a) MCE; b) OBE. 

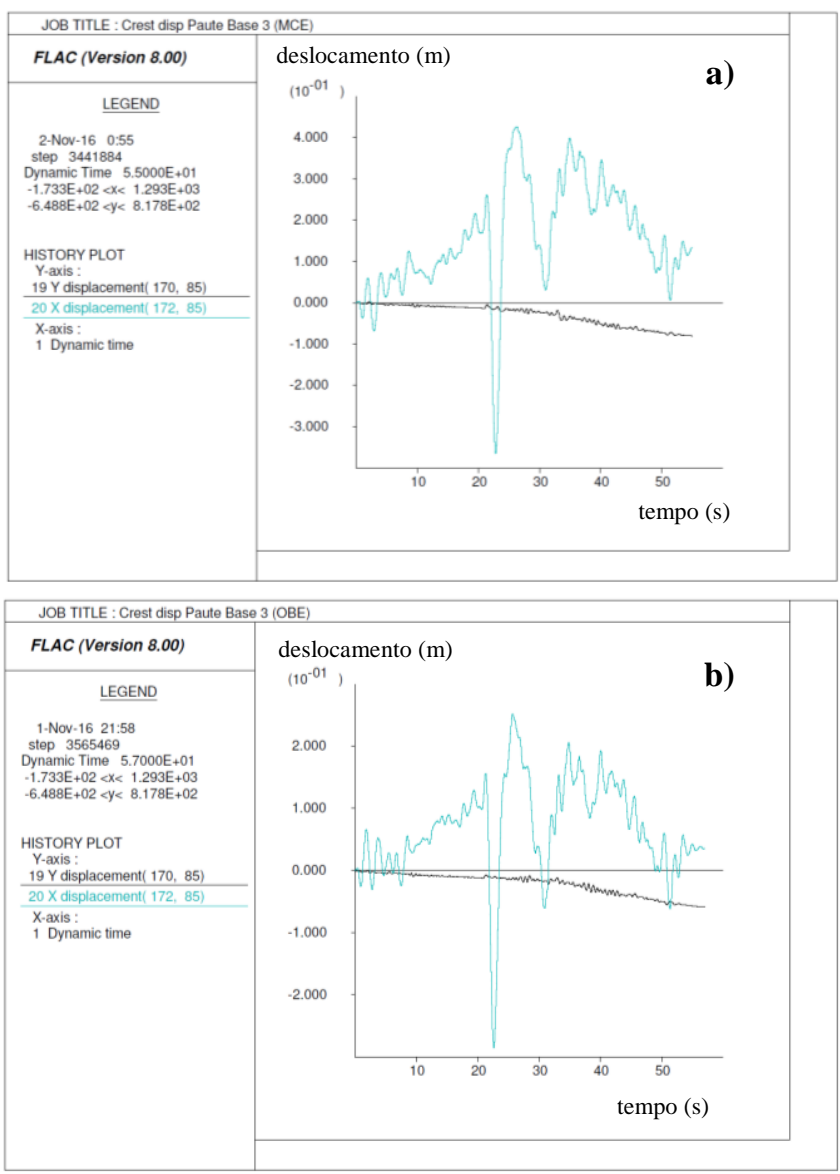

Figura 7.38 - Histórias de deslocamentos horizontal e vertical no ponto central da crista da barragem, terremoto Paute Base 3: a) MCE; b) OBE.

Na Figura 7.39 apresentam-se os espectros de resposta em aceleração horizontal na crista da barragem para verificação da resposta máxima em determinados períodos de interesse da excitação sísmica para o terremoto Paute Base 3.
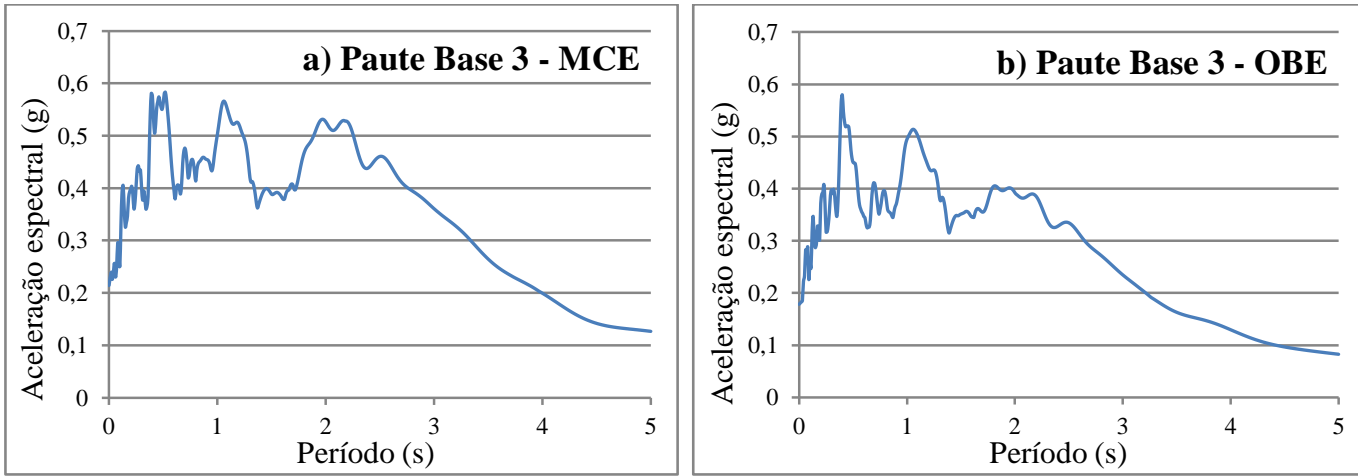

Figura 7.39 - Espectro de resposta em aceleração horizontal na crista da barragem, reservatório máxima capacidade, terremoto Paute Base 3: a) MCE; b) OBE. 
Nas Figuras 7.40 e 7.41 se apresenta o perfil de deslocamentos permanentes (horizontal e vertical) apos cada terremoto, estimados ao longo do eixo central da seção transversal da barragem de Mazar para ambas as intensidades sísmicas consideradas no estudo (MCE e OBE) na condição de reservatório a máxima capacidade.
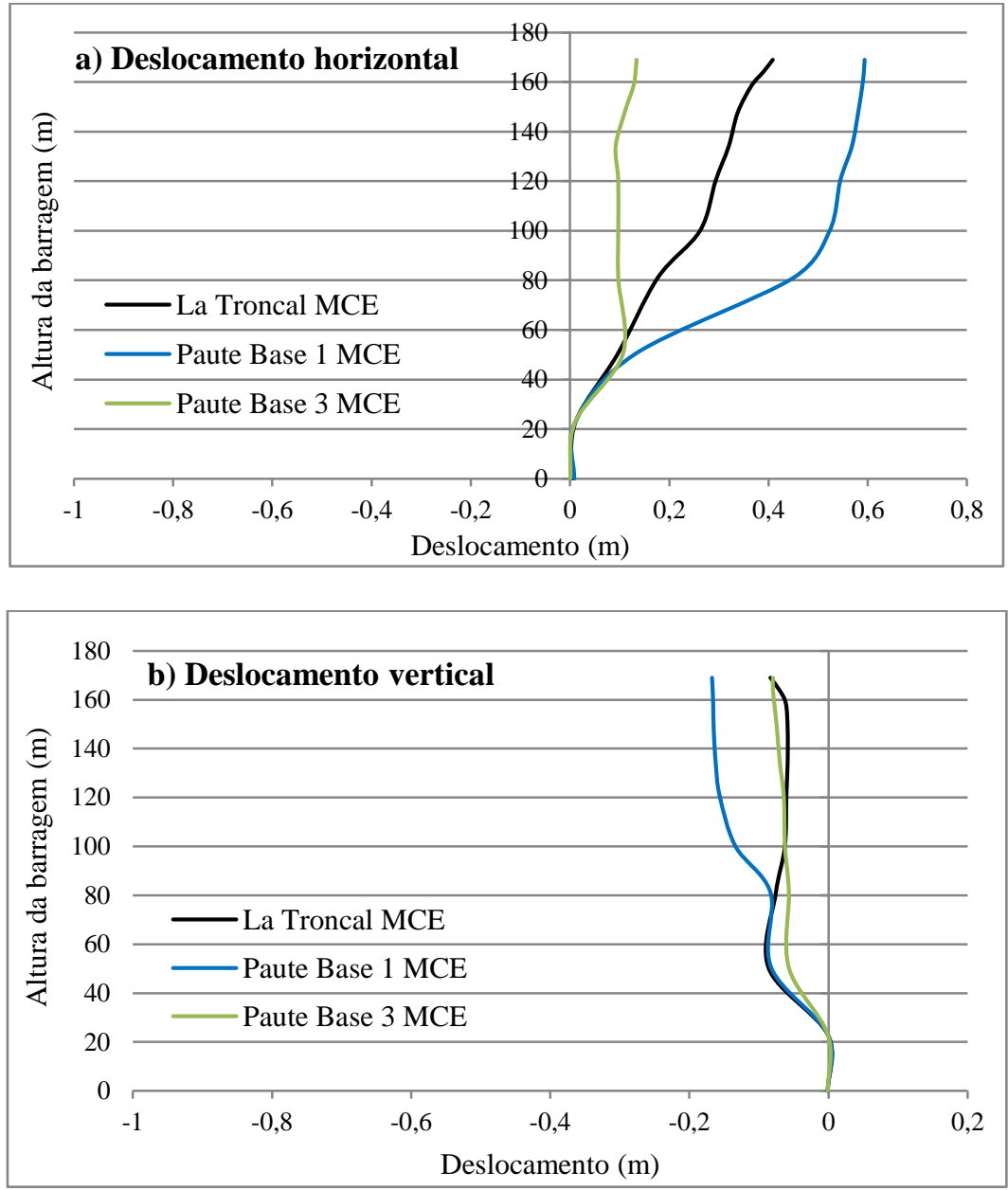

Figura 7.40 - Distribuição de deslocamentos permanentes na condição de reservatório cheio MCE: a) deslocamento horizontal; b) deslocamento vertical. 

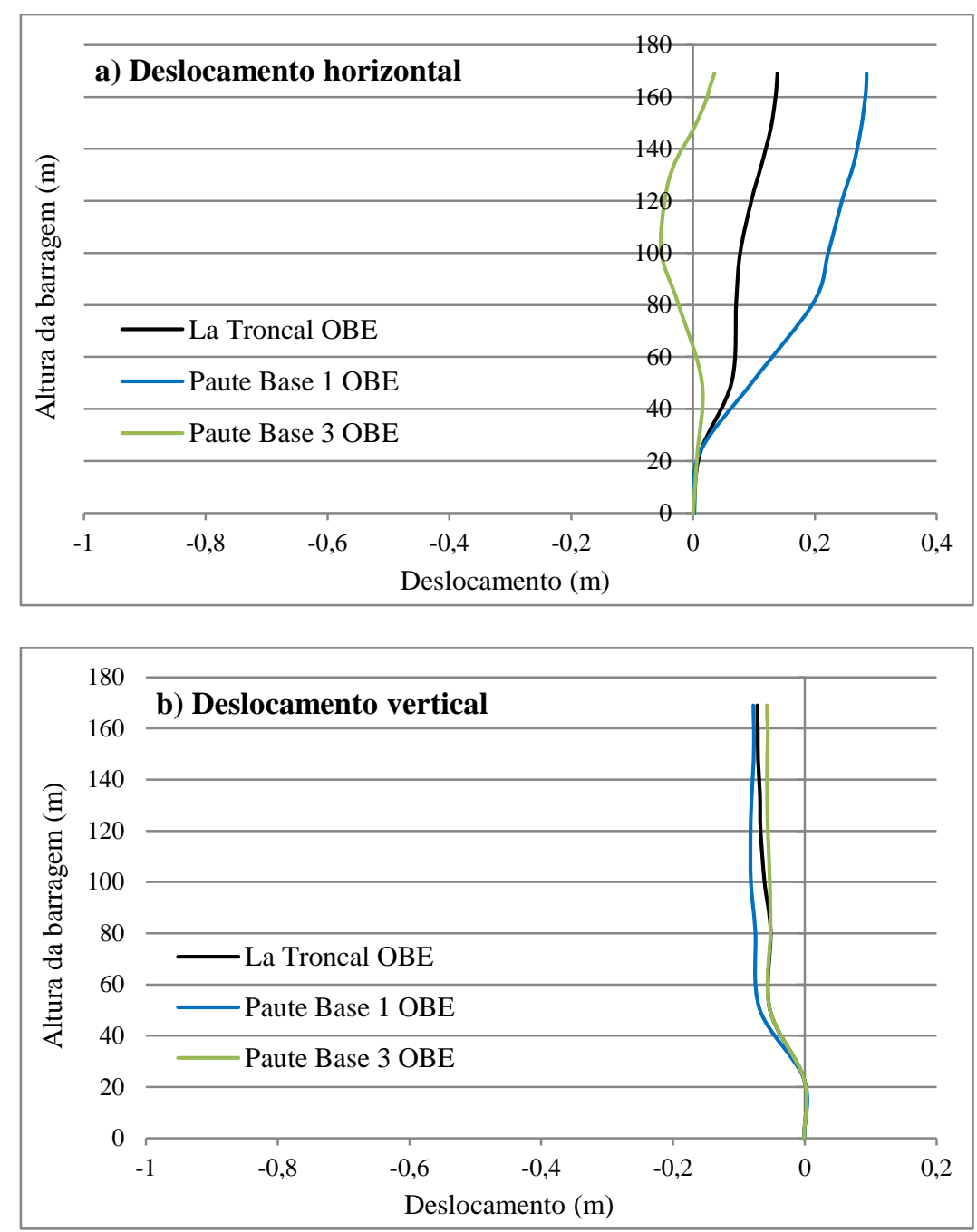

Figura 7.41 - Distribuição de deslocamentos permanentes na condição de reservatório cheio OBE: a) deslocamento horizontal; b) deslocamento vertical.

Com base nos resultados obtidos da análise dinâmica executada com o programa Flac 2D v8 conclui-se que a aceleração inicial sofre forte atenuação durante seu percurso pelo corpo da barragem ou, em outras palavras, a aceleração máxima de $0,45 \mathrm{~g}$ aplicada na base rochosa sofre marcado decréscimo ao atingir a crista da barragem $(0,28 \mathrm{~g}$ no caso do sismo La Troncal, terremoto MCE). Para verificar estes resultados foi feita uma simulação com o programa para análise linear equivalente 1D SHAKE 2000 considerando uma coluna de solo representativa da altura máxima da barragem. Os resultados obtidos estão apresentados na Figura 7.42.

Embora os valores exibidos na Figura 7.42 se diferenciem daqueles obtidos com a análise numérica (o que deve ser esperado visto a natureza 1D da análise com o programa SHAKE2000 e natureza 2D com o programa Flac 2D) o 
fenômeno da atenuação com a tendência de redução das acelerações máximas, da base rochosa para a crista do talude, também é observado.

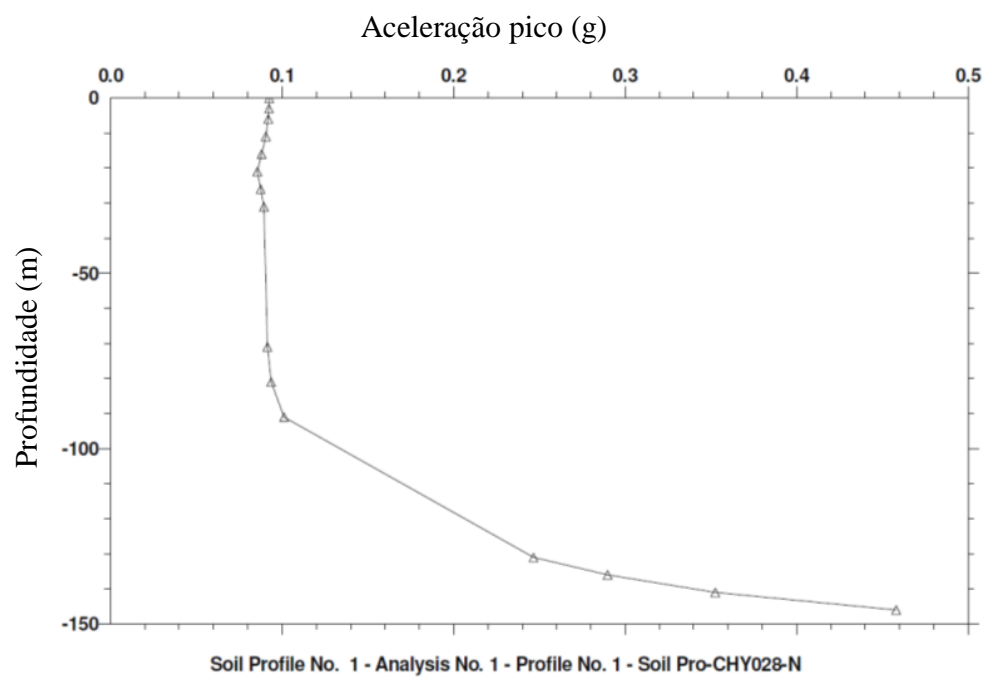

Figura 7.42 - Acelerações de pico ao longo da coluna de solo representativa da barragem de Mazar obtidas com o programa computacional SHAKE2000.

Em relação à comparação entre resultados de análises $1 \mathrm{D}$ e $2 \mathrm{D}$, Bray e Travasarou (2007) afirmam que análises 1D podem subestimar a demanda sísmica para causar deslizamentos superficiais na parte superior de sistemas bidimensionais (crista da barragem) onde a amplificação topográfica é de significativa importância. Para estes casos, sugerem que a aceleração máxima do registro sísmico em análises 1D seja majorada para 1,25 PGA (Rathje e Bray, 2001) para taludes moderadamente íngremes e para 1,50 PGA para taludes íngremes (Ashford e Sitar, 2002).

\subsubsection{2.}

\section{Reservatório vazio}

Os efeitos da ausência da pressão estabilizadora exercida pela água do reservatório no talude de montante são analisados de forma idêntica, com os mesmos procedimentos empregados para o caso de reservatório cheio.

\section{- Sismo de La Troncal}

A Figura 7.43 mostra a resposta em aceleração horizontal obtida para um ponto situado na crista no eixo central da barragem. Para o terremoto MCE foi registrada uma aceleração de pico de $0,54 \mathrm{~g}$, correspondente a uma amplificação de 1,2 vezes em relação à máxima aceleração aplicada no embasamento rochoso, 
enquanto que para o terremoto $\mathrm{OBE}$ o valor da aceleração horizontal máxima atingiu $0,40 \mathrm{~g}$, correspondendo a uma amplificação de 1,3 vezes da aceleração máxima do registro de entrada.
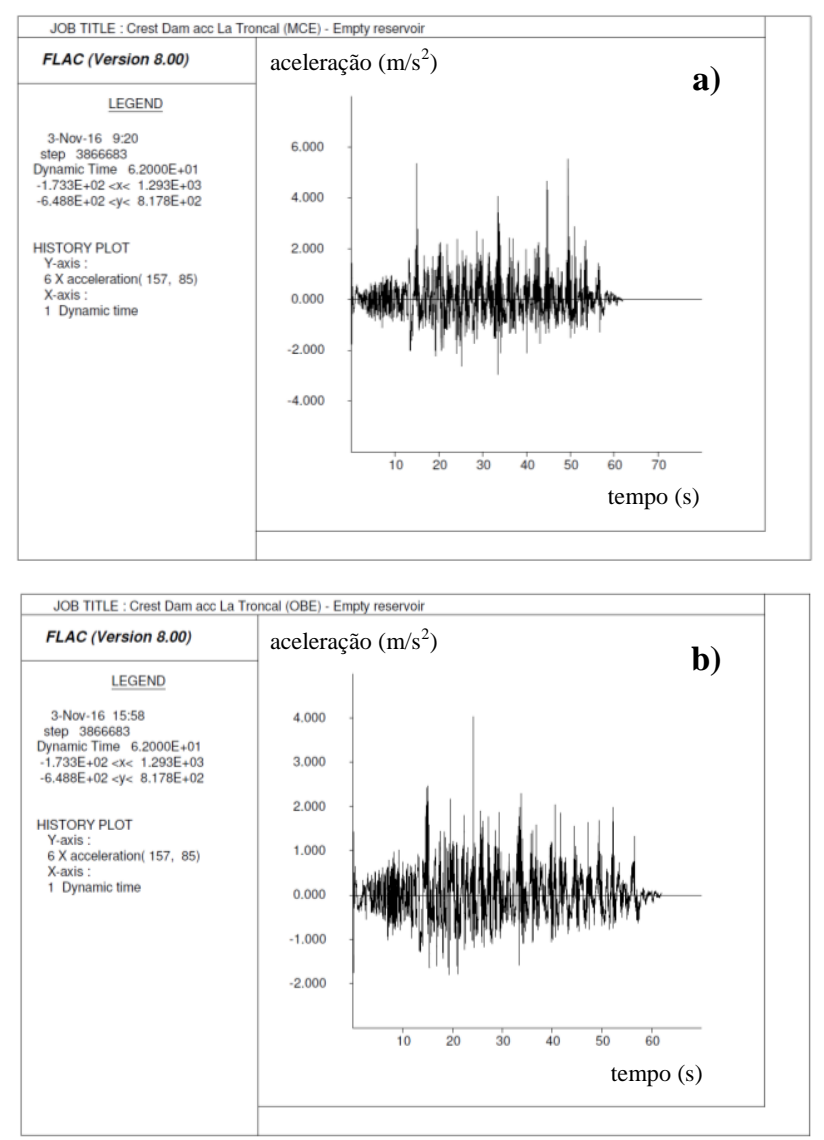

Figura 7.43 - Resposta em aceleração horizontal na crista da barragem, condição de reservatório vazio, terremoto La Troncal: a) MCE; b) OBE.

Os máximos deslocamentos horizontais permanentes na barragem ocorreram no talude de montante para os terremotos MCE e OBE com valores superiores a $3 \mathrm{~m}$, concentrados próximos à crista da barragem (Figura 7.44). Comportamento semelhante foi observado em relação aos deslocamentos verticais permanentes com deslocamentos superiores a 2,50m (Figura 7.45) confirmando a ruptura na região de montante da barragem.

A Figura 7.46 apresenta as histórias dos deslocamentos verticais e horizontais para um ponto situado na metade da crista da barragem, verificando-se que os valores tornam-se permanentes a partir do tempo aproximado $t=60 \mathrm{~s}$. Os deslocamentos permanentes atingem $0,39 \mathrm{~m}$ (componente horizontal) e $0,70 \mathrm{~m}$ (componente vertical) para o terremoto MCE e 0,25m (componente horizontal) e 0,30m (componente vertical) para o terremoto OBE. 

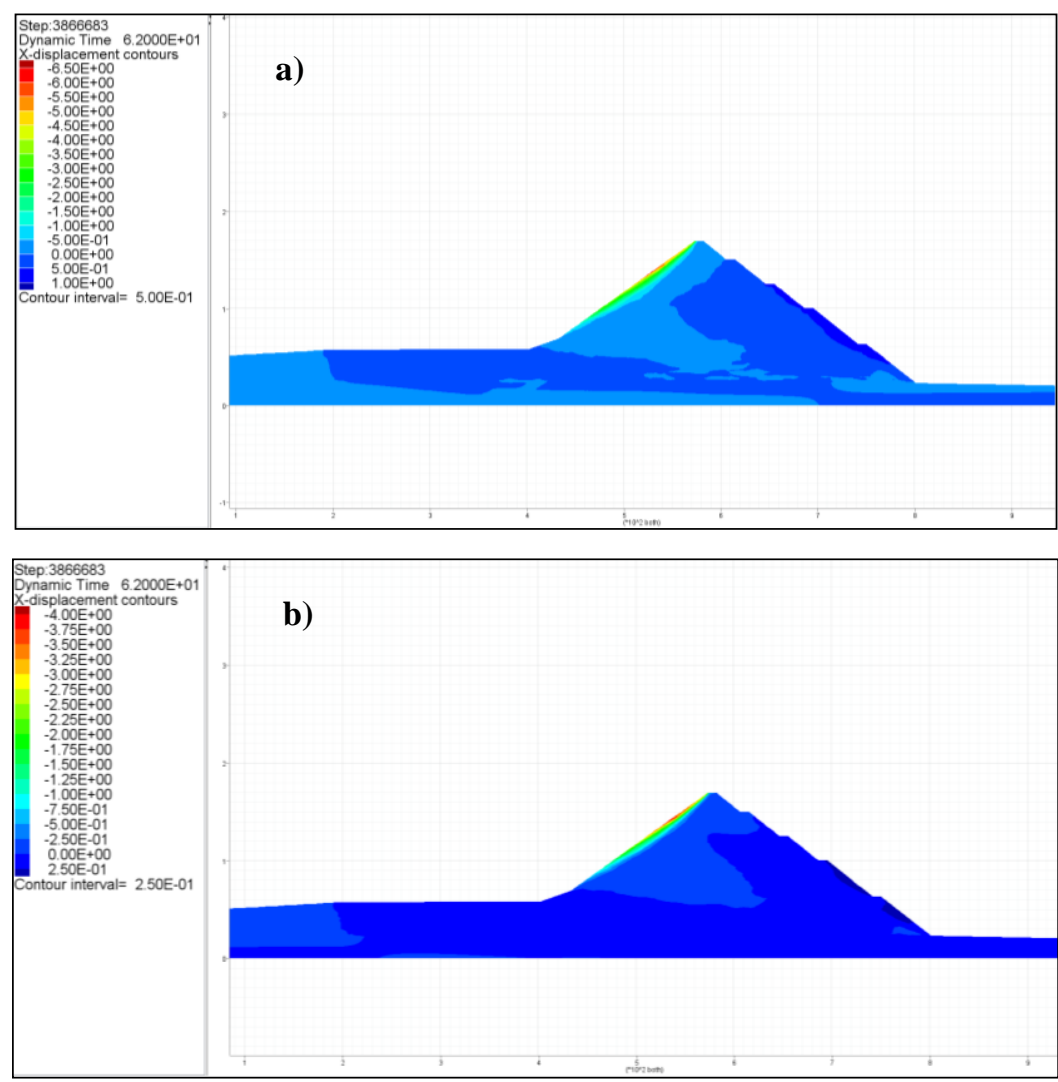

Figura 7.44 - Deslocamentos horizontais permanentes, reservatório vazio, sismo La Troncal: a) MCE; b) OBE.
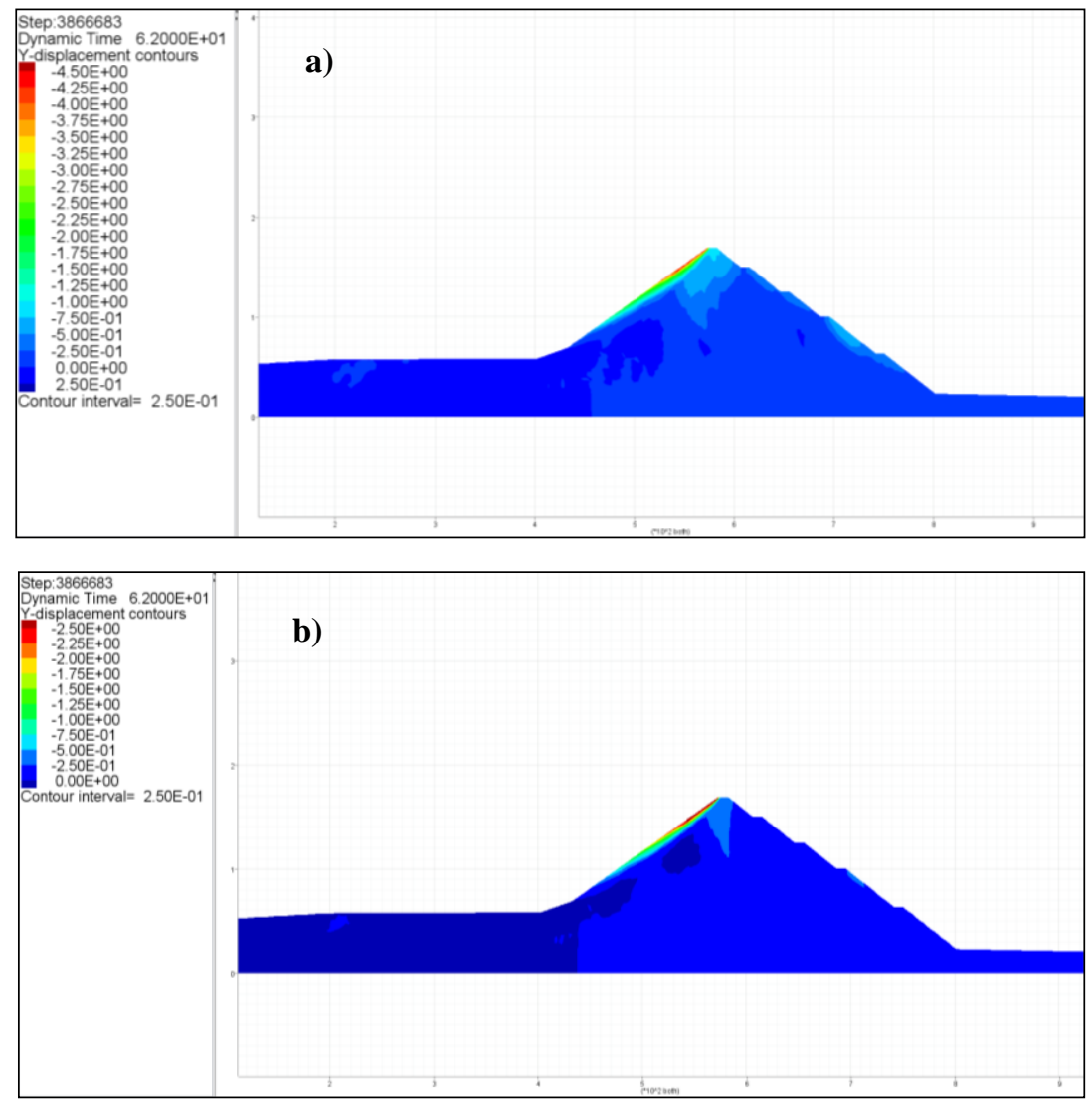

Figura 7.45 - Deslocamentos verticais permanentes, reservatório vazio, sismo La Troncal: a) MCE; b) OBE. 

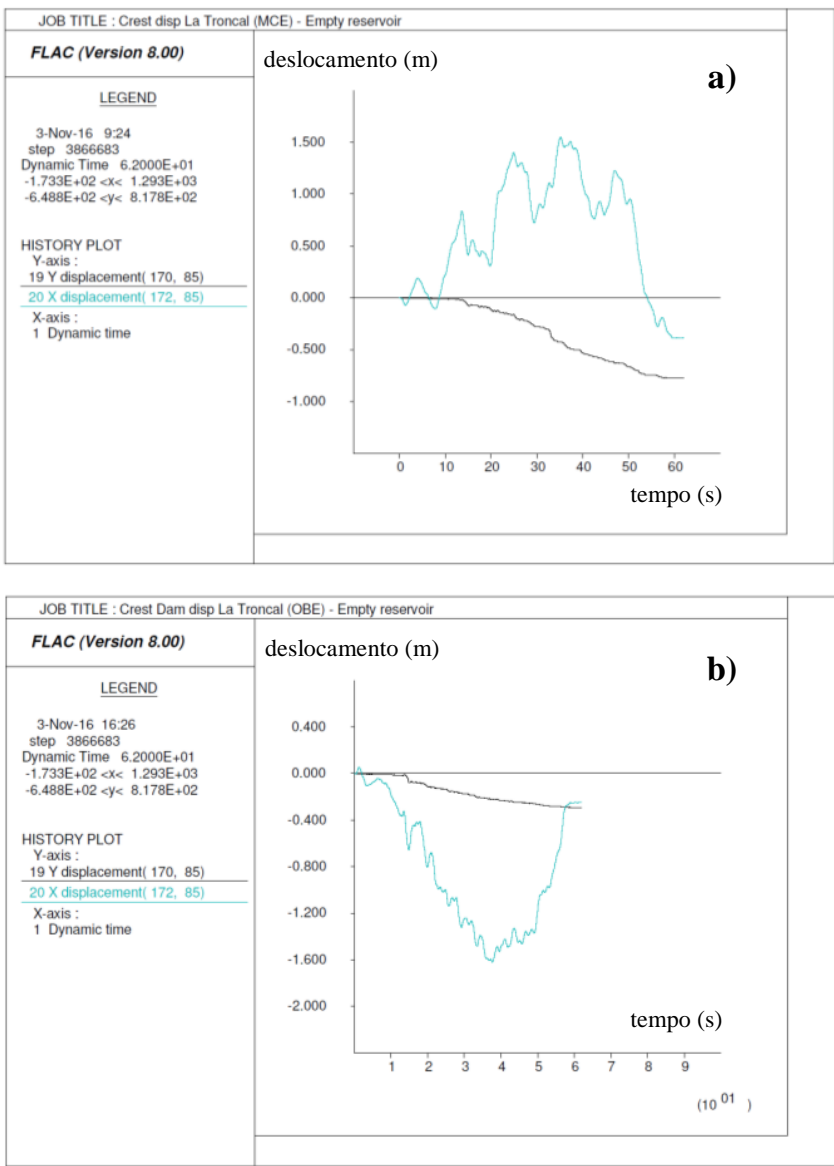

Figura 7.46 - Histórias de deslocamentos horizontal e vertical no ponto central da crista da barragem, reservatório vazio, sismo La Troncal: a) MCE; b) OBE.

Na Figura 7.47 apresentam-se os espectros de resposta em aceleração horizontal na crista da barragem para verificação das respostas máximas em determinados períodos de interesse da excitação sísmica.
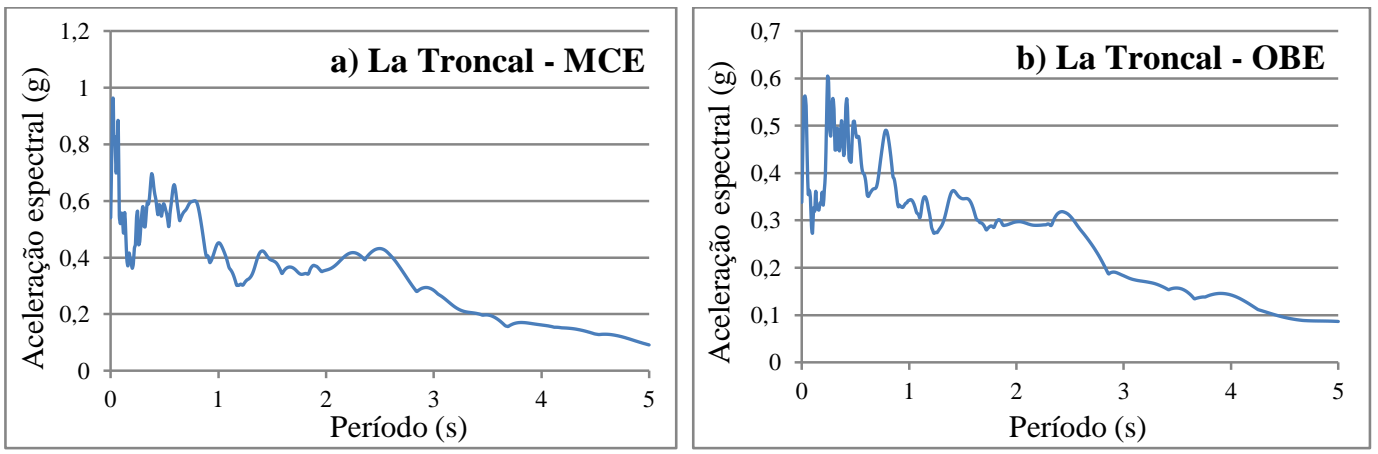

Figura 7.47 - Espectro de resposta em aceleração horizontal na crista da barragem, reservatório vazio, sismo de La Troncal: a) MCE; b) OBE. 


\section{- Sismo Paute Base 1}

A Figura 7.48 mostra a resposta em aceleração horizontal na crista da barragem: para o terremoto MCE foi registrada uma aceleração de pico de 0,53g, correspondente a uma amplificação de 1,4 com respeito à aceleração aplicada no embasamento rochoso, e para o terremoto OBE a aceleração horizontal máxima na crista atingiu um valor de $0,33 \mathrm{~g}$, correspondente a uma amplificação de $1,1 \mathrm{em}$ relação à máxima aceleração na base do modelo.

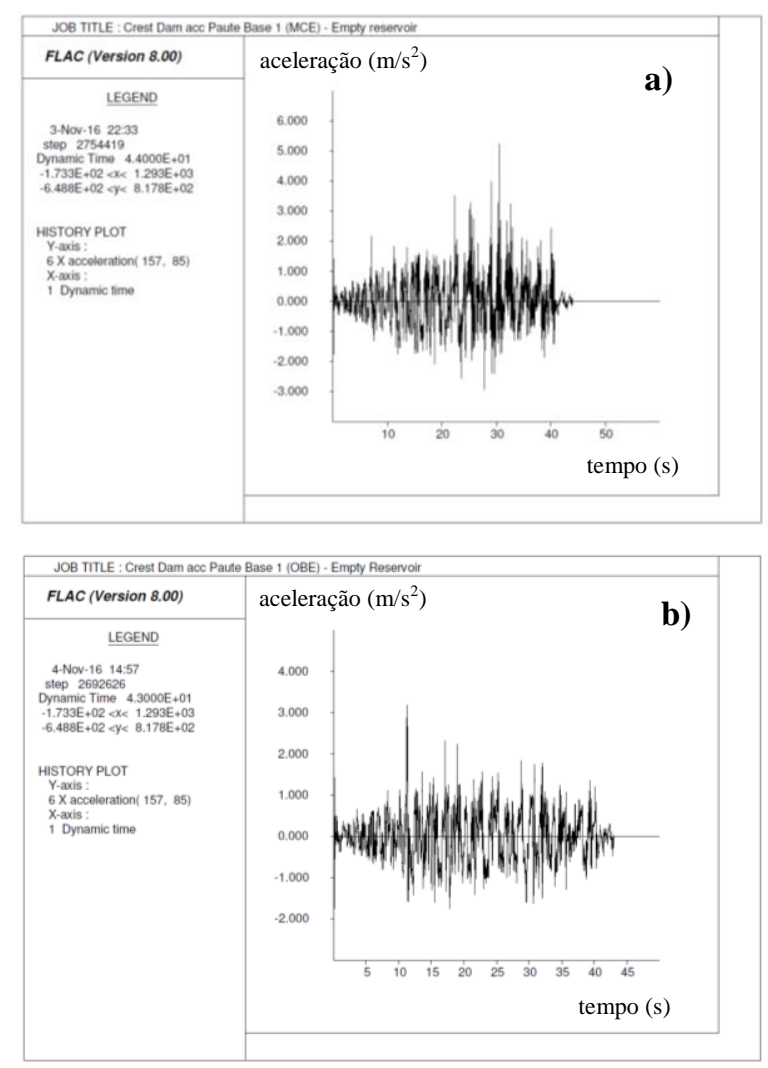

Figura 7.48 - Resposta em aceleração horizontal na crista da barragem, condição de reservatório vazio, sismo Paute Base 1: a) MCE; b) OBE.

Os deslocamentos horizontais permanentes máximos na barragem aconteceram no talude de montante. Para o terremoto MCE foi previsto valor superior a 2,5 m (Figura 7.49a) e para o terremoto OBE da ordem de 1,50 m (Figura 7.49b), na mesma região, confirmando que o material encontra-se sob escoamento plástico. Comportamento semelhante em relação aos deslocamentos verticais permanentes: valores superiores a 2,0 m para o terremoto MCE (Figura 7.50a) e superiores a 1,30 m (Figura 7.50b) para o terremoto OBE confirmando a ruptura do talude de montante. 
Na Figura 7.51 são ilustradas as histórias dos deslocamentos verticais e horizontais produzidos em um ponto situado na metade da crista da barragem, observando-se que estes se tornam permanentes a partir do tempo aproximado $\mathrm{t}=$ 40s, da ordem de 0,02 m (componente horizontal) e 0,65 m (componente vertical) para o terremoto MCE e 0,10 m (componente horizontal) e 0,46 m (componente vertical) para o terremoto OBE.
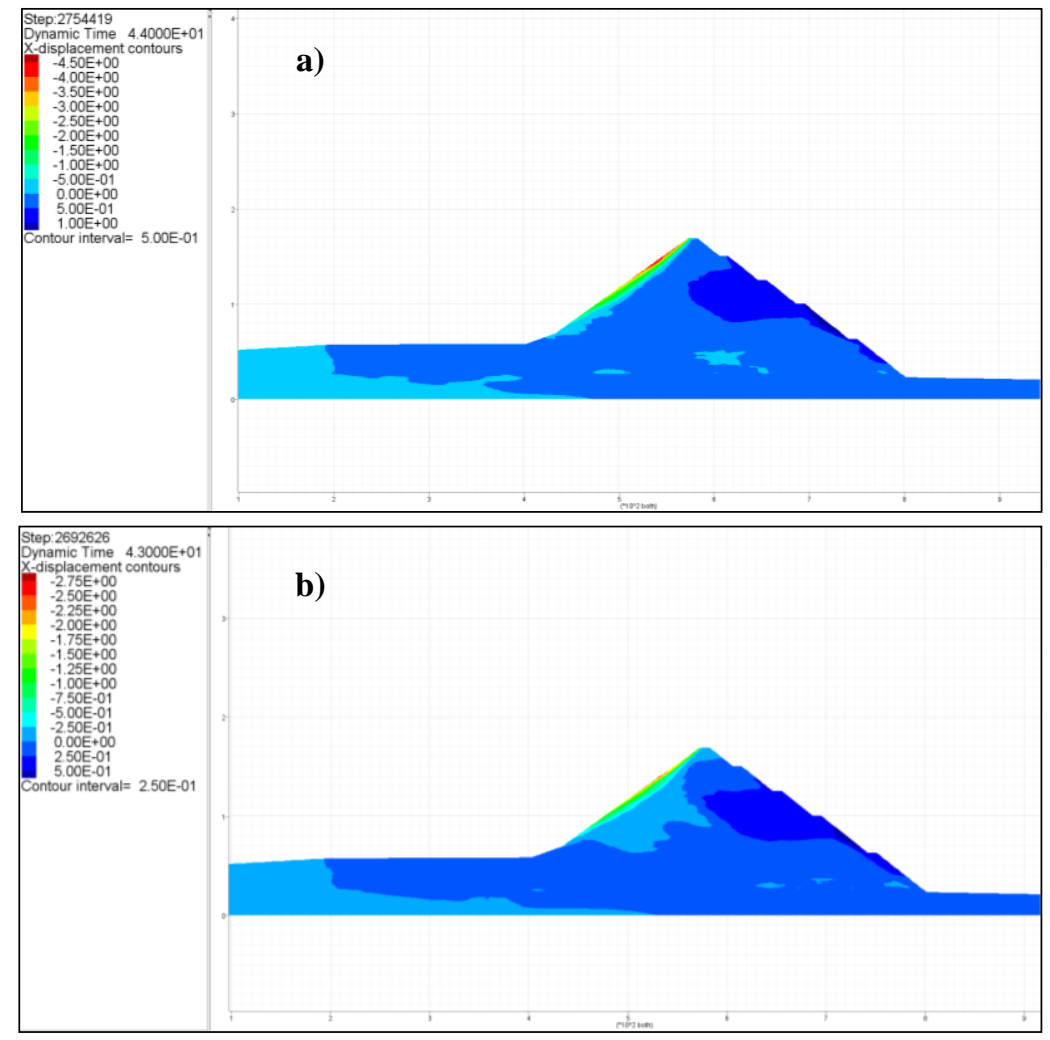

Figura 7.49 - Deslocamentos horizontais, reservatório vazio, sismo Paute Base 1: a) MCE; b) OBE.

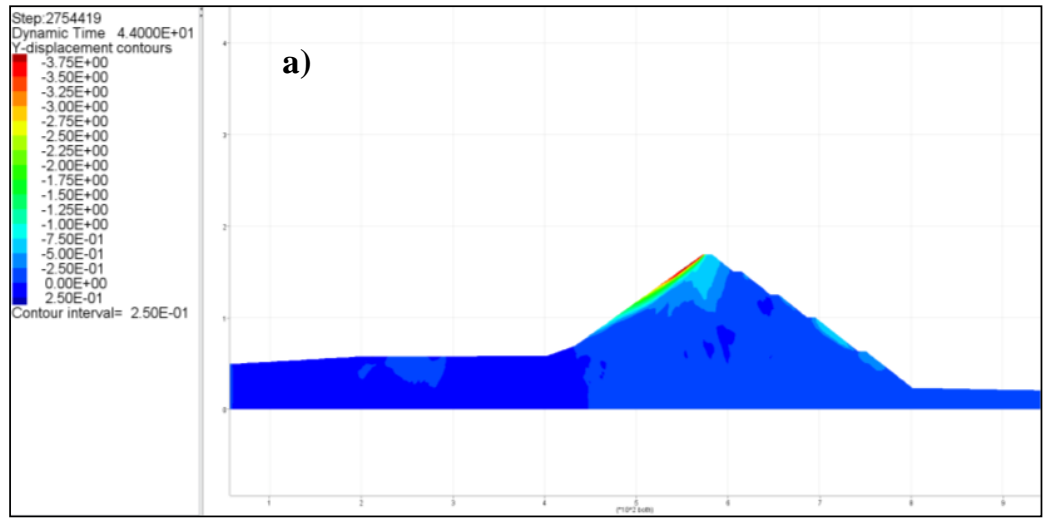




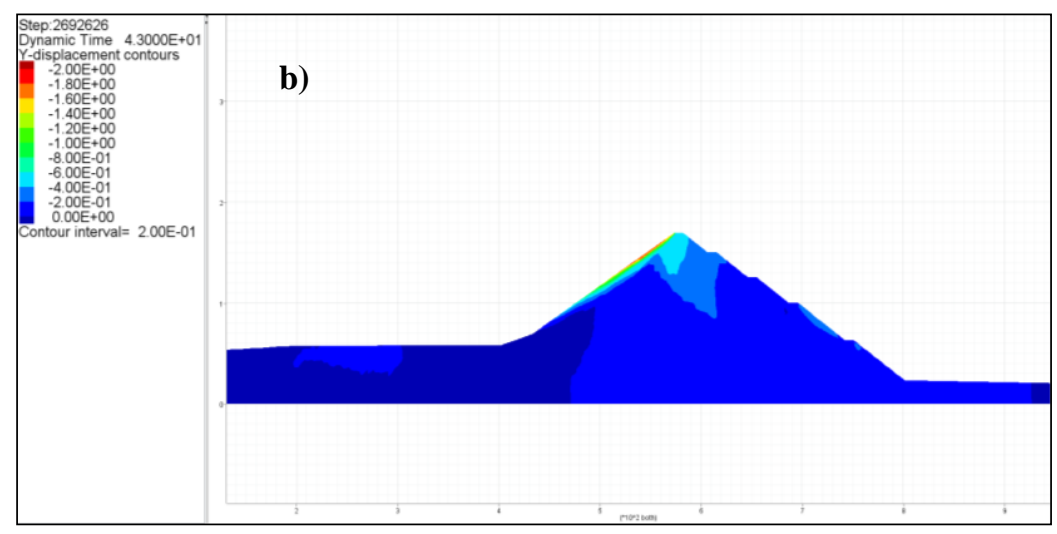

Figura 7.50 - Deslocamentos verticais, reservatório vazio, sismo Paute Base 1: a) MCE; b) OBE.
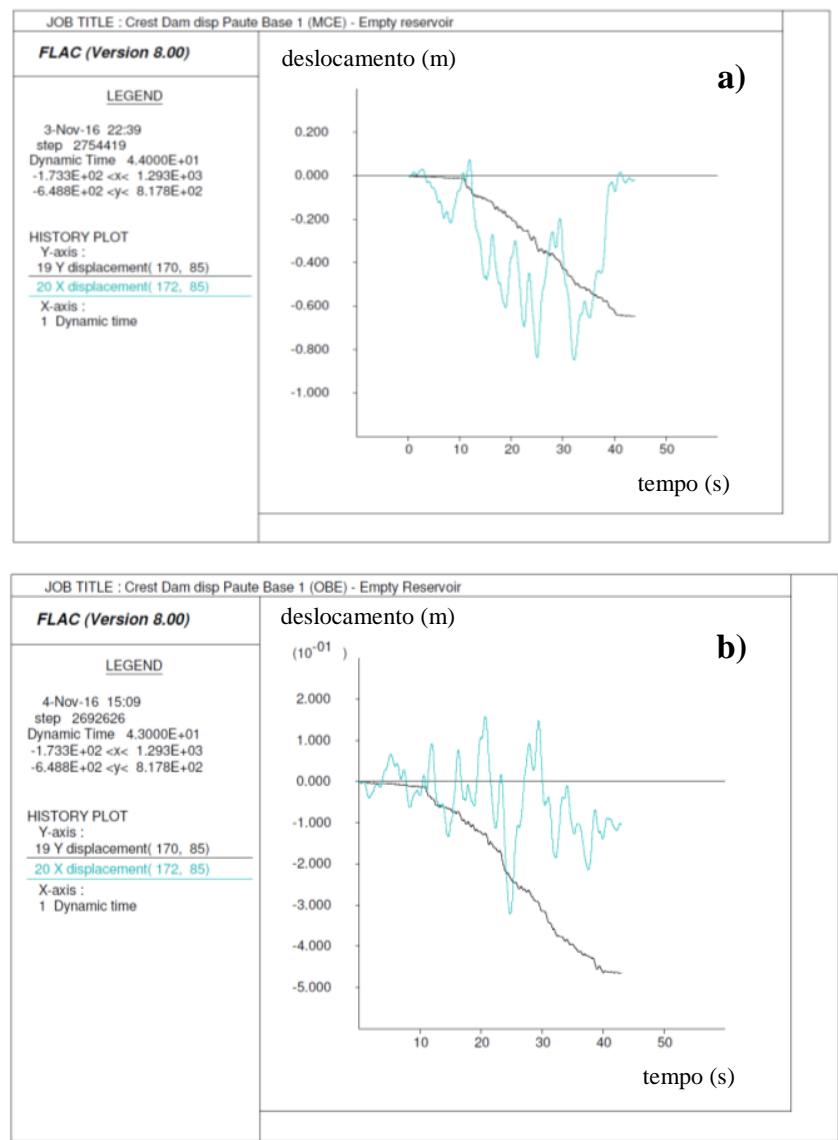

Figura 7.51 - Histórias de deslocamentos horizontal e vertical no ponto central da crista da barragem, reservatório vazio, sismo Paute Base 1: a) MCE; b) OBE.

Finalmente, Na Figura 7.52 apresentam-se os espectros de resposta em aceleração horizontal na crista da barragem para verificação das respostas máximas em determinados períodos de interesse da excitação sísmica. 

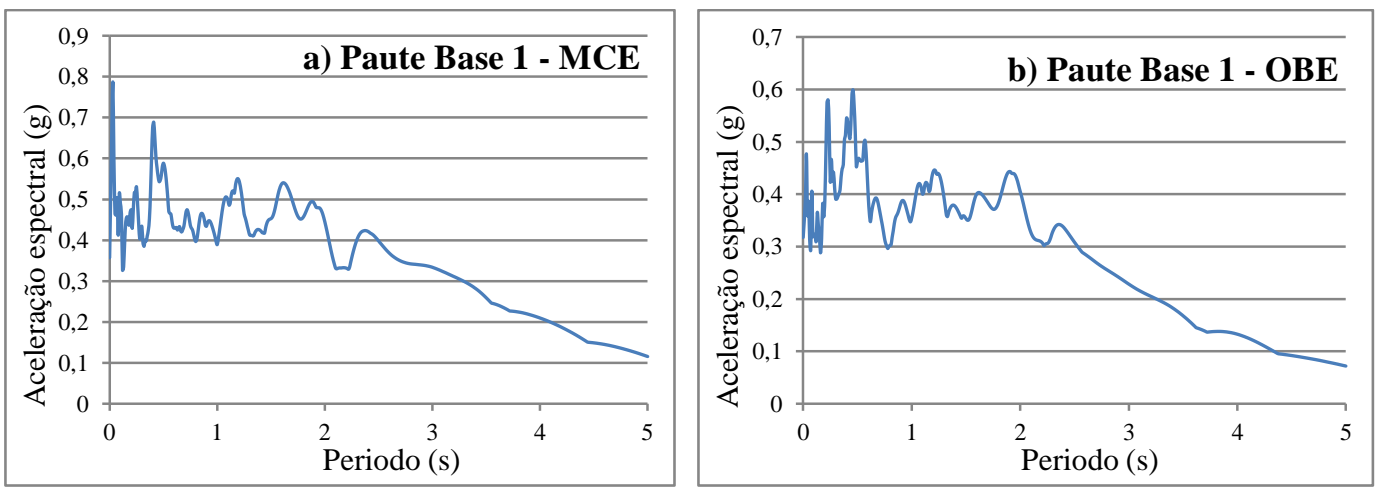

Figura 7.52 - Espectro de resposta em aceleração horizontal na crista da barragem, reservatório vazio, sismo Paute Base 1: a) MCE; b) OBE.

\section{- Sismo Paute Base 3}

A Figura 7.53 apresenta a resposta de aceleração horizontal na crista da barragem: para o caso do terremoto MCE foi registrada uma aceleração de pico de $0,6 \mathrm{~g}$, correspondente a uma amplificação de 1,4 com respeito à aceleração aplicada no embasamento rochoso, e para o terremoto OBE a aceleração horizontal máxima na crista atingiu o valor de $0,41 \mathrm{~g}$, correspondente a uma amplificação de 1,3 em relação à máxima aceleração na base do modelo.

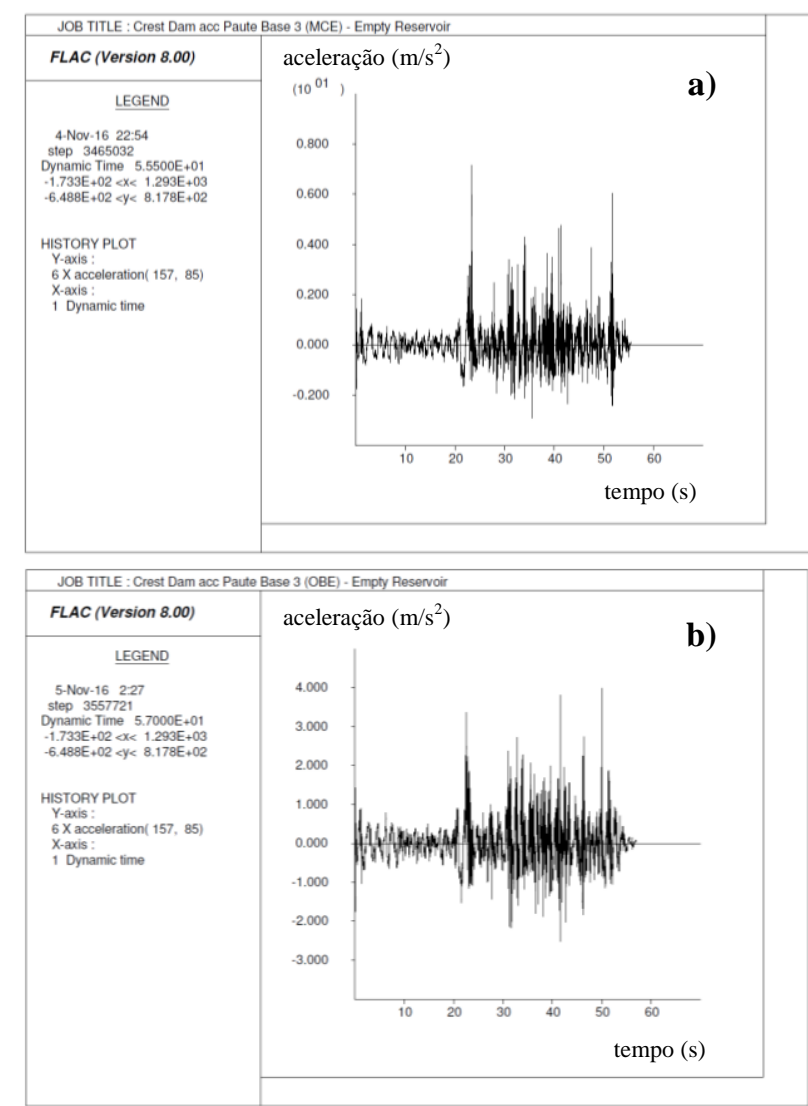

Figura 7.53 - Resposta em aceleração horizontal na crista da barragem, condição de reservatório vazio, sismo Paute Base 3: a) MCE; b) OBE. 
Os deslocamentos permanentes máximos na barragem ocorreram no talude de montante. Deslocamento horizontal superior a 4,5 m (Figura 7.54a) e vertical superior a 3,0 m (Figura 7.55a) para o terremoto MCE e deslocamento horizontal da ordem de 2,5m (Figura 7.54b) e vertical superior a 2,0 m (Figura 7.55b) para o terremoto OBE.

A Figura 7.56 apresenta as histórias dos deslocamentos verticais e horizontais para um ponto situado na metade da crista da barragem, verificando-se deslocamentos permanentes da ordem de $0,90 \mathrm{~m}$ (componente horizontal) e 0,92 m (componente vertical) para o terremoto MCE. Enquanto que para o terremoto OBE as amplitudes dos deslocamentos foram de 0,46 m (componente horizontal) e $0,37 \mathrm{~m}$ (componente vertical) a partir do instante de tempo $\mathrm{t}=52 \mathrm{~s}$.
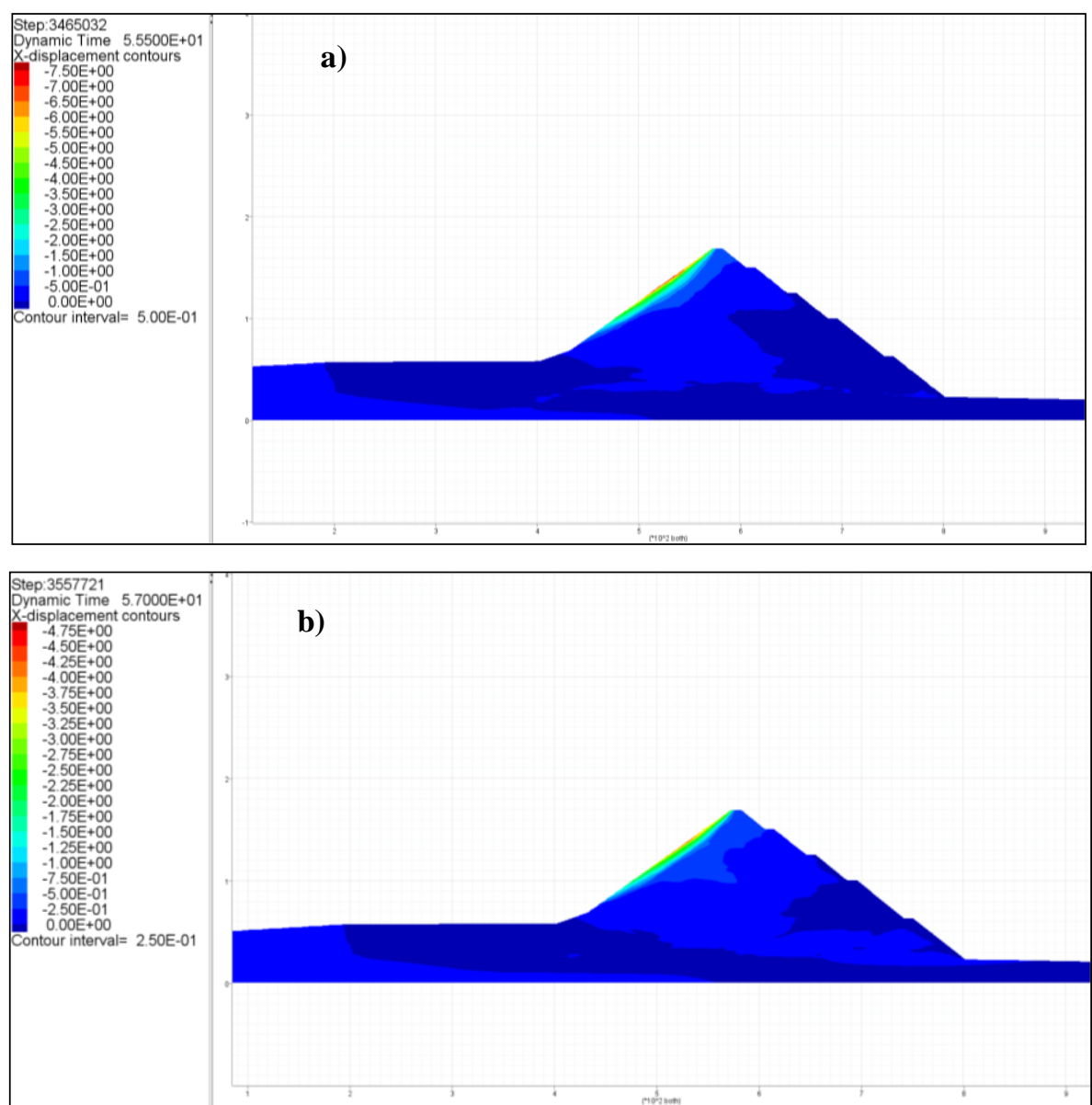

Figura 7.54 - Deslocamentos horizontais, reservatório vazio, sismo Paute Base 3: a) MCE; b) OBE. 

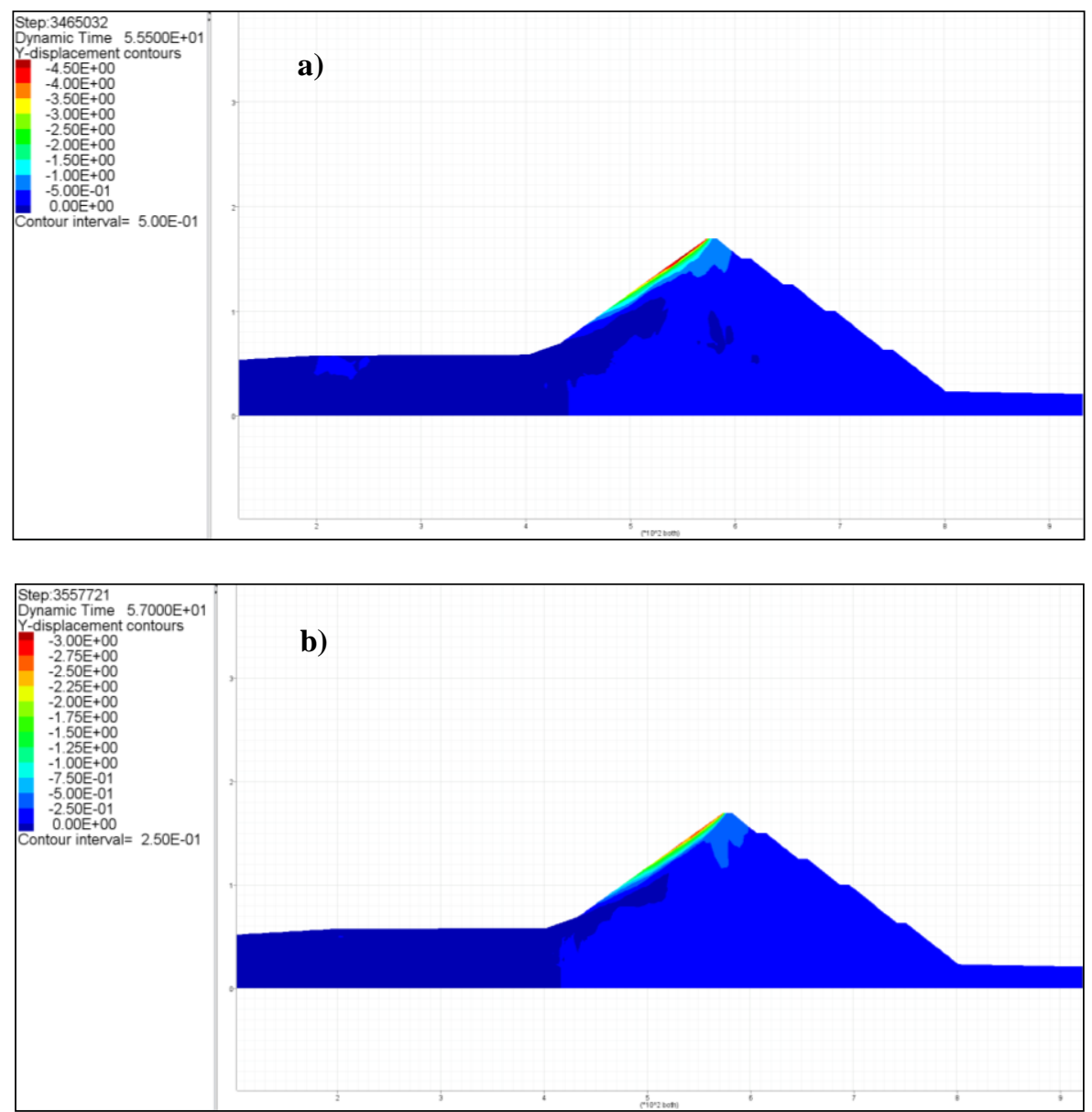

Figura 7.55 - Deslocamentos verticais, reservatório vazio, sismo Paute Base 3: a) MCE; b) OBE.

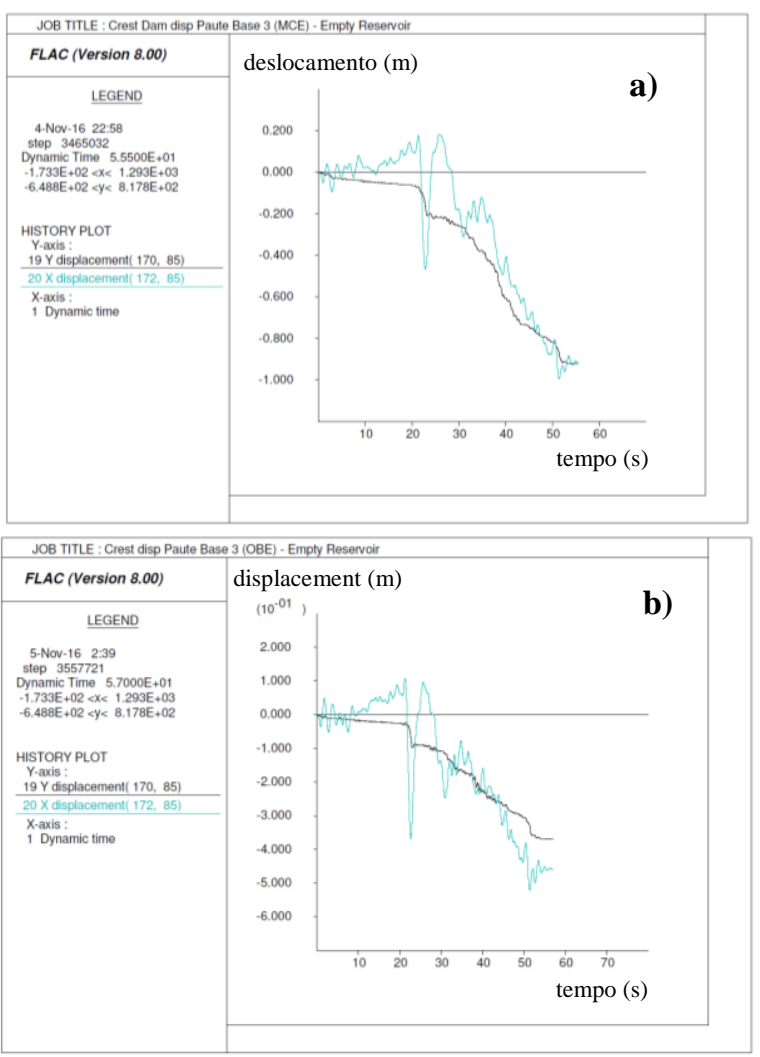

Figura 7.56 - Histórias de deslocamentos horizontal e vertical no ponto central da crista da barragem, reservatório vazio, sismo Paute Base 3: a) MCE; b) OBE. 
Na Figura 7.57 apresentam-se os espectros de resposta em aceleração horizontal na crista da barragem para verificação da máxima resposta em aceleração em determinados períodos de interesse da excitação sísmica.
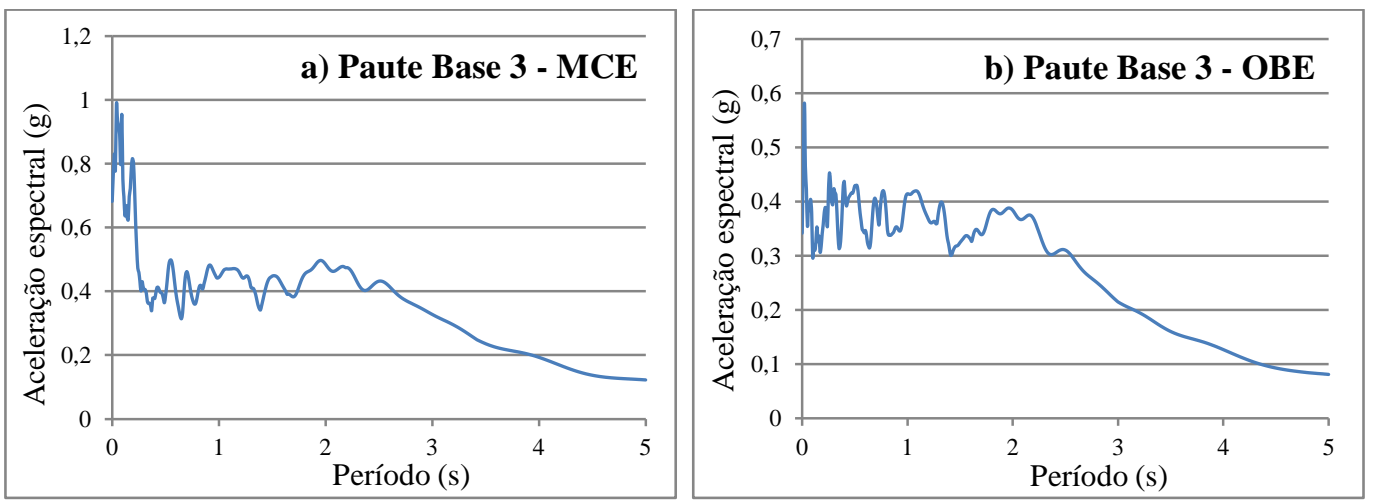

Figura 7.57 - Espectro de resposta em aceleração horizontal na crista da barragem, reservatório vazio, sismo Paute Base 3: a) MCE; b) OBE.

As Figuras 7.58 e 7.59 apresentam o perfil de deslocamentos permanentes

(horizontal e vertical) após a ocorrência de cada terremoto, estimados ao longo do eixo central da seção transversal da barragem de Mazar para ambos as intensidades sísmicas analisadas (MCE e OBE) na condição de reservatório vazio.

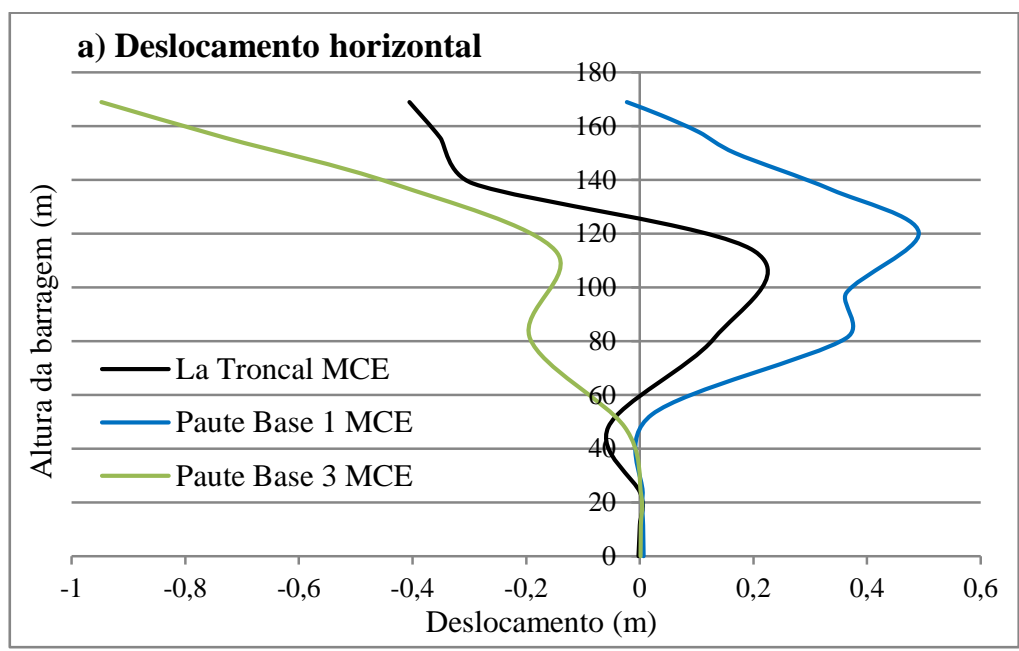




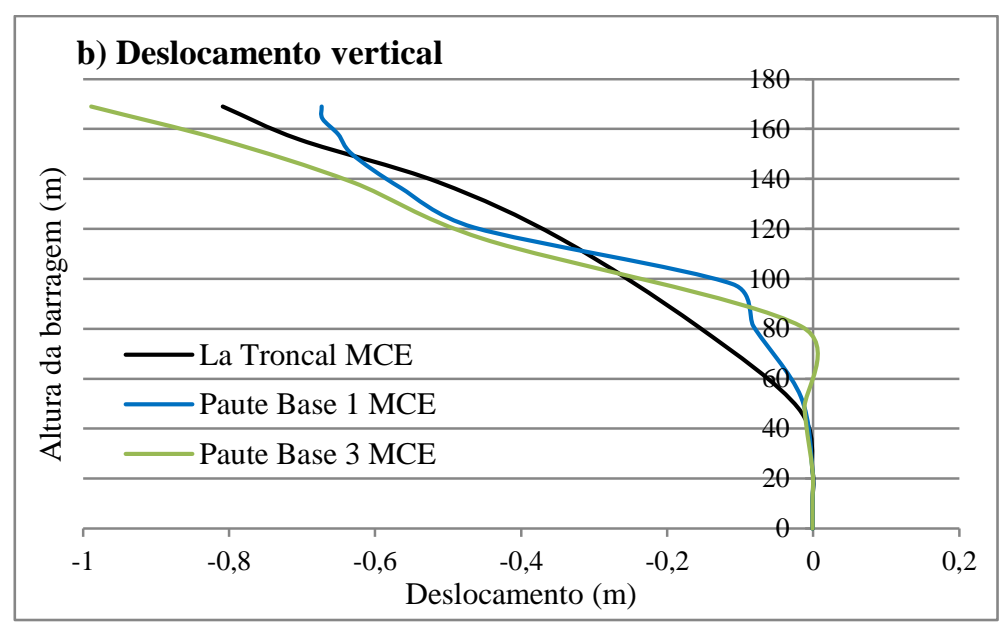

Figura 7.58 - Distribuição de deslocamentos permanentes na condição de reservatório vazio MCE: a) deslocamento horizontal; b) deslocamento vertical.
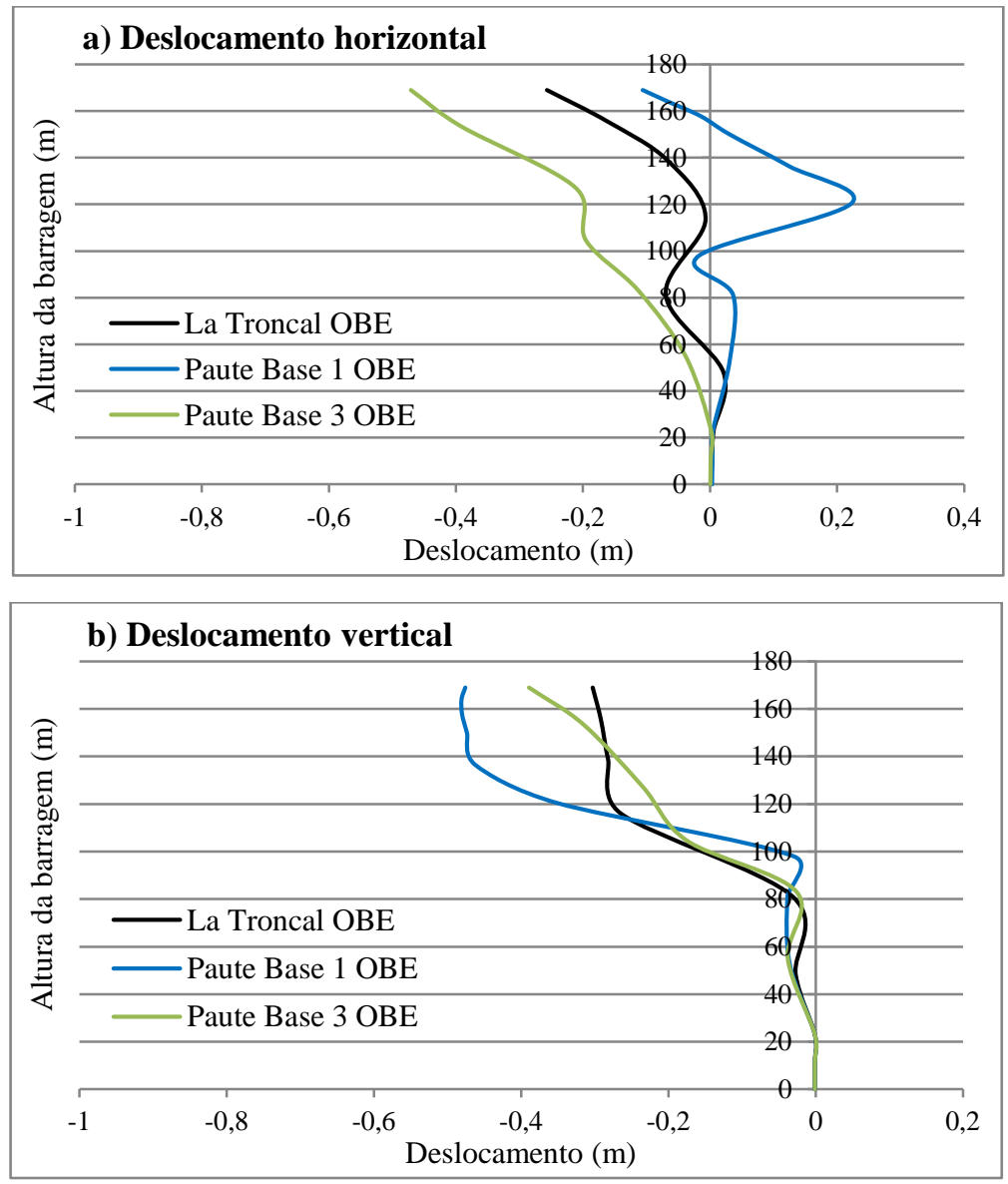

Figura 7.59 - Distribuição de deslocamentos permanentes na condição de reservatório vazio OBE: a) deslocamento horizontal; b) deslocamento vertical.

As Figuras 7.60 e 7.61 evidenciam os efeitos do amortecimento histerético na deformação cisalhante cíclica produzida em pontos situados próximos à crista da barragem, nos enrocamentos 3B e 3C, quando se aplicam as acelerações do sismo La Troncal para as condições de terremotos de projeto MCE e OBE. 

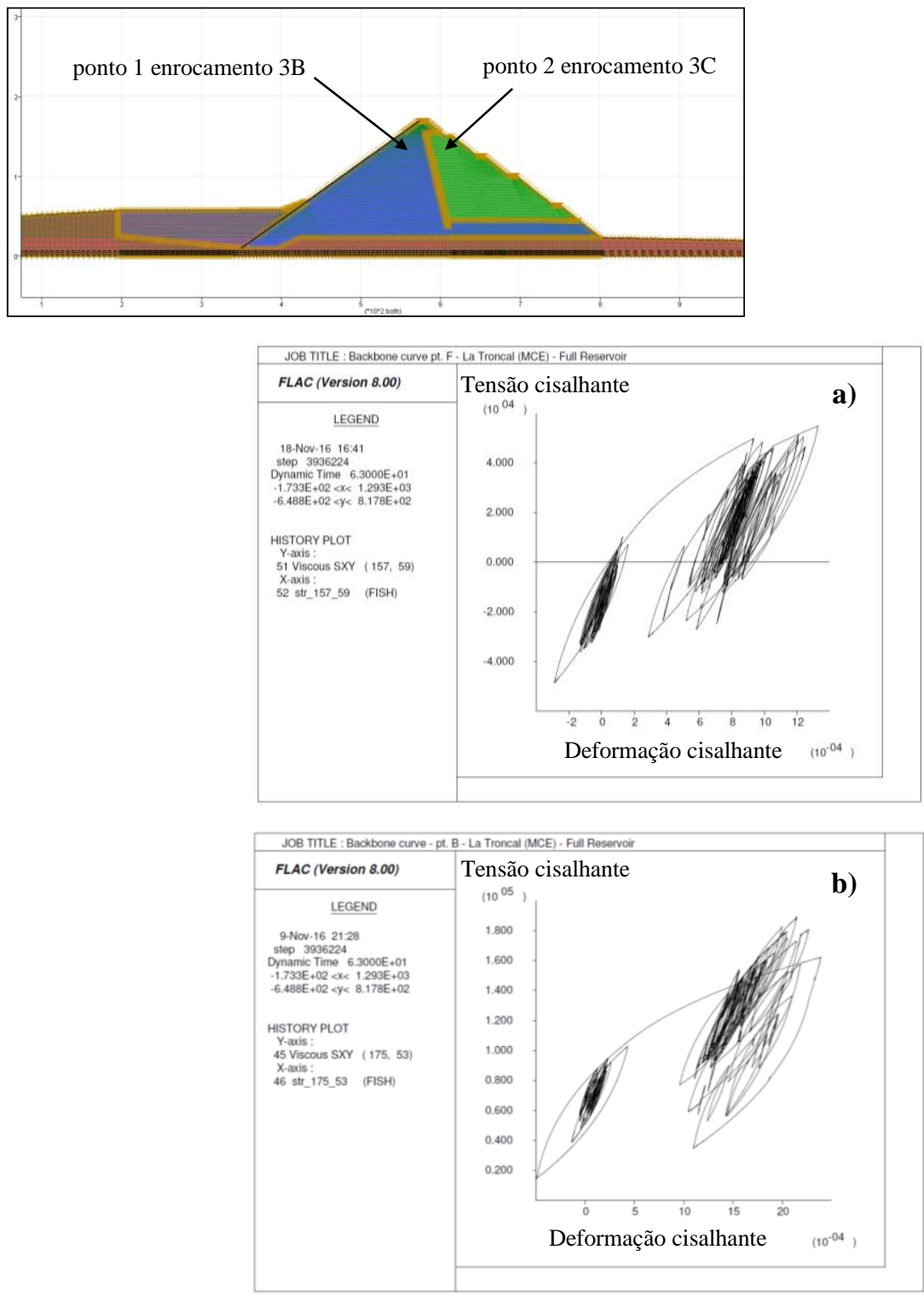

Figura 7.60 - Curvas de histerese tensão cisalhante cíclica - deformação cisalhante cíclica no sismo La Troncal, terremoto de projeto MCE: a) ponto 1 do enrocamento 3B; b) ponto 2 do enrocamento 3C.

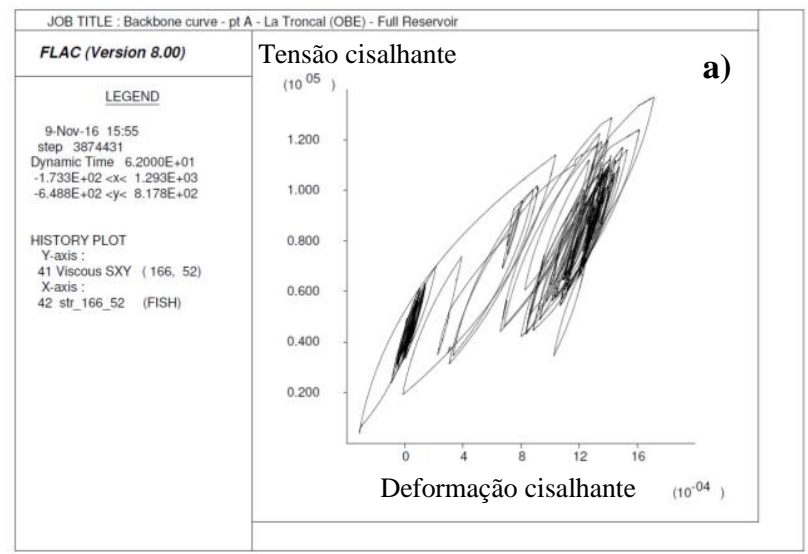




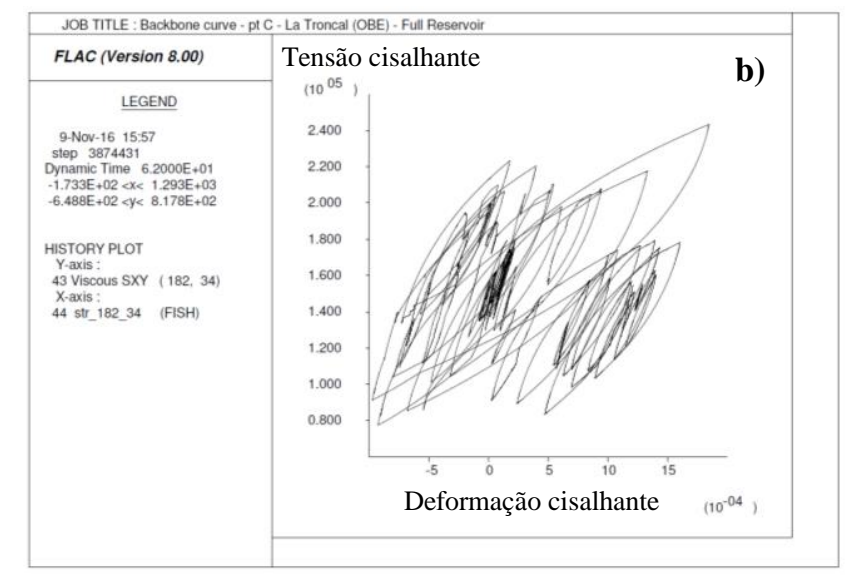

Figura 7.61 - Curvas de histerese tensão cisalhante cíclica - deformação cisalhante cíclica, sismo La Troncal, terremoto de projeto OBE: a) ponto 1 do enrocamento $3 \mathrm{~B}$; b) ponto 2 do enrocamento $3 \mathrm{C}$.

As Figuras 7.60 e 7.61 mostram que não existe uma grande redução do módulo de cisalhamento com as deformações cisalhantes cíclicas, tanto no enrocamento 3B quanto no enrocamento 3C. As máximas deformações cisalhantes cíclicas acontecem em torno de 0,20\%, conforme previsões anteriormente feitas na simulação elástica não amortecida.

Finalmente, as Tabelas 7.10 e 7.11 apresentam um resumo geral dos deslocamentos produzidos na crista da barragem para cada sismo (OBE e MCE) na condição de reservatório cheio e de reservatório vazio. Observa-se que para ambas as condições do reservatório os deslocamentos produzidos na crista da barragem são maiores para o terremoto máximo provável (MCE).

$\mathrm{Na}$ condição de reservatório cheio, pode-se concluir que os maiores deslocamentos são produzidos pelo sismo Paute Base 1, atingindo um deslocamento permanente horizontal de $0,70 \mathrm{~m}$ e vertical de $0,20 \mathrm{~m}$ com atenuação da aceleração horizontal máxima na crista da barragem.

$\mathrm{Na}$ condição de reservatório vazio, ocorre uma considerável amplificação da aceleração horizontal na crista da barragem, aumentando $30 \%$ em média em relação à aceleração máxima no substrato rochoso. Os deslocamentos permanentes previstos são significativos com 0,90 m (componente horizontal) e 0,92 m (componente vertical) para o sismo Paute Base 3, terremoto de projeto MCE. Estes resultados confirmam a hipótese mais desfavorável quando a barragem é submetida a uma excitação sísmica na condição de reservatório vazio. 
Tabela 7.10 - Resumo dos deslocamentos permanentes e acelerações de pico produzidas na crista da CFRD Mazar, com o reservatório cheio.

\begin{tabular}{|l|cc|c|c|}
\hline \multirow{2}{*}{ Terremoto } & \multicolumn{2}{|c|}{ Deslocamentos permanentes $(\mathrm{m})$} & Aceleração de pico & PGA \\
\cline { 2 - 3 } & horizontal & vertical & na crista $(\mathrm{g})$ & $(\mathrm{g})$ \\
\hline La Troncal MCE & 0,40 & 0,10 & 0,28 & 0,45 \\
Paute Base 1 MCE & 0,70 & 0,20 & 0,22 & 0,38 \\
Paute Base 3 MCE & 0,13 & 0,10 & 0,21 & 0,45 \\
\hline & \multicolumn{4}{|c}{0} \\
\hline La Troncal OBE & 0,15 & 0,07 & 0,17 & 0,30 \\
Paute Base 1 OBE & 0,30 & 0,10 & 0,18 & 0,26 \\
Paute Base 3 OBE & 0,04 & 0,06 & 0,18 & 0,29 \\
\hline
\end{tabular}

Tabela 7.11 - Resumo dos deslocamentos permanentes e acelerações de pico produzidas na crista da CFRD Mazar, com o reservatório vazio.

\begin{tabular}{|l|cc|c|c|}
\hline \multirow{2}{*}{ Terremoto } & \multicolumn{2}{|c|}{ Deslocamentos permanentes $(\mathrm{m})$} & Aceleração de pico & PGA \\
\cline { 2 - 3 } & horizontal & vertical & na crista $(\mathrm{g})$ & $(\mathrm{g})$ \\
\hline La Troncal MCE & 0,39 & 0,80 & 0,54 & 0,45 \\
Paute Base 1 MCE & 0,02 & 0,65 & 0,53 & 0,38 \\
Paute Base 3 MCE & 0,90 & 0,92 & 0,60 & 0,45 \\
\hline & \multicolumn{4}{c}{0.40} \\
\hline La Troncal OBE & 0,25 & 0,30 & 0,30 \\
Paute Base 1 OBE & 0,10 & 0,46 & 0,33 & 0,26 \\
Paute Base 3 OBE & 0,46 & 0,37 & 0,41 & 0,29 \\
\hline
\end{tabular}

De acordo com as recomendações da Califórnia Geological Survey (2008) para valores de deslocamentos observados em barragens, como índice de servicibilidade da estrutura após ocorrência de um terremoto, dispõe-se dos seguintes critérios gerais:

a. deslocamentos permanentes de até $10 \mathrm{~cm}$ provavelmente não causarão nenhuma instabilidade séria no talude;

b. no intervalo entre $15 \mathrm{~cm}$ e $100 \mathrm{~cm}$ de deslocamento permanente podem ser causadas fissuras no terreno e perda da resistência capaz de provocar uma ruptura progressiva após a ocorrência do terremoto, dependendo da geometria do talude e das propriedades dos materiais;

c. deslocamentos permanentes superiores a $100 \mathrm{~cm}$ provavelmente indicam perda da servicibilidade do talude que pode ser considerado em termos de engenharia como instável. 
De acordo com recomendações do Alaska's Geotechnical Evaluation Criteria Committe (Idriss, 1985) para taludes naturais, cinco classes de danos em função dos deslocamentos permanentes podem ser estabelecidos:

a. dano baixo para $\mathrm{D}<3 \mathrm{~cm}$;

b. dano moderado para $3 \mathrm{~cm}<\mathrm{D}<15 \mathrm{~cm}$;

c. dano alto para $15 \mathrm{~cm}<\mathrm{D}<30 \mathrm{~cm}$;

d. dano extenso para $30 \mathrm{~cm}<\mathrm{D}<80 \mathrm{~cm}$;

e. dano catastrófico para $80 \mathrm{~cm}<\mathrm{D}<300 \mathrm{~cm}$.

Considerando os critérios gerais da Califórnia Geological Survey (2008), na barragem de Mazar os deslocamentos máximos produzidos na condição de reservatório cheio tem amplitude de 1,0 m, mas ocorrem muito localmente e em pequenas áreas do talude de jusante que parecem não comprometer a estabilidade global da estrutura. Na condição de reservatório vazio observam-se valores de deslocamento superiores a 2,5 m produzidos no talude de montante da barragem, o que, sem dúvida, representa uma ameaça importante à estabilidade global da barragem. 


\section{8 \\ Conclusões e sugestões}

- O método simplificado de Newmark integra o registro sísmico das acelerações que ultrapassam o valor da aceleração de escoamento $a_{y}$. Desta forma, quando picos súbitos de aceleração ultrapassam fortemente o valor de $a_{y}$ os valores de deslocamento calculados podem ser bastante diferentes daqueles obtidos por método numérico cujos resultados dependem de todo o registro de aceleração e não apenas de valores, ou faixas de curta duração, superiores à aceleração de escoamento.

- Métodos para cálculo do deslocamento permanente em taludes podem ser classificados como analíticos, como os métodos de Newmark baseados na dupla integração no tempo do registro de acelerações, métodos simplificados desenvolvidos mediante ajuste de curvas ou análises de regressão como o método de Rathje e Saygili, métodos desacoplados nos quais o cálculo dos deslocamentos é feito em duas etapas: a) análise da resposta dinâmica; b) análise da resposta de deslocamentos como no método de Makdisi e Seed (1978), e finalmente métodos acoplados onde as respostas em termos de aceleração e deslocamentos são calculadas iterativamente como fenômeno acoplado, em aplicações numéricas baseadas nos métodos dos elementos finitos ou diferenças finitas. Em geral, métodos acoplados que teoricamente simulam o comportamento real de solos têm sido utilizados para propósitos de pesquisa porque além de precisar muito tempo de processamento, se requer de etapas previas à execução da análise, tais como construção da malha e processamento do sinal sísmico (filtragem, correções da linha base, etc.), abrangendo conhecimentos específicos. Na prática da engenharia sua aplicação é ainda reservada para análise de projetos complexos, envolvendo estruturas de grande importância, para os quais métodos simplificados sejam julgados inapropriados. 
- No caso de análises envolvendo amortecimento histerético é de fundamental importância investigar previamente o nível das deformações cisalhantes cíclicas máximas geradas pelo carregamento sísmico, mediante simulação elástica linear não amortecida, porque deformações acima de $0,2 \%$ tendem a calcular valores do módulo de cisalhamento irreais com base nas curvas de degradação $G / G_{\max }$. Adicionalmente, é importante comparar a resposta dinâmica de uma coluna de solo mediante o programa de propagação de ondas 1D SHAKE2000 (Ordoñez, 2015) para verificar os efeitos do amortecimento histerético e da necessidade de se introduzir, ou não, uma parcela de amortecimento de Rayleigh para altas frequências.

- Observou-se que os efeitos da amplificação topográfica no modelo numérico (barragem de enrocamento Mazar) são importantes quando se avalia sismicamente uma estrutura com comportamento preponderante bidimensional, isto limita aplicação de possíveis estimativas de deslocamentos permanentes mediante propagação unidimensional de ondas.

- Comprovou-se o mencionado por Bray e Travasarou (2007) que afirmam que uma analise 1D pode subestimar a demanda sísmica para deslizamentos superficiais na parte superior de sistemas bidimensionais (crista da barragem de Mazar) onde a amplificação topográfica é de significativa importância.

- A suposição inicial de condição mais crítica (perante carregamento dinâmico) da barragem de Mazar, quando o reservatório situa-se no nível máximo foi recusada, observando-se maiores deslocamentos permanentes na condição de reservatório vazio.

- Levando em consideração que o objetivo principal deste trabalho foi analisar o comportamento de geoestruturas submetidas a carregamentos dinâmicos, para este fim foram utilizados softwares específicos disponíveis no mercado, assim, é adequado estabelecer para cada um deles vantagens e desvantagens:

- Slide v7.0: este programa dispõe da opção do cálculo de deslocamentos permanentes no talude mediante o método de Newmark (1965), porém, a historia de acelerações (especificada 
para aplicação na base do modelo) é unicamente integrada acima do valor da aceleração de escoamento $\left(a_{y}\right)$ sem efetuar-se a propagação até um ponto situado na superfície de deslizamento do talude, desconsiderando nesta forma as possíveis amplificações (ou atenuações) do movimento geradas por fatores inerentes ao modelo como amplificação topográfica ou inerentes aos solos presentes (side effects).

- SHAKE2000: de grande utilidade devido a incorporar um completo e atualizado banco de dados das funções de degradação do módulo de cisalhamento e razão de amortecimento. Por outra parte como já mencionado anteriormente sua natureza de propagação 1D limita sua aplicação a camadas de solo horizontais de extensão lateral infinita, o que se constitui na principal desvantagem quando precisa-se de analise dinâmico de estruturas de terra como influência de amplificações topográficas.

- Flac 2D: a pesar da principal vantagem que apresenta este software ser a incorporação do amortecimento histerético para aproximar o comportamento dinâmico do solo, não possui um banco de dados adequado de funções de degradação do módulo de cisalhamento e aumento da razão de amortecimento para diferentes tipos de materiais granulares, pelo contrario, o ajuste a curvas obtidas em laboratório deve ser feito manualmente pelo usuário mediante funções matemáticas preestabelecidas no software (Sig3) impossibilitando a utilização direta de curvas obtidas de forma específica para materiais de interesse envolvidos na modelagem numérica. Frequentemente para a geração da malha de diferenças finitas é necessário se efetuar simplificações na geometria do modelo original.

Sugestões para futuras pesquisas são as seguintes:

- Verificar a influência na resposta dinâmica de barragens de enrocamento, para modelos 3D, em particular os efeitos associados a vales estreitos.

- Fazer um estudo atualizado de ameaça sísmica em sítios de projeto no Equador considerando diferentes leis de atenuação e incorporando dados 
de terremotos atualizados tal como o terremoto de 16 abril de 2016 com $M_{w}=7.8$.

- Estudar o comportamento dinâmico da barragem de Mazar utilizando modelos constitutivos que aproximem de melhor maneira o comportamento tensão - deformação de enrocados. 


\section{Referências bibliográficas}

ABRAHAMSON, N.A. Non-stationary spectral matching. Seismological research letters, v. 63, n. 1, p. 30, 1992.

ABRAHAMSON, N.A. Spatial variation of multiple support inputs. In: Proceedings $1^{\text {st }}$ United States Seminar on Seismic Evaluation and Retrofit of Steel Bridges, Department of Civil Engineering and California Department of Transportation, University of California at Berkeley, San Francisco, California, 1993.

ABRAHAMSON, N.A.; SILVA, W.J. Empirical ground motion models. Report Prepared for Brookhaven National Laboratory, USA, 1996.

ABRAHAMSON, N.A.; SILVA, W.J. Empirical response spectral attenuation relations for shallow crustal earthquakes. Seismological research letters, v. 68, n.1, p. 94-127, 1997.

ALARCON, J.E.; BOOTH, E.; BOMMER, J.J. Relationships between PGV and response spectral ordinates. In: Proceedings $1^{\text {st }}$ European Conference on Earthquake Engineering and Seismology, European Association of Earthquake Engineering, Geneva, 2006.

ALMEIDA, M.C.F. Análise sísmica na região sudeste brasileira aplicação a oleodutos da indústria petrolífera, Tese - Universidade Federal do Rio de Janeiro, COPPE. Rio de Janeiro. 1997.

ASHFORD, S.A.; SITAR, N. Simplified method for evaluating sesimic stability of steep slopes. Journal of Geotechnical and Geoenvironmental Engineering ASCE, v. 128, n. 2, p. 119-128, 2002.

AREVALO, J.P. Análisis probabilístico de la estabilidad de la ladera derecha sobre el vertedero de la presa de la Central de Mazar, Universidad de Cuenca, Cuenca, 2014.

ARIAS, A. Measure of earthquake intensity. Massachusetts Institute of Technology MIT, Cambridge, Massachussets. University of Chile, Santiago de Chile, 1970.

BELYTSCHKO, T.; HUGHES, J.R. Computational Methods for Transient Analysis. Computational Methods in Mechanics, v. 1, 2013.

BIGGS, J.M. Introduction to Structural Dynamics. McGraw-Hill Book Company, New York, 1964, 341p. 
BISHOP, A.W. The use of the slip circle in the stability analysis of slopes. Geotechnique, v. 5, n. 1, p. 7-17, 1955.

BLAKE, T.F.; HOLLINGSWORTH, R.A.; STEWART, J.P. Recommended procedures for implementation of DMG. Special Publication 117 Guidelines for analyzing and mitigating Landslide Hazards in California. Los Angeles Section Geotechnical Group, Document published by the Southern California Earthquake Center, Los Angeles, 2002.

BOORE, D.M.; JOYNER W.B. The empirical prediction of ground motion. Bulletin of the Seismological American Society, v.72, n. 6B, p. 269-286, 1982.

BOMMER, J.J.; ALARCON, J.E. The prediction and use of peak ground velocity. Journal of Earthquake Engineering, v. 10, n. 01, p. 1-31, 2006.

BRAY, J.D.; AUGELLO, A.J.; LEONARDS, G.A.; REPETTO, P.C.; BYRNE, R.J. Seismic stability procedures for solid waste landfills. Journal of Geotechnical Engineering, ASCE, v. 121, n. 2, p. 139-151, 1995.

BRAY, J.D; RATHJE, E.R. Earthquake-induced displacements of solid-waste landfills. Journal of Geotechnical and Geoenvironmental Engineering, ASCE, v. 124, n. 3, p. 242-253, 1998.

BUREAU, G.; VOLPE, R.L.; ROTH, W.; UDAKA, T. Seismic analysis of concrete face rockfill dams. Concrete Face Rockfill Dams - Design, Construction and Performance, ASCE, 1985, p. 479-508.

BYRNE, P. M.; PARK, S.S.; BEATY, M.; SHARP, M.; GONZALEZ, L.; ABDOUN, T. Numerical modeling of liquefaction and comparison with centrifuge tests. Canadian Geotechnical Journal, v. 41, n. 2, p. 193-211, 2004.

CALIFORNIA GEOLOGICAL SURVEY. Guidelines for evaluating and mitigating seismic hazards in California, Special Publication 117a, 2008.

CHOPRA, A.K. Earthquake effects on dams. PhD. Dissertation, University of California, Berkeley, 1966.

CLOUGH, R.W.; CHOPRA, A.K. Earthquake stress analysis in earth dams. Journal of the Soil Mechanics and Foundation Division, ASCE, v. 92, p. 197$211,1966$.

CLOUGH, R.W.; PENZIEN, J. Dynamics of Structures, McGraw-Hill, New York, 1975, 634p.

CLOUGH, R.W.; PENZIEN, J. Dynamics of Structures, 2nd Edition, McGrawHill, New York, 1994.

ClOUGH, R.W.; PENZIEN, J. Dynamics of Structures, Computers \& Structures, Inc. Berkeley, CA 94704, USA, p. 575-605, 1995. 
CONTRERAS, RAUL I. Previsão numérica do comportamento dinâmico da barragem de Breapampa no Perú. Dissertação de Mestrado, Departamento de Engenharia Civil, Pontifícia Universidade Católica do Rio de Janeiro PUC-Rio, Rio de Janeiro, 2014.

CONVERSE, A.M.; BRADY, A.G. BAP: Basic Strong-Motion Accelerogram Processing Software Version 1.0, United States Geological Survey (USGS), 1992.

CRUZ, P.T; MATERON, B.; FREITAS, M.; Barragens de enrocamento com face de concreto. São Paulo: Oficina de Textos, São Paulo, 2009.

CUNDALL, P. FLAC user's manual version 7.0. ITASCA Consulting Group, Inc., Minneapolis, 2009.

DAKOULAS, P., GAZETAS, G. Nonlinear Seismic Response Embankment Dams. In: Proceedings of the $2^{\text {nd }}$ International Conference on Soil Dynamics and Earthquake Engineering, 1985.

DAKOULAS, P.; GAZETAS, G. Seismic shear strains and seismic coefficients in dams and embankments. Soil Dynamics and Earthquake Engineering, v. 5, n. 2, p. 75-83, 1986.

DARENDELI, M.B. Development of a New family of Normalized Modulus Reduction and Material Damping Curves. PhD. Dissertation. The University of Texas at Austin, Austin, Texas, 2001.

DEPOLO, C.M.; SLEMMONS, D.B. Estimation of earthquake size for seismic hazards. Neotectonics in earthquake evaluation, Geological Society of America. Rev. Eng. Geol. v. 8, p. 1-28, 1990.

DEPOLO, C.M.; SLEMMONS, D.B. Historical surface faulting in the Basin and Range province, western North America: implications for fault segmentation. Journal of structural Geology, v. 13, n. 2, p. 123-136, 1991.

DUNCAN, J.M. State-of-the-art: Static stability and deformation analysis. In: Stability and Performance of Slopes and Embankments II. ASCE, v. 1, 1992, p. 222-266.

DUNCAN, J.M.; WRIGHT, S.G. Soil Strength and Slope Stability. John Wiley \& Sons, Inc., Hoboken, New Jersey, 2005, 308p.

DUNCAN, J.M.; WRIGHT, S.G.; BRANDON, T.L. Soil Strength and slope stability. John Wiley \& Sons, 2014.

FELLENIUS, W. Erdstatische Berechnungen mit Reibung und Kohäsion, Ernst, Berlin, 1927. 
FELLENIUS, W. Erdstatische berechnungen mit reibung und kohae-sion und unter annahme kreiszylindrisher gleitflaechen (Statistical analysis of earth slopes and retaining walls considering both friction and cohesion and assuming cylindrical sliding surfaces). W Ernst und Sohn, Berlin (in German), 1927.

FLORES-ESTRELLA, H. Método SPAC: Una alternativa para la Estimación de Modelos de Velocidades en el Valle de México. Dissertação de Mestrado, Postgrado en Ciencias de la Tierra, Instituto de Geofísica, UNAM, 2004.

GAMARRA, C.A.; AGUILAR, Z. Nuevas Fuentes Sismogénicas para la Evaluación del Peligro Sísmico y Generación de Espectros de Peligro Uniforme en el Perú. Tesis de Grado, Facultad de Ingeniería Civil, Universidad Nacional de Ingeniería Lima, 2009

GARFUNKEL, Z. Growth, shrinking, and long-term evolution of plates and their implications for flow patterns in the mantle. Journal of Geophysical Research, v.80, n. 32, p. 4425-4432, 1975.

GAZETAS, G.; DAKOULAS, P. Seismic analysis and design of rockfill dams: state-of-the-art. Soil Dynamics and Earthquake Engineering, v.11, n. 1, p. 27$61,1992$.

GEER-ATC Earthquake Reconnaissance April 16th 2016, Muisne, Ecuador Version 1. National Science Foundation - US Goverment, v.1, n. 1, 2016.

GRAFF, K.G. Wave Motion in Elastic Solids. Dover Publications Inc, New York, 1991.

GUTENBERG, B. Magnitude determination for deep-focus earthquakes. Bulletin of the Sismological Society of America, v. 35, n. 3, p. 117-130, 1945.

GUTENBER, B.; RICHTER, C.F.; On seismic Waves (third paper). Gerlands Bietraege zur Geophysik, v. 47, p. 73-131, 1936.

GUTENBER, B.; RICHTER, C.F. Earthquake magnitude: intensity, energy and acceleration. Bulletin of the Seismological Society of America, v.46, p. 104-145, 1956.

HANCOCK, J.; WATSON-LAMPREY, J.; ABRAHAMSON, N.A.; BOMMER, J.J.; MARKATIS, A.; MCCOY, E.; MENDIS, R. An improved method of matching response spectra of recorded earthquake ground motions using wavelets. Journal of Earthquake Engineering, ASCE, v. 10, p.67-89, 2006.

HANKS, T.C.; KANAMORI, H. A moment magnitude scale. Journal of Geophysical Research, v. 84, n. B5, p. 2348-2350, 1979. 
HARDIN, B.O. The nature of stress-strain behavior of soils. In: Proceedings, Earthquake Engineering and Soil Dynamics, ASCE Pasadena California, v.1, p. 3-89, 1978.

HARDIN, B.O.; BLACK, W.L. Vibration modulus of normally consolidated clay. Journal of the Soil Mechanics and Foundation Division, ASCE, v. 94, n. SM2, p. 353-369, 1968.

HYNES-GRIFFIN M.; FRANKLIN A. Razionalizing the seismic coefficient method. U.S. Army Engineer Waterways Experiment Station Vicksburg, Miscellaneous Paper GL-84-13, Vicksburg, MS. 1984.

HOUSTON, S.L.; HOUSTON, W.N.; PADILLA, J.M.; Microcomputer-Aided Evaluation of Earthquake-Induced permanent Slope Displacements. Microcomputers in Civil Engineering, Elsevier Science Publishing Co. Inc. Vanderbilt avenue, v. 2, n. 3 p. 207-222, 1987.

HUERTAS, J. Procedimentos de análise não-linear para previsão de resposta sísmica em geoestruturas. Dissertação de Doutorado. Departamento de Engenharia Civil, Pontifícia Universidade Católica do Rio de Janeiro, Rio de Janeiro, 2012.

HUDSON, D. E. Reading and Interpreting Strong Motion Accelerograms. Earthquake Engineering Research Institute, 1979.

HUNGR, O.; MORGENSTERN, N.R. High velocity ring shear test on sand. Geotechnique, v. 34, n. 3, p. 415-421, 1984.

IDRISS, I.M. Evaluating seismic risk in engineering practice. Proceedings for the $11^{\text {th }}$ International Conference on Soil Mechanics and Foundation Engineering, San Francisco, v. 1, p. 255-320, 1985.

IDRISS, I.M.; SUN, J.I.; SHAKE91: A computer program for conducting equivalent linear seismic response analyses of horizontally layered soil deposits, User's guide. Center for Geotechnical Modeling, Department of Civil and Environmental Engineering, University of California, Davis, 1992.

INSTITUTO GEOFISICO ECUATORIANO, Escuela Politécnica Nacional, Quito, Ecuador.

ISHIHARA, K. Evaluation of Soil Properties for use in Earthquake Response Analysis. In: Geomechanical Modeling in Engineering Practice, R. Dungar and J.A. Studer, Eds., A.A. Balkema, Rotterdam, the Netherlands, 1986.

ITASCA Consulting Group Inc. Fast Lagragian Analysis of Continua FLAC, version 7.0, Minneapolis, 2011.

ITASCA Consulting Group Inc. Fast Lagragian Analysis of Continua FLAC, version 8.0, Minneapolis, 2016. 
JAMIOLKOWSKI, M.; LEROUEIL, S.; LOPRESTI, D.C.F. Theme lecture: Design parameters from theory to practice. Proceedings, Geo-Coast, Yokohama, Japan, v. 91, p. 1-41, 1991.

JANBU, N. Slope stability computations. Soil mechanics and Foundation Engineering Report, Technical University of Norway, Trondheim, Norway, 1968.

JIBSON, R.W. Predicting earthquake-induced landslide displacements using Newmark's sliding block analysis. Transportation Research Record 1411, Transportation Research Board, Washington D.C., p. 9-17, 1994.

JIBSON, R. W. Methods for assessing the stability of slopes during earthquakes A retrospective. Engineering Geology. v. 122, n. 1, p. 43-50, 2011.

KANAMORI, H. The Energy Release in Great Earthquakes. Journal of Geophysical Research, v. 82, p. 2981-2987, 1977.

KAVAZANJIAN, E.; MATASOVIC, N.; HADJ-HAMOU, T.; SABATINI, P.J. Geotechnical Engineering Circular \#3, Design Guidance: Geotechnical Earthquake Engineering for Highways, Volume I - Design Principles. Report No. FHWA-SA-97-077. US Department of Transportation, Federal Highway Administration, Washignton, D.C., 1997, 196 p.

KOKUSHO, T.; ESASHI, Y. Cyclic tri-axial test on sand and coarse material. In: Proceedings of the 10th International Conference on Soil Mechanics and Foundation Engineering. 1981. p. 673-679.

KRAMER, S. L. Geotechnical Earthquake Engineering. Prentice - Hall, New Jersey, 1996, 653p.

LAMBE, T.W.; WHITMAN, R.V. Soil Mechanics. John Wiley \& Sons, New York, 1969.

LEE, K.L. Seismic permanent deformations in earth dams. Report No. UCLAENG-7497, School of Engineering and Applied Sciences, University of California at Los Angeles, Los Angeles, 1974.

LEE, K.L.; ALBAISA, A. Earthquake induced settlements in saturated sands. Journal of the Soil Mechanics and Foundations Division, ASCE, v. 100, n. GT4, 1974.

LEMOS, P.J.L.; COELHO, P.A.L.F. Displacements of slopes under earthquake loading. Proceedings. In: Proceedings of the $2^{\text {nd }}$ International Conference on recent Advances in Geotechnical Earthquake Engineering and Soil Dynamics, St. Louis, Missouri, v. 2, p. 1051-1056, 1991.

LEPS, T.M. Review of shearing strength of rockfill. Journal of Soil Mechanics and Foundations Division, ASCE, v. 96 n. SM4, 1970. 
LILHANAND, K.; TSENG, W. S. Generation of Synthetic Time Histories Compatible with Multiple-Damping Response Spectra. In: Structural mechanics in reactor technology, 1987.

LOAYZA, F. Modelagem do Comportamento Pós-Sismo de uma Barragem de rejeito. Dissertação de Mestrado. Departamento de Engenharia Civil, Pontifícia Universidade Católica do Rio de Janeiro, Rio de Janeiro, 2009, 220p.

LOPEZ, J.L.; Aplicação da Ameaça Sísmica na Previsão da resposta Dinãmica de uma Barragem de Terra. Dissertação de Mestrado. Departamento de Engenharia Civil, Pontificia Universidade Católica do Rio de Janeiro PUC-Rio, Rio de Janeiro, 2015.

LYSMER, J.; KUHLEMEYER, R.L. Finite Dynamics Model for Infinite Media. Journal of Soil Mechanics and Foundation Division, ASCE, v. 95, n.4, p. 859877, 1969.

LYSMER, J.; UDAKA, T.; SEED, H.B.; HWANG, R. LUSH: a computer program for complex response analysis of soil-structure systems. Report EERC 74-4, Earthquake Engineering Research Center, University of California, Berkeley, 1974.

LYSMER, J.; UDAKA, T.; TSAI, C.F.; SEED, H.B.; FLUSH: a computer program for approximate 3-D analysis of soil-structure interaction problems. Report EERC 75-30, Earthquake Engineering Research Center, University of California, Berkeley, 1975.

MAKDISI, F. I.; SEED, H. B. Simplified Procedure for estimating Dam and embankment earthquake-induced deformations. Journal of Geotechnical Engineering Division, ASCE v. 104, n. GT7, p. 849-867, 1978.

MAKDISI, F.I., SEED, H.B. A Simplified Procedure for Estimating EaqrthquakeInduced Deformations in Dams and Embankments. Earthquake Engineering Research Center, University of California, Berkeley, Report. No. UCB/EERC77/19, University of California, Berkeley, 1977, 66p.

MARTIN, G.R.; FINN, W.D.L.; SEED. H.B. Fundamentals of liquefaction under cyclic loading. Journal of Geotechnical Engineering Division, ASCE, v.101, n.GT5, p. 423-438, 1975.

MARTIN, P.P.; SEED, H.B. MASH - A computer program for the nonlinear analysis of vertically propagating shear waves in horizontally layered soil deposits. Report No. UCB/EERC-78/23, Earthquake Engineering Research Center, University of California, Berkeley, 1978.

MATASOVIC, N.; KAVAZANJIAN, E.; GIROUD, J.P. Newmark Seismic Deformations Analysis for Geosynthetic Covers. Geosynthetics International, v. 5, p. 237-246, 1998. 
MATASOVIC, N.; VUCETIC, M. Seismic Response Of Soil deposits Composed of Fully-Saturated Clay and Sand Layers. Proceedings $1^{\text {st. International }}$ Conference Earthquake Geotechnacal Engineering, Tokyo, Japan, v.1, 1995, pp. 611-616.

MAYNE, P.W. Stress-strain-strength and flow parametrs from enhanced in-situ tests. In: Proceedings of the International Conference on In-Situ Measurements of Soil Properties and case Histories, Bali. 2001, p. 27-48.

MEDINA, F.; PENZIEN, J. Infinite Elements for Elastodynamics. Earthquake Engineering Structural Dynamics, v. 10, n. 5, p. 699-709, 1982.

MEDINA, F.; TAYLOR, R.L. Finite Element techniques for problems of unbounded domains. International Journal of Numerical Methods in Engineering, v. 19, n.8, pp. 1209-1226, 1983.

MEJIA, L.H.; DAWSON, E.M. Earthquake deconvolution for FLAC. In: Proceedings $4^{\text {th }}$ International FLAC Symposium on Numerical Modeling in Geomechanics - 2006 - Hart \& Varona eds. paper n. 04-10, Itasca Consulting Group, Inc., Minneapolis, ISBN 0-9767577-0-2, 2006.

MENESES, J. Evaluación del peligro sísmico y determinación de acelerogramas de diseño, Colegio de Ingenieros del Perú, 2009.

MORGENSTERN, N.R.; PRICE, V.E.; The analysis of the stability of general slip surfaces. Geotechnique, v.15, n.1, p. 79-93, 1965.

NEWMARK, N. Effects of Earthquakes on Dams and Embankments. Geotechnique, v.115, n. 2, p. 139-160, 1965.

NEWMARK, N.M.; HALL, W.J. Seismic Desing Criteria for Nuclear Reactors Facilities. In: Proceedings Fourth World Conference on Earthquake Engineering, Santiago, Chile, p. 37-50, 1969.

NEWMARK, N.M.; HALL, W.J. Develop of criteria for earthquake resistant design. Report NUREG/CR-0098, Nuclear Regulatory Commision, Washington D.C.,1978, 49p.

NEWMARK, N.M.; HALL, W.J. Earthquake Spectra and Design, EERI Monograph, Earthquake Engineering Research Institute, Berkeley, California, 1982, 103p.

NORMA ECUATORIANA DE LA CONSTRUCCION, NEC-2014, Ecuador.

ORDÓÑEZ, A. G. Shake2000 Quick tutorial, 2011. 124p.

ORDÓÑEZ, A. G. Shake2000 User's manual, 2011. 252p.

PARK, C.B., MILLER, R.D., XIA, J. Multichannel analysis of surface waves (MASW). Geophysics, v. 64, p. 800-808, 1999. 
PARK, S.S. A two mobilized-plane model and its application for soil liquefaction analysis. $\mathrm{PhD}$. Thesis, Civil Eng. Dept., Um., British Columbia, Vancouver, B. C. 2005.

PARK, T.; SILVER, M.L. Dynamic soil properties required to predict the dynamic behavior of elevated transportation structures. Report DOT-TST-7544, United States Department of Transportation, Washington D.C., 1975.

PREVOST, J.H. Mathematical modelling of monotonic and cyclic undrained clay behavior. International Journal of Numerical and Analytical Methods in Geomechanics. v. 1, n.2, p. 195-216, 1977.

RATHJE, E.M.; Bray, J.D. One and two-dimensional seismic analysis of solidwaste landfills. Canadian Geotechnical Journal, v. 38, n. 4, p. 850-862, 2001.

RATHJE, E.M.; FARAJ, F.; RUSSELL, S.; BRAY, J.D. Empirical relationships for frequency content parameters of earthquake ground motions. Earthquake Spectra, Earthquake Engineering Research Institute, v. 20, n. 1, p. 119-144, 2004.

RATHJE, E.M.; SAYGILI, G. Estimating Fully Probabilistic Seismic Sliding Displacements of Slopes from a Pseudoprobabilistic Approach. Journal of Geotechnical and Geoenvironmental Engineering, ASCE, v. 137, n. 3, p. 208217, 2011.

REAL, C.R.; TENG, T. Local Richter magnitude and total signal duration in southern California. Bulletin of the Seismological Society of America, v. 63, n. $5,1973$.

REITER, L. Earthquake Hazard Analysis-Issues and Insights. Columbia University Press, New York, 1990, 254p.

RICHTER, C.F. An instrumental earthquake scale. Bulletin of the Seismological Society of America, v. 25, p. 1-32, 1935.

RODRIGUEZ-MAREK, A.; BRAY, J.; ABRAHAMSON, N. A empirical geotechnical seismic site response procedure. Earthquake Spectra. v. 17, n. 1, 2001, p.65-87, 2001.

ROWE, P.W. Anchored sheet pile walls. In: Proceedings of the Institution of Civil Engineers, v. 1, n. 1, p. 27-70, 1952.

SARMA, S. K. Seismic Stability of Earth Dams and embankments. Geotechnique, v.25, n.4, p. 743-761, 1975.

SAUTER, F. Introducción a la Sismología, Editorial Tecnológica de Costa Rica, 1989.

SCHNABEL, P.B. Effects of Local Geology and distance from Source on Earthquake Groud Motions. PhD. Thesis, University of California, Berkeley, California, 1973. 
SCHNABEL, P.B.; LYSMER, J.; SEED, H.B. SHAKE: a computer program for earthquake response analysis of horizontal layered sites. Report EERC 72-12, Earthquake Engineering Research Center, University of California, Berkeley, 1972.

SCHNABEL, P.B.; SEED, H.B. Accelerations in Rock for earthquakes in the western United States. Report No. EERC 72-2, Earthquake Engineering Research Center, University of California, Berkeley, 1972.

SCHNAID, F. In Situ Testing in Geomechanics. Taylor \& Francis Group, London, 2009, 329p.

SEED, H.B. Considerations in the earthquake design of earth and Rockfill dams. Geotechnique, v. 29, n. 3, p.215-263, 1979.

SEED, H.B. Lessons from performance of earth dams during earthquakes. Design of dams to resist earthquakes, p. 251-258, 1980.

SEED, H.B.; IDRISS, I.M. Soil moduli and damping factors for dynamic response analyses. Report EERC 70-10, Earthquake Engineering Research Center, University of California, Berkeley, 1970.

SEED, H.B., LEE, K. L., IDRISS, I.M. An analysis os Sheffield Dam failure. Journal of Soil Mechanics \& Foundation Division, ASCE, v. 96, p. 1453-1490, 1969.

SEED, H. B., LEE, K. L., IDRISS, I. M., MAKDISI, R. Analysis of the slides in the San Fernando dams during the earthquake of Feb. 9, 1971. Report No. EERC 73-2, Earthquake Engineering Research Center, University of California, Berkeley, 1973, 150p.

SEED, H.B., MARTIN, G.R. The Seismic Coefficient in earth dam design. Journal of the Soil Mechanics and Foundation Division, ASCE, v. 92, n. SM3, p. 25-58, 1966.

SEED, H.B.; WONG, R.T.; IDRISS, I.M.; TOKIMATSU, K. Moduli and Damping factors for dynamic analysis of cohesionless soils. Journal of Geotechnical Engineering, ASCE, v. 112, n. GT11, p.1016-1032, 1968.

SEISMOSOFT LTD. SeismoMatch's Help System, Earthquake Engineering Software Solutions, 2013.

SEISMOSOFT LTD. SeismoSignal's Help System, Earthquake Engineering Software Solutions, 2013.

SERFF, N.; SEED, H.B.; MAKDISI, F.I.; CHANG, C.Y. Earthquake-induced deformations of earth dams. Report EERC 76-4, Earthquake Engineering Research Center, University of California, Berkeley, 1976, 140p. 
SHARMA, M.P.; SHAH, H.C. Time varying parameter domain modeling of strong ground motion. In: Proceedings, 3rd Engineering mechanics Speciality Conference on Dynamics of Structures, ASCE, University of California, Los Angeles, 1986.

SHINOZUKA, M.; DEODATIS, G. Stochastic process models for earthquake ground motion. Journal of Probabilistic Engineering Mechanics, v. 3, n. 3, p. 187-221, 1988.

STEWART, J.P.; BRAY, J.D.; MCMAHON, D.J.; SMITH,P.M.; KROPP, A.L. Seismic performance of hillside fills. Journal of Geotechnical and Geoenvironmental Engineering ASCE, v. 127, n. 11, p. 905-919, 2001.

STEWART, J.P; Blake, T.F.; HOLLINGSWORTH, R.A. A screen analysis procedure for seismic slope stability. Earthquake Spectra, v. 19, n. 3, p. 697712,2003

SPENCER, E. A method of analysis of the stability of embankments assuming parallel interslice forces. Geotechnique, v. 17, n. 1, p. 11-26, 1967.

TATSOUKA, F.; OCHI, K.; FUJI,S; OKAMOTO, M. Cyclic undrained triaxial and torsinal shear strength of sands for different sample preparation methods. Soils and Foundations, v. 26, n. 3, p. 23-41, 1986.

TIKA-VASSILIKOS, T.E.; SARMA, S.K.; AMBRASEYS, N. Seismic displacements on shear surfaces in cohesive soils. Earthquake Engineering and Structural Dynamics, v. 22, p. 709-721, 1993.

TEIXEIRA, W. Decifrando a Terra. Oficina de textos, São Paulo, 2da reimpressão, 2003, 558p.

TERZAGHI, K. Mechanism of landslides, Application of Geology to Engineering Practice. Geological Society of America, New York, p. 83-123, 1948.

TERZAGHI K, Mechanisms of Landslides, Engineering Geology (Berkeley) Volume. Geological Society of America, 1950.

VUCETIC, M.; DOBRY, R. Effect of soil plasticity on cyclic response. Journal of Geotechnical Engineering, ASCE, v. 17, n. 1, p. 89-107, 1991.

WEGENER, A. Die Entstehung der Kontinente und Ozeane. Vieweg, Braunschweig, Germany, 1915.

WILSON, R.C.; KEEFER, D.K. Dynamic analysis of a slope failure from the 6 August 1979 Coyote Lake, California Earthquake. Bulletin of the Seismological Society of America, v.73, p. 863-877, 1983.

WILSON, J.T. A new class of faults and their bearing on continental drift. Nature, v.207, p. 343-347, 1965. 
YEGIAN, M.K.; MARCIANO, E.; GHARAMAN, V.G. Earthquake-induced permanent deformations: probabilistic approach. Journal of Geotechnical Engineering, ASCE, v. 117, n. 1, p. 35-50, 1991.

JOYNER, W.B.; CHEN, T.F. Calculation of Nonlinear Ground Response in Earthquakes. Bulletin of the Seismological Society of America, v. 65, n. 5, p. 1315-1336, 1975. 